University of Louisville

ThinkIR: The University of Louisville's Institutional Repository

Electronic Theses and Dissertations

$12-2010$

\title{
The content and critical metaphor analysis of illustrated print advertisements in China.
}

Chun Jiang

University of Louisville

Follow this and additional works at: https://ir.library.louisville.edu/etd

\section{Recommended Citation}

Jiang, Chun, "The content and critical metaphor analysis of illustrated print advertisements in China." (2010). Electronic Theses and Dissertations. Paper 688.

https://doi.org/10.18297/etd/688

This Doctoral Dissertation is brought to you for free and open access by ThinkIR: The University of Louisville's Institutional Repository. It has been accepted for inclusion in Electronic Theses and Dissertations by an authorized administrator of ThinkIR: The University of Louisville's Institutional Repository. This title appears here courtesy of the author, who has retained all other copyrights. For more information, please contact thinkir@louisville.edu. 


\title{
THE CONTENT AND CRITICAL METAPHOR ANALYSIS OF ILLUSTRATED PRINT ADVERTISEMENTS IN CHINA
}

By

Jiang, Chun

B.A., University of International Business and Economics, 1985

M.A., Korea Development Institute, 2001

\author{
A Dissertation \\ Submitted to the Faculty of the \\ Graduate School of the University of Louisville \\ in Partial Fulfillment of the Requirements \\ for the Degree of
}

Doctor of Philosophy

Department of Humanities

University of Louisville

Louisville, Kentucky

December 2010 
Copyright 2010 by Jiang, Chun

All rights reserved 



\title{
THE CONTENT AND CRITICAL METAPHOR ANALYSIS OF ILLUSTRATED PRINT ADVERTISEMENTS IN CHINA
}

\author{
By
}

Jiang, Chun

B.A., University of International Business and Economics, 1985

M.A., Korea Development Institute, 2001

A Dissertation Approved on

Oct 15,2010

By the following Dissertation Committee:

Dissertation Director 


\title{
DEDICATION
}

This dissertation is dedicated to my parents

\author{
Jiang Fan and Zhang Minhua, \\ and my husband and daughter \\ Wang Jianwei and Wang Ye,
}

who have given me invaluable and selfless support. 


\section{ACKNOWLEDGMENTS}

First of all I would like to express my sincere and heart-felt thanks to my adviser professor Robert N. St. Clair for his guidance, help and patience throughout the whole writing process. Next I would also like to express my gratitude to all the teachers in this humanities program who have given us the most enlightening instruction and systematic knowledge. The teachers who have accompanied me in the

past four years are: Annette Allen, Osbourne P. Wiggins, Elaine O. Wise, Robert N. St. Clair, Pamela Beattie, Mark E. Blum, Li Jin, Youzhong Sun, Yian Wu, Zaixin Zhang, Guohua Chen, and Jian Zhang.

In addition to that I am indebted to my family members without whose support this dissertation can never be accomplished. My parents, my brothers, my husband and my daughter have shown their full understanding and support during the last four years so that I can continue to pursue this degree to the very end with courage and confidence.

Finally I would like to show my gratitude to my university colleagues and School of English with whom I have been working in the last twenty five years. They allow me time and resources for academic research. Some of their names are: Lifei Wang, Cuiping Zhang, Xiaoshu Zhu, Weilin Dou, Jieyun Feng. 


\title{
ABSTRACT \\ THE CONTENT AND CRITICAL METAPHOR ANALYSIS OF ILLUSTRATED PRINT ADVERTISEMENTS IN CHINA
}

\author{
Jiang, Chun
}

Sept 18,2010

This dissertation takes Chinese advertisements as the research subjects to see in what way a quantifiable large number of advertisements with its metaphorical nature and instrumental mission can reflect social cultural change, in specifics, ideology and identity change of China in the last thirty years by combining four methods of research: content analysis, Critical Discourse Analysis, Conceptual Metaphor Analysis and Pictorial Metaphor Analysis. The dissertation goes through the sign or ad interpretation process of linguistic, semiotic and critical analysis of 300 sample illustrated print advertisements collected from popular and award-winning illustrated print advertisements in Chinese media in the three periods of 1980s, 1990s and 2000s respectively. After comparing and contrasting the high frequency key words, advertising appeals and metaphorical expressions and images (categories and groups) appeared in the advertisements of the three periods the following conclusions are made:

First, although advertisements in all the three periods belonged to the commercial public discourse, those in 1980 s were inclined towards public discourse without much consideration for specific target groups while those in 1990s and 2000s 
tended to denote private and personal discourse with clear target groups in mind. While the advertisements in 1980 s were characterized largely by the direct informative style, the majority of the advertisements in 1990s manifested a hybridization of both informative and involving styles. The advertisements in 2000 s demonstrated strong involving and interacting style.

Second, it can be seen from the shift of advertising appeals from the use of rational appeal to personal appeal that the overall society is moving up the ladder of Maslow's Hierarchy of Needs Analysis from the basic need satisfaction to more social need and personal need satisfaction.

Third, with regard to semiotic image categories used, the result shows the tendency that China is increasingly becoming a male-dominated society with a big increase in using male images from 1980s to 2000 s and in particular adult male images. The representational images in the ads show a decline in intimacy but an increase in positional communication. The social setting is the dominant advertising background for all the three periods. Meanwhile with regard to the typical types of metaphorical images that are used as signifieds or secondary subjects to be projected onto the signifiers or primary subjects, there is a decline in using human images as opposed to non-human images. The dominant metaphorical image types used in three periods are in concomitant with the ideology and identity needs of each specific period of time.

Fourth, on the whole the critical metaphor analysis of 300 sample illustrated print advertisements in mainland China from 1979 to 2008 has revealed 
advertisements during this period, implicitly or explicitly, have served the evolving ruling and dominant ideology very well. The dominant ideologies have changed from political ideology to economic ideology in 1980 s, from economic ideology to national ideology in 1990s, and from national ideology to balanced harmonious ideologies in 2000s. The individual consumers have transformed their identities from political self to material social self in $1980 \mathrm{~s}$, from material social self to national cultural self in 1990s, and from national cultural self to a individualized my self in 2000 s.

The dissertation contributes both theoretically and practically to the advertising research as well as visual culture research. On the one hand it confirms the critical discourse theory that discourse change can reflect socially-constructed reality. On the other hand, it contributes to pictorial metaphor theory by that visual metaphors are deep-rooted in human conceptualization and are cultural-specific. 


\section{TABLE OF CONTENTS}

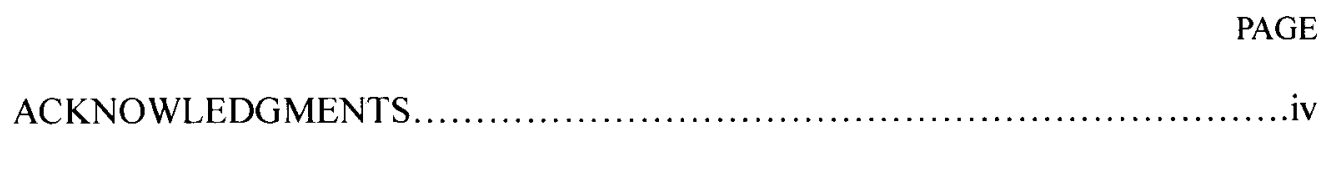

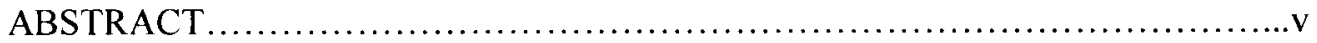

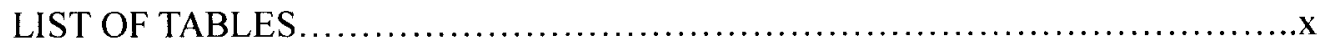

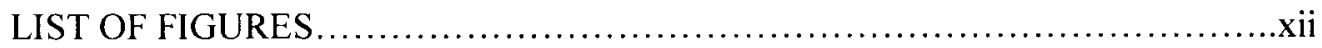

\section{CHAPTERS}

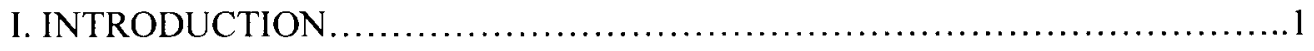

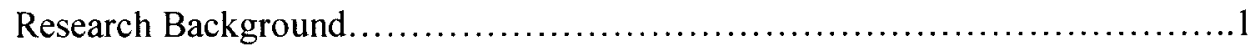

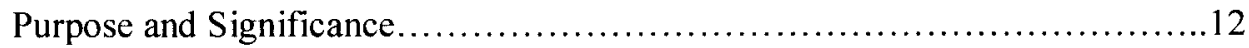

Research Assumptions and Questions................................... 16

The Organization of the Dissertation.................................... 19

II. LITERATURE REVIEW............................................... 23

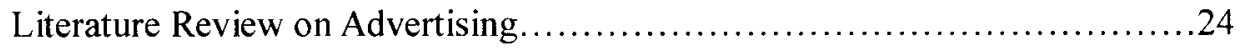

Literature Review on Advertising Research...............................31

The Interdisciplinary Nature of Advertising ...............................34

Literature Review on Critical Metaphor Analysis.........................48

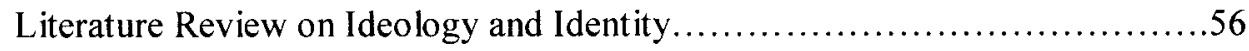

III. LINGUISTIC AND SEMIOTIC ANALYSIS $\ldots \ldots \ldots \ldots \ldots \ldots \ldots \ldots \ldots \ldots \ldots \ldots$

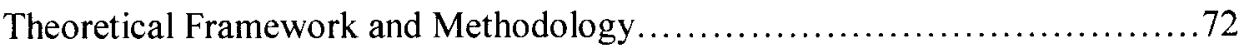


Sample Data Collection: Source and Criteria.............................. 75

Sample Data Treatment: Linguistic and Semiotic Analysis...................78

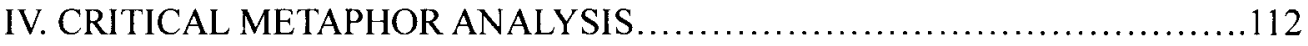

Critical Metaphor Analysis of Advertisements.........................112

The Contextual (Sign) Situation of Advertisements....................... 117

The Ideology Changes Reflected by Advertisements..................... 123

The Identity Changes Reflected by Advertisements.......................143

V. CONCLUSIONS AND IMPLICATIONS ................................ 158

A Summary of the Research into Advertisements in China...................158

Answers to the Three Research Questions..............................161

Theoretical and Practical Implications of the Research.....................177

Limitations of the Content and Critical Metaphor Analysis of Advertisements. 187

REFERENCES ....................................................... 190

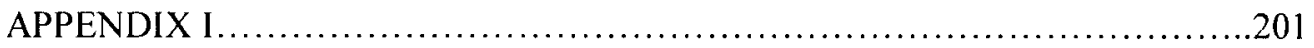

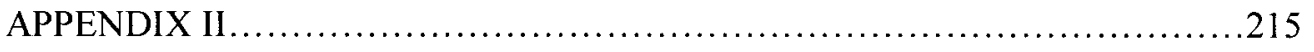

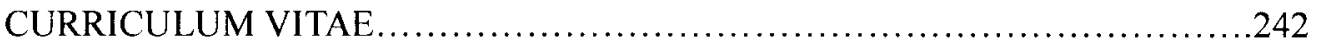




\section{LIST OF TABLES}

TABLE

PAGE

Table 1-1 Overall Research Construct for the Whole Dissertation...................19

Table 2-1 Information Processing Modes of Print and Oral Cultures...............46

Table 2-2 The Use of Contrast and Harmony to Constitute A Visual Structure........47

Table 4-1 An Overview of China's Changes in Economy and Ad Industry...........120

Table 4-2 A Comparison of Degree Changes between 1979 and $2008 \ldots \ldots \ldots \ldots \ldots 121$

Table 4-3 Social and Cultural Changes in Key Events and Bandwagon

Experiences........................................................ 123

Table 4-4 Frequently Appeared Metaphorical Images in 1980s.................... 125

Table 4-5 Frequently Appeared Metaphorical Images in 1990s...................131

Table 4-6 Frequently Appeared Metaphorical Images in 2000s.....................138

Table 4-7 A Comparison of Advertising Image Categories in Three Periods..........142

Table 5-1 A Comparison of the Frequently Used Nouns in Three Periods............ 164

Table I-1 100 Product Names, Key Words and Appeals $1979-1988 \ldots \ldots \ldots \ldots \ldots . . .205$

Table I-2 100 Product Names, Key Words and Appeals 1989-1998.................208

Table I-3 100 Product Names, Key Words and Appeals $1999-2008 \ldots \ldots \ldots \ldots \ldots \ldots . .211$

Table I-4 A Summary of the Key Words and Value Themes in Each Period..........214

Table I-5 A Content Analysis of Advertising Appeals in Each Period...............214

Table II-1 100 Metaphorical Statements, Primary Subjects and Secondary Subjects

and Their Corresponding Projected Features from 1979 to $1988 \ldots \ldots \ldots \ldots \ldots \ldots . . . \ldots 215$ 
Table II-2 100 Metaphorical Statements, Primary Subjects and Secondary Subjects and Their Corresponding Projected Features from 1989 to $1998 \ldots \ldots \ldots \ldots \ldots \ldots . . \ldots 220$ Table II-3 100 Metaphorical Statements, Primary Subjects and Secondary Subjects And Their Corresponding Projected Features from 1999 to $2008 \ldots \ldots \ldots \ldots \ldots \ldots . .226$

Table II-4 Advertisements That Contain Human Images in Each Period.............232

Table II-5 Human Representational Image Categories for Appearance..............232

Table II-6 Human Representational Image Categories for Manner................233

Table II-7 Human Representational Image Categories for Activity ................233

Table II-8 Human Representational Image Categories for Settings.................233

Table II-9 Frequently Appeared Images as Signifieds and Projected Features from

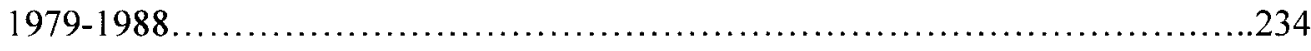

Table II-10 Frequently Appeared Images as Signifieds and Projected Features from

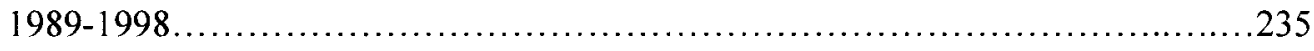

Table II-11 Frequently Appeared Images as Signifieds and Projected Features from

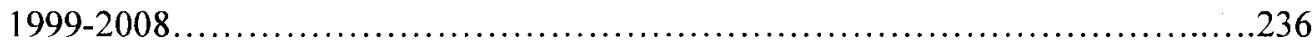




\section{LIST OF FIGURES}

FIGURE

PAGE

Figure 1-1 The Semantic Triangle of Ogden and Richards.........................

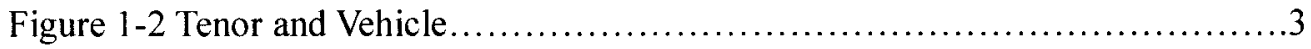

Figure $1-3$ Topic and Vehicle.............................................

Figure 1-4 Claude Levi-Strauss's Culinary Triangle...............................4

Figure 1-5 The Multifaceted Nature of Advertising ...............................

Figure 1-6 The Power of Business Organizations on Society ......................14

Figure 3-1 The Commercial and Ideological Functions of Advertisements...........73

Figure 3-2 Theoretical Framework for Pictorial Metaphor Analysis of Illustrated Print

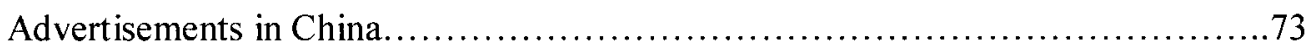

Figure 3-3 Theoretical Framework for Critical Metaphor Analysis of Illustrated Print

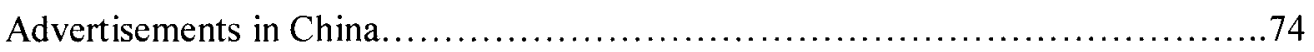

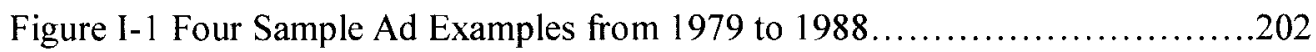

Table I-2 Four Sample Ad Examples from 1989 to $1998 \ldots \ldots \ldots \ldots \ldots \ldots \ldots \ldots \ldots . . \ldots 203$

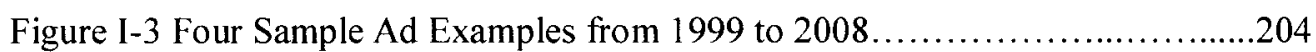

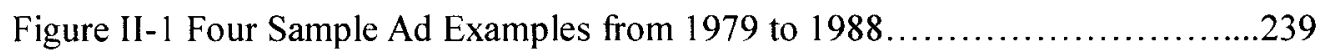

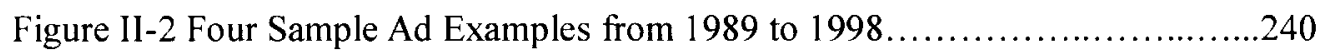

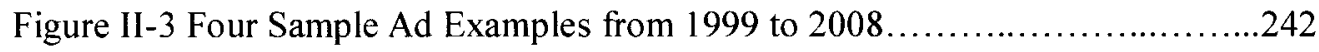


Advertising is the greatest art form of the twentieth century

Marshall McLuhan (1911-1980)

Canadian author

\section{CHAPTER 1}

\section{INTRODUCTION}

\subsection{Research Background}

Throughout almost all our life we are treating things as signs. All experience, using the word in the widest possible sense, is either enjoyed or interpreted (i.e. treated as a sign) or both, and very little of it escapes some degree of interpretation. An account of the process of Interpretation is thus the key to the understanding of the Sign-situation, and therefore the beginning of wisdom. It is astonishing that although the need for such an account has long been a commonplace in psychology; those concerned with the criticism and organization of our knowledge have with few exceptions entirely ignored the consequences of its neglect (Ogden \& Richards, 1989, pp.50-51).

This quotation comes from a book The Meaning of Meaning written by two British authors that dates back as early as 1923. It is a pioneering work about the science of symbolism, and about how language influences thought. Today, many still consider it relevant and insightful when read particularly with regard to its founding model of the semiotic triangle (symbol-thought-referent). It is a model of how linguistic symbols are related to the object that they represent. 
Figure 1-1 The Semantic Triangle of Ogden and Richards

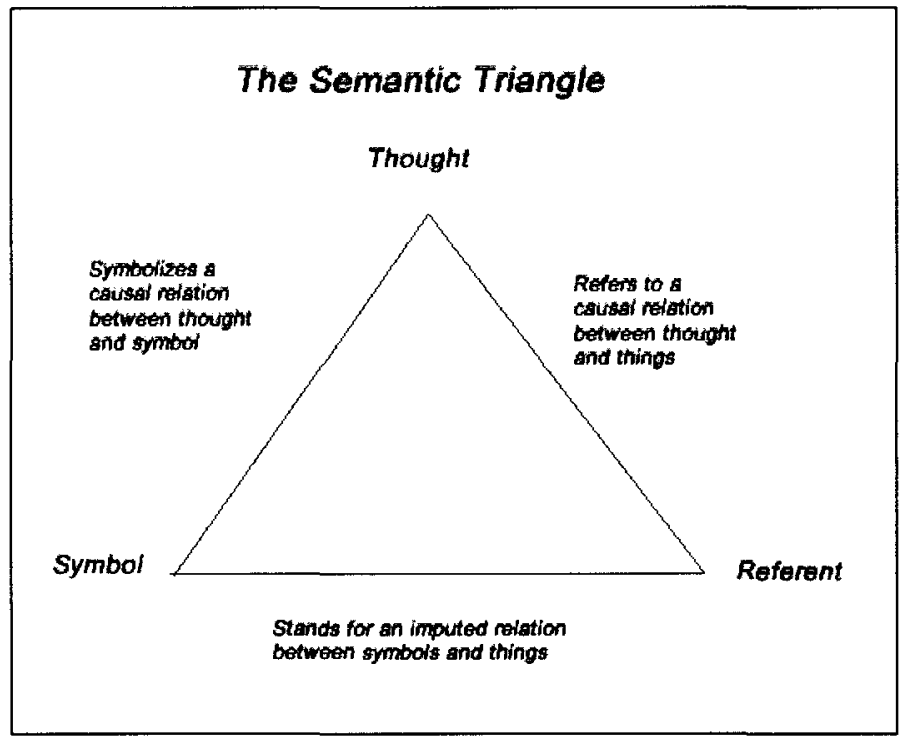

Thought in this model refers to meaning; symbols are the graphic devises used to express meanings; and referents refer to the non-linguistic thing in the world that is talked about. Most importantly, there are certain causal relationships that Ogden and Richards wanted to capture by means of their semantic triangle, viz. the relations between the triangular corners may be phrased more precisely in causal terms as follows:

1. The matter evokes the writer's thought.

2. The writer refers the matter to the symbol.

3. The symbol evokes the reader's thought.

4. The reader refers the symbol back to the matter.

Ogden and Richards argued that a major problem in human communication occurs when a speaker attempts to treat words as if they were things in reality. This is why the 
relationship between a symbol and a thing is an imputed relationship. Nevertheless, people tend to confuse "symbol" or "word" with the thing or object in reality. In addition, Richards went on to argue that words do not have a single meaning. For him, the meaning of words is determined by the past (and current) experiences of speakers who encounter these words in specific literary contexts. Since speakers interpret words with a background of unique experiences, each and every speaker is bound to interpret the same word in a unique and different way. Misunderstandings, therefore, result from speakers having different references for the same symbol. One of the reasons why these scholars are relevant to this dissertation is because they argue that metaphors are highly effective in facilitating comprehension and therefore minimizing misunderstandings. In discussing metaphors, Richards makes use of two terms: "tenor" and "vehicle."

Figure 1-2 Tenor and Vehicle

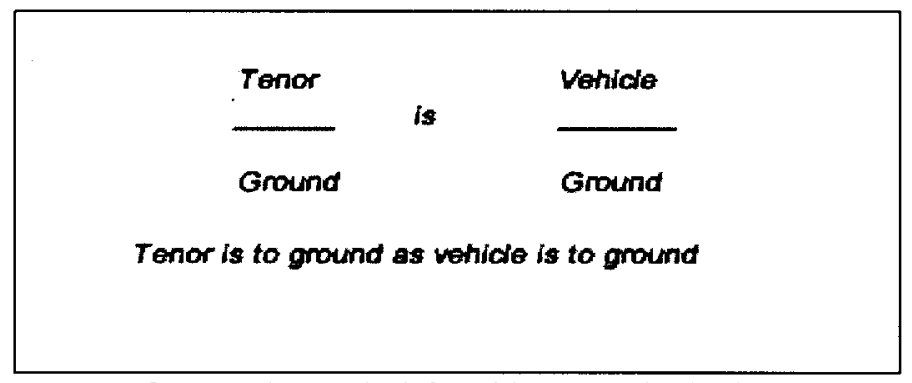

The tenor refers to the underlying idea or principal subject of the metaphor. The vehicle conveys the underlying idea, the borrowed idea, or what the tenor resembles. How they used these terms can be readily explicated by considering the metaphor, "John is a tiger." "John," the topic, represents the source of the metaphor. "Tiger" is the vehicle because it is the thing commented upon and is the target of the metaphor. As St. Clair (2004) has noted, the ground is the semantic basis for comparison, and in this case it 
would have to be an attribute such as "brave" or "strong." In other words, the metaphor represents a kind of analogy, viz., "John is strong as a tiger is strong." The common ground is the adjectival form "strong." Because other adjectives could be used, this common ground is also a symbol. What this means, in essence, is that the metaphor "John is a tiger" also implies other attributes characteristically associated with this ground adjective. Consequently, "John is a tiger" implies that Topic is to Ground as Vehicle is to Ground.

Figure 1-3 Topic and Vehicle

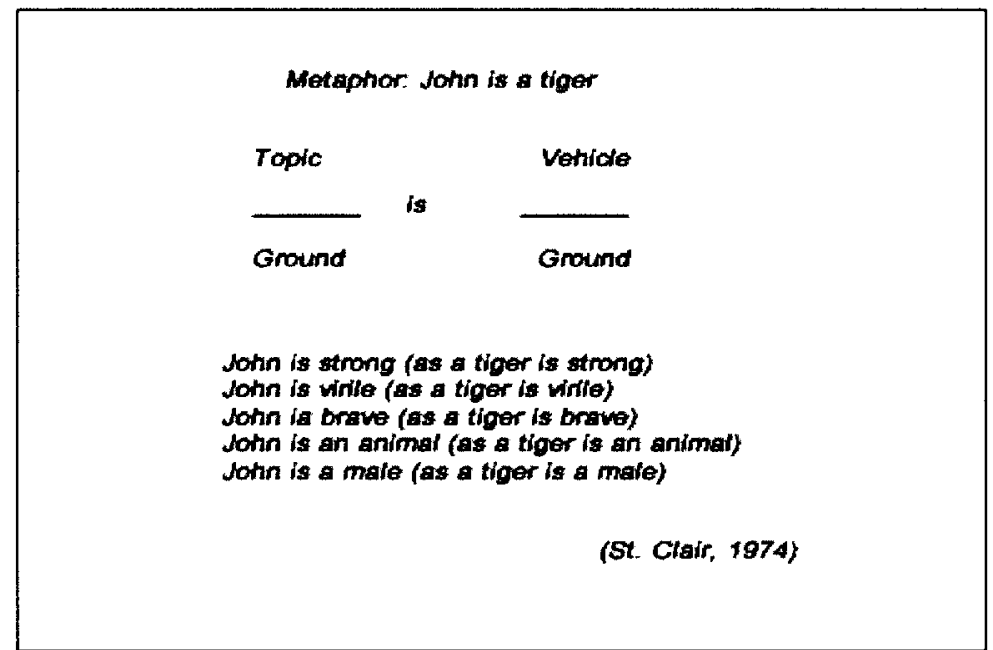

Ogden and Richards (1989) have made valuable contributions to the study of semantics and many noted scholars have benefited from their insights. Claude LéviStrauss (1972), for example, used the semantic triangle to explain cultural symbols.

Figure 1-4 Claude Lévi-Strauss's Culinary Triangle 


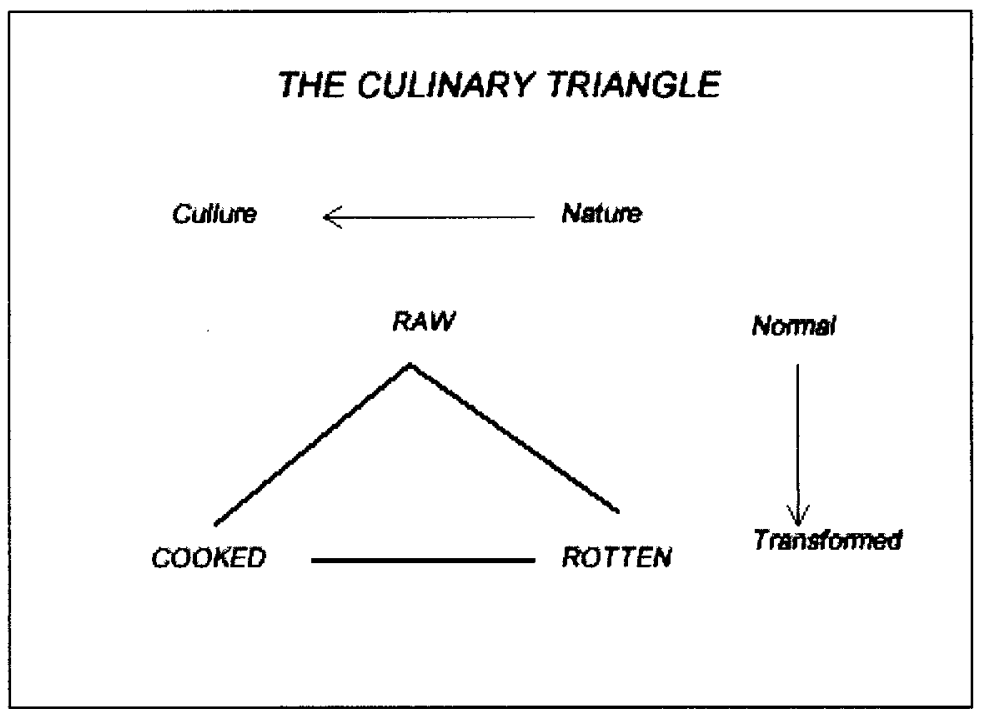

The Meaning of Meaning has provided thought-provoking ideas and general guidance for this dissertation-the semiotic triangle diagram; the sign-situation; and their analysis of perception. The book has also enlightened the author about the necessity of making account of interpretation process of signs, in particular the neglected process of interpretation on one of the more influential instruments of persuasion in business communication-advertising.

Therefore I intend to endeavor in this direction by collecting a large number of sample data signs based on advertisements in China's 30 years of development in which I investigate their sign-situations, interpret their linguistic and semiotic meanings and make critical metaphor analysis on them. Hopefully, the provision of a systematic interpretation of the signs in advertisements using relatively scientific methods can improve our understanding of the miracle and myth of China's recent development—demonstrated as a general increase in the social welfare and living standard. 
The other rationale behind the reason why I choose to explore this investigation area is based on previous contributors in mass communication theory who have defined the reciprocal relationship between the mass media and society. To be more specific, l believe that a systematic analysis of a group of sample advertisements (containing signs of both text as well as images) can reflect a society's evolving change. Human beings are sign-using animals. Sign language is essentially rooted in the reality of the culture, the communal life and customs of people and it cannot be explained without constant reference to these broader contexts of verbal text and pictorial images.

Advertising is viewed as the ultimate cultural commodity (Hay, 1989; Jhally, 1987).... Compared to other forms of mass media content, advertising comes closest to fitting older Marxist notions of ideology. It is intended to encourage consumption that serves the interest of product manufacturers but may not be in the interest of individual consumers. Advertising is clearly designed to intrude into and disrupt routine buying habits and purchase decisions (Baran \& Davis, 2003, pp.334-335).

Advertisements are what some critics call 'specific representational practices' and produce meanings which cannot be found in reality...In order to gain better understanding of the role that advertising plays in our society, we need to ask how advertising organizes and constructs reality, how ideology and meanings are produced within the ad discourse and why some images are the way they are, or how they could have been constructed (Dyer, 1997, p. 114).

Previously many well-known researchers have contributed to answer the most prominent media research question: to what extent media will influence mass media 
society or mass cultural society as a whole? Even though some significant results have been shown such as Lazarsfeld' 's widely recognized limited effects perspective, European's Neomarxist social theory ${ }^{2}$ and British Cultural Studies ${ }^{3}$, more explorations on a wider social cultural context are desired to further accomplish their work. We are now living in the era of moderate media effects perspective which combines the communication science, social semiotics theory and the media literacy (Baran \& Davis, 2003, p.18). It appears that the study of advertising, which is one of the fastest developing modes of mass media communication and one of the more significant mediated graphic forms of the twentieth century, can provide an adequate account of advertising in China through the aforementioned hermeneutic processes: social semiotics theory, conceptual metaphor theory, as well as critical and cultural studies.

Of course it must be stated very clearly that not all advertisements (signs) make complete sense, particularly in singular cases. Not all of them are meant to promote or imply acceptance of social values that everyone would agree. Some advertisements appear to degrade our images of ourselves, our language, and intend to move the emphasis of interaction in our society to (even more) consumerism. What is more, not all the advertisements can be interpreted correctly due to its polemic and metaphorical nature. This problem is hardly surprising as any research will have its methodological limitations and perspective inadequacies. Meanwhile consensus seems to have been reached that

\footnotetext{
'Lazarsfeld (Lazarsfeld, Berelson, and Gaudet, 1944) believes that the power of media can not be assumed but must be proved by hard evidence. Contrary to his assumption his research proved the opposite-media were not as nearly powerful as previously imagined.

${ }^{2}$ Some European social theorists believe that media enable dominant social elites (people who occupy privileged position in a society) to maintain their power. Media provide the elite with a convenient, subtle, yet highly effective means of promoting worldviews favorable to their interests.

${ }^{3}$ It is a perspective that focuses on mass media and their role in promoting a hegemonic worldview and a dominant culture among various subgroups in a society.

(Sources for footnotes 1, 2, 3 are: Baran S. J. and Davis D. K. (2003). Mass Communication Theory-Foundations,

Ferment, and Future Wadsworth, Thomson Learning pp. 15-17)
} 
modern society is now living in a fetish mass media society and indeed a consumer society, and it is highly capitalistic and globalized in the simplest sense. There is no doubt that modern advertising promotes a consumer culture, and helps create and perpetuate the ideology that promotes the apparent need for the products its markets, and just because of these factors the advertisements, with its rich signs and symbols, are ideal research subjects to both illustrate the interpretation process (human organization of knowledge) and demonstrate the ideological (value) of changes (human progress of wisdom).

Nicholas Mirzoeff (2003) in his edited book The Visual Culture Reader has demonstrated the visual power, the interdisciplinary nature and the development of visual culture studies over the last several decades. Part two of the book 'plug in theory' includes many well-known theorists in visual culture studies such as Rene Descartes, Karl Marx, Marshall McLuhan, Roland Barthes, Jacques Lacan, Louis Althusser, Jean Baudrillard, and Judith Butler and many others ${ }^{4}$. It is my belief that visual culture will become an emerging and rapidly changing discipline in the $21^{\text {st }}$ century. With unprecedented strength and speed, the contemporary visual communication influences every level of society. Mass media such as television, movies, newspapers, magazines, and the internet, in particular, are making and disseminating various kinds of visual symbols or icons day by day. It can be argued that with the shift from print culture to visual culture one involves a transition from a rational mode of discourse in which

\footnotetext{
${ }^{4}$ A complete name list of the writers in this book The Visual Culture Reader edited by Nicholas Mirzoeff is given here. They are Irit Rogoff, Ella Shohat, Jonathan Beller, W. J .T. Mitchell, Rene Descartes, Karl Marx, W. E. B DuBois, Marshall McLuhan, Frantz Fanon, Roland Barthes, Guy Debord, Louis Althusser, Jean Beaudrillard, Judith Butler, N. Katherine Hayles, Kobena Mercer, Paul Virilio, Nestor Garlia Canclini, Arjun Appadurai, Nicholas Mirzoeff, Lisa Bloom, Michel Foucault, Geoffrey Batchen, Wendy Chun, Lisa Nakamura, Thomas Campanella, Lisa Parks, Anne Friedberg, Lev Manovich, May Joseph, David Joselit, Tara McPherson, Toby Miller, Andrew Ross, John Fiske, Anne Reynolds, Michelle Wallace, Barbara Kirshenblatt-Gimlett, Marita Sturken, Donna Haraway, Lisa Cartwright, Anne Balsamo, Amelia Jones, Terry Smith, Timothy Mitchell, Anne MeClintock, Malek Alloula, Suzanne Preston Blier, Jill Casid, Adrian Piper, Coco Fusco, Olu Oguibe, Orianna Baddeley, Anthea Callen, Lynda Nead, Tamar Garb, Thomas Waugh, Reina Lewis, Jos Munoz
} 
language plays an inherent part to a visual medium that encourages emotional reactions to graphic information. In other words modern society is moving away from a dominant print culture into a mediated visual culture. This means, in essence, that hypo-deductive reasoning is not used, which involves the deductive arrangement of hypothesis using the syllogisms of logic. This form of thinking is being supplanted in popular culture by another kind of arrangement of ideas that are emotionally connected to a mediated visual culture. This new tendency is called analogical thinking (Dondis, 1972). Hence, there is a movement in the age of television towards a secondary orality (Ong, 1982) in which group behavior is based on visual and oral scripts. In addition, there is the rise of consumer culture in which advertising provides new scripts for human interaction in the sociology of everyday life (Ewen, 1972; Ewen and Ewen, 1982). The new age of television has created an information overload which Alvin Toffler refers to as Future Shock (1970). Toffler, it should be noted, include both print and visual information in his description of new postindustrial society. Therefore it is not only unavoidable but also necessary to focus on visual metaphors and visual symbols in this investigation. The modern world is a visual world (Arnheim, 1988, 1974, 1969; Baudrillard, 1965; Bernes, 1973; Debord, 1995). The colorful and powerful effect of visual images has made visual communication specialists take full advantage of this shift from print to visual culture. They have learned how to control visual culture for both political and public events. They have used it for business promotions such as in advertising. In addition, visual economy (or the attention-span economy of Innis) has become the talk of the day as never before in the human history (Innis, 1950, 1952). Consequently, the study of visual images in cultural symbols and cultural expressions arises quickly. Architecture, 
photography, movie, TV program, artistic work and advertising are all the important objects for the study within the scope of visual culture ${ }^{5}$.

Previously many investigations have been done on advertising. Even though many of them focus on the languages (advertising copies and slogans), the functions (business and social cultural influences), the classifications or rhetorical devices of advertisements, my focus is to use content analysis to identify words within a large data base and to apply social semiotic theory and conceptual metaphor theory. I will also take into consideration the ideological background in which these images in illustrated print advertisements are placed. This will allow me to comment on the dominant values in these prints within different periods of political and social change within China. The result will allow me to establish an identity for different periods of group behavior as evidenced in visual and cultural scripts. Some scholars (Roland Barthes, 1967; Judith Williamson, 1978; Gillian Dyer, 1982 etc) have already done researches in the last few decades from a similar perspective, but so far not enough attention has been given to the way the semiotic images in advertisements should be categorized and interpreted. This systematic research and categorization of semiotic images in advertisement merits further consideration in the light of tremendous number of commercial and public advertisements released by different media channels in China. Therefore it makes a reasonable argument that a study on the visual images from a semiotic perspective is necessary and significant.

In addition to the study of the role that visual images play in the sociology of everyday life, there has been a renewed focus on the culture of modernity. As a matter of fact, "culture has become a crucial means by which many social scientists understand

\footnotetext{
${ }^{5}$ The term 'visual culture' should be used carefully. The debate about the term can be referred to October in 1996. For the five aspects of the term and the summary of the literature please refer to Gillian Rose's Visual Methodologies. Pp. 10-14.
} 
social processes, social identities, and social change and conflict" (Rose, 2005:5). This emphasis on the culture theory is elaborated by Stuart Hall, a major contributor in cultural studies:

Culture, it is argued, is not so much a set of things-novels and paintings or TV programs or comics—as a process, a set of practices. Primarily, culture is concerned with the production and exchange of meanings-the 'giving and taking of meaning'-between the members of a society or group...Thus culture depends on its participants interpreting meaningfully what is around them, and 'making sense' of the world, in broadly similar ways (1970, p. 2).

Since the culture of modernity is highly influenced by the advertising business, this dissertation comments on business culture and its role in advertising. However, this perspective is not concerned with economics, finance, marketing, or management. It is concerned with the perspective of language, image, metaphor, and cultural expression as they form a critical component of modernity within both western and Chinese civilization. Hence, this investigation is also about the use of multimodal visual images in mass communication. Multimodal visual images are often accompanied by some text and I have taken this aspect of print advertisements into my analysis. After all, the words that are embedded within advertisements were deliberately designed by the advertising agencies to shape the way business people communicate with their consumers. However, explicit or implicit, conscious or unconscious, the advertising designers have played the role of and acted as the change agents that drive reality construction and social change. In other words I argue that advertising messages both verbalize and visualize social differences and social change. For well-known companies and successful marketing 
campaigns use advertisements to a certain extent to reflect their business philosophies and their power and their contribution to social construction (change). Hence, they play an important role in the nature of the ideology and changes in identity taking place in China.

\subsection{Purpose and Significance of the Research}

This investigation makes a contribution to both theoretical and practical significance to the study of advertisement. It is concerned with how companies (power elite and their management of information) in mainland China use words and images (verbal symbols and visual metaphors) to express their business philosophies, social and cultural concerns. In other words this dissertation is about how words and images in advertisements try to shape and influence the way people, who are undergoing tremendous economic transition and social culture change, think about the value orientation and act as group members of a society. As St. Clair (2006) has said, "Language is culture-laden. It is not a neutral code of expression." For similar reasons, the expression of signs in advertising is not neutral. The prevailing ideology in the form of a cultural habitus and the way in which events are embedded in particular periods of social and cultural history plays a role in how advertisements are constructed. This is the reason why the deliberate selection of words and images that are chosen by the copywriters and art designers in the industry play a significant role in the process of social construction. They re-enforce certain values, modify others, and re-new certain values over others.

It should be noticed that another purpose of writing this essay is to determine to what extent Chinese culture has played a role in the form of metaphors in business advertisements and to specify how pictorial metaphors are culture-bound and culture- 
specific. My investigation will illustrate the metaphorical nature and instrumental function of advertisements in the process of China's quick social change and modernization. As noted earlier, visual metaphors are effective and widely used in advertising because they involve analogical thinking rather than hypo-deductive thinking characteristically associated with print culture (St. Clair, 2002).

In the last 30 years, $\mathrm{China}^{6}$ has gone through tremendous cultural changes and social progress. All of this has happened within the span of one generation. In this short period of time, China has successfully transformed itself from a closed command and planning economy to an open global exporter and full participant in world trade. This transformation can be described and represented from many perspectives that were once foreign to Communist China. For example, China has participated in the landmark events of privatizing land; it has also established Special Economic Zones; it has encouraged the rise of private ownership; and it has fostered township enterprises. The most significant event, however, has been the entrance of China into World Trade Organization. This event along with the globalization has quickened the step of urbanization and migration from the farms to the big industrial cities. The result has been a prevalent consumer culture. Because of its rapid growth and social change, China has attracted the attention and research interest of many of the leading scholars and contributors from all over the world. What has happened during these transition periods? In what ways the economic, political, legal, social, cultural, and technological changes have fundamentally changed the lives and the lifestyles of Chinese people. The impact of these changes can also be seen with the use of advertising because they have reflected the changes in what the

\footnotetext{
${ }^{6}$ The term 'China' is used throughout the dissertation to mean 'mainland' China, excluding Hong Kong, Macao and Taiwan.
} 
Chinese people think and what they believe. It is normal for advertisers to ask what the Chinese people believe and how they identify themselves. In another word what kind of socially constructed lives that these politically and commercially motivated companies would like to accomplish in China. How do they want the Chinese people to identify themselves? I believe that advertising functions as a complex multifaceted focal point that connects business organizations, society and consumer.

Figure 1-5 The Multifaceted Nature of Advertising

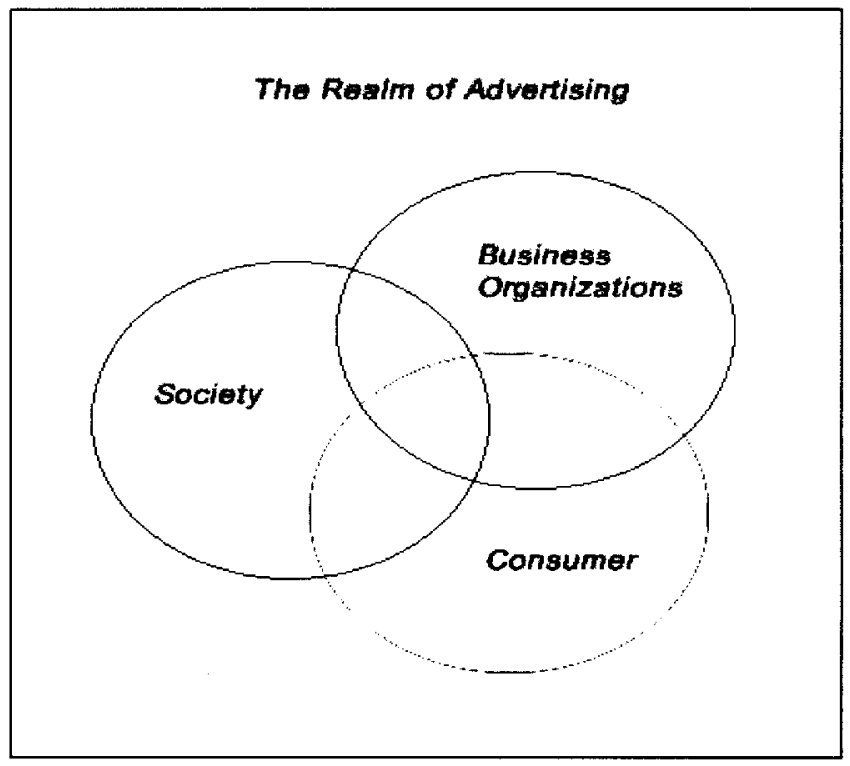

A more realistic depiction of this graph that captures the role of business in the culture of modernity would be to have business organizations as the outer circle which engulfs a consumer society.

Figure 1-6 The Power of Business Organizations on Society 


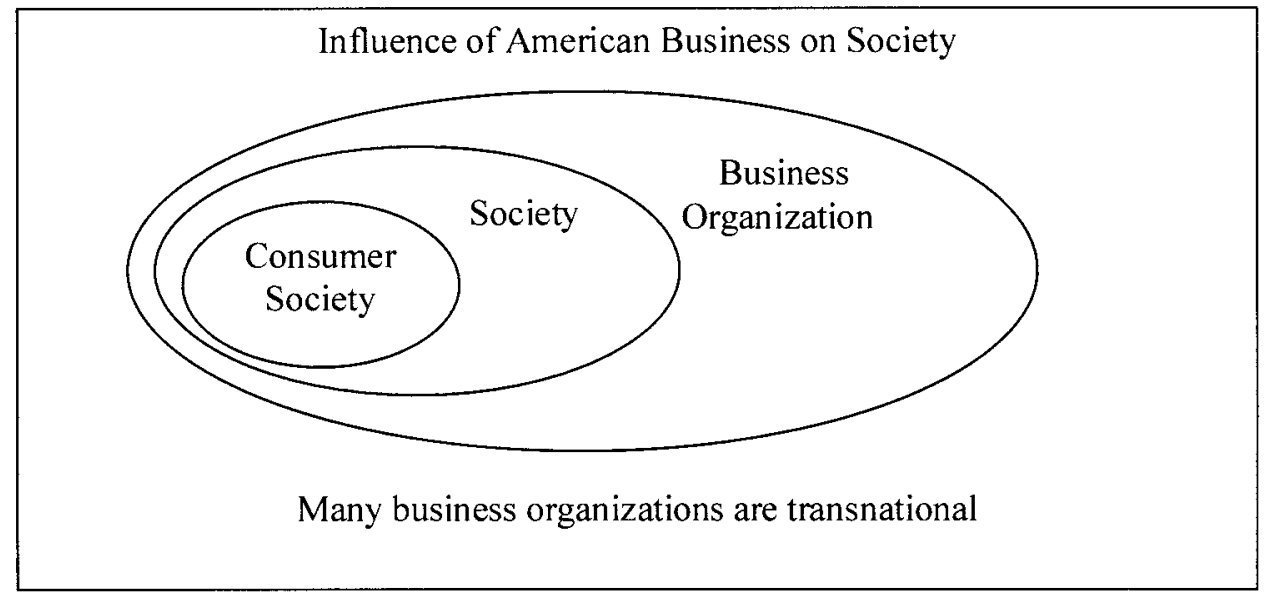

Although many modern societies are dominated by big business, it is not clear from my research that China has reached this stage of economic hegemony. The study of the use of mass media in advertising can be used as a probe to better understand the context of this economic situation in China. However, my interest is not to focus only on the economic model. I want to explain social changes that include the role of advertisements with in the sociology of everyday life.

Even though academic research has been done on advertising, most of them focus on the advertising strategies, appeals, media choice and advertising copy and slogans. Few scholars, with the exception of those involved in cultural studies, have studied it from an interdisciplinary perspective. Consequently, I want to study advertising from a combined, integrated, holistic and multi-perspective approach of metaphor theory, visual culture theory, social semiotic theory, and mass communication theory. I see illustrated print advertisements, for example, first and foremost as a communication tool. But unlike other communication tools, it contains both verbal words and visual images. With the help of the visual images the designer of advertisements intends to promote the consumption of 
products and to encourage a culture of consumption (Ewen, 1977). They want to make consumers identify with the images that they portray. For this reason, I want to study the successful advertisements in China and the way in which verbal and visual signs have represented the newly emerging ideology and identity changes in Chinese culture. There has been a power shift and a change in value orientation that merits an interdisciplinary investigation and I will limit my research paradigm to the role that advertising plays in this culture of modernity in China. As noted earlier, profit-driven organizations, especially multinational corporations, when doing publicity or marketing in other countries, try every means and methods to achieve both reach and creativity in their advertisements in order to inform and persuade consumers. Therefore, the question of how to make full use of advertising as a communication medium and how to improve the visual power and effectiveness of relevant advertisements has become an urgent task of all the companies in China, which has a large population and market. Researching this subject carries a practical significance for both foreign and local companies alike.

\subsection{Research Assumptions and Questions}

This dissertation addresses three questions based on the following three assumptions.

- First given that both individuals and societies are not just reality but socially constructed reality, the author believes advertising being at a focal and multifaceted point to connect companies, individual consumers and a society, the constructions of written texts and visual images of advertisements as shown in different periods of China's development can crystallize and pinpoint the ideology and identity changes in China. 
- Second, as mentioned above, commercial advertising, as a means of communication tool, due to its 'metaphorical nature' and 'instrumental function/mission', embodies certain pictorial metaphors that are advertisers' intentions to both influence and promote certain trend in ideology and social identity of the target consumers in a certain period of time.

- Third, a content and critical and interpretive analysis of the pictorial metaphors hidden behind words, images and symbols in the advertisements of specific periods helps bring out the social and cultural change of that period happened in Chinese society. Based on these three assumptions the author intends to explore into three specific questions.

The first task has to do with content analysis (cf. Appendix I, II) of systematically identifiable key words from advertisements' captions and copies in the three 10-year periods of $1980 \mathrm{~s}, 1990 \mathrm{~s}$, and $2000 \mathrm{~s}$. Thus the first research question is to what extent the Frequently Appeared Words (FAW) reflect advertiser's key messages and the value themes? With regard to the approaches that advertisers use to appeal the customers, what advertising appeal (functional, personal and social appeal) is used in each advertisement? How do FAW and APPEAL used in each specific period reflect evolving ideology (value orientation) and identity (who am I or what do I want to be) changes? This systematic linguistic inquiry into the verbal key words and the categorization of the key words offers clues and insight into the later identification of pictorial metaphors and critical analysis of the pictorial metaphors.

The second task is concerned with pictorial metaphors. The second research question asks what the systematically identifiable pictorial metaphors and frequently appeared 
images are that can show ideology (value orientation) and identity (visual scripts as group behavior pattern) changes in China in the last three decades. In order to answer this question, metaphorical statements with the primary subject and secondary subject match and the projected features must be identified. In another word, unique features that the signifieds from source domain projected upon the signifiers from target domain based on collected sample key words, visual images and symbols must be identified. This is done based on conceptual metaphor theory, Forceville's pictorial metaphor method and Gillian Dyer's recommended method for analysis of photographs in the ads. Gillian Dyer (1990) recommended four representational image categories, namely appearance, manner, activity and props and settings (pp. 97-106). The author has redefined and omitted certain items in each category in order to satisfy the research purposes. Possible results for this investigation will include representational image categories and most frequently used images with signifieds, projected features and visual scripts or image patterns.

The third task is based on the linguistic analysis of the FAW and APPEAL and semiotic analysis of pictorial metaphors for each period (c.f. chapter three and appendices I, II). I have conducted a critical and interpretive analysis from the resulting data based on the dictum of 'facts speak louder than words'. With the cumulative data the third research question is to answer how ideology and social identity changes of China in the last 30 years have taken place and to what extent they are coherent with and conform to or contradict with the overall social construct and social change. To answer this question the ideology theory of Marxism and Neo-Marxism, the social semiotic theory, Hofstede's national cultural theory and Alexander S. Haslam's social identity theory will be applied. The overall research construct for the whole dissertation is shown in the table 1-1. 
Table 1-1 Overall Research Construct for the Whole Dissertation

\begin{tabular}{|l|l|l|l|}
\hline $\begin{array}{l}\text { Linguistic, semiotic and } \\
\text { critical data (collection } \\
\text { \& treatment) }\end{array}$ & $\begin{array}{l}\text { Ideology change } \\
\text { (what is the } \\
\text { evolving value } \\
\text { orientations) }\end{array}$ & $\begin{array}{l}\text { Identity change } \\
\text { (who am I as in } \\
\text { group behavior) }\end{array}$ & $\begin{array}{l}\text { Overall congruity } \\
\text { with the social } \\
\text { cultural } \\
\text { environment }\end{array}$ \\
\hline $\begin{array}{l}\text { Frequently appeared } \\
\text { words \& metaphorical } \\
\text { images from 1979-1988 }\end{array}$ & & & \\
\hline $\begin{array}{l}\text { Frequently appeared } \\
\text { words \& metaphorical } \\
\text { images from 1989-1998 }\end{array}$ & & & \\
\hline $\begin{array}{l}\text { Frequently appeared } \\
\text { words \& metaphorical } \\
\text { images from 1999-2008 }\end{array}$ & & & \\
\hline
\end{tabular}

Since the illustrated print advertisements of well-known and successful companies in China are the major research subject, the author has collected 300 sample advertisements with both text and picture in each one and develops the argument that advertising as a media discourse can collectively reflect social cultural change in a given society. China's last three decades of social change and development will be divided into 3 basic periods with 10 years as the duration of each period. This is a working hypothesis. Even though there may be no clear-cut social transformation and it can be dangerous to generalize social change and put a label on each period, it is always unavoidable to stigmatize certain period as being more prominent in one feature while others in other features in a progressive pendulum. For the sake of comparison and argument development the author has operationally collected and analyzed 100 samples from each period of 1979-1988, 1989-1998, and 1999-2008 respectively, making a total of 300 sample advertisements.

\subsection{The Organization of the Dissertation}

To effectively establish and develop my argument, the dissertation is composed of six chapters. 
Chapter one is the general introduction to the whole dissertation: its research background, research motive on which the argument is established and three research assumptions and research questions. It is in this chapter the research topic and its significance is contextualized and justified.

Chapter two is the literature review on the relevant theories and previous researches and approaches towards advertising studies. It is meant to provide an academic background and research platform for the future development of the argument. No effective research can be done without establishing a forefront and foundation based on the previous knowledge system and contributors.

Chapter three is the theoretical framework and research methodology. In this section the author establishes a workable theoretical framework and explains the interpretation process of a quantifiable advertisement signs of 300 as data collection, treatment, and analysis. The theoretical framework is based on Critical Metaphor Analysis (CMA) and the research methods are a combination of content analysis, linguistic analysis, semiotic analysis and critical interpretative analysis. A detailed research plan and procedure has laid solid foundation for the development of the argument and it is shown convincingly the interplay relationship between media discourse, sign situation and social change. Owning to the nature of advertising study the methodologies per se are based on interdisciplinary theories and a holistic and multi-perspective approach.

Chapter four is the critical metaphor analysis of the 300 illustrated print advertisements in which I explain in detail how signs in advertisements are both the mirror and carrier of the social change. Based on the linguistic and semiotic analysis of the ad signs, which can be found in findings from chapter three and two appendices I put 
the results into the general economic, social, legal and cultural environment in China in order to rationalize and interpret the research findings in view of ideology and identity changes. It is expected that the research findings are in congruity with the overall social and cultural development in China. This means symbols in advertisements in different periods of 1980s, 1990s, and 2000s in China serve the instrumental mission of ideology and identity shift by manipulating people through an objectifying and subjectifying process.

Chapter five is the summary of the research findings from the sign interpretation process and critical metaphor analysis. Conclusions are drawn related to discursive and metaphorical changes. Both theoretical and practical significances have been explained and compared with the previous studies. Meanwhile limitations and further research areas are pointed out.

Chapter six contains the cited references and bibliography.

The two appendices in the end of the dissertation both account for the ad sign interpretation process and act as the foundation of supporting data for interpretative critical metaphor analysis. Appendix I illustrates the result of step-by-step linguistic analysis to the captions, slogans or ad copies of the 300 sample advertisements. The resulting frequently appeared words (FAW), advertising appeals and ad themes are categorized and analyzed with regard to the tendencies and trends they represent for each specific period of time. They serve as the data base for CMA analysis of chapter four.

Appendix II illustrates the result of semiotic analysis to identify the pictorial metaphors and representational image categories from 300 sample advertisements collected based on the theoretical as well as methodological data processing framework. 
Hopefully together with the research findings in appendix I the pictorial metaphors will produce the consistent result and will be able to support to a certain extent the ideological and identity changes happened in the last 30 years in China. It is also served as the data set for CMA analyses of chapter four. 
There can be no words without images.

Aristotle, 384-322 B. C. E.

Philosopher, Scientist and Educator

\section{CHAPTER 2}

\section{LITERATURE REVIEW}

The background for this research is based on the fact that the past three decades have eye-witnessed tremendous social, cultural and underlying ideological changes in China, which were officially initiated in November 1978 by Deng Xiaoping at the Third Plenary Session of the Eleventh Congress of the Chinese Communist Party, where the late Chairman Mao Zengdong's ideology of class struggle was replaced by the ideology of socialist "Four Modernizations" (modernizations of agriculture, industry, science and defense). With this new vision setting on agenda of the Chinese Communist Party which focused on two key words "economic reform" and "opening-up" China embarked on a modernization process which gradually changed the whole panorama with fast speed economic development and equally fast pace of social, cultural and ideological changes. The extent and scope of changes are far beyond the imagination of the country's leaders and the ordinary people alike. However, academic researches and scholarly contribution to the fast development and changes of China in the last 30 years are far lagging behind and unparalleled with the economic development and social change. So far more researches have been done on the macro and economic perspective; yet few studies have 
attempted to address the issue from the micro and discursive perspective. Therefore the present research will adopt a holistic and trans-disciplinary approach of Critical Metaphor Analysis (CMA) to address the issue of ideology and identity change in China from the visual metaphor and visual culture perspective. It is meant to illustrate how and to what extent media discourse such as advertisements can reflect and enhance social cultural change in three periods of 1980 s, 1990s and 2000s in China. Naturally the literature review will mainly be focused on previous advertising studies in the scopes of advertising as discourse, as communication, and as visual metaphor. Meanwhile Critical Metaphor Analysis, semiotic approach and content analysis that serve as both theories as well as research methods will also have to be explained and reviewed so that a comprehensive theoretical framework and analytical model based on CMA can be worked out as the guideline to help develop the argument and meaning explanations of the later chapters of three, four, and five.

\subsection{Literature Review on Advertising}

\subsubsection{Definition and History of Advertising}

Advertising can be divided into governmental or institutional advertising, political advertising as well as commercial advertising. In this dissertation the research subject is not institutional or political advertising but commercial consumer advertising which attempts to persuade its audience to purchase a good or a service. Despite its ubiquity advertising is not an easy term to define. Advertising means different things to different people. It can be an industry, a business, an art, an institution, and a cultural phenomenon. 
American Marketing Association defines the advertising $^{7}$ as 'the placement of announcements and persuasive messages in time or space purchased in any of the mass media by business firms, nonprofit organizations, government agencies, and individuals who seek to inform and/or persuade members of a particular target market or audience about their products, services, organizations, or ideas'. Wikipedia, the free encyclopedia, defines advertising as 'a form of communication intended to persuade its viewers, readers or listeners to take some action'8. Albert Davis Lasker, an American businessman who is often considered to be the founder of modern advertising, believed that advertising was news. His definition of advertising was opposed by John E. Kennedy who offered a simple three-word definition 'salesmanship in print'. An early advertising success story is that of Pears Soap. Thomas Barratt married into the famous soap-making family by launching the series of ads featuring cherubic children which firmly welded the brand to the values it still holds today. He took images considered as 'fine art' and used them to connote his brand's quality, purity (i.e. untainted by commercialism) and simplicity (cherubic children). Stanley Resor was taken to be the first man to promote advertising into a scientific field. Most of his contribution to advertising is through practice rather in theories. Raymond Rubicam was the first person to bring market and consumer research into advertising design process. Claude Clarence Hopkins proposed several principles for advertising industry. The most impressive principles are: Effective advertisement should tell a whole story. If possible, we try our best to shape a personality which can make his product popular by making himself popular. David Ogilvy, a founder of Ogilvy \& Mather, believed that advertising should be the media of communication, and not a form of art.

\footnotetext{
${ }^{7}$ The definition comes from American Marketing Association's website marketingpower.com, the dictionary at http://www.marketingpower.com/ layouts/Dictionary.aspx

${ }^{8}$ Source: http $/ /$ en.wikipedia.org/wiki/Advertising
} 
Also, he enlightened the application of consumer research and created a brand new advertising culture.

In the world history, advertisements appear in early ancient times with announcements or notice for sales or services on the cave wall, cloth, and paper. It is safe to say advertising has responded to changing business environment, media technologies, and cultural contexts. However it is not until 19th and 20th century that commercial advertising has truly become a big industry offering jobs in advertising agencies as copy writers, art directors, and idea creators as well as in different media channels such as newspaper, cinema, radio, television, outdoor posters and internet in recent years. Advertising takes full advantage of each emerging new mass media tool to induce the consumers to respond to the need creation message of advertisers. That's why modern advertising contributes to the development of monopoly capitalism by intimately bounding itself up with the emergence of new forms of media across the whole 20th century. It has become one element in corporate strategies to create, organize and where possible control markets, especially for mass produced consumer goods. Nowadays advertising has become central to the contemporary global economy and the reproduction of global production networks. Mass production necessitated mass consumption, and this in turn required a certain homogenization of consumer tastes for final products, thus the appearance of 'cultural convergence' such as Coca Cola culture, Disney culture, and McDonald's culture to harmonize consumer tastes and forge a convergence of lifestyles, cultures and behaviors among consumer segments across the world. Reflecting on the history and function of advertising, many sociologists, art critics and culture critics challenge the very existence of advertising as a whole, of which Gillian Dyer asks 
"whether consumer advertising gives us enough, or indeed any accurate information, and whether the economic function of advertising is so vital that we cannot afford to do without it whatever the cultural, social and personal drawbacks. We also need to ask who is ultimately benefiting from the advertising of consumer goods-society as a whole, or a few powerful commodity manufacturers and business corporations" $(1982$, p. 4). These questions sharpen the critical edge of advertising study and help people see through the true nature of advertising industry.

\subsubsection{Aspects of Advertising}

\section{Audience and Media Channels}

In the language of advertising, an audience is a group of individuals who receive and interpret messages sent from advertisers through mass media. Five broad audience categories are commonly described: household consumers, members of business organizations, members of a trade channel, professionals, and government officials and employees.

Household consumers are the most conspicuous audience in that most mass media advertising is directed at them. Members of business organizations are the focus of advertising for firms that produce business and industrial goods and services, such as software, supplies and office equipment. Members of a trade channel include retailers, wholesalers, and distributors who are an audience for producers of the former two audiences mentioned above. Professionals are viewed as a special target audience and are defined as lawyers, doctors and other professionals who have received special training or certification. 
Newspaper and magazine are the most accessible medium to the widest range of advertisers. Later, with the rise of public transportation means such as express way, railway, subway and aviation, billboards or posters and mail shoots by post have risen to take a big market share of advertising media channels. Print media has the advantages of large circulation, relatively low cost and easy access, however, it requires consumers to have a level of literacy and it takes time to read seriously.

Cinema, radio and television make advertisements dynamic, multi-modal and entertaining. They are slotted into entertaining radio and TV programs. People can listen to the radio and watch TV commercials while driving or working. Audio and visual commercials can be enjoyed by both literacy and non-literacy consumers thus expanding the number of target audience. This is especially true in China where TV household penetration is 100 percent $^{9}$ and is the major medium channel for people to get information and entertainment. It offers advertising the chance to be all that it can be.

The rise of new media based on computer technology and wireless mobile phone has extended and diversified advertising media and make customized individualized personto-person advertising promotion at everyone's finger tips. In fact, advertising on the new media (internet banner, flash, slot-in, mobile phone short messages etc) has aroused the keen interest of researchers in recent years with new internet language styles and group formation politics because information technology has revolutionized the communication style of people and segmentation and positioning strategies of corporations.

\section{Social Aspects of Advertising}

\footnotetext{
${ }^{9}$ China Convergent along with its subsidiaries and joint venture partners are developing a vast broadband multimedia network that can deliver services through television sets via proprietary decoding set-top boxes. Since the television ownership rate exceeds 90 percent of the population in China (TV household penetration is $100 \%$ )... this delivery channel is viewed as the leading broadband access channel for Chinese consumers. China's existing backbone cable fiber network is well developed with ample capacity to support two-way, in teractive multimedia service expansions for subscriber access. Source: http:/www.thegamesnetwork.tv/cvn.php, March. 5, 2010.
} 
The key social aspects of advertising are related to whether advertising educates consumers or mislead consumers; whether advertising increases the costs of the products that are transferred to individual customers or reduces the price; whether advertising degenerates arts and make people lose the ability to reflect and appreciate or not. Whereas many advertising opponents claim that advertising is superficial and even misleading since it frequently carries little actual or even exaggerated product information, George J. Stigler supports it. In his article "The Economics of Information" he claims that "advertising educates consumers equipping them with the information they need to make informed purchase decisions" (1961, pp. 213-220). He also writes "advertising is clearly an immensely powerful instrument for the elimination of ignorance" (ibid).

Meanwhile many economists believe advertising improves the standard of living due to the economies of scale generated by advertising. However, Richard E. Caves (1967) points out in his work American Industry: Structure, Conduct, Performance that advertising represents an inefficient and wasteful process that channels monetary and human resources in a society to the shuffling of existing total demand. Apart from that advertising does increase the cost therefore the price of the product we buy. According to Philip Kotler, the advertising guru and authoritative textbook writer, out of every dollar we pay for a burger 50 cents go to marketing. The development of huge advertising industry has produced many advertising masters and professional advertising agencies, of which David Ogilvy is an outstanding one. His famous book Ogilvy on Advertising (1983) is a must-read classic on the shelves of the business people. His teaching of regarding advertising not as an entertainment or an art form but as a medium of information as well 
as a form of salesmanship is still firmly held as tenet by many professionals. Jim Aitchison (1999), one of the world's leading ad creatives, writes a book Cutting Edge Advertising that offers a step-by-step plan for creating outstanding $21^{\text {st }}$ century print advertising. Along the way, he presents more than 300 of the world's best ads-each discussed, analyzed and critiqued, frankly and provocatively, by the brilliant creatives responsible for them. Globally-respected names like David Abbott, Tim Delaney, John Hegarty, Gary Goldsmith, Bob Barrie, Neil French and Jeff Goodby from the world's most admired advertising agencies share their secrets in a carefully structured, inspirational journey through the process of creating truly great advertising. All these creative process connotes that nowadays advertising has become so professional and technical with tricks and grinds that it is meant not only pushing up the sales but also making the real use value illusory.

\section{Ethical Aspects of Advertising}

This naturally leads to the ethical dilemma of advertising industry. The same as TV programs, Internet games, and cultural industry, advertising also faces moral hazards. Richard Linnett reported the outcry from the leading child psychologists over advertising aimed at children at the Third Annual Golden Marbles Advertising \& Promotions Awards $^{10}$. The protesters contend that children' advertising not only advocates violence but also is responsible for child obesity, a breakdown in early learning skills and the destruction of parental authority. Advertising can mislead and exaggerate the function of the products and make consumers addicted. Nina Munk, the author of Why Women Find Lauder Mesmerizing in Fortune magazine wrote that "cosmetics giant Estee Lauder spends nearly 30 cents from every dollar of sales to promote its brands as the ultimate

\footnotetext{
${ }^{10}$ Please refer to Advertising Age (November 11,2000) for the detail of the report.
} 
solution for those in search of the ideal complexion...Few companies are as canny at persuading women to spend and spend and keep spending on the unessential." She describes in detail of how Estee Lauder is able to make ladies keep on buying and be addicted to the beauty products.

\section{2 Literature Review on Advertising Researches}

Academic explorations on social-cultural change in Great China over the past three decades have primarily been confined to macro-sociological studies. However, some scholars (Wu, 2008; Feng \& Wu, 2007; Jian, 2000) have pioneered in the linguistic and communication area to carry micro-sociological studies of mainland China by focusing on the Chinese advertisements as discourse. I consider this a good research angle on the account that advertising as a media discourse and a form of business communication is both the carrier and constructor of meaning - representing and acting upon social reality through linguistic-pictorial means in concrete situations. As an inseparable part of social and cultural construct with icons, indexes and symbols integrated into advertising creation, the present dissertation attempts to continue the previous researchers to make a critical metaphor analysis of a large sample size of illustrated print advertisements in China.

Previously well-established researches have been done on advertising from different perspectives. Some of them (Elliott, 1962; Turner, 1965; Leech, 1966; Andren, 1978; Geis, 1982; Vestergaard, 1985; Myer, 1994; Tanaka, 1994; Goddard, 1998; Hermerén, 1999; Cook, 2001; Gieszinger, 2001) focus on the advertising language, history, business functions, and the rhetorical devices of advertisements. Others (Barthes, 1964; Millum, 1975; Williamson, 1978; Goffman, 1979; Dyer, 1982; Halliday, M.A.K. \& Hasan, 1985; 
Goldman, 1992; Kress, 1996; Forceville, 1996) look at advertisements from communication point of view by discussing the words and images in the advertisements from social semiotic perspective. Still others (McLuhan, 1951, 1967; Inglis, 1972; Marx, 1974; Williams, 1980; Foucault, 1983; Baudrillard, 1981, 1996, 1997, 1998; Adorno, 1991; Althusser, 2003; Lacan, 2003; and Butler 2003) look at advertising and capitalist society from cultural study point of view by exposing the fetish character and ideological function or instrumental mission of the advertisements. But so far not enough attention has been given to the way of how the semiotic images in advertisements should be categorized and interpreted in the systematic way so as to see HOW they have collectively reflected or mirrored or represented and constructed social reality and social changes. The researches for the interdependence and interaction between semiotic images in advertisements and social construct have lagged far behind compared to the tremendous number of commercial and public advertisements released by different media channels in different countries in the world. Even though critical discourse analysis led by Norman Fairclough for different kinds of economic, political and media discourse is in blossom in academic field to look at social cultural changes through the discourse change and relation change, yet advertising research as a discourse has not produced convincing result in this regard. In another word, in what way the systematic categorization and interpretation of semiotic images in the advertisements are related to or contribute to the social cultural construct of a given society?

One reason for the difficulty of carrying advertising research lies in its complex trans-disciplinary nature that goes across many disciplines such as linguistics, communication, semiology, sociology, and cultural studies. Edward F. Mcquarrie and 
David G. Mick (1999) summarize the four historical approaches in consumer research for advertising. The four traditions are: the oldest archival tradition (e.g., Assael, Kofron, \& Burgi, 1967) which reports correlations between the presence of certain advertising elements and specific audience responses (e.g., Finn, 1988; Holbrook \& Lehman, 1980; Rossiter, 1981). The experimental tradition systematically varies either the presence or absence of pictures per se (e.g., Edell \& Staelin, 1983) or the nature of some particular visual element (e.g., Meyers-Levy \& Peracchio, 1995) or the processing conditions under which subjects encounter particular visual elements (e.g., Miniard et al., 1991). The reader-response approach emphasizes the meanings that consumers draw from ads (e.g., Mick \& Politi, 1989; Mick \& Buhl, 1992; Scott, 1994b). Extended depth interviews are sometimes used to show the rich and complex interplay between elements of the advertisements and consumer responses. The text-interpretive perspective draws on semiotic, rhetorical, and literary theories to provide a systematic and nuanced analysis of the individual elements that make up the advertisements (Durand, 1987; McQuaitie, 1989; Scott 1994a; Sonesson, 1996; Stern, 1989). It treats visual and verbal elements as equally capable of conveying crucial meanings and as equally worthy of differentiation and analysis. All the four approaches per se have its strengths and weaknesses, however, Mcquarrie and Mick (1999) believe a mutual borrowing from each other and weaving them together for a particular research purpose is necessary.

Other scholars (Barthes, 1977; Williamson, 1978; Dyer, 1990; Fiske, 1990; Pollay \& Gallagher, 1990; Forceville, 1996; Messaris, 1997; Jian, 2000; Beasley \& Danesi, 2002; Bignell, 2002; Rose, 2005) have also realized the importance of multi-perspectives in the study of advertisements, of which social semiotics is at the core because of the 
assumption and truth that meanings in the media are communicated by signs and semiotics is concerned with the question of how signs work-the process of which is not and never neutral but ideological- and cultural-laden.

This dissertation is a continuation of these previous researchers in this direction. Adopting the theories of conceptual and pictorial metaphor analysis and critical cultural theory, using the methods of semiotics and content analysis in communication, I will collect a large sample size of 300 advertisements from the most representative (the awarded prize winner ads by China National Advertising Association) in the three decades of 1980s, 1990s and 2000s in order to conduct a critical metaphor analysis to see if and in what way advertisements can reflect social reality and ideological and identity change.

\subsection{The Inter-disciplinary Nature of Advertising}

\subsubsection{Advertising as Communication}

Advertising is a very important way of business communication. Based on the communication definition proposed by John Fiske (1990), advertising as a form of business communication must also involve signs and codes that are deliberately organized to signify certain construct.

I assume that all communication involves signs and codes. Signs are artifacts or acts that refer to something other than themselves; that is, they are signifying constructs. Codes are the systems into which signs are organized and which determine how signs may be related to each other (Fiske, 1990, p. 1).

According to Fiske, communication has two main study schools; one takes communication as a process of "message transmission" while the other takes 
communication as an interaction of "meaning production". The two schools also differ in their understanding of what constitutes a message. For the process school, the message is what the sender puts into it by whatever means, the semiotic school, on the other hand, believes the message is a construction of signs which produce meanings through interacting with the receivers (1990, pp. 2-4). It is the second semiotic school rather than the first process school that the present dissertation is mainly concerned with.

Gillian Dyer (1982) in her book Advertising as Communication has discussed and illustrated the historical origin and development of advertising industry in different developmental stages. In chapter four she has a comprehensive explanation on different kinds of research perspectives on advertising as communication: effects research; market research; and sociological research (in three models-the "hypodermic" model, the "socially-mediated" model, and the "cultural value" model). It is the "socially-mediated" model and "cultural value" model that is relevant to this dissertation. This chapter (Dyer, 1982 , p. 79) is also relevant and serves as a rationale support to the present research in two other ways. One is her emphasis on "the real impact of advertising on the cultural climate of society", in another word, the cultural effect of commercial advertising.

Certain values such as love, friendship, neighborliness, pleasure, happiness and sexual attraction are the staple diet of advertisements and are often confused with or transferred to the possession of things (Dyer, 1982, p. 80).

The other relevance lies in her belief that "the influence of advertising can be attributed to recent technological improvements and innovations in the production and distribution of pictorial or visual representations of reality... What the historian Daniel Boorstin (1963) calls the "graphic revolution"...We may want to agree with Marshall 
McLuhan's aphorism "the medium is the message" (that the influence of the media is a result of their technology), but we must also recognize that the images conveyed by the media have, over the past 30 years, become so sophisticated and persuasive that they now organize our experiences and understanding in a crucially significant way" (Dyer, 1982, p. $82)$.

The media or graphic revolution makes "pictorial and visual representations of reality" i.e. advertising become a form of powerful visual communication. Aldous Huxley ${ }^{11}$, suffering from a degenerative eye condition, author of the novel Brave New World and forty-six other books of philosophical and futuristic vision, contributed greatly to the visual communication theory in his 1942 work The Art of Seeing. In it he has his famous visual communication's circle dance. "The more you know, the more you sense. The more you sense, the more you select. The more you select, the more you perceive. The more you perceive, the more you remember. The more you remember, the more you learn. The more you learn, the more you know" (Lester, 2003, p. 6).

Know $\rightarrow$ Sense $\rightarrow$ select $\rightarrow$ perceive $\rightarrow$ remember $\rightarrow$ learn $\rightarrow$ know

This circular dance theory of visual communication has guided advertising and art designers and laid the research foundation for the present project as well as many other semiotic studies because of this 'the more you know, the more you see' principle. Advertisers apply this principle because the advertising images will be much more effective and memorable if signs that are understood by large groups of audience are used in a picture. Academic and semiotic researchers apply this principle by identifying and

\footnotetext{
${ }^{11}$ Huxley, Aldous. (2000a). Brave New World Revisited, New York: Harperperennial Library. Huxley, Aldous. (2000b). Complete Essays by Aldous Huxley, Robert S. Baker (ed). Chicago: Ivan R. Dee, Publisher. Huxley, Aldous. (1942). The Art of Seeing, New York: Harper.
} 
explaining the cultural-bound signs used by all the society or different societies in the world.

Paul Martin Lester explains that advertisements as visual communication are consisted of two types of narratives. One is the verbal narrative which is a rule-based linear discourse (text). The other is pictorial narrative which is presentational images. Roland Barthes described the chain of associations or a collection of signs that make up a picture's narrative. Asa Berger used the common term "codes" to mean signs and he suggested four types of codes: metonymic, analogical, displaced, and condensed.

- A metonymic code is a collection of signs that cause the viewer to make associations or assumptions such as a room with expensive paintings on the walls, wood paneling, richly upholstered furniture, subdued lighting, and a fire glowing under a mantle in a photograph in an advertisement.

- An analogical code is a group of signs that cause the viewer to make mental comparisons. Yellow paper might remind people of the yellow peel of a lemon because of its similar color.

- Displaced codes are those that transfer meaning from one set of signs to another. In a billboard advertisement the head and the tail of an airplane (in vagina, phallic shapes) picture might communicate the idea of sexual conquest.

- Finally the condensed codes are several signs that combine to form a new, composite sign. This combination of signs is cultural-bound (meaningful for one culture but confusing for another) and is where most research in semiotics needs to take place (2003, pp. 55-56). 
In the present research I will take the visual images or a collection of signs in the advertisements in China as the core research subject to see how these four types of codes are used or combined in the sample data advertisements to express certain ideology and identity trends. But it is not author's major concern to compare and contrast the techniques of how the ads creators used each type of metonymic, analogical codes, displaced and condensed codes.

According to Lester (2003) visual communication theories can be divided into "sensual" theory (gestalt and constructivism) and 'perceptual' theory (semiotics and cognitive). The word "gestalt" comes from the German noun that means form or shape. Visual perception was a result of organizing sensual elements or forms into various groups through a series of four fundamental principles/laws: similarity, proximity, continuation, and common fate. Constructivism is psychologist's effort in offering explanations of how perceptions actually give meaning to an image with limited results so far. Semiotics is vital because signs permeate every message. Since Swiss linguist Ferdinand de Saussure developed a general theory of signs and American philosopher Charles Sanders Peirce talked about the effect of signs on society, many others (the Americans Arthur Asa Berger, Charles Morris, and Thomas Sebeok; the Italian Umberto Eco; the Frenchman Roland Barthes) have concentrated on this field of study. Cognitive theory believes a viewer does not simply witness a light-structured object as in the gestalt theory, but actively arrives at a conclusion about the perception through mental operations of memory, projection, expectation, selectivity, habituation, salience, dissonance, culture and words (2003, pp. 48-59). 


\subsubsection{Advertising as Business Promotion}

In its simplest sense, the word advertising means drawing attention to something, or notifying somebody of something. Advertising is defined in Webster's dictionary "as the action of calling something to the attention of the public especially by paid announcements, to call public attention by emphasizing desirable qualities so as to arouse a desire to buy or patronize: promote." According to the American Marketing Association, advertising is the non-personal communication of information usually paid for and usually persuasive in nature about products, services or ideas by identified sponsors through various media. Advertising has long been viewed as a method of mass promotion in that a single message can reach a large audience with the functions of informing, educating, persuading and promoting. Whatever function the advertisement is designed for depends on the product lifecycle stage and nature of the product and industry.

Nowadays image promotion (both self-image and company-image) through publicity and cause-related marketing is on the rise because the companies want to establish a positive and socially-responsible image in the general public. Visual elements have become an important component of advertisements. According to Mcquarrie and Mick (1999) although the role of imagery in shaping consumer response has long been recognized (as sited in Greenberg \& Garfinkle, 1963), only recently have visual elements begun to receive the same degree and sophistication of research attention as the linguistic element in advertising (as sited from Childers \& Houston, 1984; Edell \& Staelin, 1983; Meyers-Levy \& Peracchio, 1992; Miniard et al., 1991; Scott, 1994a). The area is now characterized by conceptual and methodological diversity, with a variety of new propositions and findings emerging. 
Companies also start to use integrated marketing communication to project a consistent product image in different media channels and with product positioning. Recently advertising effect has been further enhanced as new advertising technologies and the emergence of new media outlets offer more options for targeted advertising to better target the desired market - customized advertising. Most advertisers or advertising agencies will have to formulate certain advertising strategies in order to communicate to the market the benefits or problem solutions characteristics of the product or service. What they are trying to convey through advertising and state in the strategy is what they offer to meet the consumer's need and how their products have more beneficial characteristics than the competition's and what the beneficial characteristics are.

One successful company that has attracted millions of consumers with its creative advertising talents and deep marketing savvy is American Coca Cola. Over the last 100 years Coca Cola Company has been able to sell the same classic Coke to people all over the world by successfully polling the best artists to create the most unique and attractive advertisements. These artists have given the same Coke different images and brand new positioning through creating timeless Coke images of refreshments. Meanwhile Theodore Levitt's marketing concepts theory, Philip Kotler's marketing mix theory, Don E. Schultz's Integrated Marketing Communication (IMC) theory, and Al Ries' and Jack Trout's advertising strategy book, Positioning: The Battle for Your Mind have all contributed to the establishment of modern marketing discipline, of which advertising has become central in marketing communication and business promotion strategies. 


\subsubsection{Advertising as Representation of Social Reality}

According to Alfred Politz's story, an advertisement is just like a mirror that can represent the best part of social reality. The story goes "There is a house with the most spectacular scenery outside the window, there are three mirrors hanging on the wall opposite the window. The visitor who is shown to the mirror said the first mirror is dirty, the second mirror is beautiful, and the third mirror is a piece of spectacular scenery. And that third mirror is a good advertisement" (1979, pp. 258-259).

Commercial advertising, like any other discourse, is not and has never been a neutral instrument of communication even though there may be no intrinsic political intent behind advertising. The social change and social reality as reflected in the change of ideology and identity, in another word, the promotion of certain power, right and activity in a codified, symbolic and standardized form, is transmitted or transferred through metaphorical images in the advertisements to the public by exploring everything that captures the eyes and attention of the public. This "metaphoric nature" and "instrumental mission" (Sassatelli, 2007, p. 133) of commercial advertising have aroused the keen research interest of many scholars. As Andrew Wernick has suggested "as an industry advertising may not have intrinsic interest in what the material it promotes may mean ideologically, yet, we should be alerted to the fact that advertisements have an ideological function" (1991, pp. 25-26). Roberta Sassatelli claims in her book Consumer Culture history, theory and politics:

The ideological function of advertising clearly adumbrates a complex politics of representation, which mobilizes a variety of social identities. There are two directions in which I may situate the ideological function of the commercial 
advert. The first regards the relationship between advertising images and social and cultural hierarchies. Advertising is essentially an ambivalent symbolic form: it can both reproduce the dominant socio-cultural differences and also, whilst far more rarely, support new cultural orientations and innovative social tendencies (2007, p. 133).

Contrary to many researchers, however, Linda M. Scott (1994) argues against the above underlying assumption that pictures in the advertisements are reflections of social reality; but rather visuals are convention-based symbolic system that must be cognitively processed rather than absorbed peripherally or automatically. Linda Scott argues that current conceptualizations of advertising images are incommensurate with what advertisements are really like, and that many images currently dismissed as affect laden or information devoid are, in fact, complex figurative arguments. In one word advertising images are a sophisticated form of visual rhetoric that calls for a new explanatory theory.

\subsubsection{Advertising as Visual Metaphor and Visual Culture}

\section{Definition of Metaphor}

Metaphor is a rhetorical term when one thing stands for another. Psycholinguists Lakoff and Johnson put the metaphor as "understanding and experiencing one thing in terms of another" (Lakoff \& Johnson, 1980, p. 5). "Metaphors are really statements based on some kind of analogy where two things are compared to each other" (St Clair, 2004b). Metaphors become embedded in languages to such an extent that some linguists e.g. Roman Jakobson (1960), have argued that they are one of the fundamental mechanisms for meaning-creation (the other is metonymy). Humans make sense of the world, of themselves and of their interactions by extending to unknown or new phenomena the 
characteristics of known ones, thus capturing new experience in terms of something already known. The embeddedness of metaphor is intriguing, since it is unclear how far metaphors of spatial organization (e.g. up, down, higher, lower) condition people's thinking about each other's rank. Our symbolic and social life is completely suffused with metaphor. Actually there are really no such things as 'plain English'. The choices made to produce almost any lexical string depend on embedded metaphor-here, 'lexical string' IS a metaphor; 'depend' IS a metaphor; 'embedded metaphor' IS a metaphor. As Dirven and Paprotte (1985, p. viii) say that metaphor is seen as "being situated in the deepest and most general processes of human interaction with reality". Recently, it has been generally agreed that metaphor is the way we make sense of all sort of phenomena.

\section{The Ubiquity of Metaphor Research}

Metaphors have many dimensions or are multi-dimensional. People have held different philosophical and theoretical speculations on metaphor for centuries. Aristotelian scholars use metaphor as a figure of speech and a means of persuasion; linguists study metaphors as grammatically symbolic systems; psychologists study metaphors as a speech of thought so as to complete a 'cognitive turn'; sociologists study metaphors as social and cultural construction; scientists study metaphors as theoretical models and paradigm shifts; educators study metaphors as enhancing lexical expansion and learning process; More recently some avant-garde researchers have studied metaphors as an epistemic form or new rhetoric, as a way of knowing, understanding and expressing knowledge (St. Clair, 2004a). These shifts in metaphor study represent epistemological transformations (St. Clair, 2004a) and St. Clair (2002) argued that the Kuhnian paradigmatic shifts are, in reality, metaphorical transitions. It is in this context 
that the dissertation is written. Chinese business people have their unique way of thinking and understanding business essence and business philosophies. Metaphors embody these business ideas in their speeches, writings, and advertisements.

With these interdisciplinary endeavors, particularly since the 'cognitive turn' the ubiquity and revaluation of metaphor as an important topic for cognitive and social research has happened since 1960s and prospered at such a scale that it has flourished and opened brand new scopes for cross-disciplinary metaphor study. Van Noppen et al. (1985) has published a bibliography, covering the past 15 years, that contains more entries than the one by Shibles (1971), which deals with a previous period of more than 15 centuries. Great contributors to cognitive metaphor study are found in such seminal philosophical publications on metaphor as Black (1962), Turbayne (1963), and Hesse (1966). Important books developing the cognitive approach in more recent times are MacCormac (1985), Kittay (1987), Levin (1988), Soskice (1988), and Winner (1988). New collections have been edited by Haskell (1987), Van Noppen (1990), Fernandez (1991a), and Shen (1992). Moreover, Lakoff and Johnson's Metaphor We Live By (1980) has been followed by lakoff (1987a), Turner (1987), Johnson (1988), Kovecses (1988), and Lakoff and Turner (1989). It is obvious metaphor has thus become comparable to other instruments of conceptualization. With the publication of special journal Metaphor and Symbolic Activity, the institutionalization of metaphor as a specific domain of research in the social science was completed.

\section{'Visual Metaphor' and 'Cultural Metaphor'}

The term 'visual metaphor' is explicatively elaborated by St. Clair (2004b) in his Visual Metaphor, Cultural Knowledge, and the New Rhetoric in Jon Reyhner, et alia 
(2004) Learn in Beauty: Indigenous Education for a New Century. In this part of the book St. Clair argues that since the publication of Kuhn's (1970) model of scientific thinking, rhetoricians now realize that metaphors pervade all forms of knowledge. Kuhn called these shifts in perspective paradigms. Brown (1976), a specialist in the sociology of art, sees metaphors operating in a larger context. He notes that metaphors provide a perspective on knowledge just as scientific paradigms provide a perspective on theoretical knowledge. Therefore "visual metaphor" is just like Kuhn's illustrative metaphor that provides a global perspective or point of view to understand culture. An example of an illustrative metaphor is "the atom is like a solar system." It has a nucleus just as the sun is the solar system's nucleus. It has electrons whirling around that nucleus just as the sun has planets circling around it. With the passage of time, this global view comes to be more fully articulated, the details are filled out, and what was once a simple plan for the structuring of knowledge soon emerges as an iconic metaphor, a description picturing events in photographic detail. Dr. St. Clair (2004b) then introduces Gombrich (1963), a noted art historian, who is concerned with the interpretation of symbols in art history, and his line of investigation has to do with questions of cultural value. He wants to know why gold, for example, has become a visual metaphor of value and why it has developed into derivative metaphor of noble simplicity.

According to St. Clair, metaphors can be used to understand cultural differences from the new perspective of visual images. By using the concept of 'cultural metaphor' in this dissertation I intend to expand the boundary of metaphor not simply as rhetoric but also as a persuasive way of expressing the deepest core values and cultural orientations. From this sense since advertising is a persuasive art form 'visual and cultural metaphors' 
with both words and images and symbolic associations are widely used to express the social construction of one particular culture. Chinese culture, to a great extent, is visual and pictographic by nature. This is reflected in the oracle language, the first recorded language of China with words resembling the pictorial shapes of their original objects.

Visual metaphors abound in cinema, TV and advertisements, especially in the way that concrete visualizations stand for abstract ideas: there are both novel and clichéd ways to convey 'family', 'beauty', 'the city', 'lifestyle', 'bad guy', etc. In television, visual metaphors are used to cue viewers as to the social standing of sitcom or soap opera characters or families-the style and decoration of fridges on the set, for instance. There was a vogue for spice racks, a visual metaphor that for a while was an almost infallible marker of the 'middle-class family' on British TV sitcoms (Hartley, 1996, pp. 143-144).

Why are visual metaphors important? In another word why do they need to be explained? Robert N. St. Clair (2004b, chapter 8, pp. 85-101) argues that visual metaphors provide a dominant mode of information processing (see the table 2-1) and knowledge sharing, but due to the power of print culture they are often ignored. For example each of us is bombarded by the advertisements on television, Internet as well as in newspapers and magazines. Each is a visual metaphor. Unfortunately, they are aimed at persuasion rather than at sharing relevant knowledge.

Table 2-1 Information Processing Modes of Print and Oral Cultures

\begin{tabular}{|l|l|l|}
\hline & PRINT CULTURE & ORAL CULTURE \\
\hline Cognition & $\begin{array}{l}\text { Analytical Mode: Look for the } \\
\text { details and not the whole. }\end{array}$ & $\begin{array}{l}\text { Synthesizing Mode: Look for the } \\
\text { overall meaning and how the details } \\
\text { fit together. }\end{array}$ \\
\hline Processing & $\begin{array}{l}\text { Sequential: Go from left to } \\
\text { right. }\end{array}$ & $\begin{array}{l}\text { Simultaneous: view everything at } \\
\text { once just as one would view a } \\
\text { painting. }\end{array}$ \\
\hline
\end{tabular}




\begin{tabular}{|l|l|l|}
\hline \multirow{2}{*}{ Thought } & $\begin{array}{l}\text { Relational, Logical: Reason } \\
\text { logically and use syllogisms. } \\
\text { Put people into categories. Do } \\
\text { not rely on emotions. }\end{array}$ & $\begin{array}{l}\text { Affective, Emotive: Feelings are } \\
\text { important. Use emotions to } \\
\text { understand others. }\end{array}$ \\
\hline Predilections & Mathematics, Science & Art, Music, Dance \\
\hline Legitimization & $\begin{array}{l}\text { Verbal Metaphor: Use } \\
\text { metaphors based on language. }\end{array}$ & $\begin{array}{l}\text { Visual Metaphor: Use metaphors } \\
\text { based on the reorganization of visual } \\
\text { space. }\end{array}$ \\
\hline Literacy & Print, Technology & Orality, the Arts \\
\hline
\end{tabular}

Dondis (1973) has directly addressed the issue of internal structure of the visual metaphor. He speaks of the significance of the individual elements such as tone, color, line, texture, and proportion and how these are maneuvered within a visual space to create either tension or harmony within the confines of visual syntax. He notes that visual space is organized in that it provides guidelines for the construction of art. His work provides the basic elements of art that he feels can be learned and understood by all students of visual media. He provides insight into how visual structures are created to convey visual messages, in other words visual metaphors. These techniques can be manifested in numerous ways as evidenced in the table $2-2$.

Table 2-2 The Use of Contrast and Harmony to Constitute A Visual Structure

\begin{tabular}{|l|l|}
\hline CONTRAST & HARMONY \\
\hline Instability in visual space & Balance in visual space \\
\hline Asymmetry of forms & Symmetrical forms \\
\hline Fragmentation & Unity \\
\hline Irregularity & Regularity \\
\hline Variation & Consistency \\
\hline Complexity & Simplicity \\
\hline Opacity: (Meaning is not obvious) & Transparency: (Meaning is obvious) \\
\hline Episodicity: (Life is like a TV episode) & Repetition \\
\hline
\end{tabular}

Similarly, visual metaphors can be used to understand cultural differences as visual culture. They tell us how some cultures envision space and time; how some cultures solve 
problems and handle relations. This semiotic process of differentiation, going from a simple overview into a complex and detailed result, is not limited to the scientific use of verbal metaphors 1 or to print cultures. It can also be found in the employment of visual metaphors. Gombrich (1963) argues that images and symbols have meaning and appear in different forms. They function as visual codes or emblems and evoke a sense of artistic and cultural value. Such visual metaphors require a cultural context for interpretation. He gives the example of the traffic lights in which the color red is coded to signal 'stop' and green 'go.' In China architects and advertising talents often use 'round' and 'square' shape to connote 'heaven' and 'earth' and then they are metonymically meant 'masculinity' and 'femininity'.

\subsection{Literature Review on Critical Metaphor Analysis}

\subsubsection{Critical Metaphor Analysis}

Critical Metaphor Analysis (CMA), a method first adopted and elaborated by Jonathan Charteris-Black (2004) in his book Corpus Approaches to Critical Metaphor Analysis, is an approach incorporating Critical Discourse Analysis (CDA), Conceptual Metaphor Theory (CMT) and corpus linguistics. The book addresses the rhetorical and ideological role of metaphor in discourse. He proposes a discourse model called CMA to analyze metaphors in authentic data. He argues that "Metaphor can only be explained by considering the interdependency of its semantic, pragmatic and cognitive dimensions" (Charteris-Black, 2004, p. 2) and thus integrates in his approach the areas of cognitive semantics, pragmatics, and discourse analysis. The book consists of five parts: The first part provides a general theoretical review on metaphor and explains the corpus-based approach to metaphor. Parts two to four offer extensive empirical research into metaphors 
in political discourse, press reporting, and religious discourse. The fifth part concludes with a discourse theory of metaphor or a theoretical discussion of CMA.

According to the book review by Maria José Hellin Garcia from Department of Foreign Languages and Literatures of University of West Georgia, Charteris-Black's book is an excellent contribution for CMA advances metaphor studies and it serves as a research tool for the cognitive and pragmatic analysis of metaphors in real contextualized discourse. The most interesting part of this book resides in the extensive qualitative and quantitative evidence provided through the analysis of different types of texts (political, religious, and press). However, the book can be improved if more attention can be given to the decision criteria of how the identification, interpretation, and explanation procedure is applied.

In the book Charteris-Black claims that "covert" and "possibly unconscious" intentions of language users can be revealed through critically analyzing metaphor. I borrow this idea and logically claim that "covert" and "possibly unconscious" intentions of advertisers and business communicators can be revealed through critically analyzing metaphors embedded and embodied in the verbal language and visual images of advertisements. Through the interplay of semantic, pragmatic and cognitive dimensions of illustrated print advertisements the symbolic associations projected or mapped onto the consumers will play to the hidden desired needs of consumers and indirectly realize ideology and identity functions, thus serves as the mirror or representation of social reality and social practice. 


\subsubsection{Critical Discourse Analysis (CDA)}

Critical Discourse Analysis ${ }^{12}$ (CDA) is based upon a view of semiosis as an irreducible element of all material social processes (Williams, 1977). CDA subsumes a variety of approaches towards the social analysis of discourse (Fairclough \& Wodak, 1997; Pêcheux M., 1982; Wodak \& Meyer, 2001) which differ in theory, methodology, and the type of research issues to which they tend to give prominence. CDA sees social life as interconnected networks of social practices of diverse sorts (economic, political, cultural, family etc). The reason for centering the concept of 'social practice' is that it allows an oscillation between the perspective of social structure and the perspective of social action and agency - both necessary perspectives in social research and analysis (Chouliaraki \& Fairclough, 1999). The 'social practice' includes all the social activities such as subject, objects, instruments, time and place, forms of consciousness, values and discourse. These elements are dialectically related (Harvey, 1996). Social relations, social identities, cultural values and consciousness are in part semiotic, but that does not mean that we theorize and research social relations in the same way that we theorize and research language - they have distinct properties, and researching them gives rise to distinct disciplines. (Though it is possible and desirable to work across disciplines in a 'transdisciplinary' way - see websit articles of Fairclough 2000).

CDA is analysis of the dialectical relationships between discourse (including language but also other forms of semiosis, e.g. body language or visual images) and other elements of social practices. Its particular concern (in my own approach) is with the radical changes that are taking place in contemporary social life, with how discourse

${ }^{12}$ All the ideas and explanations about CDA are from Norman Fairclough's articles 'Critical Discourse Analysis' and 'The Dialectics of Discourse' at his personal homepage hitp://www.sfu.ca/cmns/faculty/marontate $1 / 801 / 08$ spring/readings/Fairclough\%20Dialectics\%20of\%20Discourse \%20Analysis.pdf. 
figures within processes of change, and with shifts in the relationship between semiosis and other social elements within networks of practices. We cannot take the role of discourse in social practices for granted; it has to be established through analysis. And discourse may be more or less important and salient in one practice or set of practices than in another, and may change in importance over time.

Discourse figures in broadly three ways in social practices. First, it figures as a part of the social activity within a practice. For instance, part of doing a job (for instance, being a shop assistant) is using language in a particular way; so too is part of governing a country. Second, discourse figures in representations. Social actors within any practice produce representations of other practices, as well as ('reflexive') representations of their own practice, in the course of their activity within the practice. They 'recontextualize' other practices (Bernstein, 1990; Chouliaraki \& Fairclough, 1999) - that is, they incorporate them into their own practice, and different social actors will represent them differently according to how they are positioned within the practice. Representation is a process of social construction of practices, including reflexive self-construction representations enter and shape social processes and practices. Third, discourse figures in ways of being, in the constitution of identities - for instance the identity of a political leader such as Tony Blair in the UK is partly a semiotically constituted way of being.

Discourse as part of social activity constitutes genres. Genres are diverse ways of acting, of producing social life, in the semiotic mode. Examples are: everyday conversation, meetings in various types of organization, political and other forms of interview, and book reviews. Discourse in the representation and self-representation of social practices constitutes discourses (note the difference between "discourse" as an 
abstract noun, and "discourse(s)" as a count noun). Discourses are diverse representations of social life which are inherently positioned - differently positioned social actors 'see' and represent social life in different ways, different discourses. For instance, the lives of poor and disadvantaged people are represented through different discourses in the social practices of government, politics, medicine, and social science, and through different discourses within each of these practices corresponding to different positions of social actors. Finally, discourse as part of ways of being constitutes styles - for instance the styles of business managers, or political leaders.

Critical Discourse Analysis is both a theory and a research method that has been widely adopted by scholars in recent years to study and analyze variety of discourses. CDA is a powerful tool to study the interplay between language and ideology. Many researchers have contributed to the formation of CDA with their diverse theories and methods (Fairclough, 1995, 2003; Fang, 2001; Hawkins, 1997; Kuo \& Nakamura, 2005; Van Dijk, 1988, 1993, 1998, 2000, 2001; among others). Ideology, according to Marx (1776), Foucault (1989), Van Dijk $(1998,2000,2001)$ is a form of social cognition or a belief system shared by/in a group. Defined as "the basis of the social representations shared by members of a group' (Van Dijk, 1998, p. 8), ideology is constituted by 'basic propositions that represent what is good or bad for the group' (Van Dijk, 2000, p. 95). In other words, ideology is a belief system perpetuating norms and values held by a group.

\subsubsection{Conceptual Metaphor Theory (CMT)}

Conceptual Metaphor Theory (Lakoff, 1993; Lakoff \& Johnson, 1980) provides a useful tool for linguists to analyze ideologies and identities implicit within the language as well as visual images. Lakoff and Johnson in their book Metaphor We Live By (1980) 
write metaphor is "understanding and experiencing one thing in terms of another" (Lakoff \& Johnson, 1980, p. 5). Recently, it has been generally agreed that metaphor is the way we make sense of all sort of phenomena. Metaphor is deeply rooted in our sign system, thought and action, pervading everyday life. Lakoff and Johnson contend that metaphors have the persuasive power "to define reality $[\ldots]$ through a coherent network of entailments that highlight some features of reality and hide others" (1980, p. 157). Quite a few scholars have investigated conceptual metaphors for the purpose of unveiling the ideologies behind them (Charteris-Black, 2004; Koller, 2005; Semino, 2002; Semino \& Masci, 1996; White \& Herrera, 2003; among others).

One of the most distinguished researchers in metaphor is Lakoff and Johnson. Contrary to the traditional view that metaphor is a figure of speech, they (1980) argue that metaphor is also a figure of thought. The figure of speech is just a surface manifestation of such metaphorical figure of thought. They believe that metaphors can reflect the conceptual system of its speakers.

Explaining conceptual metaphor, Lakoff and Johnson suggest that metaphor is a matter of understanding one thing in terms of another. The typical formula is TARGETDOMAIN IS SOURCE-DOMAIN, or alternatively, TARGET-DOMAIN AS SOURCEDOMAIN. The source domain supports the literal meaning of the expression. The target domain is what the sentence is actually about. Lakoff and Johnson thus have coined the term metaphorical expression, a linguistic expression (a word, phrase, or sentence) that is the surface realization of such metaphorical concept (a cross-domain mapping) (Lakoff \& Johnson, 1980, p. 6). 
Metaphorical expressions, as the surface level of metaphor, are the linguistic expressions used for metaphors. Metaphorical expressions exist exactly because there are metaphors in a person's conceptual system. Metaphorical expressions in our language are closely connected to metaphorical concepts in a systematic way, so we can use metaphorical linguistic expressions to explore the nature of metaphorical concepts and to gain an understanding of the metaphorical nature of our activities.

Lakoff and Johnson also note how metaphor can be misleading through its ability to highlight some features of reality and hide others. Hence they present the idea of entailments of metaphors. It is the entailments of a metaphor-the relationships and concepts that the metaphor brings to mind-that determine its communicative power and effectiveness.

\subsubsection{Pictorial Metaphors (PM) in Advertising}

Since this dissertation deals with illustrated print advertisements in China, it is necessary to understand the pictorial metaphor, visual metaphor or multimodal metaphor. These words are meant to be used interchangeably throughout the paper as the same meaning. Pictorial Metaphor (PM) is a term first elaborated and theorized by Charles Forceville in his book Pictorial Metaphor in Advertising (1996). In it, Forceville said "Lakoff and Johnson claim in their influential book Metaphors We Live By, "metaphor is primarily a matter of thought and action, and only derivatively a matter of language (as cited from Lakoff \& Johnson, 1980, p. 153). This perspective paves the way for an investigation of the question whether other media than language can manifest metaphor as well" (Forceville, 1996, p. 1). Forceville then argues "that metaphor can occur in pictures, more specifically in printed advertisements and billboards" and he further 
proposes "a theoretical framework within which these pictorial metaphors can be analyzed" (ibid). His study has made great contribution to a theory of pictorial metaphor and how his theory can be applied in the analysis of specific advertisements. He hopes "the validation of the concept 'pictorial metaphor' has helped to advance the more encompassing theory of metaphor as a cognitive phenomenon" (ibid).

Forceville borrowed Lakoff and Johnson's metaphor theory of source and target domain, Max Black ${ }^{13}$ s interaction theory of metaphor - the match between the primary and secondary subjects, and summarized other relevant studies of pictorial metaphor (Wollheim, 1987; Hausman, 1989; Kennedy, 1982; Johns, 1984; Durand, 1987; Forceville, 1988; \& Whittock, 1990) to form a pictorial metaphor theory of his own. He concludes:

A metaphor, then, consists of two 'things': a 'literal' primary subject and a 'figurative' secondary subject. Metaphor occurs first of all on the level of cognition, and can manifest itself on the pictorial as well as the verbal level...Both the primary and the secondary subject of the metaphor can be envisaged as domains of meaning elements, ranging from verifiable facts to connotations, and including beliefs about and attitudes towards that subject... ...in each metaphor one or more features of the domain of the secondary subjects (the 'source domain') are mapped on to the domain of the primary subject (the 'target domain'). This mapping process involves the foregrounding,

\footnotetext{
${ }^{13}$ Max Black's interaction theory of metaphor is explained in detail in Pictorial Metaphor (1996) by Charles Forceville, chapter $2 \mathrm{pp}$.4-35. Further information about his work please refer to Black, M. (1962) 'Metaphor', in Models and Metaphors, Ithaca, NY: Cornell University Press, 25-47. Black, M (1972) 'How do pictures represent?' In M. Mandelbaum (ed.) Art, Perception, and Reality, Baltimore/London: Johns Hopkins University Press, 95-130. Black, M (1979a) 'More about metaphor', in A. Ortony (ed.) Metaphor and Thought, Cambridge: Cambridge University Press, 19-43. Black, M (1979b) 'How metaphors work: a reply to Donald Davidson', in S. Sacks (ed.) On Metaphor, Chicago: University of Chicago Press, 181-192.
} 
adoption or modification of certain features in the primary subject. There is thus a matching between elements from the source and target domains (1996, p. 116). Recently Charles Forceville has advanced his pictorial metaphor theory into multimodal metaphor theory. In 2006 and 2008 Forceville explained his idea of multimodal metaphor in his two papers "Nonverbal and multimodal metaphor in a cognitive framework: agenda for research" (2006) and "Metaphor in pictures and multimodal representations" (2008). In these papers he (2006, p. 379) asserted that if conceptual metaphor theory is correct we should not limit our study to coded or verbal language itself but extend to other forms of signs such as movies, music, pictures, gestures and sound, which he termed as the multimodal metaphors.

\subsection{Literature Review on Ideology and Identity}

Since this study focuses on the words and images of advertisements in China in the last 30 years and I intend to uncover the ideological and identity representations hidden behind the visual metaphors, critical theories related to ideology and identity need to be brought out and summarized. In another word in what way advertisements can reflect the ideology and identity change in China in the last three decades. An understanding of the critical perspective of advertising on media, its ideological function and self-formation politics in particular, helps us to see the true nature of advertising not only as a business communication tool but also as the carrier and representation of social reality and social change. 


\subsubsection{The Media Power in Communication}

Critical scholars and researchers have always been sensitive to the power and effectiveness of media messages in media communications. The emergence of mass society, mass media and mass culture have created a series of contemporary mass communication theories-the emergence of critical and cultural theories in particular. The Marxism and neo-Marxism theory, the Frankfurt school, political economy theory, McLuhan's media theory, social marketing theory, cultivation analysis theory and most of all Adomo's cultural industry theory have all contributed to the field of mass communication. The new trends in mass communication, visual culture and visual communication in particular, have been based on recent development in communication science, social semiotic theory and globalization trend. Two extraordinary and prominent figures in the critical front of media and culture study are Baudrillard and Adorno.

The effectiveness of the culture industry depends not on its parading an ideology, on disguising the true nature of things, but in removing the thought that there is any alternative to the status quo (Bernstein, 1991, pp. 10-11). 'Pleasure always means not to think about anything, to forget suffering even where it is shown.' Hence, pleasure is always flight 'from the last remaining thought of resistance'; the liberation promised by amusement 'is freedom from thought and negation' (Bernstein as cited from Adorno \& Horkheimer, 1973, p. 144).

This is why consideration of the culture industry is embedded in a fragmentary genealogy of reason: "the telos of instrumental rationality, the rationality first licensed by the drive for self-preservation, is the silencing of reflection in the name of the illusory 
universality pervaded by the culture industry. Instrumental rationality in the form of the culture industry thus turns against reason and the reasoning subject. This silencing of reflection is the substantial irrationality of enlightened reason" (Bernstein, 1991, pp. 1011).

William Merrin (2005) introduces Baudrillard in his book Baudrillard and the Media: a critical introduction. “... in his first book The System of Objects (SO) published in 1968, Baudrillard describes the existence and operation of the immense signifying system that constitutes contemporary western cultural experience. This is a system in which all objects, messages, and products, and all history, culture, meaning, relations and experience, communicating, in their structural interrelationships, a variety of meanings and messages" (Merrin, 2005, p. 10). "Everything is sign, pure sign" as Baudrillard claims in SO. His 1971 essay Requiem for the Media makes an even more bold assertion "the mass media are anti-mediatory and intransitive. They fabricate noncommunication-this is what characterizes them" (Merrin, 2005, p. 169). Following Durkheimian tradition Baudrillard made original analysis of the contemporary dominance of the semiotic and its impact on human relations. His works The System of Objects of 1968 and The Consumer Society of 1970 are filled with examples of the process of how the origin of the semiotic was eventually destroyed by the symbolic during the symbolic exchange. Baudrillard (1968, p. 21) described a world where it is signs and objects-even doors-that communicate, rather than people, and a world where the individual is integrated into a totalitarian code (Baudrillard, 1968, p. 29).

Derived from literary criticism and critical gurus, critical methods can also be applied to analyze pictures in order to fully appreciate visual communication. Lester 
(2003) recommended six perspectives: personal, historical, technical, ethical, cultural and critical. Personal perspective is a gut reaction to the work based on subjective opinions. Historical perspective is a determination of the importance of the work based on the medium's time line. Technical perspective explores the relationship between light, color, the recording medium used to produce the work, and the presentation of the work. Ethical perspective is the moral and ethical responsibilities that the producer, the subject, and the viewer of the work have based on six principal ethical philosophies: categorical imperative (Prussian Immanuel Kant), utilitarianism (British Jeremy Bentham), hedonism (Greek Aristippus), the golden mean (Aristotle, Confucius), the golden rule (JudeoChristian tradition), and the veil of ignorance (John Rawls). Cultural analysis of a picture involves identifying the symbols used in the image and determining their meaning for the society as a whole. Cultural perspective is closely related to semiotics approach in which symbolism may be analyzed through the stereotyped use of words, narrative structures, styles of the artwork, and the representative images (heroes and villains) Critical perspective transcends a particular image and shapes a reasoned personal reaction. A critical perspective allows the viewer to use the information learned about a medium, its practitioner, and the image produced to make more general comments about the society that accepts or rejects the images. At such, critical perspective redefines a person's initial personal perspective in terms of universal conclusions about human nature (2003, pp. 108-114). In the following chapters of data analysis I will always bear these six perspectives in mind while analyzing the sample data within the theoretical framework established in the chapter of methodology. 
Apart from the increasing visual power, which has made many social scientists shift their focus in understanding social life, “culture' has become a crucial means by which many social scientists understand social processes, social identities, and social change and conflict." (Rose, 2005, p. 5) Stuart Hall, a major contributor of culture said:

Culture, it is argued, is not so much a set of things-novels and paintings or TV programs or comics - as a process, a set of practices. Primarily, culture is concerned with the production and exchange of meanings-the 'giving and taking of meaning'--between the members of a society or group...Thus culture depends on its participants interpreting meaningfully what is around them, and 'making sense' of the world, in broadly similar way (1997a, p. 2).

\subsubsection{The Ideology and Identity Theories}

\section{The Ideology and Critical Theories}

In the last several decades, linguists and anthropologists have increasingly put their research focus on the ways that social power and control are reflected in language, language use and language ideologies. Advertisements, with its rich material of signs created by some business group, are also likely to nurture and shape individual consciousness, and taking the advantage of mass communication media they are likely to influence a large group of target audience.

Ideology is knowledge and ideas characteristic of or in the interests of a class.

By extension, ideology can refer to the ideas of groups other than classesranging from gender (male ideology) to jobs (occupational ideology). Ideology is seen as any knowledge that is posed as natural or generally applicable, 
particularly when its social origins are suppressed, ex-nominated (see exnomination) or deemed irrelevant. In cultural/communication studies, ideology is seen as the practice of reproducing social relations of inequality within the sphere of signification and discourse (Hartley, 2002, pp. 103-104). Ideology as a theoretical concept comes from Marxism. In classic Marxism, the forms, contents and purposes of knowledge, representations and consciousness are not understood as abstracted from the material and social activities of production and class antagonism. On the contrary, the activity of production gives rise directly to knowledge of nature, and this knowledge of nature is directed towards further and increasing production by bringing all its myriad aspects as closely into line with general natural 'laws' as possible. (Hartley, 2002, pp. 103-104)

We can hardly address the issue of ideology without introducing some ideas by Karl Marx, Antonio Gramsci, Louis Althusser, Frankfurt School's critical theory, and Theodor Adorno. In his book Ideology David Mclellan (1995) devoted two whole chapters to introducing Marx and the Marxist traditions. He pointed out that what made Marx's contribution important and long lasting is his critical edge on the pejorative sense of "ideology". By means of "pejorative" Marx exposed relentlessly the true nature of ideology. According to Marx, ideology as a philosophical outlook first was idealistic rather than materialistic. Yet any correct view of the world had to be materialist view. Second, ideology was connected with the uneven distribution of resources and power in society. Third, ideology was connected with conflictual nature of socioeconomic relationship (or class struggle). As Marx's famous statement put it 'the ideas of the ruling 
class are in every epoch the ruling ideas.' Therefore for Marx what made ideas ideological was that it CONCEALED the real nature of social and economic relationship and thus served to justify the unequal distribution of social and economic resources in society.

Basically all Marx's discussion of ideology was conducted within the framework of his materialist theory. Marx was familiar with his idealist German contemporaries and he criticized them in his The German Ideology. Marx started his criticism from religion by declaring religion was idealist in nature. 'Man makes religion, religion does not make man'. He also criticized Hegel's inverted conception of the State as a false consciousness. For him it was wrong to start from human consciousness (or ideas) and to proceed from this to an investigation of material reality. The correct approach should be the other way round. Ultimately it was through the 'material practices' or fundamental human activity of satisfying material needs that our human history developed. Marx's contribution was unique in exposing the true nature of capitalist ideology in Capital. The free and equal exchange of goods and services in a capitalist market concealed and inverted the real and fundamental relations of production and people, which were full of exploitation and inequality.

Since Marx developed his materialist theory his ideas have become systematized and simplified from $19^{\text {th }}$ century to the beginning of $20^{\text {th }}$ century. In a way Marx's friend Engels, through frequent exchange of letters, has helped the formation and systemization of the materialist theory. Engels who was strongly influenced by the late $19^{\text {th }}$ century rationalism and materialism connected ideology with the ethereal. Lenin on the other hand simplified Marxism by pointing out that in a society torn by class antagonisms there 
is either bourgeois or socialist ideology. He believed that Marxism was a scientific ideology in that it corresponded to an objective reality. The eventual success of the Bolsheviks in 1917 and the later Communist Party of China in 1949 meant that Lenin's simplistic version of what ideology was became Marxist orthodoxy for generations. This was ironic because contrary to Marx's criticism the concept of ideology was stripped of its negative connotations and the idea of a socialist or Marxist ideology emerged to serve the purpose of ruling proletariat working class. It was also subject to political factors.

Many scholars have debated about whether Marxism was an ideology or not; among whom Edward Bernstein was the first one. He was convinced that Marxism was an ideology on the fact that it consisted of ideas-and ideas were by definition ideological and no political program could do without 'a good dose of ideology'. Later Hungarian fellow-Communist Georg Lukacs who was famous for his slogan "who will save us from western civilization" pointed out that historical materialism was not only an ideology; it was 'the ideological expression of the proletariat in its effort to liberate itself. He believes the validity of proletarian ideology lay in the future; it would be proved right in practice. Antonio Gramsci, an Italian Marxist, pushed the discussion of Marxist ideology to a high point. In Gramsci's paradigm he drew a distinction between 'traditional' and 'organic' intellectuals, emphasizing the important role of intellectuals in diffusing the worldview of the ruling class that it has become the 'common sense' of the whole society. This conception of ideological hegemony was Gramsci's answer to the puzzle of how capitalism had been able to survive. French philosopher Louis Althusser, an antihumanist and an anti-historicist, is not interested in whether any conception of ideology is false consciousness or not, but in the functions it performs. He saw ideology not as a 
product of people's mind, but as having itself a quasi-material existence which defines what people think, and is embodied in our society in what he calls 'ideological state apparatuses' such as churches, trade unions and schools. Thus ideology is not merely an illusory representation of reality, but a social cement of a system of class domination. His contribution lies in linking ideology to an institutional context and to the practices of everyday life.

It is the Frankfurt School that first coined the term "culture industry" and systematically analyzed the development of the culture industry and its instrumental function to the pervasiveness of capitalist market. The culture industry as a system in itself is geared to the production of meaning and the production of advertising and as a final mechanism for transferring these meanings to the world of everyday life. The critiques of the culture industry in Theodor. W. Adorno and Max Horkheimer's famous Dialectic of Enlightenment (1973) contain many, although unsystematic, references to Hollywood film. Film in the culture industries has been organized like industrial production and uses standardized formulas and conventional production techniques to mass-produce films for purely commercial, rather than cultural purposes. Films reproduce reality as it is and thus encourages individuals to adjust and conform to the new conditions of industrial and mass society:

They hammer into every brain the old lesson that continuous friction, the breaking down of all individual resistance, is the condition of life in this society. Donald Duck in the cartoons and the unfortunate in real life get their thrashing so that the audience can leam to take their own punishment (Adorno \& Horkheimer, 1973, p. 138). 
The Frankfurt School eventually became best known for its theories of "the totally administered society," or "one-dimensional society." This theory exposed the increasing power of capitalism over all aspects of social life and the development of new forms of social control. The theory analyses working class integration within contemporary capitalist societies and new techniques of capitalist stabilization. According to many critical theorists, new forms of technology, new modes of organizing production, new configurations of class, and new methods of social control were producing a "onedimensional" society without opposition. It also seems that new forms of political, social, and especially cultural conformity were becoming institutionalized (Marcuse, 1964; Kellner, 1984).

To summarize the above ideological and critical theory of the previous theorists it is easy to see how consumer's daily consumption patterns are oriented and determined by the spread of instrumental rationality from the sphere of production to that of consumption and the substitution of use value with exchange-value. This re-shift of value orientations creates a large number of symbolic associations as well as illusions that are exploited by the culture industry. In order to attract large enough buyers the symbolic forms (images or signs with connotations and denotations in the process of signification) are made low and common denominator to be simplistic and conformist.

\section{The Identity and Critical Theories}

According to Nancy Bonvillain (2003) every culture has systems of beliefs about the world, including ideas about human beings, their abilities and rights, and the ways they interact with each other. Beliefs systems not only explain but also legitimate social orders and constructions of reality. Belief systems, or ideologies, are transmitted through many 
social modes, such as religious rituals, moral and aesthetic values, political displays, and the like. And they are expressed in and through various forms of communication both verbal and non-verbal as in language and pictures. Meaning is never separated from the society that creates it and once created, it becomes part of the consciousness of individuals (Bonvillain, 2003, pp. 370-371) as V. N. Volosinov put it:

The individual consciousness is a social-ideological fact...The only possible objective definition of consciousness is a sociological one. Consciousness takes shape and being in the material of signs created by an organized group in the process of its social intercourse. The individual consciousness is nurtured on signs; it derives its growth from them; it reflects their logic and laws (1973, pp. 12-13).

There is no doubt that the spread of ideology will help forge group and individual identities. The definition of identity politics is given by Hartley (2002) as well in Communication, Cultural and Media Studies - the key concept.

Social action organized around cultural rather than civic or political subjectivities. Identity politics aims to provide a form of political participation for those who are excluded from the traditional means of representation. Examples of this could include the feminist movement, gay and lesbian activism, ethno-nationalism, as well as movements based on disability, youth and the environment...... The concept of identity is now often viewed as relying on shared characteristics that are cultural rather than natural/biological. As a result, political alliances based on an essentialist identity-one fixed in nature (origin and 'blood' or genes) rather than made in culture-is often 
viewed with alarm within radical circles (as sited in Grossberg, 1996). Spivak's notion of 'strategic essentialism' (as sited in Landry and Maclean, 1996) tries to get round the problem. It suggests forgoing the notion of the socially constructed and reclaiming a fixed identity in debates over cultural politics and policies. For while we may agree that, for instance, sexuality is a culturally constructed signifier, the rights and privileges awarded to heterosexual and homosexual individuals are markedly different. Here, 'strategic essentialism' supports the notion of a group of individuals coming together under the identity of 'gay' to participate in debates over equality, access and vilification... ... Here 'identity' means more than 'living as and being accepted by others in that culture'; it means having authenticated bloodlines showing a certain ethnic descent, consequential upon which may be various entitlements and rights, from land to welfare, policed, some have suggested, by DNA testing. Such a development in other domains of identity politics-for example in relation to the sometimes posited 'gay gene'-would be highly controversial (Hartley, 2002, pp. 101-102).

Social Identity Theory (SIT) is defined as "A social psychological theory of identity formulation that privileges the role of large group identities in forming individuals' concepts of self' (Calhoun, 2003). It has its origins in his early work in Britain by Henri Tajfel on social factors in perception (e.g., Tajfel, 1959, 1969a) and on cognitive and social belief aspects of racism, prejudice, and discrimination (e.g., Tajfel, 1963; 1969b, 1970), but was developed and fully formulated in collaboration with John Turner and others in the mid to late 1970s at the University of Bristol (e.g., Tajfel, 1974, 1978, 1982; 
Tajfel \& Turner, 1979; Turner, 1982)...The basic idea is that a social category (e.g., nationality, political affiliation, sports team) into which one falls, and to which one feels one belongs, provides a definition of who one is in terms of the defining characteristics of the category-a self-definition that is a part of the self-concept" (Desrochers, 2002, p. 259). The theory was originally developed to understand the psychological basis of intergroup discrimination. Tajfel et al (1971) attempted to identify the minimal conditions that would lead members of one group to discriminate in favor of the ingroup to which they belonged and against another outgroup.

In the Social Identity Theory, a person has not one, "personal self", but rather several selves that correspond to widening circles of group membership. Different social contexts may trigger an individual to think, feel and act on basis of his personal, family or national "level of self" (Turner et al, 1987). Apart from the "level of self", an individual has multiple "social identities". Social identity is the individual's self-concept derived from perceived membership of social groups (Hogg \& Vaughan, 2002). In other words, it is an individual-based perception of what defines the "us" associated with any internalized group membership. This can be distinguished from the notion of personal identity which refers to self-knowledge that derives from the individual's unique attributes.

Social Identity Theory asserts that group membership creates ingroup/ selfcategorization and enhancement in ways that favor the in-group at the expense of the outgroup. The examples (minimal group studies) of Turner (1982) and Tajfel and Turner (1986) showed that the mere act of individuals categorizing themselves as group members was sufficient to lead them to display ingroup favoritism. After being 
categorized of a group membership, individuals seek to achieve positive self-esteem by positively differentiating their ingroup from a comparison outgroup on some valued dimension. This quest for positive distinctiveness means that people's sense of who they are is defined in terms of 'we' rather than 'I'.

Tajfel and Turner (1979) identify three variables whose contribution to the emergence of ingroup favoritism is particularly important. 1) The extent to which individuals identify with an ingroup to internalize that group membership as an aspect of their self-concept. 2) The extent to which the prevailing context provides ground for comparison between groups. 3) The perceived relevance of the comparison group, which itself will be shaped by the relative and absolute status of the ingroup. Individuals are likely to display favoritism when an in-group is central to their self-definition and a given comparison is meaningful or the outcome is contestable.

Ideology and social identity theory shows whether an individual is identified because of gender, age, race, cultural heritage, economic status, sexual orientation, or physical disability. The visual message in advertising generally communicated about that person is misleading and false. Because pictures affect a viewer emotionally more than words alone do, pictorial stereotypes often become misinformed perceptions that have the weight of established facts and can remain in a person's mind for a long time if not a lifetime. When pictorial stereotypes are repeated enough times, they become part of a society's culture or scripts. This explains how the social and ideological functions of the advertisements are realized by repeatedly exposing cultural stereotypes and playing to social ideology. But on the other hand it also conversely explains why pictorial stereotypes in the advertisements can effectively represent the social and cultural change 
in a given society. Another reason why pictorial stereotypes are constantly and widely used in advertising is that communication is easier when people share the same cultural meanings (speak the same language or use the same visual symbolism), thus successful communication requires mutual understanding of the symbols used. In this research 'pictorial stereotypes' in advertisements are referred to 'pictorial metaphors' (in the form of $\mathrm{X}$ is $\mathrm{Y}$, or $\mathrm{X}$ is like $\mathrm{Y}$, or $\mathrm{X}$ symbolizes $\mathrm{Y}$, or $\mathrm{X}$ represents $\mathrm{Y}$ in the CMA theoretical framework). Lester gave some specific examples of pictorial stereotypes of AfricanAmericans, homosexuals, women, and Native Americans in the media in America (Lester, 2003, pp. 93-101). Studies of pictorial coverage in print and broadcast media have long noted the pictorial legacy of discrimination against groups mentioned above based on stereotyping. Good researchers in this direction include Barker's work Television, Globalization, and Cultural Identities (1999), Goffman's work Gender Advertisements (1979), Kress and Van Leeuwen's Reading Images: the Grammar of Visual Design (1996), and Williamson's work Decoding Advertisements: Ideology and Meaning in Advertising (1978). 
Seeing our whole experience as an interaction with signs... is today one of the 'hot' issues of the semiotic debate

Umberto Eco

Italian eminent novelist and semiotician

\section{CHAPTER 3}

\section{LINGUISTIC AND SEMIOTIC ANALYSIS}

The main argument in this dissertation is that since metaphor is not just a rhetorical device but a matter of thought and action to increase human knowledge, this has paved way for an investigation of the question whether advertising language as both a discourse and media form can manifest metaphor and social change as well. As Forceville (1996) rightfully argues that if metaphor can occur in pictures, more specifically in print advertisements and billboards, then the very concept of "pictorial metaphor" is validated. Therefore in this research I will take "pictorial metaphor" (visual metaphor or multimodal metaphor used interchangeably) as the research subjects to see in what way visual images in commercial advertisements in China in the last 30 years can reflect ideology and identity changes. Diachronically, this research traces the well-known or award-winning illustrated print advertisements appeared in Chinese media in the last 30 years to find out value theme and visual image changes. Along the synchronic dimension, the research not only makes a systematic analysis of visual metaphors but also tries to illustrate the 
conceptual changes of values and beliefs and indirectly reflect the changes in social construct of China from 1978 to 2008 .

In this dissertation advertising is treated as culturally-bound forms of business communication, involving linguistic-symbolic activities appeared in one or more types of mass media paid by the sponsors (advertisers). The presupposition is that advertising as a media discourse and a form of business communication is both the carrier and constructor of meaning-representing and acting upon social reality through linguistic-pictorial means in concrete situations. Advertising by nature is in cross-disciplinary and multicultural domain. Therefore in recognition of diversity and variation both in the research facets and in the research methods it is only natural that the present research will have to adopt an eclectic and interdisciplinary approach in order to explain and assess the advertisements to reach the research purposes. The research perspectives involved in this project based on the research purposes are linguistic (metaphorical), semiotic, communicative and critically interpretative.

\subsection{Theoretical Framework and Methodology}

The present research will adopt a holistic, multi-perspective and interdisciplinary approach to address the issue of identity and ideology change in China. The literature review in chapter two has provided the bigger picture of the academic contextual environment with which this dissertation anchors itself. It is mainly focused on previous advertising studies in the scopes of advertising as communication, advertising as business and advertising as a media discourse. Here in this chapter the theoretical framework and methodology for Critical Metaphor Analysis (CMA) is worked out as the guideline to help carry out the data processing and meaning explanations. Based on the theories in 
literature review and previous methodological approaches, figure 3-1, figure 3-2 and figure 3-3 serve as the foundation frameworks throughout the research process for linguistic, semiotic and critical advertisement analysis and data interpretation.

Figure 3-1 The Commercial and Ideological Functions of Advertisements

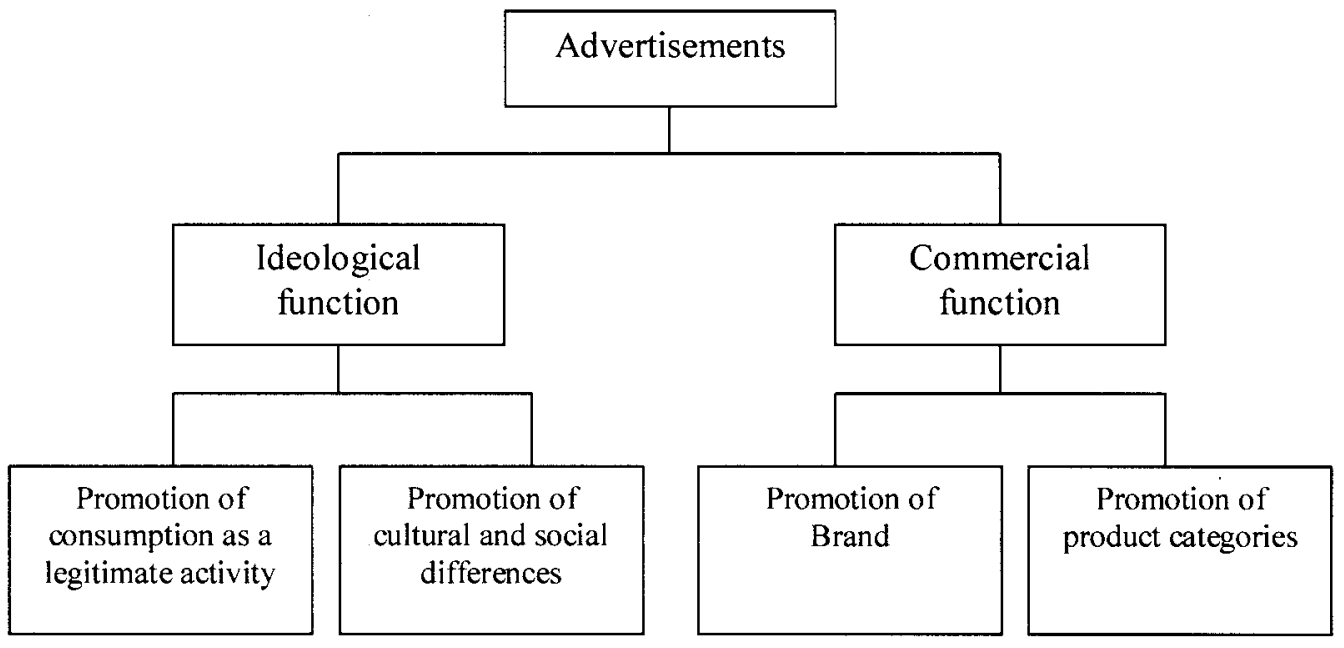

(Source: Consumer Culture - history, theory and politics by Roberta Sassatelli, 2007, p.133)

Figure 3-2 Theoretical Framework for Pictorial Metaphor Analysis of Illustrated Print Advertisements in China

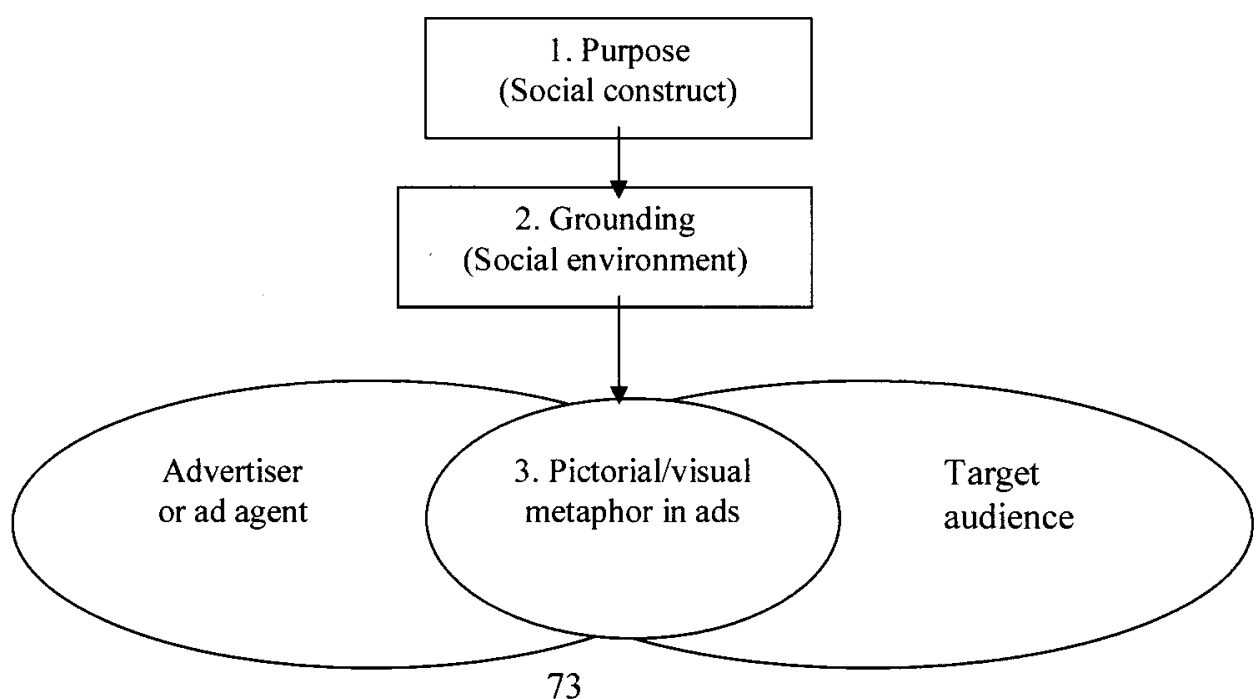




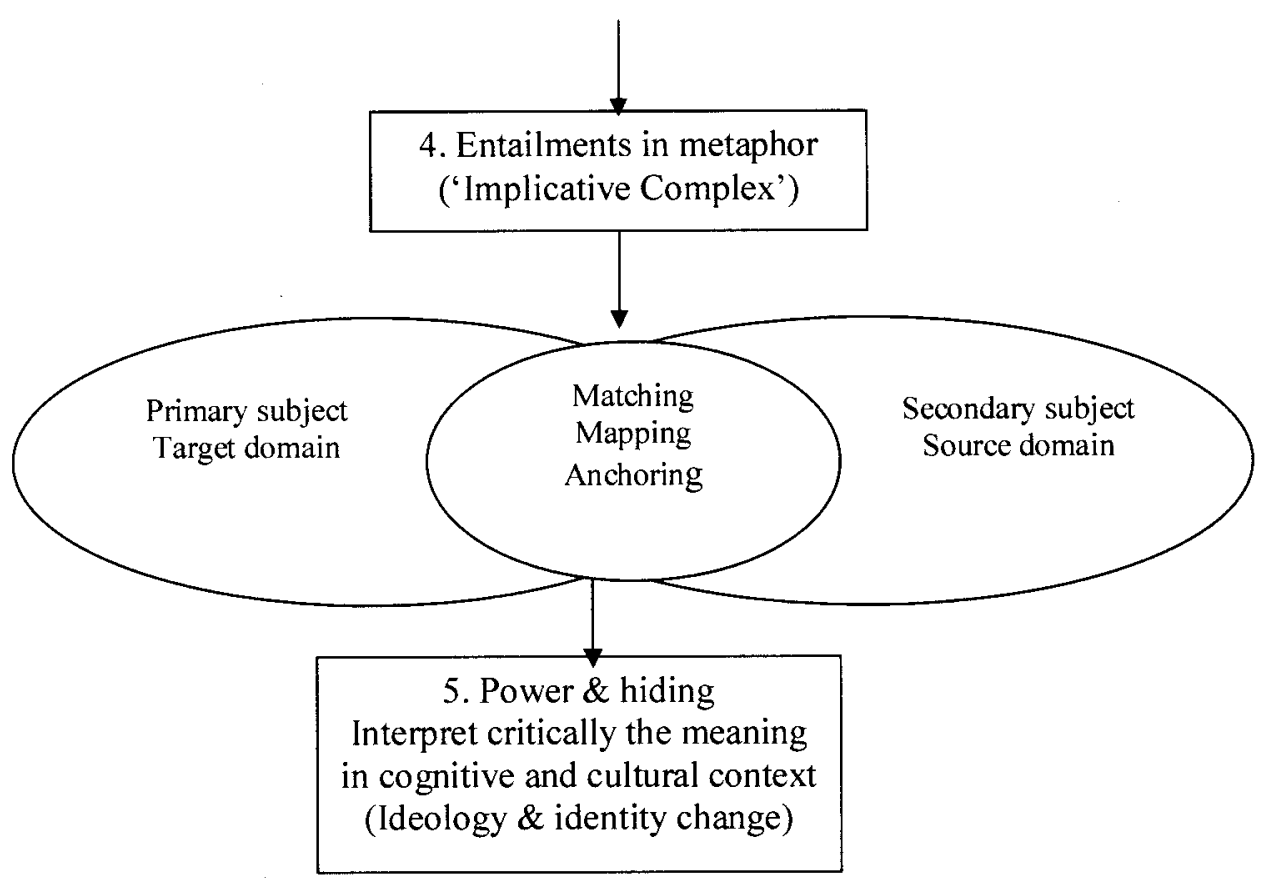

Figure 3-3 Theoretical Framework for Critical Metaphor Analysis of Illustrated Print Advertisements in China

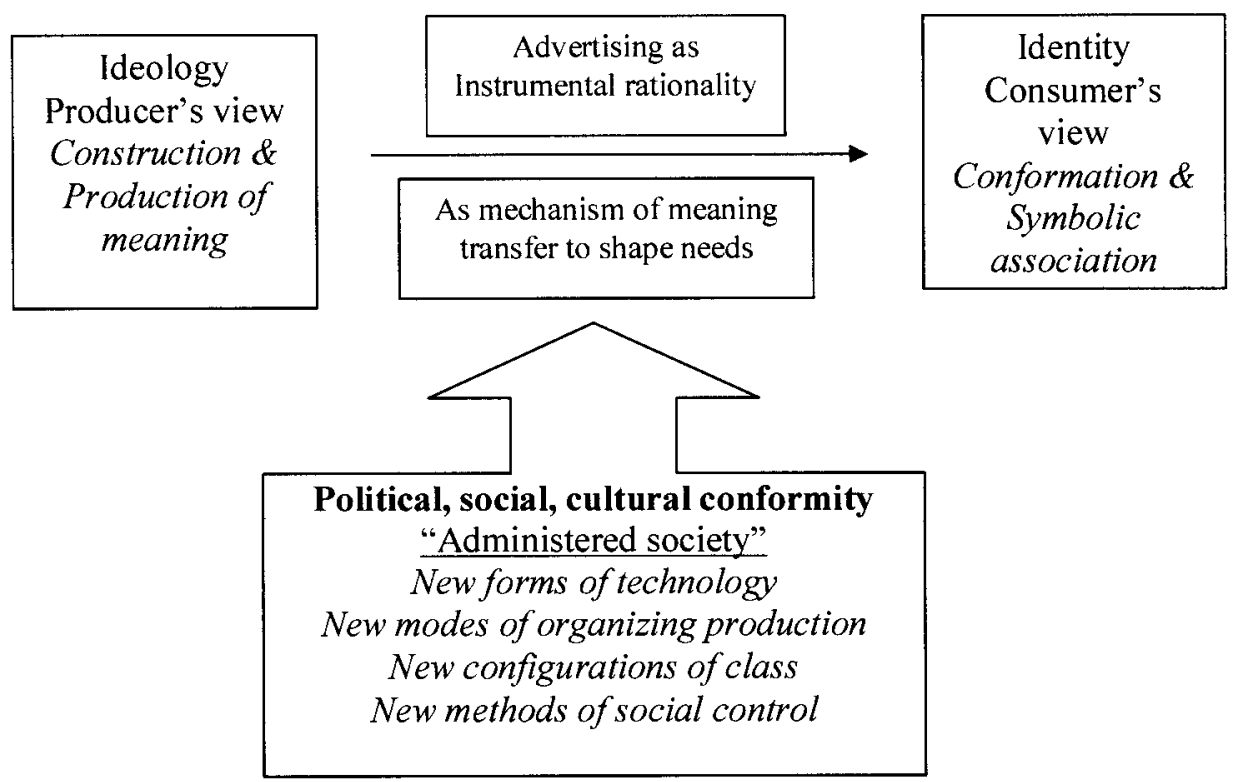


In order to answer the three research questions as explained in chapter one, it is important to be objective where the analysis of a large sample data advertisements deals with mass-produced artifacts. The criteria and methodology must be explicitly formulated and a systematic approach adopted. Following the working hypotheses in theoretical frameworks (c.f. figure 3-1, 3-2, 3-3) a systematic data analysis approach has been worked out whereby a large amount of apparently unordered material can be broken down into more manageable size and classified. A classified and organized material data provides a basic tool for the analysis and interpretation of a small corpus of advertising materials. Therefore in the following parts, I will first do a systematic linguistic analysis of the 300 illustrated print advertisements in China to find out the key words, advertising appeals and value themes. The result will be shown in Appendix I. Based on the systematic linguistic messages and key words of value themes I will then conduct a semiotic analysis to 300 advertisement images to identify the metaphors and representational (stereotyped) images and image groups. The result will be shown in Appendix II. Finally with the findings from classified linguistic data and semiotic data I will follow figure 3.3 to do a CMA to uncover any prevalent or recurring pattern in the material and eventually to discover the recurring pattern of social cultural changes in the value orientations (ideology) and group identities.

\subsection{Sample Data Collection: Sources and Criteria}

Since 1989 China Advertising Association (later together with International Advertising Magazine, International Advertising Institution and School of Advertising in

Beijing Broadcasting University) has started to celebrate a bi-annual event: China Advertising Award-winning Ceremony in order to promote and share the best-design and 
the most-creative advertisements in mainland China. It's also meant to establish a platform for advertising people to share creative ideas and indirectly record the industry development. The evaluation process for top-ranking ads must satisfy the following criteria: first, the advertisements must have exerted wide-spread influence in society (high reach and awareness); second, the advertising campaign must have caused effective sales increase (performance improvement); third, the creative design of the ads must be appealing and eye-catching through its unique advertising appeal and techniques. From the above three appraisal criteria, it is believed that the advertisements included in the award-winning collection volumes (one volume in every two years) are ideal to be the sample for analysis and to reach the research purposes because the invited judges in the panel have put into consideration both consumer popularity, organizational sales, social effect as well as aesthetic and cultural values that advertisements will exert on a given target group. However, due to the reason that this national advertising award ceremony was only initiated from 1989 , thus the representative volume for the first 10 years from 1979 to 1988 was naturally not available. To make up for this inadequacy and due to the lack of systematic collection in the early period of China's reform and open-up policy to outside world, I solve this sample collection problem by choosing 100 sample advertisements from three books, Accelerated Growth of China's Advertising Industry 1979 to $2003^{14}$ (Liu, 2004), A Profile of Industry and Commerce: classic ads in one century in China ${ }^{15}$ (Zhou, 2002) and A Pictorial History of China's Advertisements ${ }^{16}$

\footnotetext{
${ }^{14} \mathrm{Liu}, \mathrm{Libin}$ (Chief editor) (2004). Accelerated Growth of China's Advertising Industry from 1979 to 2003 . Huaxia Publishing House (The book is written in Chinese. The English book name is translated by the dissertation author). 刘 立宾《中国广告猛进史》华夏出版社 2004.

${ }^{15}$ Zhou, wei (Chief editor) (2002). A Profile of Industry and Commerce: classic ads in one century in China Guangming Daily Press (The book is written in Chinese. The English book name is translated by the dissertation author). 周伟《商侧影: 一个过纪的广告经典》光吸口报结版社 2002.
} 
(Huang, 2006). The same as the sample advertisements in the two award-winning collection volumes, they carry similar features in terms of popularity and economic and social influence on China. 100 Sample data representing 1989-1998 come from awardwinning advertisements of 1997 collection volume; and sample data representing 19992008 come from award-winning advertisements of 2007 collection volume.

During the data selection process for the 300 sample advertisements, 100 in each period respectively, I follow the criteria below:

First, since the source books or the collection volumes contain advertisements from many media vehicles such as TV commercials, radio commercials, neon light ads, outdoor posters and billboards, print ads and educational ads, the sample data are confined to print advertisements from only newspaper, magazine and posters (billboard).

Secondly, since this research will take both advertising copies (words) and visual images as the research subject, I have chosen illustrated print advertisements as the research samples. This means the advertisements must contain both words and pictures for critical metaphor analysis.

Thirdly, for the sake of having equal number of samples in each respective period, I have chosen clear and legible illustrated print advertisements for the sake of convenient analysis. Some ads are ignored either because the words are too small and illegible or because the pictures are not clear due to color, shade, size and print problems.

Fourth, since advertisements in the early period have not been categorized according to product industry as the later periods have, I try to strike a balance among different industries, which means industry and product/service variety is considered during the

\footnotetext{
${ }^{16}$ Huang, Shengmin, Ding, Junjie, \& Liu, Y inghua (2006) A Pictorial History of China's Advertisements by Nangfang Daily Press. (The book is written in Chinese. The English book name is translated by the dissertation author). 黄种 比, 丁俊杰, 刘英华《中国广告图史》2006.
} 
sample selection. Meanwhile since many advertisements are submitted for competition in series advertisements with different themes, I have chosen one company's ad only once.

Last but not least, the entire sample data (300 illustrated print advertisements in China) for content analysis are divided into three periods: sample advertisements from 1979-1988; sample advertisements from 1989-1998; and the sample advertisements from 1999-2008. I use advertisements from three award-winning collection volumes in three years, namely $1987,1997,2007$, to represent the three 10-year periods of China's development. As we all know, the developmental strategies of China in the last 30 years are gradual rather than shock therapy therefore it is hard to say which year is the most representative for the fundamental changes of China. Some years are more important than the others with higher GDP growth or significant economic and social events happening. But on the whole it is the cumulative effect that has transformed the China into its present stage. I have chosen 1987, 1997, and 2007 respectively and randomly as the representative periods for the pure reason that it is almost at the end of the 10 -year period to see the cumulative effect of development in China in each respective 10 years.

\subsection{Sample Data Treatment: Linguistic and Semiotic Analysis}

First and foremost, since this research falls into the emerging interdisciplinary field of visual culture, a holistic and multi-centric approach will be adopted. As is shown in chapter one, based on three assumptions I intend to explore into three specific research questions by using four instrumental tools - namely linguistic analysis, semiotic analysis, content analysis and interpretive critical metaphor analysis. Each of them is widely used in the research of their corresponding field and falls into the disciplines of communication, cognitive linguistics and humanities respectively. 
From a multidisciplinary visual culture perspective this research will be concerned with the long-term consequences of the ads in the media for the social construct rather than looking at how advertisements affect our individual lives. In another word macroscopic cultural theories are more concerned with how the social order as a whole is affected. How do advertisements as a whole affect the way politics is conducted, the way that a national economy operates, or the delivery of vital social services? We want to know if the commercial advertisements are intruding into or disrupting large-scale social processes. Macroscopic researchers also believe that such large-scale questions can't be answered if we focus on individuals. When our research comes to the third question to what extent the images or symbols change as well as metaphor change as applied in the advertisements in three periods respectively reflect ideology and identity change in China' the research method is mainly qualitative in which essential differences (distinctive qualities) in phenomena are highlighted. Evaluation of ideas and changes are accomplished through discussion involving proponents of contrasting positions or opposing theoretical positions. The proceeding quantitative content approach is mainly used to compile a manageable inventory of identifiable differences (distinctive qualities of value themes and pictorial metaphors) according to prevailing standards and eventually move to qualitative researches that focus more on theory development or criticism. Therefore the present research chooses to use both quantitative and qualitative method to answer the three research questions.

\subsubsection{Linguistic Analysis of 300 Advertisements}

\section{Introduction to Content and Linguistic Analysis}


Many authors (Fiske, 1990; Singletary, 1994; Rose, 2001) have recommended content analysis as one of the most useful methodologies for treating large sample sizes in mass communication and visual communication research. The tradition of content analysis of texts has the advantage of yielding quantifiable information that enables strong inferences beyond the information yielded by a sample text (Weber 1985). Many scholars have used the method of content analysis to treat advertisements samples (Hoffman, 1979; Pollay, 1983; Chinese Culture Connection, 1987; Mueller, 1987; Kress, 1987; Kress, 1996; Cheng \& Schweitzer, 1996). Linguistic and pictorial metaphor analysis has the advantage of enabling a richer analysis of both verbal and image texts by focusing on the descriptive and reciprocal interactional relationships between the two, which to some degree account for differences in what images mean, and how. Since the goal of this dissertation is to demonstrate the usefulness of combing these approaches to conduct an analysis of ideology and identity changes, also it is believed that the ideology and identity changes are embodied in the changes of dominant values and beliefs, in another word, what the upheld or prevalent values or social norms are that make people identify themselves with, thus I choose to study both linguistic features which anchor (provide 'relevance' and 'context' for) the images as well as pictorial metaphors (images) of advertisements for the simple reason that any advertisements basically consist of two primary components: text and image.

The linguistic analysis for 300 sample data advertisements is a necessary first step for data treatment because: first, the research subjects/data that I choose to study is illustrated print advertisement that contains both verbal text and pictorial images. The advertisement TEXT not only provides information about the product, the brand name, 
and the organization but also provides anchorage ${ }^{17}$ and relay ${ }^{18}$ for the image. What is more, the physical placement and properties (size, font, color, shape etc) of the text, the catch phrase and the slogan in particular, serve the purpose of catching reader's attention. Second, according to the theoretical framework and methodologies that are introduced in this chapter, advertising copies and appeals can help identify and anchor a pictorial metaphor, especially when the matching, mapping, or anchoring needs to be done between primary subject (signifier) and secondary subject (the signified). Third, despite the diversified approaches in studying advertising language such as word frequency ${ }^{19}$ (most frequently used adjectives, verbs, nouns, positive and negative words) and artful deviation ${ }^{20}$ (rhetorical devices), it is particularly helpful to study the text from the pragmatic point of view ${ }^{21}$ which provides the "relevance" for the viewer to understand cultural-specific and cultural-bound pictorial metaphors. Needless to say, any communication, including an advertisement, is unsuccessful if the hearer or the viewer can not grasp the implied primary components of meaning. In another word, advertising designers and viewers, in an information exchange process, each assumes that the others are rational and cooperative participants; therefore information exchange process moves forward as advertising viewer finds the relevance of what was said in an advertisement.

\footnotetext{
${ }^{17}$ Anchorage is text (such as a caption) that provides the link between the image and its context and the text provides relevance to the reader. This concept was introduced by Barthes in 1977.

${ }^{18}$ Relay is a reciprocal relation between text and picture, in that each contributes its own part to the overall message.

${ }^{19}$ Geoffrey N. Leech (1966) found out about the frequency of words in a sample of television advertisements and gave a thorough overview of how language is used in advertising in English in Advertising: A Linguistic Study of Advertising in Great Britain. London, Longman.

${ }^{20}$ A rhetorical figure has traditionally been defined as an artful deviation. A rhetorical figure occurs when an expression deviates from expectation. The rhetorical study of advertising language can be seen in Edward $\mathrm{F}$. MoQuarrie and David G. Mick (1996) Figures of Rhetoric in Advertising Language. Journal of Consumer Research and Corbett, Edward P. J. (1990) Classical Rhetoric for the Modern Student. 3rd ed. New York: Oxford University Press.

${ }^{21}$ For pragmatic theory of communication please refer to Grice, H.P. (1975) Logic and Conversation. In P. Cole and $\mathrm{J}$ Morgan (eds.) Syntax and Semantics 3: Speech Acts. New York, Academic Press, pp. $41-58$ and Sperber, Dan and Deirdre Wilson (1995) Relevance: Communication and cognition (2nd ed.) Oxford: Blackwell [First ed. 1986].
} 
This part will do a three-step treatment to 300 sample advertisements collected from three 10-year periods of China's well-known advertisements. The first step is to look at the verbal text-advertising slogan/caption or copy of each ad and identify the key words or the main theme/message of each advertisement. Most of these key words are taken from original advertisement texts that deliver the advertising message and realize the advertising appeals. Due to the fact that some advertisements have a long body copy to describe all the functions of the product, I will summarize the advertising copies into key words to show the main themes accompanied by either functional or emotional appeals.

The second step is to identify the advertising appeals used in each advertisement. An advertising appeal refers to the approach used to attract the attention of consumers and/or to influence their feelings toward the product, service, or cause. It is something that moves people, speaks to their need or wants, and excites their interest. Advertisements, as a creative and artful communication tool, their appeals have never been randomly chosen but are decided by careful analysis of social and cultural trend (as a relevance/contextual background) and consumer's psychological need analysis. Therefore it is of great importance to identify the advertising appeals that the ad designers use in each advertisement.

There are two major types of appeals. They are emotional appeal and rational appeal. Emotional Appeal relates to the customers' social and/or psychological needs for purchasing a product or service while Rational Appeal focuses on the consumer's practical, functional, or utilitarian need for the product or service and emphasizes features of a product or service and/or benefits or reasons for owning or using a particular brand. Both appeals are important, however, many advertisers believe an emotional appeal 
works better at selling brands that do not differ markedly from competing brands and is more effective when consumers' living standard is high and their motives for purchase decisions are emotional and psychological rather than purely physical and functional. In this dissertation I have divided the advertising appeals into three major types based on the theme of each advertisement: rational or utilitarian appeal, personal appeal and social appeal. The defining key words or value themes that are used for operational categorization of each type of appeal are given below.

Rational appeal: functions, quality, (top-ranking) brand, value price, scarcity, variety, delivery, convenience, comfort, effectiveness and efficacy, publicity (just let public know the existence of the goods).

Personal appeal: safety, security, health, fear, love, affection, humor, happiness, joy, nostalgia, sentiment, excitement, pleasure (fun-making), (sex) arousal/stimulation, sorrow/grief, pride, achievement/accomplishment, self-esteem, perfectness (splendid, extraordinary), enjoyment, ambition, humor, satisfaction, music, romance, hero, moneymaking or get rich.

Social appeal: recognition, social status, respect, involvement, participation, popularity, social embarrassment, affiliation/belonging, rejection, acceptance, approval, environmental protection, world welfare, help others, return to society, gettogether/social activity, lifestyle, reach-out, connection, relationship/network, collective power and authority. Together with the product names, research results from the first-step identification of key words and the second-step categorization or sorting of appeals used in each advertisement are shown in appendix I in the tables of I-1, I-2 and I-3. 
The third step is to do a content analysis to the resulting data in the three tables of product names, key words and advertising appeals. Contrary to its name, a content analysis of the key words and advertising appeals will produce some quantifiable results with comparable figures and facts. The result is shown in the table I-4 and I-5.

\section{Illustrations of Linguistic Analysis Process - 12 Examples}

A large sample size of 300 illustrated print advertisements from well-known newspapers and magazines and award-winning ad collections in three 10-year periods of time are treated by 3 different coders (two graduate students and I). However it is beyond the space allowed in this dissertation to go through data treatment process with all advertisements one by one. Therefore only 12 sample data advertisements are chosen as illustrations of how data are treated before the later content analysis is done. Out of the 12 samples 4 are chosen from each period of 1979-1988, 1989-1998, and 1999-2008 respectively.

Sample ad examples 1-4 belong to the first period from 1979 to 1988 (See the 4 pictures in the figure I-1 in appendix I). Example 1 (No.1.8) is Eternal brand toothbrush. It appeared on Economic Daily newspaper in Jan. 25, 1983. Unlike the previous advertisements this ad put the brand name ETERNAL in the upper center position with big-size and blocked letter to be followed by smaller product name TOOTHBRUSH on the right and the main benefits or properties of DURABILITY and VARIETY beneath the brand name. At the bottom left side is "manufactured by Shanghai Toothbrush Factory" and at the bottom right side is "distributed by Shanghai Light Industrial Product Purchase Group". In the middle we can see three different types of toothbrushes with "Shanghai" "Eternal brand" and "Order Number" on the hand of each brush. What attract 
us are the two flowers and the company logo at the right bottom side. This is a typical 1980s' advertisement with product, brand, manufacturer's name and product display on it. The advertising appeal is purely rational and functional with emphasis on quality, product origin (Shanghai), durability, and variety as the eye-catching phrase. The message is direct and clear with little room for imagination or metaphorical thinking. That's why in the table I-1 I summarize the key words based on the ad copy as "durability and variety". However this ad is better than the previous advertisements put in the media in that something extra are added - two flowers (one rose, the other chrysanthemum) even though small and minor in physical placement. The ad designer would like to add a romantic atmosphere to their product promotion as well as to increase the visual power bearing in mind that in 1983 China flowers are rarely seen in Chinese family and are despised as 'bourgeoisie' luxury lifestyle. Therefore most of advertising designers use rational appeals in ad creation.

Example 2 (No. 1.20) is one of the earliest foreign products that has come into China since 1978 when China started to open and reform-RADO Swiss Watch. It appeared on Wenhui Daily (a quality newspaper in Shanghai) in Mar. 15, 1979. The caption or ad slogan is RADO Watch - the Modern Watches. The body copy in small characters below the caption describes in detail all the major functions and benefits of the RADO watch. Below each of the three watches writes whether the watch is for 'female' or 'male' and whether they are 'water proof, shock proof, and magnetic proof'. The three watches on display in the middle attract our eyes for their modern design, high price, and multi-functions. Thus in the table I-1 the key words are 'modern features and functions'. The advertising appeal is rational rather than emotional. In 1979 China, people usually 
have to spend around 200 Yuan to buy such a watch which is an equivalence of 4-5 month salary of average city dwellers and they can only be bought in the biggest department store in central downtown area. Therefore owning such a watch became one of the three must-buy big-ticket items for newly-married couples. The other two bigticket items are bicycle and radio.

Example 3 (No.1.63) is an advertisement for Kodak color film that appeared in 1983. On top of the Example 3 is the caption 'Kodak color film VR1000, the fastest exposure Kodak color film'. Below are several lines of body copy with detailed introduction about technical advantage and benefits of this film. At the bottom right hand 'Kodak (Foreign Trade) Corporation' together with Kodak's logo can be seen. However the viewer can understand the benefits of VR1000 without making special effort to read the small-letter words because the ad designer started to use metaphorical image. The picture is very-well anchored in the text that even in a very dark background with a little candle light the foreign lady's face can still be photographed clearly by using a box of Kodak color film VR1000 shown on the left comer of the ad. The relay between the words and images shows a reciprocal mapping or matching. Thus in the table I-1 the key words are 'colorful and fastest exposure'. The advertising appeal is rational (functional).

Example 4 (No. 1.77) is an advertisement for Shanghai Specific toothpaste appeared on newspaper in 1985. Compare with example 1 toothbrush ad (No. 1.8) which is clumsy and explicit, this advertisement is simple and implicit with only one caption 'Shanghai Specific Toothpaste' in both Chinese and English. However the designer purposely enlarge the Chinese characters of '上海-Shanghai' and English word 'Specific' respectively to emphasize the city of origin (at that time made-in Shanghai products 
enjoy good reputation in China) and the benefit of SPECIFIC efficacy. The happy smiling up-looking young lady with beautiful and white teeth against a red (lucky and protective color in China) background fits in (anchors) harmoniously with the context provided by the words on the top left and echoed by the words on the up-lifted toothpaste in a pair of delicate hands. This ad shows that after only a few years of professional development in Chinese advertising industry, already the ad professionals are using fewer words but more aesthetic images to express the intended meanings. Even though this ad still uses rational appeal of EFFICACY, the viewers can use their imagination and association to identify themselves with the fresh-looking young lady in that, if I use this toothpaste I will become happy, fresh-looking, up-mobile, and protected.

Sample ad examples 5-8 belong to the second period from 1989 to 1998 (See the 4 pictures in the figure I-2). All the ads collected as samples in this period come from the award-winning ads in 1997 collection.

Example 5 (No. 2.18) is Meidina Nutritional Liquid for fruits and vegetables. There is only one line ad slogan below the Chinese character 田 (field). However the simple and colorful Chinese character $⿴$ (field) looks like a picture of field due to the iconic and pictorial nature of Chinese language. This 'field' is made of colorful fruits and vegetables such as tomato, grapes, pear, orange, date, watermelon and strawberry. The iconicity between the colorful field and the key word is echoed by the ad slogan 'Meidina writes colorful field (H)'. Down below at the right hand bottom we can see the name of the brand and product 'Meidina nutritional liquid for fruit and vegetables'. The key words for this ad are 'colorful field' and the designer uses social appeal because the field is part of nature and being close to nature. 
Example 6 (No. 2.28) is Nippon Airox spray paint. The caption is a line of words 'extraordinary color comes from me (butterfly)' with the key word 'color' enlarged in red and yellow. The ad uses a big butterfly image with a bottle of Airox spray paint in the middle as the body of the butterfly to metaphorically denote "our paint is as bright and colorful as a butterfly'. Down below the small words relay the meaning above. On the bottom left are the words 'Nippon Paint shines everywhere'. On the bottom middle the benefits and functions (one layer is enough, patent registration, lasting color and no odor and suitable places for use) are specified. On the bottom right are the words 'Airox spray paint recommended retail price $Y 13.8^{\prime}$. Therefore the key words for this ad are summarized as 'extraordinary and outstanding color'. The advertising appeal is personal based on the definition list for rational, personal and social appeals above.

Example 7 (No.2.37) is Harbin beer. This ad has three lines of words on the upper right hand literally translated as 'a centenary image, glitteringly on stage, Harbin beer.' On the bottom left are the manufacturer 'Harbin Beer Group' and the company logo. What is impressive about the ad is the man holding a cup of beer looking mysteriously at us. The small words beneath the image read 'what can you read from the eye of Sartre ${ }^{22}$ ?' In order to understand the link between Sartre and beer one needs to know the essence of Sartre's work and philosophy-freedom and existentialism. Another link between Sartre and the beer is the well-known coffee bar in Paris that Sartre often went to drink and think. From the image we can guess that during 1990s Sartre's philosophy is popular enough in China, at least among intellectuals and students, to be used as an icon for beer. Thus to drink Harbin beer denotes the meaning of freedom, truth-seeking, and thought-

\footnotetext{
${ }^{22}$ Jean-Paul Sartre (1905-1980) was a French existentialist philosopher, playwright, novelist, screenwriter, political activist, biographer, and literary critic. Sartre's consistent message throughout his lifetime seems to be we are condemned to be free, but we have to make good use of our freedom to make lives worth-living.
} 
provoking. Naturally the advertising appeal is a social one because the key words are centenary image and glistering on stage.

Example 8 (No. 2.39) is an advertisement for Modern Advertising magazine. On the top left side are two lines of words 'modern advertising' in both Chinese and English. On the right bottom side is the specific information about an issue of magazine - China professional advertising magazine, second issue of 1997, ISSN number, bar code and recommended retail price. What impressed us is the image of traditional Chinese saint (a knowledgeable and respectable person) holding a scroll with four Chinese characters '文 明进步 civilization and progress.' Just above these four characters on the chest of the saint can be seen two characters '广告 advertisement.' The audience will easily associate 'advertisement' with 'civilization and progress' and this message of 'our advertisement is the carrier of civilization and progress' is convincingly delivered by a respectable image of Chinese saint who wears national color of red and royal color of yellow. The colors echo with the red and yellow color in the two key words 'Modern Advertising.' The saint looks humble in expression and fortunate in body shape. Naturally the key words for this ad is 'civilization and progress' and the advertising appeal is a social one.

Sample ad examples 9-12 belong to the third period from 1999 to 2008 (See the 4 pictures in the figure I-3). All the ads collected as samples in this period come from the award-winning ads in 2007 collection. This period has many series advertisementswhich are series of ads launched in different periods of time based on popular social event and cultural trend.

Example 9 (No.3.1) is a popular advertisement of China Telecom. In this advertisement there are four pictures that show rainforest, desert, ocean and mountain top. 
On each picture there is the same advertising slogan/caption 'the city is far but the world is near.' Beneath the slogan there can be seen very small words 'China Telecom, wireless wideband access service, anywhere anytime, access to the world at your finger tip, keeps you connect to the world at all time.' Immediately next to these small white words can be seen Internet access slot on the tree, cactus, coral, and rock. Therefore the key words in this ad is 'far city but near world - Internet connection.' The idea of world connection makes it a suitable social appeal. Compared to the previous two periods this ad holds a broader horizon of world view (keeping in touch with the world) and transcendentalist feeling. It expresses a common feeling of modem people: we have a desire to be away from the city to the remote natural scenery but still we want to be connected with the secular world.

Example 10 (No. 3.10) is an advertisement for Motorola's new mobile phone named 明 which can be literally translated as 'insightful, brilliant, light.' The two pictures at the upper hand have the caption of MOTO Insight to be followed by the small-word body copy on the top left hand. The body copy has described the five functions of the new mobile phone (crystal flip cover, 2 million pixels digital camera, smart identification card, RealPlayer MP3, handwrite key in). These small words are echoed or relayed by the mobile picture on the top right hand and the Intel Inside at the bottom left hand. The two pictures at the lower hand have the caption of MOTO New Horizon to be followed by the small-word body copy beneath it. Unlike the two pictures above the small body copy describes the multi-meaning of the word 明 (to perceive with sharp eye; to make a clear distinction between....and; to be wise and sensible). These small words are echoed or relayed by the mobile picture next to them on right hand and the Intel Inside at the 
bottom left hand. The two captions (INSIGHT and NEW HORIZON as the main theme of the ad), multi-functions and multi-meanings of the Chinese character 明 as explained in the body copies provide a good anchorage for the four people who look insightful, brilliant, and vogue. From the different styles of clothes each of them is wearing simultaneously, we can see they are multi-tasking, playing multi-roles, and opening up new horizons with insightful sharp eyes. All these can not be achieved without the help of the mobile phone MOTO 明.

Example 11 (No.3.15) is an advertisement for China Life Insurance. It consists of three parts: umbrella, wardrobe, and car park. In each part we can read a caption of 'a colorful world that belongs to me; a personal space that belongs to me; a reserved car park that belongs to me' respectively. A line of small words beneath each caption is the same [life insurance for children] 'reserve a big enough space for your child's future.' At the bottom left hand is China Life Insurance Group in green color with the logo. It is obvious the key words for this ad are 'personal and reserved space' (for child's future development). The metaphorical implicative is that buying our life insurance for your kid is buying reserved personal space for your child's future development. From the three pictures we can see the big space already reserved despite the little green umbrella, the little green jacket and the little yellow car. The campaign theme of personal, private, and reserved space can only be seen in 2000 s when China is becoming quickly modernized and globalized. Naturally the advertising appeal is personal rather than rational or social.

Example 12 (No. 3.62) is a Hong Kong advertisement for Reebok sports wear. The key words in both pictures are a very individualistic and expressive slogan 'I am what I am.' The upper picture boy (Fang Lishen or Alex Fong) used to be a Hong Kong 
professional swimmer that took part in Sydney Olympic Game and still held many swimming records in Hong Kong. Now the boy is a successful movie star. On the upper right hand is his quotation: "Everybody says I am a flying fish, I say I don't just excel in swimming pool." His words are echoed by the electric fish with water bubbles and cool facial expression and muscled chest. All these come from a black Reebok coat. The lower picture girl (He Yunshi or Denise Ho) is a Hong Kong pop singer who has always been reported by the media as a suspect of lesbian. The small words on the top right hand are what she said. "Which one do I like, man or woman? I won't explain. I don't care if you like me or not, but I like myself." Her quotation is supported by the loose tie on her neck, the rough buckle on the jean and the scornful expression on her face. The key words for this ad are 'I am what I am' or 'be myself' and the appeal is personal.

\section{Results for Key Words and Advertising Appeals}

Appendix I contains all the resulting tables and figures of data treatment for 300 collected sample advertisements. In the three tables of I-1, I-2, and I-3 there lists and demonstrates clearly the names (types) of the products, the advertising appeals and the key words (value themes) in the three columns from the left to the right. The table I-4 is a summary of the key words and value themes in three periods respectively. For the convenience of comparison 100 key words appeared in each specific period are arranged according to time periods, priority and frequency. The arrangement of the key words is done based on the most Frequently Appeared Words (FAW) in each period and I assume that FAW is a measure of importance and emphasis. The counting result of the frequently appeared words (including nouns, adjectives, and verbs) shows both the focus and priority differences in different time periods and the similarities or commonness that 
appeared consistently throughout all the time periods. The table I-5 shows the statistical results of different advertising appeals used by advertisers in three specific 10-year periods of time.

During the conduction of linguistic analysis of 300 advertisements I have the general impression that the frequently appeared key words are relatively fewer in number and more focused with a relatively high level of consensus in 1980s, however in 1990s and especially in 2000 s the key words become diversified with low level of consensus in theme orientations. The second impression is the body copies (the small descriptive words on each ad) become less used and the ad designers tend to use more visual and metaphorical images rather than direct language descriptions to illustrate their creative ideas. This reduction both in terms of consensus for creative ideas (ad themes) and in the use of descriptive words is in concomitant with China's economic and social cultural change when people become too busy to read and when diversified value themes are prevalent. Therefore it deserves a further discussion in the next part to see how visual metaphorical images are used semiotically in these 300 advertisements to help enhance the value themes and meaning elements expressed in the verbal text.

\subsubsection{Semiotic Analysis of 300 Advertisements}

\section{Introduction to Content and Pictorial Metaphor Analysis}

Following the previous part of linguistic analysis of the advertising slogans or captions and copies, which has produced three lists of frequently appeared words and advertising appeals typical of each period, in this part I will use both content and semiotic approach to do a pictorial metaphor identification and analysis to the same 300 sample advertisements. The rationale behind this research approach is based on both cognitive 
metaphor theory and linguistic semiotic theory as is shown in the theoretical framework in figure 3-2. According to Charles Forceville:

A metaphor, then, consists of two 'things': a 'literal' primary subject and a 'figurative' secondary subject. Metaphor occurs first of all on the level of cognition, and can manifest itself on the pictorial as well as the verbal level—and possibly in yet other ways. Both the primary and the secondary subject of the metaphor can be envisaged as domains of meaning elements, ranging from verifiable facts to connotations, and including beliefs about and attitudes towards that subject. According to Black, in each metaphor one or more features of the domain of the secondary subject (the 'source domain') are mapped on to the domain of the primary subject (the 'target domain'). This mapping process involves the foregrounding adoption or modification of certain features in the primary subject. There is thus a mapping between elements from the source and target domains. The similarity between the two terms of the metaphor is not necessarily pre-existent, but is often created by the metaphor itself (1996, p. 116). I take this quotation as the guidance and foundation throughout the whole process of pictorial metaphor identification for 300 sample data advertisements. However a few methodological and operational issues need to be clarified before pictorial metaphors can be identified.

First, during the identification and interpretation of the pictorial metaphors, how to avoid and reduce the level of subjectivity? How can we be sure the metaphorical statements and the projected features identified are the addressor's intentional meaning? Should we follow a 'best guess' approach of the ad designer's intentional 'meaning 
element' or should we take the immediate responses of a large group of viewers as the correct 'meaning element' projected from secondary subject (source domain) to primary subject (target domain)? Due to the tremendous amount of time necessary for the fixation of intentional meaning (element) by the original ad designers as well as by the large number of viewers, I finally decide to use the former 'best guess' method rather than the later 'viewer's response' for the simple reason that all the sample research advertisements collected are either popular and influential advertisements in China during that specific period or the award-winning advertisements. As it is explained in chapter three the criteria for the research subject collection of advertisements have guaranteed their geographical sales success and intended group identity among Chinese people (at least among consumer groups). Through the large public exposure in the media these advertisements have exhibited their 'metaphorical nature' and materialized their 'instrumental mission'. Meanwhile I believe that this 'best guess' method could be applied because it is in accordance with Sperber and Wilson's (1995) relevance theory that an advertisement (an utterance) is an interpretive expression of the ad designer's thought and the ad viewer makes an interpretive assumption about the ad designer's informative intention (usually the 'best guess' for the 'strong implicatures').

Let us say that an utterance is an interpretive expression of a thought of the speaker's, and that the hearer makes an interpretive assumption about the speaker's informative intention. It follows from our general account of inferential communication that an utterance should be an interpretive expression of a thought of the speaker's. However, we see no reason to postulate a convention, presumption, maxim or rule of literalness to the effect that this 
interpretation must be a literal reproduction. How close the interpretation is, and in particular when it is literal, can be determined on the basis of the principle of relevance (Sperber \& Wilson, 1995, pp. 230-231).

From the quotation above, it is evident that for ostensive advertising communication to be successful it is enough if it is mutually manifest to both ad designer and ad viewer that the viewer has recognized the informative intention.

In commercial advertising the informative intention always boils down to some kind of positive claim about the product or service advertised... It organizes the addressee's responses to all elements, verbal and non-verbal, in the advertisement, and it considerably narrows down the number of potential interpretations of an advertising billboard (Forceville, 1996, p. 99).

Beijk and Van Raaij (1989) propose a helpful mechanism in understanding the processing of advertisements by (prospective) consumers with two important notions. One is "schemas", sometimes called "scripts", which include both person-schemas and event-schemas. Similar to Sperber and Wilson's "cognitive environment" they are coherent clusters of information stored in people's memory serving as "interpretative frameworks" that predispose people to certain emotions and behavior. The other is "selfschemas" that contain information about the kind of person one is, thinks one is, or would like to be, with regard to various domain of behavior. The products or the metaphorical images in advertisements work best when they fit or enhance favored identities or avoid undesirable ones. Of course they also partially contribute to the formation and evolving changes of schemas and self-schemas (Beijk \& Van Raaij, 1989, pp. 13-17). Therefore it is safe to say the success of any commercial advertisement depends on the creation of 
consensus on person schemas and event schemas and make these schemas become everyone's desirable self-schemas.

Second, during the operation of identification for pictorial metaphors in the sample advertisements, how pictorial image signs can be analyzed semiotically as systems of signification? De Saussure proposed a distinction between the "syntagmatic relation and paradigmatic relation". Roland Barthes elaborates the concept of "denotation and connotation" in Elements of Semiology (1967a). Peirce distinguishes three levels of signification: "iconic, indexical and symbolic". In yet another perspective of metaphor as a figurative speech, how to deal with different layers of figurative meanings and different kinds of figurative devices such as simile (The sunset is like blood), synecdoche (bread represents food, rose represents love), metonymy (The kettle boils-the water in the kettle boils), and metaphor (Life is a journey) that the advertising designers use to evoke resemblance, relevance, associations, and connections? One way to answer the former question is to borrow Peirce's iconic, indexical and symbolic sign typology to explore the three levels of signification: direct resemblance/likeness (iconic meaning), sequential or causal connections (indexical meaning) and conventional and contractual relations (symbolic meaning). However, all these tend to complicate the operational process and may not directly relate to the research purposes. Therefore I choose to simplify the above complications and narrow three levels of signification to only two: signifier and signified. The relation between these two can either be direct resemblance, causal connections or conventional relations. As for the later question of figurative speech, I decides to operationally ignore the differences caused by four figurative devices and use an allembracing umbrella term 'metaphor' consistently throughout the whole dissertation to 
express the relationship of similarity or analogy between the two sides of the representations as long as any features of secondary subject (an image) is transferred (mapped, matched, fit) on to the primary subject (a product, service, brand). The exact figurative meaning out of many layers of meaning will have to be brought out or determined by the combination of three factors: key words and value themes, the images, and the sign-situation (cognitive environment created by social cultural environment). This is exactly the three-stage process of critical metaphor analysis that I follow to analyze 300 sample advertisements throughout the dissertation. Only my research purpose is not put on the design and creation of each individual advertisement, but on the collective impact these advertisements have on Chinese society as a whole.

The research approach in this part will follow two stages.

In the first stage, pictorial metaphor statements will be identified from each advertisement to be followed by primary subject (target domain or signifier) and secondary subject (source domain or signified). Then the projected features (meaning elements matched between signifier and signified) and representational images will also be identified. The result is shown in Appendix II in three tables of II-1, II-2, and II-3 with pictorial metaphor statements on the left column, primary and secondary subjects in the middle column, and projected features and images on the right column.

The second stage is a content analysis to the resulting data in the three lists of metaphorical statements, signifiers and signifieds and their corresponding projected features. These images and metaphors will be categorized so that ultimately a table of representational semiotic image categories will be formed to see the stereotyped images/metaphors appeared in China in 1980s, 1990s, and 2000s respectively. As it is 
said before contrary to its name, a content analysis of representational or stereotyped metaphorical images will produce some quantifiable results with comparable figures and facts.

\section{Illustrations of Pictorial Metaphor Analysis Process - 12 Examples}

In linguistic treatment of the data ads 12 advertisement sample examples are illustrated with regard to how to identify FAWs, advertising appeals and value themes in three periods of time. Based on the methodological and operational considerations per se, this part will do a semiotic analysis to the same 12 sample examples (c.f. figure $\mathrm{I}-1, \mathrm{I}-2$, and I-3) in order to identify the pictorial metaphors with signifiers, signifieds and corresponding projected features (meaning elements matched).

Example 1 (No.1.8) is Eternal brand toothbrush.

The identified metaphorical statement is 'the toothbrush is a flower'. The primary subject (the signifier) is the Eternal brand toothbrush. The secondary subject (the signified) is the flower (one rose, the other chrysanthemum). The flower has the following features: flower is beautiful, flower is fragrant, flower is romantic, and flower is bourgeoisie life style (in 1970s' China). Which features from the domain of the flower are transferred to the domain of the toothbrush? Here since the toothbrush is metonymically represented as teeth thus the features of beauty and fragrance of the flowers are transferred to teeth through toothbrush. The connotation is if you use our Eternal brand toothbrush, your teeth will be as beautiful and fragrant as flowers.

Example 2 (No. 1.20) is RADO Swiss Watch.

In this advertisement there can be seen no other images except for three RADO watches on display, thus no metaphorical statement can be identified. This is partially due 
to the fact that RADO Swiss Watch is one of the earliest foreign products that have come into China since 1978 when China just started to open and reform. This advertisement is obviously meant to inform rather than persuade by using direct rational and functional appeal. However the caption or slogan, which is 'RADO Watch-the Modern Watch', helps to identify the meaning intentional or the projected feature - modernity. Since China claimed itself to embark the march towards the 'four' modemization process in 1979 therefore the very word 'modern' has its unique attraction and appeal to Chinese people as a whole. Meanwhile the direct display of the high quality modern Swiss watches is enough at that time to attract Chinese consumers' attention and imagination when material supply is inadequate and foreign products are rarely seen.

Example 3 (No.1.63) is an advertisement for Kodak color film.

The identified metaphorical statement is 'Kodak color film is a foreign beauty in the candle light.' The primary subject (the signifier) is Kodak color film VR1000. Here Kodak color film metonymically denotes the meaning of 'the effect of using Kodak color film.' The secondary subject (the signified) is a foreign beauty in a candle light. Since this metaphor is actually a simile we can easily interpret the meaning of it as 'the effect of using Kodak color film to take photos is just like a foreign beauty in a candle light.' Thus it can be further denoted that Kodak color film VR1000 is so good that with a little candle light we can still see the facial profile of a foreign lady clearly. The connotation or implicative of the pictorial metaphor (actually simile) in this ad is not realized by projecting (or matching) any features of the secondary subject (a foreign beauty) to the primary subject (Kodak color film) but through establishing a sequential or causal connections among the candle light, the foreign lady, and the effect of Kodak color photo 
film. Therefore the rhetorical device in this ad is simile; the image is a foreign lady and the projected feature is good exposure.

Example 4 (No. 1.77) is an advertisement for Shanghai Specific toothpaste.

The identified metaphorical statement is 'Shanghai Specific toothpaste is a happy girl'. Since the caption in Chinese has expressed the meaning of 'specific efficacy' and 'made in Shanghai' very clearly, the image of the girl is just a pictorial illustration of this ad copy. The primary subject (the signifier) is the Shanghai Specific toothpaste. The secondary subject (the signified) is a Chinese girl. The girl has the following features: she is holding and using Shanghai Specific toothpaste; she is white-teethed and white skinned; she is happy; she is up-looking; she looks refreshing. Which features from the activity and description of the girl are transferred to the domain of the toothpaste? All of the above. The connotation is if you use our toothpaste just as she does, you will be looking as white-teethed, refreshing and happy as she is.

Example 5 (No. 2.18) is Meidina Nutritional Liquid for fruits and vegetables.

The identified metaphorical statement is 'Meidina Nutritional liquid for fruit and vegetable is a colorful field made of fresh fruit and vegetable.' The primary subject (the signifier) is the nutritional liquid. The secondary subject (the signified) is colorful field. This field is made of fresh and ripe fruit and vegetables. Here the ad designer uses the iconicity between the shape of crop field and the Chinese character field (田) to express the resemblance, connection and association. The colorful (mainly golden color) field can project the following associations: it is a season of harvest, it is natural, and it is ripe fruit and vegetable. Which features from the domain of colorful field are transferred to the domain of the nutritional liquid? Harvest season for ripe fruits and vegetables. The 
connotation is if you use our Meidina Nutritional liquid you will have a harvest season for your fruits and vegetables as is shown in the colorful field (田).

Example 6 (No. 2.28) is Nippon Airox spray paint.

The identified metaphorical statement is 'Nippon Airox spray paint is a butterfly'. The primary subject (the signifier) is the Nippon Airox spray paint. The secondary subject (the signified) is a butterfly. The ad designer has cleverly put the Airox spray paint bottle in the middle of the two butterfly wings as its body. The big brightly colored butterfly has projected one feature-bright and diversified color-onto the primary subject Nippon Airox spray paint. The ad caption 'extraordinary color comes from me' helps to explain the meaning. The signification is if you use our Nippon Airox spray paint you will have a diversified and bright color choice.

Example 7 (No.2.37) is Harbin beer.

The identified metaphorical statement is 'Haerbin Beer is Jean-Paul Sartre (a French philosopher)'. The reason why the man in the picture was identified as Sartre is because of a line of small words under the picture: 'what can you see/read from Sartre's eyes?' The primary subject (the signifier) is Haerbin beer. The secondary subject (the signified) is French philosopher Jean-Paul Sartre. Philosopher Sartre as an influential person in 1990s China particularly among young people and academics may project the following features: he is an existentialist. He is truth-seeking. He loves and fights for freedom. He likes to drink in a café while writing. Which features from the domain of Sartre are transferred to the domain of Haerbin beer? From the picture above it can be seen that Sartre's facial expression is a satisfied one though a bit mysterious while holding up a cup of Haerbin beer. Here since the beer is metonymically represented as the person who 
drinks beer, thus all the features of Sartre are transferred to the person who drinks the same Haerbin beer. The analogy is if you drink our Haerbin beer you will become Sartrekind of person by living his lifestyle and drinking often in a café.

Example 8 (No. 2.39) is an advertisement for Modern Advertising magazine.

The identified metaphorical statement is "Modern Advertising magazine is a traditional Chinese saint'. The primary subject (the signifier) is the magazine. The secondary subject (the signified) is a traditional Chinese saint. What is impressive about the image is the traditional Chinese saint holds a scroll with four Chinese characters '文 朋进步 civilization and progress'. Just above these four characters on the chest of the saint can be seen two characters '广告 advertisement'. Thus the audience will easily connect and associate 'advertisement' with 'civilization and progress.' This message of 'our advertisement is the carrier of civilization and progress' is convincingly delivered by a respectable image of Chinese saint who wears national color of red and royal color of yellow. The colors echo with the red and yellow color in the two key words 'Modern Advertising.' The saint looks humble in expression and fortunate in body shape. A traditional Chinese saint is usually considered to be an insightful and respectable person who has humble manner but extensive knowledge. These features will be projected and transferred to the Modern Advertising magazine. The image and color choice also denote the meaning that the magazine will use traditional Chinese elements to illustrate modern business.

Example 9 (No.3.1) is a popular advertisement of China Telecom.

The identified metaphorical statement is 'China Telecom is forest, desert, ocean and mountain'. The primary subject (the signifier) is the China Telecom. The secondary 
subject (the signified) is four remote non-urban places (forest, desert, ocean and mountain). Further on the picture it is shown that in these far-away places Internet access slots can be seen on the tree in forest, on the cactus in desert, on the coral in the ocean, and on the rock on top of the mountain. Thus the metonymical metaphor can be read as 'China Telecom is Internet access slots on trees, cactuses, corals and rocks.' The Internet access slots provide us with the following feature: wireless wideband access service, anywhere anytime, access to the world at your finger tip, keeps you connect to the world at all time. All these features from the domain of Internet access slots installed in the remote places are transferred to the China Telecom. The signification is: if you use China Telecom wireless wideband access service will enable you to connect to the world at your finger tip anywhere anytime.

Example 10 (No. 3.10) is an advertisement for Motorola's new mobile phone named 明 which can be literally translated as 'insightful, brilliant, light.' There are four people in this advertisement. Two of them at the upper pictures have western faces and figures while the other two at the lower pictures have oriental faces and figures. However they all look fashionable and capable. Thus the identified pictorial metaphorical statement is 'Motorola's mobile phone 明 is insightful, brilliant and capable multi-tasking heroes.' The two pictures at the upper hand have the caption of MOTO Insight. The body copy has described the five functions of the new mobile phone (crystal flip cover, 2 million pixels digital camera, smart identification card, RealPlayer MP3, handwrite key in). It can be inferred paradigmatically the multi-function mobile phones makes the man and woman in the picture multi-tasking heroes. The boxing glove, golf club, little baby, halfformal and half-sporty dress, and their determined eyes and confident manner all help 
connote the meaning that Motorola mobile phone 朋 makes capable multi-tasking heroes who can balance their professional and personal life very well. The two pictures at the lower hand have the caption of MOTO New Horizon. Unlike the two pictures above the small body copy describes the multi-meanings of the Chinese word 明, which means to perceive with sharp eye; to make a clear distinction between... and; to be wise and sensible. It can be inferred paradigmatically the multi-meanings of the word 明 makes the man and woman in the picture multi-tasking heroes who constantly look for opening up new horizons. The blending of two captions (INSIGHT and NEW HORIZON), description of multi-functions of mobile phone together with multi-meanings of the Chinese character 明 as explained in the body copies provide a good anchorage for the four people in the pictures who look sharp and insightful, brilliant, and vogue. From the different styles of clothes each of them is wearing simultaneously, we can see they are multi-tasking, playing multi-roles, and opening up new horizons with insightful sharp eyes. The primary subject (the signifier) is Motorola's newly-launched mobile phone 明. The secondary subject (the signified) is four multi-tasking heroes. The features for the four capable heroes are common even though they may have different nationalities: insightful, brilliant, new horizon opening, determined and confident. When these features are metonymically transferred onto the users of the mobile phone the meaning is clear: if you use our newly-launched Motorola mobile phone 明 you will become a capable multitasking hero.

Example 11 (No.3.15) is an advertisement for China Life Insurance.

There are three pictures in this advertisement. In the first picture it can be seen a small green umbrella among many big colorful umbrellas. The second picture shows a 
small green jacket in a big wardrobe. The third picture is a small yellow toy car in a big parking lot. The common thing that all three pictures share is despite the mini size of umbrella, jacket, and car; they all occupy the same amount of space as the big ones do. Thus the identified pictorial metaphorical statement is "China Life Insurance is umbrella, wardrobe, and car park.' In each part a caption can be read as 'a colorful world that belongs to me; a personal space that belongs to me; a reserved car park that belongs to me'. A line of small white words beneath each caption is the same words [life insurance for children] 'reserve a big enough space for your child's future.' The primary subject (the signifier) is China Life Insurance. The secondary subject (the signified) is umbrella, wardrobe, and car park. The umbrella has the feature of being protective and colorful. The wardrobe has the feature of being private and spacious. The car park has the feature of being personal and reserved. All these features from the domain of umbrella, wardrobe and car park are transferred to the domain of life insurance. Combining the caption words with the pictures the signified meaning is clear: if you buy China Life Insurance for your children they will own a colorful world, personal and reserved space and their future is protected.

Example 12 (No. 3.62) is a Hong Kong advertisement for Reebok sports wear.

In this advertisement there are two celebrities from Hong Kong. The upper picture boy (Fang Lishen or Alex Fong) used to be a Hong Kong professional swimmer that took part in Sydney Olympic Game and still held many swimming records in Hong Kong. Now the boy is a successful movie star. On the upper right hand is his slogan: "Everybody says I am a flying fish, I say I don't just excel in swimming pool." His words are echoed by the fish with water bubbles and cool facial expression and muscled chest. 
He looks absolutely masculine and cool. He wears a black Reebok coat. The lower picture girl (He Yunshi or Denise Ho) is a Hong Kong pop singer who has from time to time been reported by the media as a suspect of lesbian. The small words on the top right hand are what she said. "Which one do I like, man or woman? I won't explain. I don't care if you like me or not, but I like myself." Her quotation is supported by the loose tie on her neck, the shining buckle on the Reebok sports wear and the scornful expression on her face. Thus the identified pictorial metaphorical statement is 'Reebok sports wear is HK famous swimmer, movie star and singer'. The primary subject (the signifier) is the Reebok sports wear. The secondary subject (the signified) is HK famous swimmer and movie star, and singer. The caption 'I am what I am' and quotations help us identify the projected features from two HK stars onto the Reebok sports wear: excel in various professions but enjoy being unique and controversial. The connotation is if you put on Reebok sports wear they will make you excel in your career and unique (even controversial) and standing out of the pile among the public.

\section{Content Analysis of Representational Human Image Categories}

After analyzing 300 sample advertisements in the same manner as the 12 sample illustrations shown above, three lists of pictorial metaphorical statements are produced with primary and secondary subjects as well as projected features (metaphorical entailments) as embodied in the photographic image of each advertisement. The three tables of pictorial metaphors are shown in Appendix II as tables of II-1, II-2, and II-3.

In this part a summary is made to produce representational semiotic image categories and frequently appeared metaphors. After counting the number of pictures that contain metaphorical images (images other than the product picture or brand logo itself) 
as the table II-4 shows, the 100 advertisements from 1979 to 1988 contain only 68 metaphorical images other than the product images itself while the 100 advertisements from two other periods from 1989 to 1998 and from 1999 to 2008 contain 98 and 99 metaphorical images in their advertisements respectively ${ }^{23}$. This shows that during the first 10 years when China has just started to open and reform advertising agencies tend to use the key words and direct methods such as the picture of the product or a beauty to directly tell the audience about the advantages and benefits of their products and services. They did not (or did not know how to) use many complicated images to induce the audience to connect, associate, or metaphorically think about the relevance between the product and the image. The professionals in the advertising industry lack the skill to use metaphorical images for symbolic association. On the other hand, when they do use the indirect method of associative images, they tend to use safe and popular images such as well-known movie stars. However when it comes to 1990 s and 2000 s variety of symbolic images appear in the advertisements to make audience establish relationship between the image and the products or relate themselves to and even identify themselves with the images. Human images such as popular movie stars or (foreign) beauties are less used in comparison with the first 10 years.

Out of the 265 (68 in 1980s, 98 in 1990s, and 99 in 2000s) metaphorical images that have either direct resemblance/likeness (iconic meaning), or sequential and causal connections (indexical meaning) or conventional and contractual relations (symbolic meaning) in their representational advertisements, I have conducted two types of semiotic analysis. One type is to identify all the advertisements with human figures (totaled 96 ,

\footnotetext{
${ }^{23}$ The other 35 advertisements don't contain any metaphorical images but only the product and brand images. They are referred to as N.A in the table II-1, II-2, II-3.
} 
including both individual and group pictures) and make a content analysis for the four representational image categories, i.e. representations of appearance, manner, activity, and props and settings. I intend to see how the human images in the ads in three periods are artistically presented or projected and in what way these variations of presentation can reflect the social and cultural differences. The other type of semiotic analysis to the 265 metaphorical images is to identify and categorize the frequently appeared metaphorical images into 10 groups. I intend to compare what type of image groups or symbolic associations that advertising designers use with relatively high frequencies in different periods of time. With these data at hand it is hoped that in the following chapter I can make a comparative critical analysis of the pictorial metaphors appeared in 1980s, 1990 s, and 2000 s in order to find out to what extent these pictorial metaphors together with the identified key words can reflect China's social and cultural changes, in another word, ideology and identity changes in the last three decades.

With regard to representational image categories, i.e. image categories that contain human images (see table II-4), after counting 300 advertisements it is found that designers have used 42 human images in 1980s, 24 human images in 1990s and 30 human images in $2000 \mathrm{~s}$, accounting for $62 \%, 24 \%$, and $30 \%$ of the metaphorical images respectively. All these advertisements that have human images in the three tables of II-1, II-2, and II-3 have been marked with a smiling face $\odot$.

In order to categorize all the 96 advertisements with human images into their specific representational image categories they must first of all be properly defined for operational purpose. First, with regard to appearance, all the advertisements with human figures will be divided into four-item groups: single or group picture, young or middle 
aged group, male or female group, and head or whole body group. All the ads with more than 2 people in them will be defined as group picture. The young or middle aged group will be distinguished by my subjective judgement. Babies are counted into young group. Old people are included in the middle-aged group. The head group is defined as any pictures with human head, close-ups of faces, upper body or cropping of upper body. For the second category-manner, it will be divided into three item groups, namely, with or without facial expression, with or without eye contact, with or without pose. The 'with' or 'without' facial expression and pose is determined by whether the expression and pose are 'artificial' or 'natural' ones. Any human figures in the pictures with 'artificial' expression and pose are defined as 'with' facial expression and pose. The third category is activities. If representational human figures in the ad use, own, or touch the products or have intimate contact with each other in the group pictures, they will be defined as touch and intimacy. Body movement is defined as any figures appeared in the ads that are in the process of certain activities. Positional communication is defined as primary or secondary relationship between representative figures and products. In another word it illustrates whether the camera man uses photographic techniques such as focus, close-ups, cropping, lighting, colour and special effect in order to emphasize the representative figures as the primary and the products as the secondary, or vice versa. Last but not the least, props and settings are divided into five types: family setting, natural setting, workplace setting, social setting (restaurants, parties, singing, dancing, metropolitan cities etc) and no (cannot identify) settings. The result for the identification of the representational human image categories for 96 advertisements is shown in the table II-5, II-6, II-7 and II-8 respectively in Appendix II. 


\section{Content Analysis of Frequently Appeared Metaphorical Images}

Frequently appeared metaphorical images can appear in both human advertisements as well as in non-human advertisements in which certain qualities or features of representational images (signifieds) that have either direct resemblance or analogy or show connection and association are projected or transferred upon the product or service (signifiers) being advertised. I use 'frequently appeared metaphorical images' rather than 'metaphorical image stereotypes' for two reasons. One is to be coherent and consistent with the expression 'frequently appeared words' which I have used in this chapter for a content analysis of key words and advertising appeals. The second reason is that stereotype is usually derogatively defined as '(someone or something that represents) a fixed set of ideas about what (someone or something) is like; regard as an example of a general type' (Longman Dictionary of Contemporary English, 1998, p. 1509). I take a neutral and non-judgmental attitude while categorizing and conducting a content analysis of all the images that appear in the advertisements in the last 30 years.

The categorization of signifieds and their corresponding projected features is arbitrarily divided into 10 groups after the researchers have listed all the available images and counted each one into a category. The 10-group results are based on most frequently appeared image types and the researchers try to be all-inclusive without having to incur too many categories. The signifieds and projected features appeared in the three periods of time are summarized in the tables of II-9, II-10, and II-11 respectively as is shown in Appendix II. 
The greatest thing by far is to be a master of metaphor.... since a good metaphor implies an eye for resemblance ${ }^{24}$

Aristotle, 384-322 B. C. E.

Philosopher, Scientist and Educator

\section{CHAPTER 4}

\section{CRITICAL METAPHOR ANALYSIS}

\subsection{Critical Metaphor Analysis of Advertisements}

In chapter three I have conducted linguistic and semiotic analysis to the 300 illustrated print advertisements with foci on the key words (ad captions and copies) and pictorial metaphors (advertising images and their projected features) respectively. In this chapter cultural materialism by Marvin Harris, critical discourse analysis by Norman Fairclough and consumer culture theories are also applied to sharpen the critical edge of how advertisements as a media discourse can play as an agent (or even a catalyst) as well as symbolic representation for China's social change. Despite the complexity of factors involved in the process of social change, many researchers have proved the pivotal role of media discourse of which Baudrillard's work on the critique of media is now widely recognized, in which he describes how people are separated from symbolic modes of relation ('symbolic exchange' process) and are integrated into the semiotic modes of relation ('sign exchange' process). I see the same change from symbolic exchange to

${ }^{24}$ Source: http://www.lcc.gatech.edu/gallerv//hetoric/terms/metaphor.html Aug.7, 2004 
semiotic exchange in China in 30 years of time. In this chapter it is my intention to exhibit that social changes are founded on economic progress, and that ideology in media discourse such as advertisements helps the promotion of certain power, right and activity in a codified, symbolic and standardized form. These ideologies are transmitted to the public by exploring everything (advertising appeals) that captures the eyes and attention of the public. Lakoff and Johnson (1980) contend that metaphors have the persuasive power 'to define reality $[\ldots]$ through a coherent network of entailments that highlight some features of reality and hide others' (Lakoff \& Johnson, 1980, p. 157). Thus the objective of a CMA of advertisements may go beyond the codes in advertisement to "openly espouse certain values and use these values to evaluate and criticize the status quo" (Baran \& Davis, 2003, pp. 224-225).

Methodologically, Marvin Harris and Norman Fairclough have both realized the paramount importance of geographic, economic, social, cultural, and technological conditions and their interrelated and interplay dialectical relations even though they have different orientations and approaches towards the social change issue. Marvin Harris focuses on the development of a systems theory of society-cultural materialism to account for cultural origin, maintenance, and change. He believes the various parts of society are interrelated. When one part of society changes, e. g. economic condition, other parts must also change. Therefore cultural phenomena should not be looked at in isolation from economic, political and religious conditions of that given society. While Norman Fairclough develops a 'transdisciplinary ${ }^{25}$, way through dialogue with other disciplines and theories to address the issue of contemporary processes of social change.

${ }^{25}$ Here 'transdisciplinary' is used as opposed to merely 'interdisciplinary' or 'postdisciplinary' according to Sum (N-L.) \& Jessop (B) 2001 in "On pre- and post-disciplinarity in (cultural) political economy" New Political Economy 6 pp.89101. 
He believes social changes are changes in discourse. Social changes are relation changes in discourse and changes in other, non-discousal elements or 'moments' of social life. In one word, discourse '(re)constructs' social life in processes of social change. Thus the aim for Critical Discourse Analysis (CDA) is to identify the particular linguistic, semiotic and 'interdiscursive' features of 'texts' and give accounts of the ways which are a part of processes of social change. In view of this and based on this, advertising as a discourse (or as 'texts' with words and images) also carries linguistic, semiotic and other interdiscursive features that can be analyzed by applying CDA approach combined with Conceptual Metaphor Analysis (CMA) and Pictorial Metaphor Analysis (PMA) to account for the contemporary social change in China in the last 30 years.

From the view point of consumer culture and culture industry it is easy to see how consumer's daily consumption patterns are oriented and determined by the spread of instrumental rationality from the sphere of production to that of consumption and the substitution of use value with exchange value. This re-shift of value orientations creates a large number of symbolic associations as well as illusions that are exploited by the culture industry. In order to attract large enough buyers the symbolic forms (images or signs with denotations and connotations in the process of signification) are made low and common denominator to be simplistic and conformist ${ }^{26}$. The rationale and process of how signs in advertisements can be or should be interpreted by a large number of consumers are summarized in the figure 3-3 in chapter three. From the figure 3-3 we can see how the general political, social, and cultural conformity is 'created' and the whole society is 'administered' through the advertising as instrumental rationality and mechanism of

\footnotetext{
${ }^{26}$ The ideas of this paragraph and the figure 3-3 in chapter three are borrowed and quoted from Sassatelli, Roberta. Consumer Culture: History, Theory and Politics. London: Sage Publications Ltd. (2007). P.75
} 
meaning transfer via variety of mass media in order to effectively shape our wants and motivations, out of which advertising is at the core.

For decades, advertising has been the subject for criticism both for its impact on society as well as for its impact on individuals. All criticism on cultural industry, consumer culture and popular culture, the best-known being Frankfurt School, has been keen to explore and expose the true functions of marketing, advertising and media industries - its 'massification' (Jean Baudrillard), 'commodity fetishism' (Theodor Adorno) and 'subjection' (Michel de Foucault) nature. The scope of criticism has been extensive ranging from economic, cultural, aesthetic to political and moral concerns. In particular the major developments in social semiotics theory ${ }^{27}$ in the last several decades have been applied to advertising (Baudrillard, 1968; Barthes, 1977; Williamson, 1978; Wernick, 1991) and have immensely increased our understanding on how advertisements function symbolically. As Judith Williamson argues:

Advertisements must take into account not only the inherent qualities and attributes of the products they are trying to sell, but also the way in which they can make those properties mean something to us... Advertisements are selling us something besides consumer goods; in providing us with a structure in which we, and those goods are interchangeable, they are selling us ourselves (1978, p. 13).

From this sense, advertisements do not simply sell us products they are selling us self-identity and self-image. They manipulate us (even though the degree of manipulation and cultivation is not the main concern of this research) and reduce us to the status of

\footnotetext{
${ }^{27}$ It is the integration of communication science and critical and cultural studies focusing on audience activity to understand how audience members make sense of media messages in Stanley J. Baran and Dennis K. Davis (2003), Mass Communication Theory-Foundations, Ferment, and Future Wadsworth, Thomson Learning. P. 16.
} 
objects. They create structures of meaning and the meaning is objectified into symbolic forms. In another word, advertisements function by transforming an object into something which is given meaning in terms of people. For example the persuasive power of advertising using self-identity images ${ }^{28}$ (beautiful woman; masculine man; sexy youth; bourgeoisie, modern, or cool lifestyle), celebrity endorsement or stereotyped interior and exterior settings to create desire and consumption with reduced autonomy has been now widely recognized and analyzed. The meaning element or certain feature of one thing that we favor or value (in our study the secondary subject or the signified) is transferred to or made interchangeable with another quality whose use value attaches itself to the product or service (in our study the primary subject or the signifier). Williamson calls this transfer of meaning between signs in an advertisement 'currency'. This process of seemingly equal 'exchange' of value (meaning elements) through signs (signified and signifier) is made quite explicit by me in this dissertation in chapter three and appendices I and II for the linguistic and semiotic metaphor analysis of 300 Chinese advertisements. What is not explicit and needs further exploration are cultural-laden and cultural-specific representations or signs that help this 'use value' to 'exchange value' process. In what way the signification or the representation has evolved or changed in relation to the changes of economic and social conditions. How have the ideology and identity changes in China been made possible through advertising representational image changes? It is argued in this research that advertising texts with key words and representational images (for instance men and women images) can reflect the economic, social and cultural

\footnotetext{
${ }^{28}$ Self-identity image advertisements are defined as a symbolic image of an idealized person type and invite the potential consumers of the product to identify themselves in some way with that image. John Douglas Bishop in his article gives the examples of 'beautiful Chanel Woman' and 'Masculine Marlboro Man' and 'Calvin Klein sexy teen' in John Douglas B ishop “Is Self-identity Image Advertising Ethical?" Business Ethics Quarterly, Volume 10, Issue 2. 2000. pp.371-398.
} 
changes of a given society and help promote the dominant ideology and identity changes. This observation is concomitant with Marvin Harris's cultural materialism and seems to be self-evident. However, very few researchers have tempted to provide large quantity of evidence to illustrate and support his idea. This dissertation has made an attempt to make up for the inadequacy in this respect.

As it is said above, for the sake of manipulating consumer's needs all the symbolic forms in the advertisements (which include advertising slogans and captions as well as images or signs with connotations and denotations) are made low and common denominator to be simplistic and conformist. Now I will conduct a three-part analysis to see what these low and common denominators are. To be more specific, what kind of economic, social and cultural environment have the symbolic forms lived in China, i.e., the sign situation of the symbols or the context of the symbolic forms? How has the ideology (mainstream values and promoted power and legitimate activities) evolved to serve the instrumental functions of China's transformation from a socialist planning economy to a socialist market economy? How have the 'self-identity' images or 'selfformation' politics evolved from consensus Veblen, Bandwagon and Snob effect to autonomous conspicuous consumption and status effect?

\subsection{The Contextual (Sign) Situations of Advertisements}

The dramatic social changes happened in China in the last 30 years are unprecedented in China's history. Throughout thousands of years of history China has experienced many revolutionary changes, most of them endogenous, with one dynasty replacing another. The governance model has been the paternalistic and autocratic with emperor as the representative of royal power in control. Even though there appeared 
some prosperous dynasties such as Han (206 B.C - 220 A.D) and Tang (618 - 907 A.D), during which the commercial exchange and cultural hybridization or mélange reached its highest point, China's basic agrarian civilization remained unchanged. Majority of Chinese people live under poverty and sustenance constantly worried about the war and survival. During the 100 years from 1840 Opium War onward to the establishment of New China in 1949, humiliation and suppression from both internal warlords and constant foreign invaders have greatly damaged the overall economic strength and depleted the country into the state of bankruptcy. The Communist new China since 1949 has been trying to restore the economic and social stability and build a unified strong socialist economy. However due to the internal political and ideological movements such as Cultural Revolution and external Cold War, China was excluded and marginalized from the rest of the world. For a long time the country has remained in a closed and underdeveloped state until 1978 when Deng Xiaoping led the country onto the road of economic reform and open-up. Since then dramatic changes have taken place in the 1980s, 1990s, and 2000s when China formally entered the era of full-rounded 'economic reform and open-up policy' and its 'four modernization' process ${ }^{29}$. In general, the last 30 years of development has the following prominent features: first, in its long history China's economy has never developed at such a high speed of 9.5 percent on average for 30 consecutive years resulting in its GDP doubled and then quadrupled to become now

\footnotetext{
29 The Four Modernizations were the goals of Deng Xiaoping's reforms. They were first introduced by Zhou Enlai in 1975 at the Fourth National People's Congress in one of $h$ is last public acts. After his death and Mao's soon thereafter, Deng Xiaoping assumed control of the party in late 1978. In December 1978 at the Third Plenum of the 11 th Central Committee, Deng Xiaoping announced the official launch of the Four Modernizations, formally marking the beginning of the reform era. The Four Modernizations were in the fields of agriculture, industry, technology, and defense. The Four Modemizations were designed to make China a great economic power by the early 21 st century through exportled growth, a more open market, and attraction of foreign investment and access to advanced technology and management expertise. (Source: http://en.wikipedia.org/wiki/Four_Modernizations)
} 
the third largest economy in the world. The long history of struggling for basic necessity and survival is over. Second, China has never been so open and so closely woven into the world family and the globalization process. This can be proven by China's contribution to world trade, finance, education, sports, tourism and cultural exchange programs. Third, taking the full advantage of late-mover effect China has never benefited so much from the development of world technology, in particular telecommunication, transportation and information technology. As a result of these strategic yet flashy changes China quickly steps onto the modemization process and is ambitious to become a global economic powerhouse/engine. All these have definitely resulted in sequential and consequential social and cultural changes. As a matter of fact these large-scale lifestyle changes are so fast and profound that they have blown people dizzy and scared. They have brought about new challenges and social problems with the uneven distribution of wealth and power and the existence of large fragments of disadvantaged and marginalized people. The deep-rooted and long-term sense of egalitarianism is now being replaced by the strong sense of competition and pressure for personal achievement and material success (the main theme of lifestyle). All in all in the last 30 years from 1979 to 2008 China has experienced dramatic changes in economic development, this economic improvement has resulted in deep social and cultural changes accompanied by and demonstrated in ideology (the dominant and promoted value-orientations to be desired by the ruling power or 'knowledge class') changes and identity (self-image identity and group norms) changes. The extent of China's economic progress and corresponding social cultural changes in the last 30 years can be seen from the numbers in the tables of 4-1 and 4-2. 
Table 4-1 An Overview of China's Changes in Economy and Advertising Industry

\begin{tabular}{|c|c|c|c|c|c|}
\hline Time & $\begin{array}{l}\text { Annual GDP } \\
\text { (Unit: RMB } \\
\text { billion } \\
\text { Yuan) }\end{array}$ & $\begin{array}{l}\text { Annual } \\
\text { Growth } \\
\text { Rate }\end{array}$ & $\begin{array}{l}\text { National Ad } \\
\text { Revenue } \\
\text { (Unit: RMB } \\
\text { billion Yuan) }\end{array}$ & $\begin{array}{l}\text { Advertising } \\
\text { budget in } \\
\text { percentage } \\
\text { of GDP }\end{array}$ & $\begin{array}{l}\text { Per Capita } \\
\text { Advertising } \\
\text { Spending } \\
\text { (Unit: RMB } \\
\text { Yuan) }{ }^{30}\end{array}$ \\
\hline $1979^{31}$ & 406.26 & 7.6 & 0.01 & 0.0025 & 0.01 \\
\hline 1980 & 454.56 & 7.8 & 0.015 & 0.0033 & 0.015 \\
\hline 1981 & 489.16 & 5.2 & 0.118 & 0.024 & 0.118 \\
\hline 1982 & 532.34 & 9.1 & 0.15 & 0.028 & 0.148 \\
\hline 1983 & 596.27 & 10.9 & 0.234 & 0.039 & 0.227 \\
\hline 1984 & 720.81 & 15.2 & 0.365 & 0.051 & 0.35 \\
\hline 1985 & 901.60 & 13.5 & 0.605 & 00.067 & 0.571 \\
\hline 1986 & 1027.52 & 8.8 & 0.845 & 0.082 & 0.786 \\
\hline 1987 & 1205.86 & 11.6 & 1.112 & 0.092 & 1.017 \\
\hline 1988 & 1504.28 & 11.3 & 1.493 & 0.99 & 1.345 \\
\hline 1989 & 1699.23 & 4.1 & 1.999 & 0.118 & 1.774 \\
\hline 1990 & 1866.78 & 3.8 & 2.502 & 0.134 & 2.188 \\
\hline 1991 & 2178.15 & 9.2 & 3.509 & 0.161 & 3.03 \\
\hline 1992 & 2692.35 & 14.2 & 6.787 & 0.252 & 5.792 \\
\hline 1993 & 3533.39 & 13.5 & 13.409 & 0.379 & 11.314 \\
\hline 1994 & 4819.79 & 12.6 & 20.026 & 0.415 & 16.709 \\
\hline 1995 & 6079.37 & 10.5 & 27.327 & 0.45 & 22.562 \\
\hline 1996 & 7117.66 & 9.6 & 36.664 & 0.515 & 29.957 \\
\hline 1997 & 7897.30 & 8.8 & 46.196 & 0.585 & 37.368 \\
\hline 1998 & 8440.23 & 7.8 & 53.783 & 0.637 & 43.092 \\
\hline 1999 & 8967.71 & 7.1 & 62.205 & 0.694 & 51.84 \\
\hline 2000 & 9921.46 & 8.0 & 71.266 & 0.718 & 56.30 \\
\hline 2001 & 10965.52 & 7.3 & 79.489 & 0.725 & 61.15 \\
\hline 2002 & 12033.27 & 8.0 & 90.315 & 0.751 & 69.47 \\
\hline 2003 & 13582.28 & 9.1 & 107.868 & 0.794 & 82.98 \\
\hline 2004 & 15987.83 & 9.5 & 129.44 & 0.81 & 99.57 \\
\hline 2005 & 18386.79 & 9.9 & 152.74 & 0.83 & 117.50 \\
\hline 2006 & 21087.10 & 10.7 & 375.275 & 1.78 & 286.67 \\
\hline 2007 & 24661.90 & 11.4 & 441.50 & 1.67 & 339.62 \\
\hline 2008 & 30067.00 & 9 & 500 & 1.66 & 384.62 \\
\hline
\end{tabular}

Source 1: Liu, Libing. (Chief editor 2004) Accelerated Growth of China's Advertising Industry 1979 to 2003 Huaxia Publishing House. Pp. 284-291.

\footnotetext{
${ }^{30}$ Figures for per capita advertising spending have taken the increase of China's population into consideration. ${ }^{31}$ Figures on column 3, 4,6 about GDP growth rate, national advertising revenue and per capital ad spending are copied from Source 1. GDP numbers in column 2 are from Source 2. Column 5 is the result of author's calculation by dividing GDP value with annual advertising revenue. Since figures from 2004 to 2008 in Source 1 are not available, they are added by I from website information in Source 3.
} 
Source 2: Wang Haibo, Wang Weiguang (chief editor) (2008). Studies on the Thirty Years of Economic Development in China. China Social Science Press. Pp.413414

Source 3: http:/www.stats.gov.cn/tjgb/ndtjgb/qgndtjgb/t20020331 15373.htm http://finance.sina.com.cn/stock/t/20080131/11081978060.shtml http://www.jiaodong.net/news/system/2009/01/22/010443423.shtml

Table 4-2 A Comparison of Degree Changes between 1979 and 2008

\begin{tabular}{|l|l|l|l|l|l|}
\hline $\begin{array}{l}\text { 30 years of } \\
\text { changes } \\
\text { from 1979 } \\
\text { to 2008 }\end{array}$ & $\begin{array}{l}\text { GDP } \\
\text { Changes } \\
\text { (Y billion) }\end{array}$ & $\begin{array}{l}\text { Average } \\
\text { annual } \\
\text { GDP } \\
\text { Growth }\end{array}$ & $\begin{array}{l}\text { Advertising } \\
\text { revenue } \\
\text { changes } \\
\text { (Y billion) }\end{array}$ & $\begin{array}{l}\text { Advertising } \\
\text { budget } \\
\text { changes in \% } \\
\text { of GDP }\end{array}$ & $\begin{array}{l}\text { Per Aapita } \\
\text { Advertising } \\
\text { Spending } \\
\text { changes }\end{array}$ \\
\hline 1979 figure & 406.26 & & 0.01 & 0.0025 & 0.01 \\
\hline 2008 figure & 30067.00 & & 500 & 1.66 & 384.62 \\
\hline $\begin{array}{l}\text { Degree of } \\
\text { changes }\end{array}$ & 74 times & 9.5 & 50,000 times & 664 times & 38,462 times \\
\hline
\end{tabular}

If the table 4-1 shows the evolving chronological changes of China's GDP, advertising revenue, and per capita spending on advertising, the table 4-2 illustrates convincingly the rapid economic progress in the last 30 years and the explosive development of China's advertising industry. The average annual Gross Domestic Product (GDP) growth rate is kept at 9.5 percent and GDP value in 2008 being 74 times of that in 1979. The total advertising revenue spent on newspaper, radio, television and other media channels stands at 10 million and 500 billion Renmibi respectively, accounting for 0.0025 percent of the total GDP in 1979 and 1.66 percent in 2008 . The degree of changes for annual advertising revenue and advertising budget in percentage of GDP is an amazing 50,000 times and 664 times respectively. The degree of changes in per capita advertising spending in 30 years is 38,462 times with each individual person spending only 10 cents on advertising in 1979 and 385 Yuan $(\$ 57.46)^{32}$ in 2008. Even

\footnotetext{
${ }^{32}$ The exchange rate in 2008 between US dollar and Chinese RMB is around 6.7 thus $\$ 57.46=385 / 6.7$.
} 
though the gap is still big compared with per capita average spending of $\$ 540^{33}$ on advertising in the USA, the total number is huge taking China's large population into consideration.

From this explosive increase of advertising revenue, advertising budget in percentage of GDP and per capita spending on advertising, of which the degree of changes is far bigger than that of economic GDP changes, one thing is certain: advertising as a media discourse and social change agent plays a very important role, if not the pivotal role, in China's implementation of national strategy of 'reform and openup.' It is an important indicator to show that advertising has become part of Chinese people's life and help people change in ideology and identity. It plays the instrumental function of shaping and promoting China into a consumer society.

Another way to look at China's social and cultural changes in conformity with Fairclough's CDA is to study the most popular/vogue experience or bandwagon events that Chinese people are eager to follow in each year (in chronological order from 1979 to 2008). Many advertising copies or slogans and image figures or settings are designed following each year's main cultural theme and trend. They can vividly illustrate what kind of binge or rush that Chinese people craze to 'jump-onto-the-bandwagon'. A more detailed illustration and study on China's social and cultural changes from the perspective of key events and popular experience can be found in a book A Dictionary of Key Words-A Record of Major Events in China's 30 Years of Reform and Open-up from 1978 to 2008 by Guan, Xinping (Chief editor, 2008). These key words and key events

\footnotetext{
* According to IPR Strategic Business Information Database on December 14, 2005 Gulf Saatchi and Saatchi, that the per capita average spending on advertising in the Arabian Gulf region hit \$1 12.2 annually based on 2004's statistics compared with $\$ 139$ in South Korea, $\$ 342$ in Australia and $\$ 540$ in the USA
} 
offer a panorama view of China's social changes and how social realities are constructed and reconstructed.

Table 4-3 Social and Cultural Changes in Key Events and Bandwagon Experiences

\begin{tabular}{|c|c|c|c|}
\hline 1978 & $\begin{array}{l}\text { National entrance exam, } \\
\text { Spending time in the library }\end{array}$ & 1993 & $\begin{array}{l}\text { CCTV program "Hot social } \\
\text { issues" }\end{array}$ \\
\hline 1979 & $\begin{array}{l}\text { Ball dancing; wear bellbottom } \\
\text { trousers }\end{array}$ & 1994 & Credit cards \\
\hline 1980 & $\begin{array}{l}\text { Learning English; campus song } \\
\text { from Taiwan }\end{array}$ & 1995 & $\begin{array}{l}\text { Western style marriage and } \\
\text { photo taking with bridal dress }\end{array}$ \\
\hline 1981 & Disco; philosophy study & 1996 & Patriotism; pyramidal sales \\
\hline 1982 & Writing poems, inner feelings & 1997 & Nostalgia \\
\hline 1983 & $\begin{array}{l}\text { Martial arts novels; Reader's } \\
\text { Digest magazine }\end{array}$ & 1998 & $\begin{array}{l}\text { Surf on the Internet; foot } \\
\text { massage; mobile phone }\end{array}$ \\
\hline 1984 & $\begin{array}{l}\text { Denglijun song, Chinese New } \\
\text { Year's Eve CCTV Gala Shows }\end{array}$ & 1999 & $\begin{array}{l}\text { TV series "Emperor' daughter } \\
\text { Huanzhu" }\end{array}$ \\
\hline 1985 & Sea food dinner & 2000 & Internet beauty women writers \\
\hline 1986 & $\begin{array}{l}\text { Taiwanese romantic fiction } \\
\text { writers Qiong Yao \& San Mao }\end{array}$ & 2001 & $\begin{array}{l}\text { New Millennium computer } \\
\text { bugs; Computer games }\end{array}$ \\
\hline 1987 & Becoming a businessman & 2002 & Internet company, e-commerce \\
\hline 1988 & Human body art; bragging & 2003 & Health consciousness \\
\hline 1989 & $\begin{array}{l}\text { Rock ' } n \text { ' Roll; western style } \\
\text { democracy }\end{array}$ & $2004^{34}$ & $\begin{array}{l}\text { Stamp/antique collection, Puer } \\
\text { tea trading }\end{array}$ \\
\hline 1990 & Marriage crisis & 2005 & Real estate boom \\
\hline 1991 & Karaoke & 2006 & Car and travel boom \\
\hline 1992 & Buying and selling stocks & 2007 & Stocks, houses, private equity \\
\hline & & 2008 & $\begin{array}{l}\text { National pride in Olympic } \\
\text { Game and Dream }\end{array}$ \\
\hline
\end{tabular}

(Source: adapted from Liu, Libing (Chief editor, 2004) Accelerated Growth of China's Advertising Industry from 1979 to 2003. Huaxia Publishing House. Pp. 284-291).

\subsection{The Ideology Changes Reflected by China's Illustrated Print Advertisements}

In both operational definition and literature review I have accounted for the idea of ideology which in this dissertation refers to the dominant or mainstream valueorientations to be desired by the ruling power or 'knowledge class,' thus the promotion of certain rights as the legitimate activities. As it is righteously debated, 'ideology' in

\footnotetext{
${ }^{34}$ Since the book only provides the key events and bandwagon experiences from 1979 to 2003 , I have added the key events from 2004 to 2008 by consulting the book A Dictionary of Key Words-A Record of Major Events in China's 30 Years of Reform and Open-up from 1978 to 2008 by Guan, Xinping Chief editor. (2008)
} 
advertising discourse helps the promotion of certain power, right and activity in a codified, symbolic and standardized form. These ideologies are transmitted to the public by exploring everything that captures the eyes and attention of the public.

China's national or ruling ideologies and ideological changes in the last 30 years can best be understood from the political campaign slogans of the three generations of Chinese Communist leaders. These campaign slogans are similar to the 'mission statement' of a corporation that can be used to guide the future direction of the country and increase the national sense of mission and purpose. The fact that nearly all the Chinese people can recite these slogans proves their prominence and dominance.

\subsubsection{The Transformation from Political to Economic Ideology}

As a consequence of China's national strategy of economic reform and open-up policy, the ruling and dominant value-orientations promoted in 1980 s by the Chinese Communist Party is a natural shift from rigid political ideology to dynamic economic ideology as Deng Xiaoping ${ }^{35}$ has put it: the national strategy for economic reform and open-up must remain steadfast for 100 years, thus the promotion of consumption and getting rich has become a legitimate activity rather than the class struggle and egalitarianism previously promoted in Chairman Mao Zedong's era. Below I describe how social and cultural atmosphere based on 'making economic construction as the core' from 1979 to 1988 shapes the bandwagon effect (the most popular event or thing that Chinese people are keen to experience). In what way advertising appeals, most frequently used key words, and most frequently appeared metaphorical images in China's

\footnotetext{
${ }^{35} \mathrm{He}$ is Chairman Mao's successor and the second generation leader of Chinese Communist Party who initiated China's 'reform and open up policy' in 1978.
} 
advertisements in this period help shift the transition from political ideology to economic ideology.

Ideology changes: From political to economic ideology from 1979 to 1988.

Percentage of rational, personal, and social appeals used: $51 \%, 29 \%, 20 \%$.

Bandwagon experiences: what is 'in' during 1980s?

1978: National entrance exam; spending time in the library

1979: Ball dancing; wear bellbottom trousers

1980: Learning English; campus song from Taiwan

1981: Disco dancing; philosophy study

1982: Writing poems; inner feelings

1983: Martial arts novels; Reader's Digest magazine (American)

1984: Denglijun ${ }^{36}$ song; lunar New Year's Eve CCTV Gala Show

1985: Sea food dinner

1986: Taiwanese romantic fiction writers Qiong Yao \& San Mao

1987: Everyone wants to become a businessman and get rich

1988: Human body art; bragging or boasting (a symbol of free expression).

Frequently appeared words in advertisements in priority: publicity (campaign), quality (guarantee), value price (value for money), efficacy, (life)style, tradition (family), beauty, happiness, health, popularity, manner (smile, grace, posture), get-together, service.

Table 4-4 Frequently Appeared Metaphorical Images in Advertisements of 1980s

\begin{tabular}{|l|l|l|l|l|}
\hline 1980s & Frequency & Metaphorical images appeared & & \\
\hline Women & 23 & Beautiful, smiling and happy ladies (9), smiling \\
\hline
\end{tabular}

${ }^{36}$ Deng lijun is a Hong Kong female pop star. Her songs are soft and romantic melodies which are forbidden as the bourgeoisie in mainland China during 1970 s. Her song became extremely popular in mainland China in 1980s. 


\begin{tabular}{|c|c|c|}
\hline & & $\begin{array}{l}\text { stewardesses (2), gymnasts ( } 2 \text { ), Chinese movie } \& \text { sport stars } \\
\text { (4), foreign beauties ( } 3 \text { ), a nymph in heaven, a bikini girl } \\
\text { surfing, a girl on the swing }\end{array}$ \\
\hline $\begin{array}{l}\text { Group } \\
\text { images }\end{array}$ & 10 & $\begin{array}{l}\text { Family photo, family picnic, family reunion, matched } \\
\text { couple (2), woman whispering to man, cross-talk actors, } \\
\text { many faces, party scene, lady models }\end{array}$ \\
\hline Men & 8 & $\begin{array}{l}\text { Smiling \& successful man (2), movie } \& \text { sport stars (2), boys } \\
(2) \text {, ancient guard, an animation cartoon figure }\end{array}$ \\
\hline Tradition & 7 & $\begin{array}{l}\text { Martial arts, festive decorations, kites, the Great wall, } \\
\text { legendary figure Monkey King, Monkey King fighting } \\
\text { against door guard, red lanterns }\end{array}$ \\
\hline $\begin{array}{l}\text { Natural } \\
\text { scenes }\end{array}$ & 5 & Rose \& chrysanthemum, flowers (2), orchid, countryside \\
\hline $\begin{array}{l}\text { Modern } \\
\text { convenience }\end{array}$ & 3 & Airline logo, TV tower, antique car \\
\hline Animals & 2 & Tiger, crane \\
\hline $\begin{array}{l}\text { Daily } \\
\text { necessity }\end{array}$ & 2 & coffee, silk ribbon \\
\hline Recreation & 2 & Radio \& movie, newspaper \\
\hline Others & 6 & $\begin{array}{l}\text { new China, the White House, trophy, gift, Wuyang city, } \\
\text { Beijing }\end{array}$ \\
\hline Total & 68 & \\
\hline
\end{tabular}

From the bandwagon experiences it is shown that the overall social and cultural

environment at that time tends to serve the dominant economic ideology of 'making economic construction as the core'. However, the bud for the emergence of mass culture in China begins to set in. First, the economic ideology can not be realized without a large number of knowledge workers and well-educated labor force. Therefore the most popular events in 1978 and 1979 are spending time in the library and national entrance examination. Everyone is eager to go to the university (the enrollment has been suspended for 10 years due to Cultural Revolution) in order to secure a decent job, change their Hukou ${ }^{37}$ and become an urban dweller. Secondly ball-dancing, learning English and disco dancing are also necessary for economic reform and open-up because many joint venture and export-oriented companies want to recruit people with English

\footnotetext{
${ }^{37}$ Hukou is a Chinese Pinyin for the household registration system, which decides the place you live and work.
} 
language proficiency and socializing skills such as dancing and reception. Thirdly, private businesses began to emerge. By the time of 1987 everyone wants to become a businessman, a broker or middleman to be exact, and get quick money through buying and selling most needed products in order to enjoy material comfort and success. However, as a natural result of opening up to the outside world, Chinese people are attracted by the romantic and love songs and martial art novels (with Chinese-style heroic complex) from Hong Kong and Taiwan, which used to be considered 'bourgeoisie' and forbidden. They are also influenced by the western ideology (not only the bourgeoisie lifestyle but also political system) and are eager to copy the western lifestyle and political system. Studying philosophy and bragging together can be seen as a symbol of looking for life-meaning and free-expression. These events happen at the super-structural level but they serve as the symbols of spiritual liberation and ideological transition from rigid political class struggle to a more utilitarian materialism after Chinese people have suffered from autarchy self-sufficiency and are bored with homogeneous revolutionary songs and operas. These vogue experiences create the general atmosphere necessary for the change from 'political ideology' to 'economic ideology' and from an 'egalitarian society' to a 'utilitarian or material society', thus they lay the foundation for commodity fetishism of modern consumer culture in China. On the other hand since 'popular culture has been celebrated as a domain of resistance against dominant power relation,' (Hermes, 2005 , p. 3) it can be seen the struggle and revolt against dominant socialist ideology of communist regime is substituted by the capitalist ideology and democratic political system and free-expression. 
This ideology shift can be illustrated by the frequently appeared key words as they are shown above. The very word 'consume' does not exist in China when political ideology is in rein. However, the encouragement of consumption culture in 1980s is materialized by frequently using the following words in the advertising caption or slogans: publicity (campaign), quality (guarantee), value price (value for money), efficacy, comfort lifestyle, tradition (a strong family tie), beauty, happiness, health, popularity, manner (smile, grace, posture), get-together, service. Even though beauty, health, 'value for money' (high quality but low price) are universal benefits for all the consumers alike, publicity, a strong family tie, manner and get-together have unique Chinese implications. Chinese traditionally believe that publicity or promotion in marketing is not necessary as long as your products are of high quality. Chinese people also cherish a strong sense of family tie and enjoy social get-togetherness. Manner in China is related to establishing social relations which demonstrate itself as social scripts and rituals in which face, grace, expressions and postures are absolutely necessary for hospitality and courtesy.

As for the most frequently appeared images in the table above they have shown that what the Chinese consumers are dreaming to have is beauty, health, happiness, success, care-free lifestyle and intimate family relationship. To support these value-orientations the most frequently used iconic pictures/images are smiling, happy, beautiful ladies including many foreign beauties and successful men images and family photos (The top two most frequently used images are women and group pictures that account for $49 \%$ ). Due to the reason that the simple happiness is deprived from common Chinese people before 1978 when people are faced with daily necessity insufficiency and constant political movements, this period has used many smiling and happy ladies, beautiful 
movie stars and intimate family or group images. These images denote exactly how much Chinese people are longing for the right to be happy, beautiful, healthy, close and intimate, successful, and to desire for a comfortable and care-free lifestyle. Taking advantage of this need, the 'ruling and knowledge class' now tells you, with the consumption of the material goods promoted in the advertisements such as food, drink (chocolate drink, coffee, Coca Cola), silk blouse and raincoat, shoes, toiletries, soft mattress, Swiss watches, Japanese electronics, sports products, herbal nutrition, and cameras and tape recorders ${ }^{38}$ etcetera, Chinese people can acquire happiness, health, beauty, care-free lifestyle, and even success and intimate family relationship. These products are represented by beautiful ladies, popular stars and Chinese favorite traditional images such as Monkey King and martial arts masters, thus the projected features of these iconic images are transferred metonymically, metaphorically or analogically to the products, and then to consumers as well through the consumption of the products, thus the completion of shift from use value to exchange value.

It is the advertising appeals, which are designed to attract consumers' attention, that both reflect and help establish the dominant 'economic ideology' with 'rational appeal' accounting for $51 \%$, personal appeal $29 \%$, and social appeal ${ }^{39} 20 \%$. The 'rational consumption' through rational appeal has become the preoccupied legitimate activity. Also in this period representational images are mainly human figures and traditional images which accounts for 71 percent. Iconic images related to daily necessity, modern convenience and recreational activities are a bare 10 percent. Natural scenes, animals,

\footnotetext{
${ }^{38}$ Please refer to table $\mathrm{I}-1$ in appendix I for all the products that are promoted in 100 sample advertisements for 1980 s. ${ }^{39}$ The criteria and operational definition for different appeals are discussed in 3.4.1 in chapter three.
} 
and other images accounts for 19 percent. The general pattern in this period for the promotion of rational consumption activity is a feminist 'smiling beauty + quality'.

\subsubsection{The Transformation from Economic to National Ideology}

However when it comes to 1990 s, Chinese Communist Party has experienced the most difficult choice and is faced with complex domestic and international environment. 1989 TianAnmen Square political turmoil in the capital city of Beijing has pushed the Party to the crossroad of either socialist regime or capitalist democracy. 10 years of reform and open-up policy have made many foreign ideologies and philosophical ideals pour into China. Soviet Union, Eastern Europe and many other former socialist countries have adopted a 'shock therapy' to become a capitalist economy overnight. Challenged with domestic problems such as corruption, social disorder, legal loopholes, and corporate governance dilemma of large-scale state-owned enterprises, the established economic ideology is insufficient to handle this volatile and complex environment. Faced with this ideology crisis, Chinese Communist Party has taken a middle road (maybe under the influence of Confucius Golden Means): socialist democracy as Jiang Zemin ${ }^{40}$ has put it: Chinese Communist Party must always keep abreast with the latest development of time and become 'three representatives,' namely the representatives of common people's interest, advanced technology and advanced culture. Thus the ruling and dominant ideology to deal with the complex social environment at that time has changed from economic ideology to 'national ideology', of which the promotion of national pride and individual (men's) success has become a legitimate activity rather than women beauty and getting rich as previously promoted in Deng Xiaoping's era.

\footnotetext{
${ }^{40}$ Deng Xiaoping's successor and the third generation leader of Chinese Communist Party who continued 'reform and open-up policy' and passed the political crisis of 1989 successfully.
} 
Ideology changes: From economic to national ideology from 1989 to 1998.

Percentage of rational, personal, and social appeals used: $13 \%, 57 \%, 30 \%$.

Bandwagon experiences: what is 'in' during 1990s?

1989: Rock ‘n' Roll; western style democracy

1990: Marriage crisis

1991: Karaoke (Japanese style singing in KTV); bar

1992: Buying and selling stocks

1993: CCTV program "Hot social issues"

1994: Credit cards

1995: Western style marriage ceremony and photo taking with bridal dress

1996: Patriotism; pyramidal sales

1997: Nostalgia

1998: Surf on the Internet; foot massage; mobile phone

Frequently appeared words in advertisements in priority: Chinese six fortunes (affection, happiness, friendship, wealth, longevity, smoothness), perfectness, success, (mutual) care, world, man/people, beauty, emotion (feeling), insight, value for money, work, miniature, speed and space

Table 4-5 Frequently Appeared Metaphorical Images in Advertisements of 1990s

\begin{tabular}{|l|l|l|}
\hline 1990s & Frequency & Metaphorical images appeared \\
\hline Tradition & 16 & $\begin{array}{l}\text { Mahogany armrest, labyrinth, paper cuts, abacuses, moon } \\
\text { cake, Peking opera masks, proverb story of Buole, Chinese } \\
\text { six fortunes, temple of Heaven, double happiness sign, } \\
\text { Yuan Ming Yuan Garden, Dai ethnic water festival, Putala } \\
\text { Palace \& the Great Wall, Chinese style marriage, prophet } \\
\text { calendar, match-maker }\end{array}$ \\
\hline Men & 15 & $\begin{array}{l}\text { Man's broad shoulder, Olympic hero, trouble-free man, } \\
\text { man's head, Einstein, gymnast, Jean-Paul Sartre, Chinese } \\
\text { ancient saint, father's hand, foreign man's face, man on the }\end{array}$ \\
\hline
\end{tabular}




\begin{tabular}{|c|c|c|}
\hline & & $\begin{array}{l}\text { sky ladder, legendary person - Zhu Geliang, man holding a } \\
\text { rose, athlete, happy foreign man }\end{array}$ \\
\hline $\begin{array}{l}\text { Daily } \\
\text { necessity }\end{array}$ & 13 & $\begin{array}{l}\text { Cups, (pen, tie, button), ear-picker, unfolded world map, } \\
\text { apple, (dictionary, tea cup, football, fashion), (whistle, pop } \\
\text { can, water tap), bundle of grapes, home, (cactus, swords, } \\
\text { knives), strapped chair, sleeping pill, (kettle, cup, Putala } \\
\text { Palace) }\end{array}$ \\
\hline $\begin{array}{l}\text { Modern } \\
\text { convenience }\end{array}$ & 11 & $\begin{array}{l}\text { Train, filter, PK game, steamer or oven, submarine, air } \\
\text { cushion, airliner, clock, electro-kymograph, bearings, } \\
\text { spanner or wrench }\end{array}$ \\
\hline Animals & 11 & $\begin{array}{l}\text { Cat, hen \& egg (2), camel, butterfly, fish \& bear paw, piggy } \\
\text { bank, rooster \& horse, sheep, cows \& horse, fat pig }\end{array}$ \\
\hline $\begin{array}{l}\text { Natural } \\
\text { scenes }\end{array}$ & 9 & $\begin{array}{l}\text { Fields (2), the moon, lake, rainbow, green shade, road } \\
\text { scenery, modern city view, four season scenery }\end{array}$ \\
\hline Women & 7 & $\begin{array}{l}\text { Bride, foreign beauties ( } 2 \text { ), female doctor on express, lady's } \\
\text { facial expression, disc-made face, beauty protected }\end{array}$ \\
\hline Others & 7 & $\begin{array}{l}\text { Praise sign (Ok, thumb up, A's work, No.1), arithmetic } \\
\text { signs }(+,-, \times, \div) \text {, trouble-free parents, the White House, } \\
\text { embryo in womb, incubator, man/woman's faces }\end{array}$ \\
\hline Recreation & 5 & $\begin{array}{l}\text { Piano, musical instruments, snooker opening strike, golf } \\
\text { club striking the ball, orchestra performance }\end{array}$ \\
\hline Group & 4 & $\begin{array}{l}\text { Group prey, factory workers, happy faces, American } \\
\text { presidents }\end{array}$ \\
\hline Total & 98 & \\
\hline
\end{tabular}

From the bandwagon experiences it is shown that the overall social and cultural environment at that time tends to reflect the complexity of social cultural environment and the necessity of change from economic to national ideology with the rising influence of western lifestyle, freedom and democracy. First, marriage crisis means the divorce rate is on the rise when people are looking for marriage of love rather than marriage of convenience, which are common during the Cultural Revolution period. Secondly, people are eager to try western lifestyle by singing Rock ' $n$ ' Roll in Karaoke and drinking in the bar area. Thirdly, politically Chinese people are more concerned about the social corruption issues as exposed in CCTV 'Focus' program and hope to implement political reform in parallel with fast economic reform. All these beliefs and longings to copy 
western development model and revolt against socialism are collectively erupted in 1989 TianAnmen Square democratic movement. Chinese Communist Party is condemned and then isolated by the international community for the crackdown of this social upheaval. The dominant ideology of 'making economic construction as the core' is suspended. The GDP growth in 1989 and 1990 stands only at 4.1 and 3.8 percent respectively ${ }^{41}$, the lowest in the 30 reforming years. Faced with this loss of authority and rise of anarchy, the main economic ideology gives way to traditional and national ideology, which emphasizes traditional Chinese culture and patriotic sentiments. Several events happened during this period help promote this national ideology. One is the American missile falling into Chinese embassy in former Yugoslavia during the Kosovo War. The second one is the national flood fighting in 1994. The third one is the peaceful return of Hong Kong and Macau to China in 1997. The large-scale media coverage for these events together with the high-pitched patriotic hype has effectively promoted a widespread sense of pride and nationalism. From this respect Chinese Communist Party is very successful and skillful in using 'national sentiments and traditional culture' to combat the spread of anarchy and various difficulties. Two other factors also contribute to the establishment of national ideology in China. Over thousands of years China has been an authoritarian society as well as a hierarchical society. This concentration of power and hierarchy of power relation help the establishment of nationalist ideology. Meanwhile allured by the wonderful economic opportunities such as buying and selling stocks and IT boom, idealism gives way to pragmatism. The emergence of newly-rich and the rise of vast middle class have effectively differentiated and separated them out from the radical democratic movement from which no immediate economic benefits can be seen.

\footnotetext{
${ }^{41}$ Please refer to table 4.1 for the annual GDP growth rate from 1979 to 2008.
} 
This ideology shift can be illustrated by the frequently appeared key words as they are shown above. First, frequently used Chinese six fortunes (affection, happiness, friendship, wealth, longevity, smoothness) in the advertising themes and messages have aroused awareness and sentiments for the traditional Chinese 'fortune' culture. The resurgence of deep-rooted traditional Chinese culture strikes a big contrast with the prevalent western culture. It plays the function of social hinge and cohesion at a time of transition. Secondly, it is emphasized in the advertising copies and captions that individual success comes from human perfectness, detailed and hard work, (mutual) care, a worldly view and insight. The isolation pressure from international community and the social turmoil have actually helped Chinese people to calm down and reflect. Meanwhile the themes of beauty, emotion (feeling), value for money and miniature (small size), are reserved as the universal benefits in the advertisements and as features desired by all the consumers around the world. Two key words that have never appeared in 1980s advertisements but have in 1990s are 'speed' and 'space' which denote the attention to time (efficiency) concept and space (open world horizon). Therefore the general pattern in this period for the promotion of personal consumption as the legitimate activity is a masculine 'tradition and national pride + material success.'

This general pattern is supported by the frequently used metaphorical images in the table above. While the 'ruling and knowledge class' continue to promote the national strategy of 'making economic construction as the core,' the value-orientations used to support it has changed from beauty, health, happiness, and quality in 1980s to traditional Chinese values such as 'six fortune' culture, perfectness, hard work, (mutual) care, insight and speed and space in 1990s. The striking difference between the most 
frequently appeared metaphorical images in this period (1990s) and that of $1980 \mathrm{~s}$ is the rise of traditional and men's images (such as men's strong shoulder and father's hands), which accounts for almost 31 percent. The essence and diversity of Chinese tradition is demonstrated through advertising images of historical heritage of the Great Wall, Temple of Heaven, and Tibetan Putala Palace, to name just a few, as well as cultural relics of Peking opera masks and paper cuts. On the contrary, the use of women and group images accounts for only 11 percent compared to the dominant 49 percent in 1980s. This can be explained by the deliberate promotion of paternal authority power and masculine culture against the feminine and anarchical culture. The second frequently used image types are daily necessity, modem convenience and recreations, which accounts for 29 percent while in 1980 s they account for only 10 percent. This can be seen as evidences of improved living standard as well as the evidence of rising commodity fetishism in China. Individual success depends on how many modern convenience and daily necessity products you have owned and consumed. The images related to animals and natural scenes have reached 20 percent, a symbol for the promotion of mutual care and natural out-worldliness. These metaphorical images help realize and reinforce the 'national ideology' to combat the western cultural influence and social conflicts. To fully deploy from national sentiments and traditional culture, the 'ruling and knowledge class' now tells you, with the consumption of the material goods promoted in the advertisements such as real estate gardens, German and Japanese cars, variety of family appliances, alcohol, wine, beer, tea and bottled waters, American and Hong Kong sportswear and fashions, and different hygienic liquid and nutritional capsules ${ }^{42}$ etcetera, Chinese people can acquire human perfectness, individual success, and highly valued traditional six

\footnotetext{
${ }^{42}$ Please refer to table I-2 in appendix I for all the promoted products in 100 sample advertisements for $1990 \mathrm{~s}$.
} 
fortunes. Furthermore, the consumption of the material goods is embodied with and embedded in a strong sense of national pride and patriotism. These products are represented by metaphorical images that Chinese people are familiar with and even in favor of such as well-known historical sites and cultural relics, thus the projected features of these iconic images are transferred metonymically, metaphorically or analogically to the products, and then to consumers as well through the consumption of the products, thus the completion of shift from use value to exchange value. By the time of 1996 and 1997 the most vogue or bandwagon experience has become patriotism and nostalgia respectively, a declaration of complete success of 'national ideology'.

It is interesting to see how the advertising appeals, which are designed to attract consumers' attention, both reflect and help establish the dominant 'national ideology' with 'rational appeal' reduced to $13 \%$, personal appeal reaching $57 \%$, and social appeal ${ }^{43}$ $30 \%$. The 'national or patriotic consumption' through personal appeal has become the preoccupied legitimate activity. The key characteristics of this period is the increasing use of tradition, male and modern commodity as the representational images, which accounts for a total of 60 percent, in order to establish an authoritarian male-dominated nationalist commercial society. Therefore it is well-grounded to summarize the general pattern in this period for the promotion of personal consumption as the legitimate activity as masculine 'tradition and national pride + material success.'

\subsubsection{The Transformation from National to Scientific and Harmonious Ideology}

Twenty years after China's reform and open-up policy, the ruling and dominant value-orientation that needs to be promoted in 2000 s has changed again from 'national

\footnotetext{
${ }^{43}$ The criteria and operational definition for different appeals are discussed in 3.4.1 chapter three.
} 
ideology' to 'scientific and harmonious ideology' as $\mathrm{Hu} \mathrm{Jintao}^{44}$ has said China must uphold a view of scientific development and construct a harmonious society, thus the promotion of consumption as a legitimate activity through harmony, personal success, and scientific development.

Ideology changes: From national ideology to scientific and harmonious ideology from 1999 to 2008.

Percentage of rational, personal, and social appeals used: $21 \%, 57 \%, 22 \%$

Bandwagon experiences: what is 'in' during 2000s?

1999: TV series "Emperor's Daughter Huanzhu"

2000: Internet beauty women writers

2001: New Millennium computer bugs; computer games

2002: Internet company; e-commerce

2003: Health consciousness

2004: Stamp/antique collection; Puer tea speculation

2005: Real estate boom

2006: Car boom; travel boom

2007: Stocks; super girl PK competition

2008: National pride in Olympic Game; economic downturn

Frequently appeared words in priority: Traditional Chinese culture (balance, harmony, Peking opera $\&$ martial art, tea manner), (the power of, being close to) nature, world, happiness, hero (icon), longevity (health), system/way, space, (life)style, connection, instinct, self-identity (status), comfort \& convenience, money (investment)

\footnotetext{
${ }^{44}$ Jiang Zemin's successor and the fourth generation leader of Chinese Communist Party who deepened 'reform and open-up policy' and is presently facing economic, social, and political problems caused by world financial crisis and domestic difficulties.
} 
Table 4-6 Frequently Appeared Metaphorical Images in Advertisements of 2000s

\begin{tabular}{|c|c|c|}
\hline $2000 s$ & Frequency & Metaphorical images appea red \\
\hline $\begin{array}{l}\text { Group } \\
\text { images }\end{array}$ & 15 & $\begin{array}{l}\text { Family photo, multi-tasking heroes, cool instinctive } \\
\text { youngsters, basketball stars, HK celebrities, smiling super } \\
\text { boy \& girl, happy customers eating \& talking, } \\
\text { extraterrestrial being, human brain made of nude bodies, } \\
\text { looter \& hacker, basketball players, farewell ceremony for } \\
\text { warriors of war on the Great Wall, (bounded hands, blind } \\
\text { eyes, shackled feet), performers propping out of water, date } \\
\text { with the sea }\end{array}$ \\
\hline $\begin{array}{l}\text { Modern } \\
\text { convenience }\end{array}$ & 14 & $\begin{array}{l}\text { Telephone in change, computer game, airplane, golden key, } \\
\text { tricycle taxi, (halved spanner, gas pump, car key), car- } \\
\text { driving in different weather, car on folded fan, (credit card, } \\
\text { car, ice box), (plane, fashion, car), (lightening arrestor, door } \\
\text { fastener, fire extinguisher), overloaded lift, TV aerial in } \\
\text { countryside, commodity bar-codes }\end{array}$ \\
\hline Animals & 13 & $\begin{array}{l}\text { (fish, antelope, wild goose), ape, peacock in forest, tortoise, } \\
\text { wild goose, (fish, shrimp, crabs), half fish \& half man, } \\
\text { (paws, cobra, lions), bird's singing, (panda, dinosaur, tiger), } \\
\text { (porcupine, globefish), (bee \& bird), swan in nature }\end{array}$ \\
\hline $\begin{array}{l}\text { Daily } \\
\text { necessity }\end{array}$ & 13 & $\begin{array}{l}\text { (Umbrella, wardrobe, car park), Christmas tree, black coffee } \\
\& \text { red Latin, cooking oil, heart \& house made of smiling } \\
\text { faces, swinging pendulum, comb \& speedy ticket, stainless } \\
\text { tea \& coffee cup, circle \& recycle of tissue, bundle of } \\
\text { Orchids, (lady's underwear, body shape, wine cups), letter } \\
\text { arrival with wet glue, match boxes }\end{array}$ \\
\hline Tradition & 12 & $\begin{array}{l}\text { (Taihe Temple, the Summer Palace, Yuan Mingyuan, } \\
\text { Yueyang Pagoda), (Baroque-style vase, wall, flower); } \\
\text { (upturned eaves, vault, bamboo courtyard); Yoga \& Taiji } \\
\text { boxing, Snow White fairy tale, maze or labyrinth hunting, } \\
\text { guardian gods, Chinese character of fire and water, the } \\
\text { Great Wall \& Athenian Parthenon, time-honored store with } \\
\text { two brands, traditional tea process methods, (Monkey king } \\
\text { vs. superman, Nezha vs. Harry Porter, Huamulan vs. Snow } \\
\text { White) }\end{array}$ \\
\hline $\begin{array}{l}\text { Natural } \\
\text { scenes }\end{array}$ & 11 & $\begin{array}{l}\text { Remote natural places (forest, desert, ocean, mountain), } \\
\text { Tibetan mountain \& rain forest, night stars, metropolitan } \\
\text { city, Tibetan highland, lake view, sea waves \& white } \\
\text { clouds, Alps, wind attack and mountain defend, drips of } \\
\text { water, natural plant and flowers }\end{array}$ \\
\hline Men & 8 & $\begin{array}{l}\text { Superman, Chinese cartoon figure, Spiderman \& superman, } \\
\text { foreign baby, Gongfu master Li Xiaolong, man breaking out } \\
\text { of a cage, run-away black ghost, son ordering food }\end{array}$ \\
\hline Recreation & 6 & $\begin{array}{l}\text { Amusement park (skyscraper wheel, rollercoaster, merry- } \\
\text { go-round), water therapy, footprint } \& \text { shoeprint, catapult }\end{array}$ \\
\hline
\end{tabular}




\begin{tabular}{|l|l|l|}
\hline & & $\begin{array}{l}\text { ribbon \& silky cord, Football World Cup, Mahjong playing } \\
\text { on a football field }\end{array}$ \\
\hline Women & 4 & Sexy lady, triangle love affair, throat savor, stripping girl \\
\hline Others & 3 & well-grown Ginseng, sensational news, big brand names \\
\hline Total & 99 & \\
\hline
\end{tabular}

From the bandwagon experiences it is shown that after 20 years of reform and open-

up the overall social and cultural environment at this period tends to resist and revolt against the dominant economic ideology of 'scientific and harmonious ideology'. It is argued by me that the social and cultural environment has shown an open, modem, and increasing commodity fetishism tendency. First, people in the whole country are eager to jump onto the bandwagon of Internet technology, real estate (investment), stock market, car boom and travel. Second, embraced into the world family and WTO and empowered by China's rising strength in economy the whole society has shown worship for superman, super sport star and heroic and individualistic success. Third, competition, PK system and 'catch up with the Joneses' have become well-established lifestyle and success model. As a result of this severe competition and fast-pace of industrialization and urbanization, social and environmental conflicts are quickly on the rise, in particular the social welfare system, increasing gap between the rich and poor, medical and educational resources, traffic congestion, the lack of energy resources, and air and water pollution. Therefore the dominant ideology must be changed from a national ideology to scientific and harmonious ideology, thus balance and harmony (between human activity and nature, between external world and internal psyche, between individual and national relations), happiness and longevity, heroic success and connection become the legitimate activity.

This ideology shift can be illustrated by the frequently appeared key words as they are shown above. Different from the first period which has a foreign exotic admiration 
psychology and unlike the second period which focuses on tradition and national pride, this third period is a period of keeping balance between western and eastern, between modern and tradition, between human and nature. From the key words (the main advertising themes) in this period it can be seen how the representational value themes and images reflect the general tendency in social cultural trends and environment. It seems that the more modern and globalized Chinese society becomes the more traditional and national the representational value themes and images are. This is in conformity with the instrumental function and metaphorical nature of the advertisements. Taking this period of $2000 \mathrm{~s}$ as an example, with the rise of Internet technology and e-commerce, real estate boom, antique, Puer tea and stock market speculation, the whole country is filled with capitalist pragmatism and heroic individualism. Meanwhile the whole society is troubled by the environmental problem and social disparity. It is only natural that the most frequently appeared key words in advertisements in this period have added features of traditional Chinese culture such as balance, harmony, being close to nature or return to nature, way (Daoism) and tea manners in addition to the previously used words of worldly view, happiness and longevity, Peking opera masks and martial arts in order to attract the middle-aged group consumers. These traditional cultural heritage is supplemented by words of hero (icon), system, space, (life)style, connection, (release) instinct, and self-identity (status) to reflect a lifestyle change and mentality change of post $80 \mathrm{~s}$ and $90 \mathrm{~s}$ generation in China. Therefore the general pattern in this period for the promotion of personal consumption as the legitimate activity is a balanced 'harmonious society + heroic individualism.' 
This pattern is supported by the frequently used metaphorical images in the table 4-6. While China has achieved its goal of national strategy in "making economic construction as the core,' its fast pace of wealth accumulation and dynamic economy has made some western economists start to talk about 'Beijing Consensus' as against 'Washington Consensus' to show their eagemess to theorize China's economic success. However, China's 'ruling and knowledge class' is not so optimistic. They are more concerned with what they called 'sustainable and balanced' development. Contrast to the most frequently used iconic pictures/images in 1980s which are smiling, happy, beautiful ladies including many foreign beauties and successful men images and family photos; different from the most frequently appeared metaphorical images in 1990s which are traditional Chinese values such as 'six fortune' culture, perfectness, hard work, (mutual) care, insight and speed and space; the value-orientations of 'scientific and harmonious development' as a dominant ideology in 2000 s are supported by a balanced image representations. The relatively balanced top six image groups are group pictures (15\%), modern convenience $(14 \%)$, animals $(13 \%)$, daily necessity $(13 \%)$, tradition (12\%), and natural scenes $(12 \%)$. In contrast in 1980s the top two most frequently used image groups are women and group pictures that account for $49 \%$ while the top two most frequently used image groups in 1990s are tradition and men's images such as men's strong shoulder and father's hands, which accounts for almost 31 percent. This is by no means accidental. As the table 4-7 illustrates, advertisements in 1980s show a feministic and collectivist tendency with women and group images dominating the list and few daily necessity and modern conveniences to be used as images. Advertisements in 1990s have demonstrated a strong masculine and nationalist tendency with men and tradition prioritizing the list and daily 
necessity, modern convenience and animals to be followed. But when it comes to $2000 \mathrm{~s}$ women image becomes the least important to be replaced by a balanced representational image groups, modern convenience, daily necessity, animals, tradition and natural scenes. Evidence from the table Il-5 in appendix II shows that Chinese society is becoming increasingly male-dominated as the male versus female image percentage has increased from 20 percent in 1980 s, to 69 percent in 1990 s to 92 percent in 2000 s.

The advertising appeals help establish the dominant 'scientific and harmonious ideology' with rational appeal accounting for $21 \%$, personal appeal $57 \%$, and social appea $\left.\right|^{45} 22 \%$. Similar to 1990 s in proportion of using 57 percent of personal appeals to promote dominant ideology with 'traditional and individualistic consumption' as the preoccupied legitimate activity, the key characteristics of this period is the balanced use of the representational images that can attract consumers from different walks of life and from different age groups. While continuing the process of establishing a male-dominated consumption society, a higher level of personal appeal such as personal achievement/accomplishment, self-esteem, perfectness (splendid, extraordinary), humor, satisfaction, heroic complex and ambition becomes the major catch point. The implied meaning behind these personal appeals is heroic individualism and self-esteem can be realized through consuming our products or services just like those celebrities and heroic icons, thus the projected features of these iconic images are transferred metonymically, metaphorically or analogically to the products, and then to consumers as well through the consumption of these products, thus the completion of the shift from use value to exchange value.

Table 4-7 A Comparison of Advertising Image Categories in Three Periods

\footnotetext{
${ }^{45}$ The criteria and operational definition for different appeals are discussed in 3.4.1 in chapter three.
} 


\begin{tabular}{|l|l|l|l|l|l|l|l|l|l|l|}
\hline & W & M & G & T & A & MC & N & R & DN & O \\
\hline $1980 s$ & 23 & 8 & 10 & 7 & 2 & 3 & 5 & 1 & 2 & 7 \\
\hline $1990 s$ & 7 & 15 & 4 & 16 & 11 & 11 & 9 & 5 & 13 & 7 \\
\hline 2000s & 4 & 8 & 15 & 12 & 13 & 14 & 11 & 6 & 13 & 3 \\
\hline
\end{tabular}

(W: women M: men G: group T: tradition A: animal MC: modern convenience $\quad \mathrm{N}$ : nature $\mathrm{R}$ : recreation $\mathrm{DN}$ : daily necessity $\mathrm{O}$ : others)

\subsection{The Identity Changes Reflected by China's Illustrated Print Advertisements}

The very idea of 'identity' is a complex one in philosophical field. In this dissertation I agree with Peter Geach's radical position that there is only relative identity. Personal identity changes over time due to the fact that both external environment and internal properties such as age, occupation, and social roles change. As Heraclitus argued that one could not bathe in the same river twice because new waters were ever flowing in. Hume argued that identity over time was a fiction we substitute for a collection of related objects $^{46}$.

In this research 'identity' means 'sameness'. To say that things are identical is to say that they are the same. Things with qualitative identity share the common or the same properties, so things can be more or less qualitatively identical. Taking this premise into the present advertising research, all the representative images are objectified and embodied with certain properties or qualitative identity. To acquire the same properties or to become the same kind of person/thing the easiest way is to identify themselves with it through the means of consumption. As Judith Williamson argues advertisements do not simply sell us products they are selling us self-identity and self-image. Advertisements function by transforming an object into something which is given meaning in terms of people. The well-known self-identity images in the west include beautiful Channel

\footnotetext{
${ }^{46}$ For more detailed explanation about these concepts please visit http://plato.stanford.edu/entries/identity/ First published Wed Dec 15, 2004; substantive revision Sat Nov 7, 2009
} 
woman; masculine Marlboro man; sexy Kevin Klein youth; and countless luxury celebrities or stereotyped interior and exterior settings. Their function of creating desire and conformity with reduced autonomy has been now widely recognized and analyzed. Our question for inquisitive exploration here is to see how the 'self-identity images' and 'self-formation' politics has evolved in China in the last 30 years. What are the wellknown self-identity images in China? In what way this 'use value' to 'exchange value' process or 'symbolic exchange' to 'semiotic exchange' process is realized?

In social psychology there is the social identity theory or self categorization theory that offers insights into our social experiences. This theory (Tajfel \& Tumer, 1986; Oakes, Haslam, \& Turner, 1994) believes an individual can be understood at two different levels: one is at the individual (personal identity) level and the other is at the collective level (social identity). In the latter case - social identity level, 'individuals act as group members, understand and judge the behaviors of self and others in terms of group memberships, and tend to deindividuate both self and others' (Harwood, 2006, p. 85). Media researchers (Harwood \& Roy, 2005; Mastro, 2003; Hogg \& Tindale, 2005) have illustrated to us that media discourse, just like any communication form, constructs the meanings of particular social identities. Studies show how 'social identification' and 'group prototypicality' (Harwood, 2006, p. 88) can influence group behavior.

Chinese people, being in an agrarian society for thousands of years, have a very strong sense of group-identity or a strong sense of belonging according to Geert Hofstede's research on national culture. In his widely quoted as well as debated five national cultural dimensions China is stigmatized as a high power distance, uncertainty 
avoidance, collectivist, feministic, and long-term orientation society ${ }^{47}$. In one later research Chinese Value Survey (CVS) developed by Chinese social scientists the data supported the first three social behavior dimensions of culture identified previously, i.e., power distance, individualism versus collectivism, and masculinity versus femininity. Uncertain avoidance, however, did not show up in the CVS. Instead, the CVS revealed a dimension that had eluded Western researchers. This dimension is called by Hofstede as 'Confucian Dynamism' which concerns several aspects of culture that appear to be strongly linked to the fast economic growth of Newly Industrialized Countries (NICS) and regions of South Korea, Singapore, Chinese Hong Kong and Chinese Taiwan. I tend to believe they can also partially explain from cultural perspective the fast economic takeoff in present mainland China. Hofstede explains that these aspects concern:

---A search for virtue rather than a search for truth is held by the majority of society.

---Persistence (perseverance) is a general tenacity in the pursuit of a goal.

---Ordering relationships by status reflects the presence of societal hierarchies.

---Observing this order indicates the acceptance of complementary relations.

---Thrift manifests itself in high saving rates.

---A sense of shame leads to sensitivity in social contacts.

Hofstede notes that these values are widely held within the Asian high-performing countries and regions, but that the presence of these values by themselves is not sufficient to lead to economic growth. Two other institutional conditions are necessary: the existence of a market and a supportive political context. Despite the criticism in recent

\footnotetext{
${ }^{47}$ For detailed information about his work please refer to his books Hofstede, Geert (1980). Culture's consequences: International differences in work-related values. Newbury Park, CA: Sage. Hofstede, G. (1991). Cultures and organizations: Software of the mind. London: MoGraw-Hill UK.
} 
years both on his generalization and his methodological approach, I argue in this dissertation that Chinese cultural values as described by Hofstede supports my argument that Chinese people as groups, due to the collectivist culture, are more likely fallen into the trap of massification, subjectification, 'catch-up with the Joneses' and 'jump-onto bandwagon' even though at individual level and with exception this is a biased and stereotyped opinion. As a highly collective society with ' face $^{48}$, consumption, as a result of the power of 'word of mouth' from friends and family members and with the help of daily media advertising exposure, few people in China can resist or afford to resist the temptation of 'bandwagon experience' and 'keep up with the Joneses' shopping. Through the publicity campaign of mass media with eye-catching signs and symbols more people follow the identification process or self categorization process (want to be 'in', afraid to be 'out') out of mass psychology, naturally causing the result of irrational mass consumption. As the advertising slogan in one TV commercial for a beer-like tea drink put it: "You're out la..." In China 'in' and 'out' has double meaning. One is to be in fashion and in trend rather than out of date, the other is to be in group and an insider rather than out of circle and an outsider. The idea of being excluded and lagging behind can be a severe punishment for collectivist Chinese.

In Re-reading Popular Culture (2005) Joke Hermes combined the ideas of Foucauldian framework (1979), Fiske and John Hartley (1970s, 1980s) and Toby Miller $(1993,1998)$ to theorize "the politics of self-formation" of how individuals change from political/national self to cultural/media self to DIY (do-it-yourself) self and from consensus to difference (Hermes, 2005, p. 3-9). During the whole process discipline with

\footnotetext{
${ }^{48}$ For a complete picture and understanding of Chinese 'face' concept please refer to Huang, Guangguo and Hu, xianjin Face: power game of Chinese people Beijing: Renmin University Press. 2004.
} 
self-imposed rules plays a key role in inviting and inciting people to their moral obligations. This theoretical explanation about self-formation and identity formation can be empirically supported and reflected in self-image changes of China's advertisements.

Below I will analyze how "self-identity images" and "self-formation politics" in China in the last 30 years have been reflected in China's awarded illustrated print advertisements. As explained above, in conformity with ruling and dominant ideologies in the three periods which are 'economic ideology,' 'traditional and national ideology,' and 'scientific or harmonious ideology' respectively, self-identity images and selfformation politics in each corresponding period follow the patterns of 'smiling beauty + quality', 'traditional and national pride + material success' and 'balance and harmony + heroic individualism.' Below I will give specific image examples to illustrate how disciplined selves are invited and incited to recognize their moral obligations? How is conformation (massification, objectification, and subjectification or manipulation) realized through symbolic association? In another word, what are the symbolic associations that make people identify themselves with? What are the low common denominators (metaphors and images) to be made simple and conformist?

\subsubsection{The Transformation from Political Self to Material Social Self in 1980s}

In 1970s' China the general political atmosphere is 'taking class struggle as the core activity' and being a member of working class and proletariat is a source of pride and identity (i.e. to be a political self). Any wish for better living condition and material comfort is denounced as bourgeoisie vanity. However, since 1978 when China started its reform and open-up policy new forms of technology have brought about new modes of organizing production; and new modes of organizing production have resulted in a new 
configurations of class; and new configurations of class have called for new methods of social control.

The new social control is realized through promoting dominant 'economic ideology—making economic construction as the core activity.' However, the economic ideology is an abstract concept that has to be specified into simple denominators such as metaphorical images and real life heroes to make common people identify themselves with them and produce relevant symbolic associations. As new products and new ideas have been introduced into the country, people gradually recede from political self who identifies themselves with politically sensitive solemn-faced model workers to material social self who identifies themselves with happy, healthy and smiling beauties (including both men and women $)^{49}$. These happy, healthy and smiling beauties become common self-identity images in this period because they own high quality and new style of clothes, shoes, woolen sweaters and big-ticket items such as watches, bicycles and family appliances of TV, washing machine, refrigerator and tape-recorder which ordinary people can not afford or can not buy without 'coupons' or 'back door' channels.

During this period, when crowded community people living together find their neighbors and relatives enjoying multiple colors and styles of clothes and the modern conveniences of imported family appliances there is the spread of a green-eye and ripple effect. Naturally people are invited and incited to follow suit. Chinese people by nature are hard-working and self-disciplined. Many parents believe it's their moral obligation to do some small business and moon-lighting in order to save enough money to buy new clothes, pieces of furniture, and big-ticket item electronic goods, just to improve the life

\footnotetext{
${ }^{49}$ Please refer to table II-1 for all the human images appeared in this period's 68 advertisements with metaphorical images.
} 
of their children. When the new forms of technology come into China such as electronic technology, there appear many joint ventures and wholly foreign-owned companies in China with Japan, the United States and European countries to produce electronic goods, toys, shoes, and cars. As a result of new technology the way of organizing production has also been changed. Millions of rural farmers come into city to become assembly line workers, construction workers and household maids. Millions of urban youngsters who labor in the countryside return to cities to study for national university entrance exam or to find a job. The temptation for a happy, healthy, beautiful and better living condition life is so strong it spreads out like a wild fire that makes people full of hope and vitality.

The common denominators, i.e. metaphorical images that people identify with at that time are smiling beauties and healthy youngsters who own some electronic or quality products. Taking pictures $1.5,1.26,1.59$ and 1.77 in the figure II-1 in appendix II as image examples of this period from 1978 to 1989 the metaphorical expressions are: the silk blouses are beautiful ladies and happy couples; Sanyo TV is a happy boy (holding a TV); Yanwu tape recorder is a singing and dancing boy; and Specific toothpaste is a white-teethed fresh-looking beauty. The symbolic associations through projected features or entailments of these metaphorical images are: I belong to this group of beautiful, happy, natural and homely, fun-making, and healthy and fresh-looking people if I identify myself with these people and buy the products they own or use. Since my friends and classmates are all using and buying these products I must also buy them in order to catch up with the Joneses and be 'in'.

\subsubsection{The Transformation from Material Social Self to National Cultural Self in $1990 \mathrm{~s}$}


Toby Miller (1993, 1998) understands cultural citizenship as the disciplining of subjects in the cultural realm in capitalist social formations (Hermes, 2005, p. 5). Cultural citizenship is a realm of subjection, and hence a realm of both disciplining and seduction with self-imposed rules and group norms.

Cultural citizenship can be defined as the process of bonding and community building, and reflection on that bonding, that is implied in partaking of the textrelated practices of reading, consuming, celebrating, and criticizing offered in the realm of (popular) culture (Hermes, 2005, p. 10).

In 1980s' China the general political atmosphere is 'taking economic construction as the core activity' and being a member of middle class and knowledge class is a source of pride and identity (i.e. to be a happy person and own some material goods-to be an material social self). If any family members and relatives are studying in universities in China or abroad or working in a joint venture or wholly foreign owned companies they become the envy of others and a symbol of social status. However, since 1989 when China has experienced TianAnmen political turmoil followed by ideology and identity crisis, the government has taken notice that many Chinese people adore foreign culture (including liberty and democratic system) and identify themselves with western icons and idols, out of which the Statue of Liberty in New York Harbor, Elvis Presley, fast food icon KFC's colonel Sanders, and basketball sensation Michael Jordan are among a few most prominent. Meanwhile computer industry and telecommunication come into China, which brought about new political environment, new modes of organizing production; new configurations of class. They in turn called for new methods of social control. 
This time the new social control is realized through promoting dominant "traditional and nationalist ideology-making people feel proud of Chinese culture.' The abstract concept - nationalist ideology is specified into low and simple denominators of metaphorical images to make common people identify themselves with them. As new products such as computers, insurance, real estates and cars have come onto Chinese purchasing list, people gradually recede from material social self who identifies themselves with happy, healthy and smiling beauties (including both men and women) to national cultural self who identifies themselves with filial sons, responsible fathers, Chinese 'fortune culture' and worship for cultural and historical relic symbols.

During this period, big ticket items have changed from electronic family appliances to computers, pagers, water heater for bath shower, real estate houses and family cars. When crowded community people living together find their neighbors and relatives enjoying multiple kinds of drinks (pure water, Coca Cola, beer, green tea, herbal wine, nutritional drinks), eating in varieties of restaurants and buying modern conveniences and comfort, there is naturally the same spread of a green-eye and ripple effect. Chinese people are invited and incited to follow suit but for a different reason as in 1980s. Many people believe it's their moral obligation in this period from 1989 to 1998 to solute and respect the traditional Chinese culture and consume as a patriotic nationalist. When the new forms of technology come into China such as computer and telecommunication technology, apart from the dynamic private and township enterprises in manufacturing industry in 1980s, many newly-returned graduates from the United States and other advanced countries start their own computer and Internet companies. There is also a successful turnaround of powerful state-owned enterprises (SOES) in the field of 
transportation, telecommunication, energy, commercial banks, and insurance as a result of sequential initial public offering (IPO) of these companies on the Shanghai Stock Exchange and Shenzheng Stock Exchange as well as in Hong Kong and New York Stock Exchange. As a natural result of the IT boom and modern businesses millions of students become MBA students and learning English (either to go abroad or to work in foreign companies) has never become so hot. Chinese people start to feel proud of their traditional culture and national achievement in the event of return of Hong Kong and Macau and the successful bidding for 2008 Olympic Games. By the time of 1998 the temptation for a patriotic, proud, successful and cultured life is so strong that many people's identity has changed from western admiration identity in 1989 to national proud identity.

As a result, 1990s have seen 'tradition and men' as the top two self-identity image groups contrary to 1980 s which have 'women and groups' as the top two self-identity image groups. The traditional Chinese images appear in this period's advertisements as common denominators are: mahogany armrest, paper cuts, abacuses, moon cake, Peking opera masks, proverb stories, Chinese six fortunes, Temple of Heaven, double happiness sign, Yuan Ming Yuan Garden, Dai ethnic water festival, Putala Palace and the Great Wall, Chinese style marriage, prophet calendar, match-maker, Chinese ancient saint, and legendary person - Zhu Geliang ${ }^{50}$. These traditional icons and idols become common self-identity denominators in this period because they are attached to and embodied with a sense of national pride and patriotism. Only three foreign icons appear in this period, which are Albert Einstein, Jean-Paul Sartre, and the sculpture of American Presidents.

\footnotetext{
${ }^{50} \mathrm{Zhu}$ Geliang $(181 \sim 234 \mathrm{AD})$ is a statesman, diplomat, military strategist and inventor and a house-known name in China. Please refer to table 6.5 for all the traditional and national images appeared in this period's 98 advertisements with metaphorical images.
} 
Taking pictures $2.8,2.20,2.44$ and 2.73 in the figure II-2 as image examples of this period from 1989 to 1998 the metaphorical expressions are: China Telecom is father's broad reliable shoulder; GFO accounting software is 6 abacuses/chips; Herbal wine is heart, fan, Opera mask, money god, paper cut and kite; Nortel Communication is Putala Palace in Tibet and the Great Wall in Beijing. The symbolic associations through projected features or entailments of these metaphorical images are: I belong to this group of people if I identify myself with these people and buy the products they own or use. They show care and condolence; they can do fast calculation and is shrewd in business; they own all the six fortunes of love, happiness, friendship, wealth, longevity, smoothness; they keep themselves connecting with the world at great historical and cultural relics. Since my friends and colleagues are all using and buying these products I must also buy them in order to catch up with the Joneses and be patriotic and nationalist.

\subsubsection{The Transformation from National Cultural Self to Individualized My Self in} $2000 \mathrm{~s}$

As previously analyzed, in 1980s and 1990s Chinese people have been thought to have primarily organized their sense of belonging, rights, and duties as material social selves and nationalist selves such as political citizenship - at a more practical level social citizenship. In 2001 China has entered into WTO and been closely intertwined into the globalization process. People are no longer satisfied with self-identity images such as being a member of middle class, knowledge class or national class. They want to belong to a unique 'my' class and just be myself, thus the sources of self-identity images becoming more diversified and more balanced with regard to the representing image groups as is shown in the table 4-7. By this time popular culture and fan culture has 
become an important source of self-identity. With the grown-up of post $80 \mathrm{~s}$ and $90 \mathrm{~s}$ in China the younger generation tends to identify themselves with pop music stars, Internet heroes or heroines, sport champions or alien movie stars, computer game, and cartoon figures. Young people spread these popular culture or fan culture icons to express their unique selves and to show their resistance or rebellions against more powerful adult world or dominant power relations.

Internet has become a new media battling ground in China with more than 100 million netizens by the end of 2008 . The dominant and ruling 'scientific and harmonious ideology' is an illustration to this new diversified identity sources, but it faces severe challenge and competition from international media conglomerates as well as from popular and fan cultures that invite people into new types of collectivities that stretch far beyond national borders and produce small self-enclosed enclaves within the nation (Hermes, 2005, p. 1). This diversified identity sources again pose threat and challenge to the method of social control.

This time the new social control is realized through promoting dominant 'scientific and harmonious ideology—making people care about the environment and social harmony.' The abstract concept of balance and harmony is embodied into simple denominators of metaphorical images. As new products such as credit card, mobile phone, personal financial investment instruments have come onto Chinese people's purchasing list people gradually recede from conforming social self who identifies themselves with traditional Chinese sign symbols such as filial sons, responsible fathers and Chinese 'fortune culture' to a more individualistic my self who identifies themselves with modern unique individualistic personalities. 
During this period the arrival of digital technologies has made Chinese middle class and the newly-rich buy new 'big-ticket' items of mobile phones, credit cards, family sedans and big houses. When newly-formed community (either in the working place, family circles, the Internet community or personal hobby groups) find others using fancy mobile phones, paying by credit cards, driving luxury sedans and investing in stock markets and real estate markets, there is naturally the same effect of envy and follow-suit. As always Chinese are eager to jump onto the bandwagon and keep up with the Joneses. They are invited and incited to join in the big craze of mobile phone, internet, stock market and real estate and produce one after another either the boom or the bubbles of speculation. Leveraging on this mass psychology advertising designers and commodity producers made it their moral obligation (actually vanity) for consumers in 2000s to establish themselves as unique and successful social elite. In this period companies and media are eager to sponsor Super-girl, Super-boy and other PK contests and to forge the winners into new identity images in order to attract millions of post $80 \mathrm{~s}$ and 90 s. Movie stars and Olympic medalists are another group of identity symbols. Luxury lifestyle and status symbol products are a growing industry to differentiate and segment people.

If 1990s have seen 'tradition and men' as the top two self-identity image groups as opposed to 1980 s which have 'women and groups' as the top two self-identity image groups, the 2000s have eye witnessed common denominators as: multi-tasking heroes, cool instinctive youngsters, basketball stars, HK celebrities, spider man and superman, regular diners at well-known restaurants, extraterrestrial being, human brain made of nude bodies, looter and hacker, warriors of war on the Great Wall, talent PK performers, (Taihe Temple, the Summer Palace, Yuan Mingyuan, Yueyang Pagoda), (Baroque-style 
vase, wall, flower; upturned eaves, vault, bamboo courtyard); Yoga \& Taiji boxing, Snow White fairy tale, labyrinth hunting, guardian gods, Chinese character of fire and water, the Great Wall \& Athenian Parthenon, traditional tea process methods, (Monkey king vs. superman, Nezha vs. Harry Porter, Huamulan vs. Snow White $)^{51}$. These hybridized and worldly icons and idols, many of which is a comparison and a combination between eastern and western culture, between tradition and modern culture such as eastern vs. western architecture, fairy tale stories, and traditional and modern heroic manta, have become common self-identity denominators in 2000 s because they are labeled and packaged with a sense of self-achievement, personal success and heroic individualism. The most frequently used words in this period's advertisements from the table II-4 are: balance, harmony, Peking opera \& martial art, tea manner, nature, world, happiness, hero, longevity, system/way, space, lifestyle, connection, instinct, self-identity (status), comfort $\&$ convenience, money (investment). They support the individualistic 'be' myself identity.

Taking pictures $3.10,3.19,3.54$ and 3.62 in the figure II-3 as image examples of this period from 1999 to 2008 the metaphorical expressions are: Moto mobile phone is multitasking heroes; Lubao car is a love affair and intruder; The Great Wall wine is the Great Wall and Athenian Parthenon in wine cups; and Reebok is HK famous swimmer and movie star. The symbolic associations through projected features or entailments of these metaphorical images are: I am unique and out of the pile if I identify myself with these outstanding people and buy the products they own or use. If I use the Ming mobile phone

\footnotetext{
${ }^{51}$ Monkey King is a rebellious and extraordinary figure in a well-known Chinese novel "Journey to West" who helped a Chinese monk Xuan Zang (a true person 602-664) to travel to India to seek for the Sutra, the Buddhist holy book. When Xuan returned to China, the Great Tang at that time, he started to translate the sutras into Chinese, thus making a great contribution to the development of Buddhism in China.

Nezha is said to be the third son of the Heavenly K ing Li and a legendary hero boy who has the almighty power to conquer and beat up the demons. He often appears in different novels in Yuan, Ming, and Qing dynasties.

HuaMulan is a woman hero in folk lyric who disguised herself as man and go to the war field to fight on behalf of her father against the Northern Mongolians.
} 
I can become insightful, brilliant, capable and multi-tasking heroes. If I buy a Lubao car I will become timely and have a love affair with someone. Successful people on special occasions must drink the Great Wall wine because it combines the eastern civilization of the Great Wall with the western civilization of Athenian Parthenon. If you buy Reebok sportswear you are just like these two Hong Kong celebrities who are successful but also controversial in their personal life and sex orientation. The caption for the picture 3.62 is 'I am what I am. I like being myself.'

Since self-formation politics is the process of making self-identity images conform to the needs of the ruling and elite class, therefore in this chapter I have demonstrated from the analysis per se of how the process and the self-identity transformation is made possible and carried out in China in the last 30 years through the careful weaving and presenting of the self-identity images in China's illustrated print advertisements. In 30 years of time from 1978 to 2008, as key themes and metaphorical image categories in 300 advertisements in China have demonstrated, in congruity with the rapid economic and technological development in China, advertising discourse can facilitate the instrumental social function as well as commercial function thus indirectly (re)constructs social reality and enhances social change. 
The influence of symbols upon human life and thought in numberless unexpected way has never been fully recognized. C. K. Ogden and I. A. Richards ${ }^{52}$ British linguists and semiotician

\section{CHAPTER 5}

\section{CONCLUSIONS AND IMPLICATIONS}

\subsection{A Summary of the Research into Advertisements in China}

The preliminary assumptions on which this dissertation is based are: First, given that both individuals and societies are not just reality but socially-constructed reality, I believe advertising being at a focal and multi-interest point to connect companies, individual consumers and a society, the constructions of written texts and visual images of advertisements as shown in different periods of China's development can crystallize and pinpoint the ideology and identity changes in China. Second, commercial advertising, as a means of communication tool, due to its 'metaphorical nature' and 'instrumental mission', embodies certain pictorial metaphors that are advertisers' intentions to both influence and promote certain trend in ideology and social identity of the target consumers in a certain period of time. Third, a content and critical and interpretive analysis of the pictorial metaphors hidden behind words, images and symbols in the

\footnotetext{
52 C.K. Ogden and I.A. Richards are two British authors of the book The Meaning of Meaning (1923), a pioneering work about the science of symbolism, and about how language influences thought.
} 
advertisements of specific periods helps account for the social and cultural change of that period in Chinese society.

This investigation inquires into the issue of the dramatic social cultural changes in China in the last 30 years by adopting content and Critical Metaphor Analysis through studying illustrated print advertisements in China in the time span of 30 years. I hope to find out to what extent a quantifiable large number of advertising samples can collectively reflect the social cultural change of a given society in a given period. The general conclusion after systematically analyzing the cumulative data of 300 sample advertisements seems to have confirmed the preliminary hypothesis, i.e. a quantifiable large number of advertising samples can reflect collectively the social cultural change of a given society in a given period of time. This conforms with Fairclough's proposition that social change can be illustrated and reflected by studying (relation) changes in discourse, what he promotes as the trans-disciplinary Critical Discourse Analysis. It is shown through the evolving argument in the previous chapters that, advertising as a media discourse, their frequently appeared key words, the advertising appeals, the representational images (categories), the metaphorical expressions and the mapping between the primary subject and the secondary subject in the advertisements have, to a certain extent, confirmed the overall trends in social cultural changes in the last 30 years in China. Below is a summary of the social cultural environment and the consequential ideology and identity changes that have been illustrated and reflected in the advertisements on which the whole dissertation is embedded.

First, it is shown in the advertisements in 1980s that immediately following the dramatic political environment change and harsh survival living conditions, even though 
people still follow the relatively rigid and homogeneous socialist political and social orders they start to look for better living conditions and more material comfort, "value products, beauty, personal health and happiness' become the main ideologies to pursue and group identities are to follow beautiful movie stars and sports stars, female images in particular. Despite the self-disciplined and self-suppressive harsh living environment, Chinese people have exhibited their eagerness to learn and know more about the world and western ideologies.

Second, it is shown in the advertisements in the 1990s that the initial recovery of economic activities, the social political instability both at home and abroad and the inflow of foreign culture and ideology as a result of opening and reform policy in the previous years have made the whole society want to get rid of bondage from dogmatism. On the one hand people in the society share a strong sense of crisis and urgency, on the other hand people refuse to obey and follow blindly any authority and dogmatism but look for pragmatism and independent thinking. The ideology pursuit in 1990s has been expanded from material comfort to a higher level of spiritual freedom and cultural diversity. 'Traditional Chinese fortune culture, perfectness, success, and care' become the main ideology to pursue and people identify themselves with legendary figures in China and foreign countries and successful male celebrities become the dominant image group in this period.

Thirdly, it is shown in the advertisements in 2000 s that Chinese advertising industry is very different from that in 1980 s both in aesthetic design and its target consumers. Rather than targeting the mass consumer groups without differentiation with public announcements and quality guarantee products in 1980 s, advertisers in 1990 s send out 
more caring, private and personal messages to involve people in. By the time of $2000 \mathrm{~s}$ advertisers play to the taste of the more individualistic post 80 s and $90 \mathrm{~s}$ who grew up in the post-reform period with relative material comfort and in the globalized digital world. Therefore Chinese advertisements in 2000 s have exhibited both diversity and global view in terms of values themes, visual appeals and symbolic associations. In ideology they become deliberately and increasingly 'expressive, individualistic and horizontal in world view and connection' by striking a balance between tradition and modernity, between east and west, between country and city. The concerns and lifestyles denote the interests and appeals of different social groups and power needs. The group identity pursuit has shown an expanded dimension from material comfort in 1980 s to personal success in 1990s to national prosperity in 2000 s, from specific material comfort and social success to abstract self-confidence and self-expression. Below I use the data sets from chapter four, five and six to elaborate the three general conclusions per se and specifically to answer the three research questions as proposed in chapter one.

\subsection{Answers to the Three Research Questions}

\subsubsection{Findings Related to Question One}

To answer question number one, the research result in the key words, advertising appeals and value themes in chapter three and appendix I has demonstrated that linguistically or discursively: 1) Although advertisements in all the three periods belonged to the commercial public discourse, those in 1980 s were inclined towards rational public discourse without much consideration for specific target groups while those in 1990 s and 2000 s tended to denote private and personal discourse with clear target groups in mind; 2) While the advertisements in 1980s were characterized largely 
by the direct informative style with functional appeals, the majority of the advertisements in 1990s manifested a hybridization of both informative and involving styles. The advertisements in 2000 s demonstrated strong involving and interacting style with more emotional appeals.

This conclusion can be supported by the choice of frequently used nouns as is shown in the table I-4 and the table 5-1. Linguistically there are FOUR key words that appear stubbornly and repeatedly in all three periods. But the meaning or connotations and its priority for the same words may vary from period to period. They are 'value for money; health (longevity); happiness; and (Chinese) tradition/fortune'. For example 'value for money' in the 1980 s simply means superior quality, effectiveness and durability. In 1990s 'value for money' has the connotation of detailed work, calculative and shrewd use of your money. While in 2000s 'value for money' has the implicative of efficiency and flexibility. It will bring comfort and convenience to your life and 'value for money' is to make wise investment of your money. It can be seen that the concept of 'value for money' has been evolving from a public sphere of quality and value price to all consumers to a private and personal sphere of quality life or improvement of life quality. In terms of priority 'value for money' has gradually declined in importance ranking from the second most important in 1980 s to the least important in 2000 s.

'Health (longevity) and happiness' also appear in all three periods and these two terms are inter-related because Chinese people consider good health and longevity the top priority and the sources of all happiness. Actually the oldest and founding Chinese philosophy Daoism and its founder Laozi talks about the life (health) philosophy, the 
essence of which is to strike a balance between human and nature, between Yin (femininity) and Yang (masculinity) and between physical world and mental world.

The word 'tradition' denotes, on the one hand, the consistent respect and identity of Chinese people to the age-old tradition and civilization. American anthropologist Lucy Benedict used the "cultural script" theory to denote the shared but unique national cultural features. Generally speaking the Chinese advertisement designers employ three types of Chinese culture in their advertising creation: national culture, regional/sub/local-culture, and popular culture. China's 5000 years of written history and geographical condition determine the commonly-shared features in Chinese national culture have been abundantly instilled in the advertisements (Song \& Wang, pp. 157-187). It is found that the key theme words of 'preordain/pre-destination', 'Zen', 'homesick or hometown', 'dragon', 'mother or filial son', 'nostalgia' , 'heaven and earth are one' and 'harmony' are constantly used value themes.

On the other hand the extensive use of the words and concepts related to 'fortune' in Chinese advertisements is similar to Adorno's analysis of the astrology column of the Los Angeles Times. In 'The Stars Down to Earth' Adorno contends "the occult of astrology columns is a 'secondary superstition', that is, the occult appears as 'institutionalized, objectified and to a large extent, socialized"' (Bernstein, 1991, p. 13). The purpose is to make readers or consumers "seeing through and obeying at the same time." In Chinese advertisements in 1980 s the 'fortune' pronounces itself as a strong family tie and gettogetherness, in 1990s as fortune culture (affection, happiness, friendship, longevity, and smoothness) while in 2000s as philosophical ideal of balanced life and harmonious world. 
Despite the commonality and consistency of the four key words there are variations and focus shift in the usage of the key words. The words 'beauty', 'world', 'space' and '(life)style' appear as the second group of frequently used words throughout three periods, namely 'beauty' appearing in 1980s and 1990s; 'world' and 'space' in 1990s and 2000s; and '(life)style' in 1980s and 2000s. The word 'beauty' is easily understood as people at that time wear almost the same (dark) color and same style clothes and behave in the same manner, thus 'beauty' in 1980 s is accompanied by the frequently appeared adjectives of 'popular', 'colorful', and 'modern.' But in 1990s the word 'beauty' has the added meaning of being 'colorful' as well as 'romantic' and 'vogue'. The words 'world' and 'space' in both 1990s and 2000s demonstrate China's expanded world view and its fast pace of catching up with the world as well as its ambition for space travel and exploration and lunar landing program. The 'world' view is supported by other nouns such as 'insight', 'horizon', 'space' and 'connection'. The word '(life)style' appears in both 1980 s and 2000s. However the same word has to be understood in different context and relevance with different orientations. In 1980s the 'lifestyle' refers to modern and western lifestyles that appeal to consumers with material comfort and diversified ways of living. In 2000 s the '(life)style' has shifted to the dichotomy of western style vs. eastern style, modem style vs. traditional style, global versus local style. The gradual orientation shift from no style, to western style to (traditional) Chinese style is obvious and selfevident from the advertising themes and the metaphorical signifieds.

Table 5-1 A Comparison of the Frequently Used Key Nouns in Three Periods

\begin{tabular}{|l|l|l|l|}
\hline Nouns & $\begin{array}{l}\text { Appear in all three } \\
\text { periods }\end{array}$ & Appear in two periods & Appear in one period \\
\hline $1980 \mathrm{~s}$ & $\begin{array}{l}\text { Value for money; } \\
\text { Health (longevity); }\end{array}$ & Beauty; (life)style & $\begin{array}{l}\text { Publicity; quality; } \\
\text { popularity; manner }\end{array}$ \\
\hline
\end{tabular}




\begin{tabular}{|l|l|l|l|}
\hline $1990 \mathrm{~s}$ & $\begin{array}{l}\text { Happiness; Chinese } \\
\text { tradition \& fortune }\end{array}$ & $\begin{array}{l}\text { Beauty; world and } \\
\text { space; }\end{array}$ & $\begin{array}{l}\text { Perfectness; success; } \\
\text { care; man; emotion }\end{array}$ \\
\cline { 4 - 5 } & & $\begin{array}{l}\text { world and space; } \\
\text { (life)style }\end{array}$ & $\begin{array}{l}\text { Nature; hero; system; } \\
\text { connect; instinct; self }- \\
\text { identity; comfort \& } \\
\text { convenience }\end{array}$ \\
\hline
\end{tabular}

The above conclusion can also be supported by the choice of most frequently used verbs as is shown also in the table I-4. Linguistically the choice of the key verbs illustrates the evolving discursive change from public sphere to private and personal sphere and from informative style to involving and interactive style. For example the verbs in 1980s are chosen for making public announcements and promises to all the consumers mainly to satisfy the functional needs such as 'be, publicize, welcome, establish, satisfy, choose \& select, guarantee (promise)'. The advertising copies are product-oriented and manufacturer-oriented rather than marketing-oriented and consumer-oriented in a factual tone and informative style. The sentence patterns are: 'We are..., we welcome..., we are established manufacturer..., you can choose and select..., we guarantee'. Whereas in 1990 s the verbs have changed to 'appreciate, design, strategize, relax, make, accompany, help, connect, get rid of, reveal, prey, awaken' which are more personal and caring. They involve consumers into doing something both individually (make, relax) and collectively (accompany, connect); both functionally (design, strategize, get rid of) and emotionally (appreciate, help, prey). When it comes to 2000 s the verbs have shown a blend of individualistic and interactive style towards targeted consumer groups especially the post $80 \mathrm{~s}$ and $90 \mathrm{~s}$ who 'grow, (un)change, experience, search, release, share, exchange, enhance, drink, free, help, save, dare, run away, re-cycle \& re-born, hack, I am what I am, it's time to...date, win, shine'. These verbs are dynamic, powerful and exhibitive of younger Chinese in digital age who have 
the confident individualism combined with collective concern for world welfare. The advertisements have brought the consumers into a higher level of needs satisfaction (the personal and social need) through involving and interacting with others and collective effort.

Secondly, it can be seen from the shift of advertising appeals from rational appeal to personal appeal that the overall society is moving up the ladder of Maslow's Hierarchy of Needs Analysis. When basic physiological needs are satisfied the selling points or the value themes in the advertisements gradually shift to the satisfaction of personal needs and social needs. As it is shown in the table I-5 advertisers in 1980s use more rational and utilitarian appeals while in 1990s and 2000s they use more personal and social appeals to attract consumers. Generally speaking, the rational appeals that focus on the consumer's practical, functional, or utilitarian need for the product or service and emphasize features or properties of a product or service and benefits or reasons for owning or using a particular brand have shown a tendency of decline from $51 \%$ in 1980 s, to $13 \%$ in 1990 s, to $21 \%$ in 2000 s. This is a natural tendency when Chinese people improve their living standards. Chinese consumers are more likely to shun away from the basic and utilitarian needs satisfaction such as quality, value price, efficacy, and guarantees. But rather they are attracted by emotional appeals consisting of personal and social factors such as happiness, perfectness, success, mutual care, world view, man/people-orientation, beauty, and personal feelings. This tendency is shown clearly by the consistently high percentage (57\% in both 1990 s and 2000 s) of using personal appeals to attract customers.

Despite being generally identified as a collective society as defined by anthropologist Geert Hofstede in his 1980s four national cultural dimensions research, the 
present research, however, shows a different result if not a completely opposite result. The same high percentage of 57 for using personal appeals in both 1990s and 2000s in their advertising execution surprises me as it has been expected a higher percentage for social appeals in 2000 s. But this same high percentage of personal appeals does not stand for the same implications or value theme choices. While people show the same tendency for good health, happiness and the world view, in 1990s Chinese people care more for personal feelings, 'six fortune' in traditional Chinese culture and material success through perfectness and efficiency. By the time of 2000s Chinese people develop more heroic (or iconic) complex and a broader sense of connection with the world thanks to the development in information technology. They pay more attention to individual selfidentity and social status and want to escape from the urban life and return to nature. The lower level of social appeal in 2000 s is by no means accidental. They conform to the present Chinese condition where majority of people DO not consider it their top priority for 'environmental protection, world welfare, help others, return to society, the so-called philanthropy or charity' (They are defined as social need). Their major focus is still on lifestyle changes, reach-out, connection, relationship/network, collective power and authority. It can be anticipated after more years of economic development in China the social appeals will be the major attention devices or value themes appeared in advertisements. This denotes that the time for 'bigger love' - the highest level of selfactualization which is demonstrated both as philanthropic cause and a deep care for human welfare in China, has not arrived yet because China is still the largest developing country in the world. 
In spite of the fact that there are low percentages of using social appeals, which are at $21 \%, 30 \%$ and $22 \%$ in $1980 \mathrm{~s}, 1990 \mathrm{~s}$ and 2000 s respectively, in terms of key words and value orientations, the advertisers have exhibited ideology and identity differences in three periods of time. The social needs in 1980s are met through consensus need satisfaction of family ties, social get-together, popularity, and new lifestyles while in 1990s social needs are more related to traditional Chinese five-fortunes: love, happiness, friendship, longevity, and smoothness. They are about social relationship/network, acceptance, participation and social recognition and affiliation/belonging. When it comes to 2000 s the social needs demonstrate a dynamic world view and diversified needs satisfaction such as reach-out, freedom, connection, environmental protection, world welfare, help others, being involved and accepted.

To sum up the conclusion for question one, as the explanation shows above linguistically the key words (nouns and verbs) and advertising appeals appeared in 300 advertising copies from 1980 s to 1990 s to 2000 s have exhibited the social cultural changes in China. They have played the dual functions of both instrument and mirror as part of social agents to carry out ideology and identity change in China in the last 30 years.

\subsubsection{Findings Related to Question Two}

With regard to second research question, it is concerned with what pictorial metaphors can one be ascertained from the sample illustrated print advertisements in three different developmental periods in China and what are the systematically identifiable pictorial metaphors and frequently appeared image groups that can show ideology (value orientation) and identity (visual scripts as group behavior pattern) 
changes in China in the last three decades? The research findings in chapter three and appendix II have demonstrated that 1) with regard to semiotic image categories (appearance, manner, activities and settings/props used), the result shows the tendency that China is increasingly becoming a male-dominated society with a big increase in using male images from 1980 s to 2000 s and in particular adult male images. Semiotically the representational images in the ads show a decline in intimacy but an increase in positional communication. The social setting is the dominant advertising background for all the three periods. 2) With regard to the typical types of metaphorical images that are used as signifieds or secondary subjects to be projected or mapped onto the signifiers or primary subjects, there is a decline in using human images as opposed to non-human images. The dominant metaphorical image types used in three periods are in concomitant with or comply with the ideology and identity needs of each specific period of time.

First, with regard to semiotic image categories of human images (96 altogether) I have found out that despite being defined as a highly collective society by Dutch anthropologist Hofstede, the result of more single person pictures $(71 \%, 67 \%$, and $43 \%$ respectively) than group pictures as is shown in the table II-5 denotes the opposite from what I have expected. Meanwhile, it is not clear whether the gradual increase in the percentage of group pictures means China is becoming more collective or it is out of the need of drama (story-telling) design of the advertising execution technique that requires more group image in the advertisements. However, one thing is clear and proved that semiotically the dramatic increase in percentage of using more male images than female figures appeared in the advertisements from $20 \%$ in 1980 s to $92 \%$ in 2000 s shows that China is becoming increasingly a male-dominated society. The choice of more middle- 
aged male person than the youth or female person to represent the product shows on the one hand the economic power is concentrated on the middle-aged man and on the other hand consumers tend to trust and identify themselves more with the successful male images for their maturity and authority image in different levels of Chinese society. This is especially true when it comes to the promotion of big-ticket items or durable products. The advertisements in 2000 s tend to use more complete body size than the partial upper body or close-up faces or heads. This is out of the need for more complicated story telling and interactive and involving discourse effects.

It is shown very clearly in the table II-6 that almost two thirds of 1980 s human images carry natural or smiling facial expressions in contrast to only one third doing the same in 2000s. Most of the human figures in 2000s advertisements carry artificial, serious, motionless or cool facial expressions. If eye contact is a symbol of warmth and friendliness in a society, then 1990s seems to indicate this inclination with 83 percent of human images showing eye contact. Due to the limited skill and low level of advertising execution most of the early period advertisements (1980s) have their images posed in an either artificial or exaggerated manner and the relationship between the primary subject and the secondary subject seems to be imposed rather than a natural one. 1990s advertisements have more natural poses than artificial ones. 2000 s advertisements strike a balance between the artificial and natural poses.

In general nowadays Chinese society becomes less communal and more distanced or indifferent in terms of human intimate relations where people used to know and care about what their neighbors are doing although Chinese people join electronic communities on the internet with strangers. This tendency is shown very clearly on the 
table II-7 that the touch and intimacy level become increasingly lower when the bubble space between human image and product or the bubble space among human images become bigger. In 1980s the representational images appearing in the advertisements stay close to each other in group pictures with body touch whereas this kind of intimacy of human images together is rarely seen. It indicates the eventual disappearance of the product or a complete separation between the actual product and the endorsers. Sophisticated customers/viewers do not have to see the actual use of the product by the endorsers in the advertisements and still are able to understand the benefits of the product through abstract association and analogy. This is in line with the high percentage of metaphorical images in 2000 s $(99 / 100)$. The body movement illustrates the similarity between 1980 s and 2000 s which all use interactive style to emphasize the process of using the product. The positional communication relationship is rather consistent throughout all the three periods with representational images or figures (such as celebrity endorsers) as the primary foci and the products as the secondary subordinates. This is not a unique feature of Chinese advertisements. It is actually in line with Adorno's assertion that the real benefits and original point of use value of a product can never be reached, to be replaced by the exchange value, which is the analogy of using menu to replace food.

The statistical results for most frequently used settings are rather consistent as is shown in the table II-8. They all have about 40 percent of non-identifiable props. Out of the $60 \%$ identifiable props, the most often used settings for all the three periods are social scenes, showing a total rise of $7 \%$ from $19 \%$ in 1980 s to $21 \%$ in 1990 s to $26 \%$ in 2000 s. This shows that Chinese people love to socialize either in restaurants, shopping centers or natural environment. They enjoy/party themselves as city dwellers on any kind of 
weekend retreat. What draws our attention is the decreasing use of working props at $7 \%$ in 2000 , only half of the working settings in 1980 s and even less than half in 1990 s at $14 \%$ and $17 \%$ respectively. This decrease of working scene is compensated by the increase of natural props in $2000 \mathrm{~s}$, which stands at $20 \%$ compared to $14 \%$ and $12 \%$ in 1980s and 1990s. Does that show a willingness of returning and being close to nature when Chinese people are faced with ever-increasing pressure and competition in their daily lives? Another interesting point is the gradual decline of the use of family scene from $12 \%$ in 1980 s to $8 \%$ in 1990 s and to $7 \%$ in 2000 s. Does this mean that Chinese people pay less attention to family values? This may not be true because another explanation could be that Chinese families have turned to natural scenes or social scenes for family activities such as traveling together or eating out rather than just staying at home.

Secondly, with regard to the typical types of metaphorical images that are used as signifieds or secondary subjects to be projected or mapped onto the signifiers or primary subjects, as the table 4.7 shows, in 1980 s the dominant metaphorical images are human images (women, group pictures and men), which accounts for 60 percent whereas in 1990s tradition, men and daily necessity images become the dominant metaphorical image type, which accounts for 45 percent. When it comes to 2000 s the dominant metaphorical image types used by advertising agencies become a balanced spread out of group image, modern convenience, animal, daily necessity, tradition, and nature, with each type accounting for 11 to 14 percent. As explained and elaborated in chapter four, I have found that in general the choice of the metaphorical images used in the advertisements in each period complies with or serves the need and purpose of the 
ideology and identity changes in each specific period in China. These widely publicized commercial advertisements can be successful because advertising designers have successfully created consensus on person schemas and event schemas (coherent clusters of information stored in people's memory serving as 'interpretative frameworks') and make these schemas become everyone's desirable self-schemas (recognized selfidentity). The advertising agencies are able to organize the addressee's responses to all elements (both verbal and pictorial) in the advertisements towards the intended interpretation and meaning of the advertisements and it considerably narrows down the number of potential interpretations.

\subsubsection{Findings Related to Question Three}

To answer the third research question, based on the linguistic and semiotic data as is evidenced in chapter three and the CMA or ideology and identity change analysis as evidenced in chapter four, I have illustrated convincingly that on the whole illustrated print advertisements in mainland China from 1979 to 2008 , implicitly or explicitly, has served the evolving ruling and dominant ideology very well. Through the lens of advertisements (which include texts and pictures), taking advertisements' metaphorical nature and instrumental mission or rationality into consideration, I also demonstrate how ideology and social identity changes of China in the last 30 years have taken place and to what extent they are coherent with and conform to the overall social (re)construct and social change.

From 1979 to 1988 the dominant ideology of 'making economic construction as the core' shapes the bandwagon effect and the value themes of advertisements in China, thus the promotion of consumption and getting rich have become a legitimate activity rather 
than the class struggle and egalitarianism as previously promoted in Mao Zedong's era. The general metaphorical image pattern in this period for the promotion of rational consumption activity is a feminist 'smiling beauty + quality'. In 1990s the ruling and dominant ideology to deal with the complex social and political environment at that time has changed from 'economic ideology' to 'national ideology', of which the promotion of national pride and individual (men's) success has become a legitimate activity rather than the women beauty and getting rich previously promoted in Deng Xiaoping's era. The general metaphorical image pattern in this period for the promotion of personal consumption as the legitimate activity is a masculine 'traditional fortune culture + material success.' Twenty years after China's reform and open-up policy, the ruling and dominant value-orientation that needs to be promoted in 2000 s has changed again from 'national ideology' to 'scientific and harmonious ideology' as Hu Jintao has said China must uphold a ideology of scientific development and construct a harmonious society, thus the promotion of consumption as a legitimate activity is done through balanced use of metaphorical image types of tradition vs. modern, western vs. eastern, nature vs. urban, the young vs. the middle aged. The general metaphorical image pattern in this period for the promotion of personal consumption as the legitimate activity is a balanced 'harmonious society + heroic individualism.'

While weaving the main thread of "making economic construction as the core and legitimate activity' by using most up-to-date shifting value orientations, it is proved that the representational metaphorical image groups in three different periods help 'manipulate' and 'administer' mass consumers towards the desired value orientations by making them identify themselves with the most up-to-date icons and celebrities through 
symbolic associations. The group behavior under the influence of mass psychology of 'keeping up with the Joneses' and 'jumping onto the bandwagon' and 'being IN rather out OUT' have been the main personal or group identity tools to make people obey and lose the capacity for reflection. As Adorno states at the conclusion of the section on the culture industry in Dialectic of Enlightenment "The triumph of advertising in the culture is that consumers feel compelled to buy and use its products even though they see through them" (Adorno, 1973, p. 167). The process of objectification (to replace use value with exchange value) and subjectification is realized through obliging moral obligations by self-disciplined individuals who care about social status and material success; therefore, "rational self-interest as normally understood is pushed to extremes so as to become irrational" (Bernstein, 1991, p. 13).

It can be seen from identity analysis in chapter four of how individual consumers transform themselves from political self to material social self in $1980 \mathrm{~s}$, from material social self to national cultural self in 1990s, and from national cultural self to a individualized my self. The common denominators in three periods have shifted from smiling beauties and happy families in 1980 s, to strong man and fortune tradition in 1990s, to multi-tasking heroes, cool instinctive youngsters and sport stars in 2000 s. The symbolic associations through projected features or entailments of the metaphorical images, however, remain the same throughout the three periods: I belong to this group of people (I am IN rather than OUT) if I identify myself with these people and buy the products or services they own or use.

We can conclude the socially-constructed reality and the dramatic social cultural changes in the last 30 years in mainland China have been both reflected and carried 
forward by the ever rising importance of advertising industry and powerful media. The same as Adorno's critic on cultural industry, advertising has illusory and objectifying nature as well (to treat unlike things as like, unequal things as equal). The real original promise is not even on offer. The promissory note is in reality all that is on offer, making the original promise illusory (Bernstein, 1991, pp. 10-11). The audience of the advertisement must be satisfied with exchange value rather than use value, as the diner must be satisfied with the menu rather than food. The audiences of the advertisements realize both the instrumental/irrational nature (thus to destroy reasoning and reflection) and manipulating and subjectifying nature but still follow through self-discipline and moral obligation, taking the buying behavior as trend setting ('seeing through but still obeying'). This effective process of manipulating and subjectifying consumers in following advertisements is similar to the effective process of manipulating and subjectifying audience in cultural industry.

Despite being critical and interpretive during the data analysis process so that the true nature of advertisements and its instrumental functions can be exposed; the three research questions can be answered; and the working hypothesis tested, I firmly believe that the collective and large sample data analysis of Chinese advertisements can give a relatively objective account to China's overall economic, social and cultural development. It holds to be true also that the accurate data description and the critical interpretation can hardly be done without a savvy understanding of the sign situation from which the advertising data are drawn. This dissertation was based on the previous research results of other social scientists who summarize the institutional factors for China's strategically 
planned reform in economic field even though I cannot guarantee the absence of personal bias in offering this contextual situation as 100 percent impartial.

\subsection{Theoretical and Practical Implications}

China's dramatic social and cultural changes in the last 30 years are a subject worth exploring and have been studied and explored from many different angles and perspectives. A critical metaphor analysis of illustrated print advertisements in China offers a new perspective and a new trans-disciplinary approach to look at these changes in a relatively objective way. This approach has attempted to make systematic theoretical inquisition into cognitive metaphor and visual cultural theory and systematic practical application of critical discourse analysis and pictorial metaphor analysis, all combined into advertising as a media discourse, a communication means and a business vehicle. A discussion of the changing advertising themes/appeals and conceptual metaphors involved in relation to the macro-social structures and the underlying ideologies and identity changes in the past three decades has not only added empirical evidence to the conceptual metaphor theory and critical discourse and pictorial metaphor analysis method, but also has expanded the research angle for the issue of social cultural change from a new perspective of advertising as discourse. It is hoped that the present study could contribute to the theoretical and methodological development of social-cultural studies as well as to the effort of advertising study as a pictorial metaphor.

First, this dissertation contributes to the conceptual metaphor theory of cognitive linguistics by offering evidences to support Lackoff and Johnson's argument that metaphor is not just a rhetorical device but a way of thinking. In the monograph Metaphors We Live By (1980), cognitive linguists Lakoff and Johnson suggests that 
metaphor is a matter of understanding one thing in terms of another. The typical form is TARGET-DOMAIN IS SOURCE-DOMAIN, or, TARGET-DOMAIN AS SOURCE DOMAIN. With the analysis of metaphorical expressions, their entailments and metaphorical images of 300 sample advertisements in three decades it is shown how Chinese advertising people think about the society and help construct the society by using cultural-bound metaphors to express the meaning elements. The conceptual change and cultural change of Chinese society and people in the last 30 years can be seen and reflected from the metaphorical statements, some of them are cultural-universal while many of them are cultural-specific metaphors unique to Chinese tradition and conventions. The extensive use of legendary figures, historical architectural buildings and cultural relics, and 'fortune' culture has fit in the person schema or event schema of older-generation advertising audience and made them feel inclusive and belonged. The extensive use of popular culture stars such as Spiderman and sport stars and modern lifestyle has fit in the person schema or event schema of the younger generation advertising viewers and made them feel a shared part of the fashion trend. Therefore the conceptualization of abstract categories or the cognitive models of abstract phenomena such as consumer culture and ideology and identity changes are grounded on the basic experiences and become an essential part of the experimental view of language. The 300 sample advertisements and their illusive nature to social cultural changes bring evidences to the concept of entailments of metaphor: the connections through the resemblance, causal link and analogy that metaphors bring to mind that determine its power and richness. They explain that metaphor and thought, as well as metaphor and culture, share inner consistency between each other. 
Second, this dissertation contributes and acts as a side effect to Fairclough's Critical Discourse Analysis. The research has proved with linguistic and semiotic evidences and through the critical analysis of the advertising discourse in chapter three and four that not only the various parts of society are interrelated but also the social discourse and the society are interrelated. When one part of society changes, e. g. economic condition, other parts of society and the social discourse must also change accordingly. Therefore cultural phenomena from which advertisements borrow heavily as the creative idea fountain should not be looked at in isolation from economic, political and religious conditions of that given society. As I have demonstrated systematically in chapter three and explained in chapter four that, in paralleled with the CDA, the aim for CMA is to identify the particular linguistic, semiotic and 'interdiscursive' features of advertisement 'texts' and give accounts of the ways which are a part of processes of social change. It has also proved that social changes are relation changes in discourse and changes in other, non-discousal elements or 'moments' of social life. During the 30 years of 'reform and open up' to the outside world human relations and class relations in China have changed dramatically with the emergence of newly rich, professional white-collared class and blue-collared salary class. This reshuffle of social classes and economic wealth as nondiscursive elements is definitely reflected in metaphorical images in Chinese advertisements as lifestyle changes and differentiation positioning of the products. In one word, advertising discourse helps '(re)constructs' social life in the processes of social change.

Third, it is my belief that the most important contribution of this dissertation lies in the practice of a new inter-disciplinary or trans-disciplinary approach to advertising as a 
discourse research. It serves as a supplement to Jonathan Charteris-Black's Corpus Approaches to Critical Metaphor Analysis (2004), in which he addresses the rhetorical and ideological role of metaphor in discourse. He proposes a discourse model called Critical Metaphor Analysis (CMA) to analyze metaphors in authentic data. He argues that "Metaphor can only be explained by considering the interdependency of its semantic, pragmatic and cognitive dimensions" (Charteris-Black, 2004, p. 2). He also claims that "covert" and "possibly unconscious" intentions of language users can be revealed through critically analyzing metaphor. I borrow this idea and adopts this method by incorporating Critical Discourse Analysis (CDA), Conceptual Metaphor Theory (CMT) and content analysis to claim logically that 'covert' and 'possibly unconscious' intentions of advertisers and business communicators can be revealed through critically analyzing metaphors embodied in the advertising copies, visual images and symbols of illustrated print advertisements. The research results have shown, the same as political discourse, press report discourse and religious discourse, business discourse such as advertising with words and images carries linguistic, semiotic and other interdiscursive features that can be analyzed by applying Fairclough's CDA approach combined with Conceptual Metaphor Analysis (CMA) by Lakoff and Johnson (1980) and Pictorial Metaphor Analysis (PMA) by Charles Forceville (1996) to account for the contemporary social changes in not only China but many other countries and regions as well. Therefore, CMA of the advertisements in large quantifiable sample data size opens a new ground as a methodological instrument for future researchers who are interested in the study and description of social changes through the lens of advertisements. 
Fourth, this research contributes to the study of advertising as both a discourse and a business communication tool. Most of the previous explorations on social-cultural change in mainland China over the past three decades have primarily been confined to macrosociological studies. Since advertising is not just a commercial activity aiming to make sales, it is also an inseparable part of cultural and reality construction with trendy ideas and symbols integrated into its creation, the present study attempts to go beyond the previous studies by taking a cultural-communicative perspective toward advertising study. As mentioned at the beginning of chapter one by Ogden and Richards (1989), "an account of the process of Interpretation is the key to the understanding of the Signsituation, and therefore the beginning of wisdom," I feel justified to adopt the theory of pictorial or multimodal metaphor using the method of content analysis in communication and critical discourse analysis in linguistics in order to compare and contrast critically the metaphorical construction of 300 popular and award-winning advertisements in newspapers, posters and magazines from 1979 to 2008 . The account of this metaphor interpretation process of quantifiable large sample groups of advertisements in China is clearly illustrated in three separate chapters of four, five and six, each from one perspective of linguistic analysis, semiotic analysis and critical analysis answering the three research questions. The research results as illustrated in previous chapters have proved and confirmed the research hypothesis that advertisements as a communication tool, with its metaphorical nature and instrumental rationality, not only can reflect social cultural changes in a given country in a specific time period but also can reflect social cultural changes in a relatively objective way with a cumulative large size of sample data advertisements. 
This research has also shown the gradual progress of China's advertising industry together with and in the same pace with China's overall economic development. As we can see from the data analysis in the previous three chapters of three, four and five that Chinese advertisements have experienced the evolving changes/progress in both concept creation and artistic execution. The research has demonstrated how the advertising industry has realized the functional changes from a utilitarian function by using informative style language and more functional appeals, of which the sole purpose is to inform product benefits and promote sales, to a ceremonial function by adopting an involving style and interactive style language and more emotional appeals, of which the advertised products have become the symbol of individual personality and group identity. This increasing trend of ceremonial function of advertisements is comparable to Adorno's critic on the ersatz character of the pleasure the culture industry offers the consumers. The real product benefits are not even on offer. In reality it is the representational images (their beauty, achievements, and success stories) that are on offer making the original promise illusory ${ }^{53}$. Everybody knows that even if they buy and use this product they can never reach the stage or point as promised by the representational images. Still people would like to continue this self-deceiving game and keep their fantasy and dream. There is no wonder why John Goodis, the advertising executive, said: “Advertising doesn't mirror how people are acting, but how they are dreaming." The functional change in advertising in China from 1980 s to 2000 s coincides with the historical transition in the west from ascetic mentality to hedonist mentality that reflects the dramatic social and cultural change of China in the last 30 years to quickly become a so-called consumer society. Multiple factors have contributed to this change:

${ }^{53}$ The idea comes from the Dialectic of Enlightenment (1973) translated by John Cumming. London: Allen Lane. P. 139. 
unprecedented economic development, mastery of promotional techniques, hedonistic ethics, the emergence of new spaces and institutions, globalization trend and western cultural influence. During this unprecedented period of 30 years, while Chinese consumers, by and large, remain instrumentally rational being, the natural result of the profound change in ideologies, identities and social relations is evidently and collectively illustrated in the media discourse of advertisements. It has shown a "Veblen", "Bandwagon" and "Snob Effects" 54 which is accompanied by "conspicuous" consumption of being novel or being the first and "status" competition among classes of being luxury and snobbish.

Last but not the least, in terms of communication theory, evidences produced by collective sample advertisements in the last 30 years of China have confirmed partially the correctness of social semiotic theory and social marketing theory in accordance with mass communication theory ${ }^{55}$; advertisers and media institutions in China have assumed the role of benign information provider and have been promoting information deemed by elite sources to be socially valuable. They give increasing attention to audience activity and the need to reach target audience with the information they seek so that target audiences are identified with the slogans and images to their information needs. As a result the advertisers and media institutions in China have used the techniques to increase the effectiveness of mass media-based information campaigns; to effect attitude change and social cultural change by tailoring to situations where powerful elite sources are able

\footnotetext{
${ }^{54}$ Thorstein Veblen's seminal work on the American 'Leisure class' has proposed the notion of conspicuous consumption, while Georg Simmel's celebrated essay on fashion has stressed both the role of status competition among the classes, and the centrality of novelty as a modern, bourgeois cultural value.

${ }^{55}$ Readers who are interested in social marketing theory, please refer to Baran \& Davis, 2003; Goldberg. Fishbein, \& Middlestadt, 1997; Rice \& Atkin, 1989; Rogers, 1983.
} 
to dominate elements of the larger social system and through greater understanding and manipulation of aspects of societal and psychological factors.

In the last 30 years the evolving changes of advertisements together with the changes of ideology and identity in China have confirmed the "cultivation analysis" in that advertising, just like television as a pervasive means of communication, "cultivates" or creates a world view that, although possibly inaccurate, becomes the reality simply because people believe it to be the reality and base our judgments about our own, everyday worlds on that "reality." Even though many researchers have questioned Gerbner's conclusions on the causal link between social reality and television influence that is reflected in his so-called Violence Index and Cultural Indicators ${ }^{56}$ with which he used to measure the effectiveness of television influence, yet no one can deny televisions' impact on our collective sense of reality is real and important, even though that effectiveness may beyond clear-cut scientific measurement. The same logic goes to the present study where the research subject has been changed to another pervasive massmedia content - advertisements. In the present research we are looking at whether the illustrated printed advertisements in China in the last three decades can 'reflect' and 'cultivate' the evolving ideology and identity changes. In what way this "reflection" and "cultivation" process has happened and by giving an account and interpretation of this process, the very nature of advertisements of 'objectification', 'manipulation' and 'subjectification' can be exposed and understood. It has therefore supported and testified the "cultivation analysis" theory from another media angle theoretically.

\footnotetext{
${ }^{56}$ During 1960s and 1970s two national exam inations of the media were undertaken by the National Commission on the Causes and Prevention of Violence in 1967 and 1968 and by Surgeon General's Scientific Advisory Committee on Television and Social Behavior in 1972 respectively. Gerbner as a scientist was involved in both.
} 
What is advertisements' contribution to social reality? In what way advertisements can reflect social and cultural change in China? To what extent printed illustrated advertisements can illustrate the ideology and identity change in China in the last 30 years? Cultivation theorists argue that its major contribution is "cultivation", a cultural process relating "to coherent frameworks or knowledge and to underlying general concepts...cultivated by exposure to the total and organically related world of television rather than exposure to individual programs and selections" (Gerbner, 1990, p. 255). This cultivation occurs in twos ways: the first is "mainstreaming", where, especially for heavier ad viewers; advertisement's symbols in metaphors monopolize and dominate the sources of information and lifestyle ideas about the world. Chinese people, without realization, internalized the social realities promoted in ad campaign and eventually move toward the "mainstream", not a mainstream in any political sense, but a culturally dominant reality that is more closely aligned with advertisement's reality than with any objective reality. The second way cultivation function of advertisement manifests itself is through "resonance", when viewers see things on advertisements that are most congruent with their own everyday realities. In essence, Chinese advertising viewers, the TV viewers in particular, get a "double dose" of cultivation because what they see on the advertisements resonates with their actual lives and they deem to follow the group behavior driven by mass psychology of 'jumping onto the bandwagon' and 'catching up with the Joneses' . To be an outsider and a lagging behind is the worst thing in Chinese 'collective' and 'face' society.

The study of Chinese advertisements as a discourse and communication tools has practical significance for both domestic as well as foreign companies operating in China. 
The implications in advertising design and artistic creation are: first, when advertising agencies are brainstorming and creating advertisements the choices of value theme, the key words, the representational images, and the advertising appeals together with ad message and execution must all be based on careful analysis and study of social and cultural environment (the SIGN situation) and social cultural changes - the fashion trends, bandwagon events and vogue experiences in particular. Then, the analysis result must be compared with or contrast with personal schema and event schema and make them into or matched with specific desirable self-schema of the target market consumers. Finally through the power of mass media and cultivation process the most popular ideology and identity images are embodied and instilled into advertisements in order to attract a large enough viewers and responses from audience thus completing the process of making personal consumption as a self-disciplined and self-fulfilled experience.

The most popular and award-winning advertisements in China in the last 30 years have shown Chinese cultural signs have been widely used in advertising metaphors and metaphorical images in Chinese advertisements. Peking opera masks, paper cuts, tea culture, heaven and earth as one, the legendary figure of monkey king Wukong, the house-known strategist Zhu Geliang, the historical relics of the Great Wall, Yuan Mingyuan Garden, and the Temple of Heaven, Chinese moral teaching of filial piety, preordain, harmony and internal balance and peace as well as idiomatic stories are constantly used signifieds or secondary subjects to be projected upon the signifiers or primary subjects to show the resemblance, the causal connections and analogies between the two. Since China is a country with 5000 years of long written history and with shared common national culture, the implicit idioms and pictorial images used in the 
advertisements can easily arouse the common schema/scripts and interpretations for the implications behind them. Thus Chinese culture can become an advantageous weapon for advertising sponsors to apply. But the advertisements in 2000 s have shown a combination of western, eastern, traditional and modern popular culture. The influence of globalization in fashion idols, professional sport stars, American blockbusters and internet technology can be easily seen but blended into the carefully designed traditional concepts. These global plus local images (glocalization images) are prominent in advertisements of automobile, computer, drink and mobile phone product categories. They target and play to the younger generation consumers who are grown up in the post $80 \mathrm{~s}$ and $90 \mathrm{~s}$ era and are more individualistic and trend-conscious than their collectivist saving parents of 1960 s and 1970 s.

\subsection{Limitations of Content and Critical Metaphor Analysis of the Advertisements}

Researches for social issues and social changes have been conducted from many different perspectives and with many different approaches. This dissertation takes advertisements as the research subjects to look at the social changes in China by doing a critical metaphor analysis of illustrated print advertisements in China. Apart from taking a few representative advertisements in different periods to do a detailed and descriptive analysis as illustrations of sample analysis, I adopt the content analysis methods to go through the linguistic, semiotic and critical analysis to all the 300 sample advertisements to see to what extent a collective large sample advertisements can reflect social and cultural change in a given society in a given periods. The result is convincing enough. However there are many rooms for improvement that need be desired in many respects in this research. 
First, as everyone can see the more inclusive the sample advertisements for research, the more precise and accurate the result will be. Since this research combined the quantitative content analysis with the qualitative interpretative analysis, it is best to enlarge the size of the sample data advertisements and establish a corpus of advertisements in three research periods for comparison. 300 data advertisements with 100 advertisements for each 10-year period are far from being ideal as quantitative data base.

Second, statistically speaking whether the numbers in comparison have the probability level to be effectively and significantly different has to be decided by the statistical figures and facts. This research has not done a complicated statistical analysis to the resulting figures in the tables in chapter four, five and six. This reduces the validity and reliability of the research. However since social cultural research can not be fully understood and demonstrated by numbers as in the scientific research I take this inadequacy as a limitation of the research. There is no a hundred percent correct answer to any humanity issues and questions. I mainly take an explorative and interpretative approach towards the research subjects rather than the empirical approach as used by many other social science researchers.

Third, it will be interesting to do a comparative analysis of Chinese advertisements and American advertisements within the same number of sample advertisements and in the same kind of industry in the same period of time. To what extent the advertising images, metaphorical expressions and advertising slogans reflect national cultural differences and social construct in two different countries. To what extent they are in conformity with or in contrast with the prevalent social and cultural environment. With 
the rise of Internet and popular culture many researchers believe advertisements in media will develop to become diversified and individualistic against the dominant ideology and mainstream value. The group identity and group behavior will tend to be more fragmentary rather than consensus. The present research is limited without taking comparative approach.

Fourth, adopting the approach of critical metaphor analysis to a relatively large sample size of advertisements is a trial experiment and it opens a new field for advertising research, therefore I do not have many prior researches for references. Naturally it has many limitations with regard to the research steps, guiding theories to follow, analyzing anchors and research results even though it does open a new research ground for later researchers to further the advertising study in a comprehensive and transdisciplinary perspectives. 


\section{REFERENCES}

\section{English Sources:}

Adorno, T. W. \& Horkheimer, M. (1973). Dialectic of Enlightenment translated by John Cumming, London: Allen Lane, p. 144. [1947].

Adorno, T. W. (1991). The Culture Industry: Selected Essays on Mass Culture, London: Routledge.

Aitchison, J. (1999). Cutting Edge Advertising, Prentice Hall, Singapore.

Althusser, L. (2003). Ideology and Ideological State Apparatuses. In Mirzoeff, N. (Eds.) The Visual Culture Reader $2^{\text {nd }}$ ed. London: Routledge.

Andren, G. et al. (1978). Rhetoric and Ideology in Advertising, Stockholm: Liber Forlag. Arnheim, R. (1969). Visual Thinking, Berkeley: The University of California Press. . (1974). Art and Visual Perception, Berkeley: The University of California Press revised and expanded edition. . (1988). The Power of the Center, Berkeley: The University of California Press.

Baran, S. J. \& Davis, D. K. (2003). Mass Communication Theory: Foundations, Ferment, and Future, Wadsworth: a division of Thomson Learning, Inc.

Barker, C. (1999). Television, Globalization, and Cultural Identities, Philadelphia, PA: Open University Press.

Barthes, R. (1972). Mythologies, Hill \& Wang, a division of Farrar, Straus Giroux [1957].

Barthes, R. (1964). The Rhetoric of the Image. In Image-Music-Text (1977), London: Fontana.

Baudrillard, J. (1981). For a Critique of the Political Economy of the Sign, London: Telos Press, [1972]. . (1981). Simulations, New York: Semiotexte [1981]. . (1996). System of Objects, London: Verso [1968]. 
. (1997). Objects, Images and the Possibilities of Illusion. In M. Zurbrugg (Eds.) Jean Baudrillard, Art and Artefact, London: Sage. (1998). The Consumer Society: Myths and Structures, London: Sage [1970].

Beijk, J. \& Van Raaij, W. F. (1989). Schemata: Information Processing, Persuasion Strategies and Advertising, Amsterdam: VEA.

Benson, P. J. (1997). Problems in Picturing Text: A Study of Visual/verbal Problem Solving. Technical Communication Quarterly, 1997, 6 (2): 141-160.

Berelson, B. (1952). Content Analysis in Communication Research, Glencoe, Ill: Free Press.

Berger, J. (1972). Ways of Seeing, London: British Broadcasting Association and Penguin. Bernstein, J. M. (1991). Theodor W. Adorno The Culture Industry-Selected Essays on Mass Culture, London \& New York: Routledge.

Black, M. (1962a). Models and Metaphors, Itaca, N.Y.: Cornell University Press.

Bonvillain, N. (2003). Language, Culture, and Communication - the meaning of messages, $4^{\text {th }}$ ed. New Jersey: Prentice Hall.

Budd, R.W., Thorp, R.K., \& Donohew, L. (1967). Content Analysis of Communications, New York: The Macmillan Company,

Butler, J. (2003). Prohibition, Psychoanalysis and the Heterosexual Matrix. In N. Mirzoeff (Eds.). (2003). The Visual Culture Reader, $2^{\text {nd }}$ ed. London: Routledge.

Caillat, Z. \& Mueller, B. (1996). Observations: the Influence of Culture on U.S. and British Advertising: An Exploratory Comparison of Beer Advertising. Journal of Advertising Research, 1996 (36:3): 79-88.

Calhoun, C. (2002). Social Identity Theory. In Dictionary of the Social Sciences in Politics and Social Sciences, UK: Oxford University Press, Inc. Internet Explorer. www.oxfordreference.com (16 June 2003).

Cameron, L. (2003). Metaphor in Educational Discourse, New York: Continuum.

Caves, R. E. (1967). American Industry: Structure, Conduct, Performance, Englewood Cliffs, N.J.: Prentice Hall.

Cheng, H. (1997). Toward an Understanding of Cultural Values Manifest in Advertising: A Content Analysis of Chinese Television Commercials in 1990 and 1995. Journalism Quarterly, City University of Hong Kong. 
Chouliaraki, L. \& Fairclough, N. (1999). Discourse in Late Modernity: Rethinking Critical Discourse Analysis, Edinburgh: Edinburgh University Press.

Clancy, J. J. (1989). The Invisible Powers: the Language of Business, Toronto: Lexington Books.

Clark, W. (2004). Human and Culture, Beijing: Commercial Press.

Cook, G. (2001). The Discourse of Advertising, $2^{\text {nd }}$ ed. London \& New York: Routledge.

Deely, J. (1990). Basics of Semiotics, Bloomington: Indiana University Press.

Desrochers, S., Andreassi, J., \& Thompson, C. (2002). Identity Theor: A Sloan Work and Family Encyclopedia Entry, MA: Boston College.

Doctoroff, T. (2007). Billions: Selling to the New Chinese Consumer, Shanghai: Orient Publishing Center.

Dondis, D. A. (1973). A Primer of Visual Literacy, Massachusetts: MIT Press.

Duranti, A. (1997). Linguistic Anthropology, London: Cambridge University Press.

Dyer, G. (1982). Advertising as Communication, London \& New York: Routledge.

Elliott, B. B. (1962). A History of English Advertising, London: London Business Publications Ltd.

Fairclough, N. (1989). Language and Power, $2^{\text {nd }}$ ed. New York: Pearson Education Ltd. . (1992a). Critical Language Awareness, New York: Longman Group UK Limited. . (1992b). Discourse and Social Change, $4^{\text {th }}$ ed. Cambridge: Polity Press. . (1995a). Critical Discourse Analysis: The Critical Study of Language. London: Longman. . (1995b). Media Discourse, London: Edward Arnold. . (2003). Analyzing Discourse-Textual Analysis for Social Research. London: Routledge.

Fina, A. D., Schiffrin, D., \& Bamberg, M. (Eds.). (2006). Discourse and Identity, Cambridge: Cambridge University Press.

Fiske, J. (1989). Understanding Popular Culture, London \& New York: Methuen (1990). Introduction to Communication Studies, $2^{\text {nd }}$ ed. New York: Routledge.

Forceville, C. (1996). Pictorial Metaphor in Advertising, London and NY: Routledge.

Foucault, M. (1978). History of Sexuality, Vol. 1, Harmondsworth: Penguin [1976]. 
. (1983). The subject and power. In H.L. Dreyfus \& P. Rabinow (Eds.). Michel

Foucault: Beyond Structuralism and Hermeneutics, Chicago: University of Chicago Press.

. (1988). Techniques of the Self. In L. H. Martin et al. (Eds.). Technologies of the Self. A Seminar with Michel Foucault, London: Tavistock.

. (1990). The Archaeology of Knowledge and the Discourse on Language, New York: Random House.

Fowler, R. (1991). Language in the News: Discourse and Ideology in the Press, London: Routledge.

Frank, J. (1985). Advertising, Macdonald \& Evans.

Geach, P. (1972). Logic Matters, Oxford: Basil Blackwell.

Gee, J. P. (2000). An Introduction to Discourse Analysis: Theory and Method, Beijing: Foreign Language Teaching and Research Press.

Geis, M. (1982). The Language of Television Advertising, New York: Academic Press.

Gieszinger, S. (2001). The History of Advertising Language: the Advertisements in the Times from 1788-1996, Peter Lang.

Goddard, A. (1998). The Language of Advertising: Written Texts, London and New York: Routledge. Goffman, E. (1979). Gender Advertisements, Cambridge and MA: Harvard University Press.

Goldman, R. (1992). Reading Ads Socially, London: Routledge.

Gombrich, E. H. (1963). Meditations on A Hobby Horse and Other Essays on the Theory of Art, London, UK: Phaidon.

Gumperz, J. J. (Eds.). (1982). Language and Social Identity (Studies in interactional sociolinguistics), Cambridge University Press.

Griffin, E. A. (2004). A First Look at Communication Theory, $5^{\text {th }}$ ed., Boston: McGrawHill Companies, Inc.

Hall, E. T. (1990). The Silent Language, New York: Anchor Books, A Division of . Random House, Inc.

Hall, S. (1997a). Introduction. In S. Hall (Eds.). Representation: Cultural Representations and Signifying Practices, London: Sage, 1-12. 
. (1980). Encoding/decoding. In S. Hall, D. Held, \& T. McGrew (Eds.). Media,

Culture, Language, London: Hutchinson, 128-38.

Hartley, J. (1996). Popular Reality, London: Edward Arnold.

. (1999). The Uses of Television, London: Routledge.

. (2002). Communication, Cultural and Media Studies - the Key Concept, $3^{\text {rd }}$ ed.

London and New York: Routledge.

Harvey, D. (1996). Justice, Nature and the Geography of Difference, Oxford: Blackwell.

Harwood, J. (2006). Communication as Social Identity. In G. J. Shepherd, St. John, J.

Jeffrey, \& T. Striphas, (Eds.). Communication As... Perspectives on Theory. London: Sage Publication, Inc.

Haslam, A. S. (2001). Psychology in Organizations - The Social Identity Approach, London: Sage Publications Ltd, Chapter 2: The Social Identity Approach, pp. 26-57.

Hay, J. (1989). Advertising as a Cultural Text (Rethinking Message Analysis in a

Recombinant Culture). In B. A. Dervin, L. Grossberg, B. J. O'Keefe, \& E. Wartella

(Eds.). Rethinking Communication: Paradigm Exemplars, Volume 2, Newbury Park, CA: Sage.

Hermerén, L. (1999). English for Sale: A Study of the Language of Advertising, Lund:

Lund University Press.

Hermes, J. (2005). Re-reading Popular Culture, Blackwell Publishing Ltd.

Hoffman, E. (1979). Gender Advertisements, Cambridge, MA: Harvard University Press.

Hofstede, G. (1997). Cultures and Organizations: Software of the Mind, The Netherlands: McGraw-Hill.

. (1984). Cultural Consequences: International Differences in Work-Related

Values, The Netherlands: McGraw-Hill.

Hoopes, J. (1991). Peirce on Signs, Chapel Hill NC: The University of North Carolina

Press.

Inglis, F. (1972). The Imagery of Power, London: Heinemann.

Jakobson, R. (1960). Concluding Statements: Linguistics and Poetics. In Sebeok, T.

(Eds.). Style in Language, Cambridge, Massachusetts: MIT Press.

Jhally, S. (Ed) (1987). The Codes of Advertising: Fetishism and the Political Economy of Meaning in the Consumer Society, New York: St. Martin's. 
Jian, W. (2000). Foreign Advertising in China: Becoming Global, Becoming Local, Iowa State University Press.

Jonathan, B. (1997). Introduction to Semiotics, Manchester: Manchester University Press. Jonathan Charteris-Black. (2004). Corpus Approaches to Critical Metaphor Analysis, New York: Palgrave MacMillan.

Kress, G. \& Van Leeuwen, T. (1996). Reading Images: The Grammar of Visual Design, London: Routledge.

Krippendorff, K. (1961). Content Analysis: An Introduction to Its Methodology, West Port, CT: Greenwood Press.

Lacan, J. (2003). Four Fundamental Concepts of Psychoanalysis. In Mirzoeff, N. (Eds.). The Visual Culture Reader, $2^{\text {nd }}$ ed. London: Routledge.

Leech, G. N. (1966). English in Advertising: A Linguistic Study of Advertising in Great Britain, London: Longman.

Lakoff, G. \& Johnson, M. (1980). Metaphors We Live By, Chicago: University of Chicago Press.

Lester, P. M. (2003). Visual Communication: Images with Messages, $3^{\text {rd }}$ ed. Wadsworth: A Division of Thomson Learning Inc.

Mac Cormac, E. R. (1985). A Cognitive Theory of Metaphor, Cambridge, Mass.: MIT Press.

Marchand, R. (1985). Advertising the American Dream, Making Way for Modernity, 1920-1940, Berkeley: University of California Press.

Marx, K. (1973). Grundrisse: Foundations of the Critique of Political Economy, London: Penguin [1857]. . (1974). Capital, Vol. I, London: Allen and Unwin [1867].

McLellan, D. (1995). Ideology $2^{\text {nd }}$ Ed. Minneapolis: University of Minnesota Press. (Chapter $2 \& 3$ on Marx and Marxists, 2-30).

McLuhan, M. (1951). The Mechanical Bride, London: Routledge \& Kegan Paul. . (2003). Woman in a Mirror. In N. Mirzoeff (Eds.) The Visual Culture Reader, $2^{\text {nd }}$ ed. London: Routledge.

McLuhan, M. \& Fiore, Q. (1967). The Medium Is the Massage, New York: Bantam Books. 
McQuail, D. (1987). Mass Communication Theory: An Introduction, London: Sage Publications. . (2000). McQuail's Mass Communication Theory, London: Sage Publications.

McQuarrie, E. F \& Mick, D. G. (1999). Visual Rhetoric in Advertising: Text-Interpretive, Experimental, and Reader-Response Analyses. Journal of Consumer Research, Vol. 26, June 1999.

Merrin, W. (2005). Baudrillard and the Media: a critical introduction, Cambridge and Malden: Polity Press.

Miller, T. (1993). The Well-Tempered Self: Citizenship, Culture, and the Postmodern Subject, Baltimore: John Hopkins University Press. . (2006). A Companion to Cultural Studies, Blackwell Publishing Ltd.

Millum, T. (1975). Images of Women: Advertising in Women's Magazines, London: Chatto \& Windus.

Milner, A. \& Browitt, J. (2002). Contemporary Cultural Theory: An Introduction, London \& New York: Routledge.

Mirzoeff, N. (1998). What Is Visual Culture? In N. Mirzoeff(Eds.). The Visual Culture Reader, London: Routledge. . (1999). An Introduction to Visual Culture, London: Routledge. . (Eds.). (2003). The Visual Culture Reader $2^{\text {nd }}$ ed. London: Routledge.

Muller, W. G. \& Fischer, O. (Eds) (2003). From Sign to Signing-Iconicity in Language and Literature, Amsterdam/Philadelphia: John Benjamins Publishing Company.

Munk, N. (1998). Why Women Find Lauder Mesmerizing. Fortune, May 25, 1998.

Myer, G. (1994). Words in Ads, Arnold.

Ogden, C.K. \& Richards I. A. (1989). The Meaning of Meaning: A Study of the Influence of Language upon Thought and of the Science of Symbolism, San Diego \& New York: A Harvest/HBJ Book Harcourt Brace Jovanovich, Publishers.

Ogilvy, D. (1964). Confessions of an Advertising Man, London: Longman. . (1983). Ogilvy on Advertising, New York: Random House Inc.

O'Guinn, T. C. er al (1998). Advertising, Dalian: Northeast University of Finance and Economics Press.

Ortony, A. (1979). Metaphor and Thought, London: Cambridge University Press. 
Peirce, C. S. (1960). Collected Papers of Charles Sanders Peirce, Volume 2. In C. Hartshorne and P. Weiss (Eds.). Cambridge, MA: Harvard University Press.

Politz, A. (1979). On the Origin of Space Perception. Philosophy and Phenomenological Research 40, December 1979: 258-264.

Riffe, D., Lacy, S., \& Fico, F. G. (1998). Analyzing Media Message: Using Quantitative Content Analysis in Research, Mahwah, NJ: Lawrence Erlbaum Associates.

Rose, G. (2005). Visual Methodologies - An Introduction to the Interpretation of Visual Materials, London: Sage Publications.

Samuel R. L. (1988). Metaphoric Worlds: Conceptions of a Romantic Nature, New Haven: Yale University Press.

Sassatelli, R. (2007). Consumer Culture: History, Theory and Politics, London: Sage Publications Ltd.

Scott, L. M. (1994). Images in Advertising: The Need for a Theory of Visual Rhetoric. Journal of Consumer Research, Vol. 21 September 1994.

Shepherd, G. J., St. John, J., \& Striphas T. (Eds.). (2006). Communication as-: perspectives on theory, Thousand Oaks: Sage Publications Ltd.

Simpson, P. (1993). Language, Ideology and Point of View, London/New York: Routledge.

Singletary, M. (1994). Mass Communication Research: Contemporary Methods and Applications, New York \& London: Longman Publishing Group.

Sperber, D. \& Deirdre W. (1995). Relevance: Communication and cognition, $2^{\text {nd }}$ ed. Oxford: Blackwell [First ed. 1986].

St. Clair, R. N. (2002). The Major Metaphors That Constitute European Thought Growth, Dramaturgy, Machine, Game, Language as Form, Time and Space, University of Louisville Press. . (2004b). Visual Metaphor, Cultural Knowledge, and the New Rhetoric. Chapter 8 in J. Reyhner et alia. (Eds.). Learn in Beauty: Indigenous Education for a New Century, Flagstaff, Arizona: Northern Arizona State University. . (2006). The Framing of Culture: Interdisciplinary Essays on Culture Theory, Beijing Foreign Studies University. 
Steen, G. (1994). Understanding Metaphor in Literature: An Empirical Approach, New York: Longman.

Stephan, D. (2000). Branding in Asia, Chichester: Wiley.

Stigler, G. J. (1961). The Economics of Information. Journal of Political Economy, June 1961, 213-220.

Tajfel, H. \& Turner, J. C. (1986). The Social Identity Theory of Inter-group Behavior. In S. Worchel and L. W. Austin (Eds.). Psychology of Intergroup Relations, Chigago: Nelson-Hall.

Tanaka, K. (1994). Advertising Language: A pragmatic approach to advertisements in Britain and Japan. London \& New York: Routledge.

Toffler, A. (1970). Future Shock, NY: Random House.

Turner, E. S. (1965). The Shocking History of Advertising, Harmonds-worth: Penguin.

Turner, J. C. (1982). Towards a Cognitive Redefinition of the Social Group. In H. Tajfel (Eds.). Social Identity and Intergroup Relations, Cambridge: Cambridge University Press.

Turner, M. (1987). Death Is the Mother of Beauty: Mind, Metaphor, Criticism, Chicago: University of Chicago Press.

Tyson, L. (1999). Critical Theory Today-A User-Friendly Guide, New York and London: Garland Publishing, Inc.

Van Dijk, T. A. (1988a). News as Discourse, Hillsdale, N. J.: L. Erlbaum Associates. . (1988b). News Analysis: Case Studies of International and National News in the Press, Hillsdale, N. J. L. Erlbaum Associates. . (1993). Principles of critical discourse analysis. Discourse \& Society, 4(2).

Vestergaard, T. \& Schrøder, K. (1985). The Language of Advertising, Oxford: Blackwell.

Volosinov, V. N. (1973). Marxism and the philosophy of Language, Cambridge, MA: Harvard University Press. [1923].

Wang, Mingyu \& Song Yao (2003). The Study of Semiotics in the Last Two Decades in China. Journal of Foreign Languages.

Wang, Mingyu (2004). Linguistic Semiotics from the Semiotic Perspective. Journal of PLA University of Foreign Languages.

Weber, R. P. (1985). Basic Content Analysis, London: Sage. 
Wernick, A. (1991). Promotional Culture: Advertising, Ideology and Symbolic Expression, London: Sage.

Wheeler, D. R. (1988). Content Analysis: An Analytical Technique for International Marketing Research. International Marketing Review, 1988(5:4): 34-40.

Williamson, J. (1978). Decoding Advertisements: Ideology and Meaning in Advertising, London: Marion Boyars.

Williams, R. (1977). Marxism and Literature, Oxford: Oxford University Press.

Williams, R. (1980). Advertising: Magic System. In R. Williams (Eds.). Problems in Materialism and Culture, Selected essays. London: Verso.

Wodak, R. \& Meyer, M. (2001). Methods of Critical Discourse Analysis, London: Sage Publications.

\section{Chinese Sources:}

(Note: The translation of the sources below is done by the dissertation author) 鸿捷蕴. 中国大陆的文化价值研究：以 2004 年网络广告内容分析为例, 现代传 播, 2004 年第 5 期。

(Feng, Jieyun. (2004). The Study of Cultural Values in Mainland China: Taking Internet Advertisements of 2004 as Examples. Modern Communications, 2004, Vol.5).

顾亚奇, 常仕本, 章晓宇. 伟大的历程 中国改革开放 30 年小信出版社 2008 年.

(Gu, Yaqi, Chang, Shiben, Zhang, \& Xiaoyu (2008). The Great Journey-A Record of 30 Years of China's Reform and Open-up, China CITIC Press).

关信平主编. 中国改革开放 30 年【关键词】1978-2008 湖南人民出版社 2008 年.

(Guan, Xinping Chief editor. (2008). A Dictionary of Key Words-A Record of Major Events in China's 30 Years of Reform and Open-up from 1978 to 2008, Hunan People's Press).

胡壮麟. 认知隐喻学 北京: 北京大学出版社 2004 年

(Hu, Zhuanglin (2004). Cognitive Metaphor, Beijing: Beijing University Press). 黄合水主编, 雷莉副主编. 品牌与广告的实证研究北京大学出版社 2006 年. (Huang, He Shui \& Lei, Li (2006). Empirical Research on Brand and Advertising, Beijing: Peking University Press). 
蒋原伦. 传统的界限 符号、话语与民族文化, 北京师范大営出版社, 1:88年

(Jiang, Yuanlun (1998). The Boundary, Sign, Discourse, and Folk Culture of Tradition, Beijing: Beijing Normal University Press).

刘立宾, 丁俊热, 黄升民. 《IAI 中国广告作品年鉴》中国传媒大学出版社: 2007 年

(Liu, Libin, Ding, Junjie, \& Huang, Shengmin (2007). LAI China Advertising Yearbook 2007 Beijing: China Media University Press).

刘立宾. 中国广告猛进史华夏出版社. 2004 年

(Liu, Libin (Chief Editor) (2004). Accelerated Growth of China's Advertising Industry from 1979 to 2003. Huaxia Publishing House).

潘杫伟主编李友梅等著.中国社会生活的变迁中国大百科全书出版社 2008 年.

(Pan, Shiwei \& Li, Youmei (chief editors) (2008). The Evolving Changes in China's Social Life-Series of Commemorating 30 Years' Reform and Opening up Policy, China Encyclopedia Press).

宋尤书王纯菲主编 高凯征主审.广告文化学一广告语社会互动的文化阐释长沙: 中南大学出版社 2004 年 5 月

(Song, Yushu \& Wang, Chunfei (2004). Advertising and Culture - a cultural interpretation to the interaction between advertising and society. Changsha: Zhongnan University Press).

王伟光 总主编 汪海波著. 中国经济发展 30 年. (1978-2008). 中国社会科学山版社. 2008.

(Wang, Haibo \& Wang, Weiguang (chief editors) (2008). Studies on the Thirty Years of Economic Development in China from 1978-2008, China Social Science Press). 徐式谷, 杨枕旦 定稿 朱原等译. 当代高级英语词典（英英 - 英汉双解）商务印书 馆和朗文中国，1998 年

( Xu, Shigu; Yang, Zhendan; \& Zhu, Yuang as Chief Editors (1998). Longman Dictionary of Contemporary English (English-Chinese), The Commercial Press and Addison Wesley Longman China Limited).

【英】约翰・斯道雷杨竹山, 郭发勇, 周辉译. 张一兵主编 周宪 周晓虹副主编 文 化理论与通俗文化导论 (第二版) 当代学术棱镜译丛 南京大学出版社 2006 年 6 月 
(John Storey (1993) Prentice Hall/Harvester Wheatsheaf 1997. An Introductory Guide to Cultural Theory and Popular Culture, translated by Yang, Zhushan, Guo, fayong, and Zhou Hui. $2^{\text {nd }}$ ed. is published by arrangement with Pearson Education Limited. Chinese language copyright by Nanjing University Press 2000)

周伟. 工商侧影: 一个世纪的广告经典 光明日报出版社 2002 年.

(Zhou, Wei Chief Editor (2002). A Profile of Industry and Commerce: classic ads in one century in China, Guangming Daily Press).

中国广告协会编《第五届全国优秀广告作品展获奖广告作品集》广州: 岭南美术出 版社 1997 年

(China Advertising Association (Ed) (1997). Award-Winning Ad Collections from the Fifth National Popular Advertising Exhibition, Guangzhou: LingNan Fine Arts Press). 


\section{APPENDIX I}

Figure I-1 Four Sample Ad Examples from 1979 to 1988

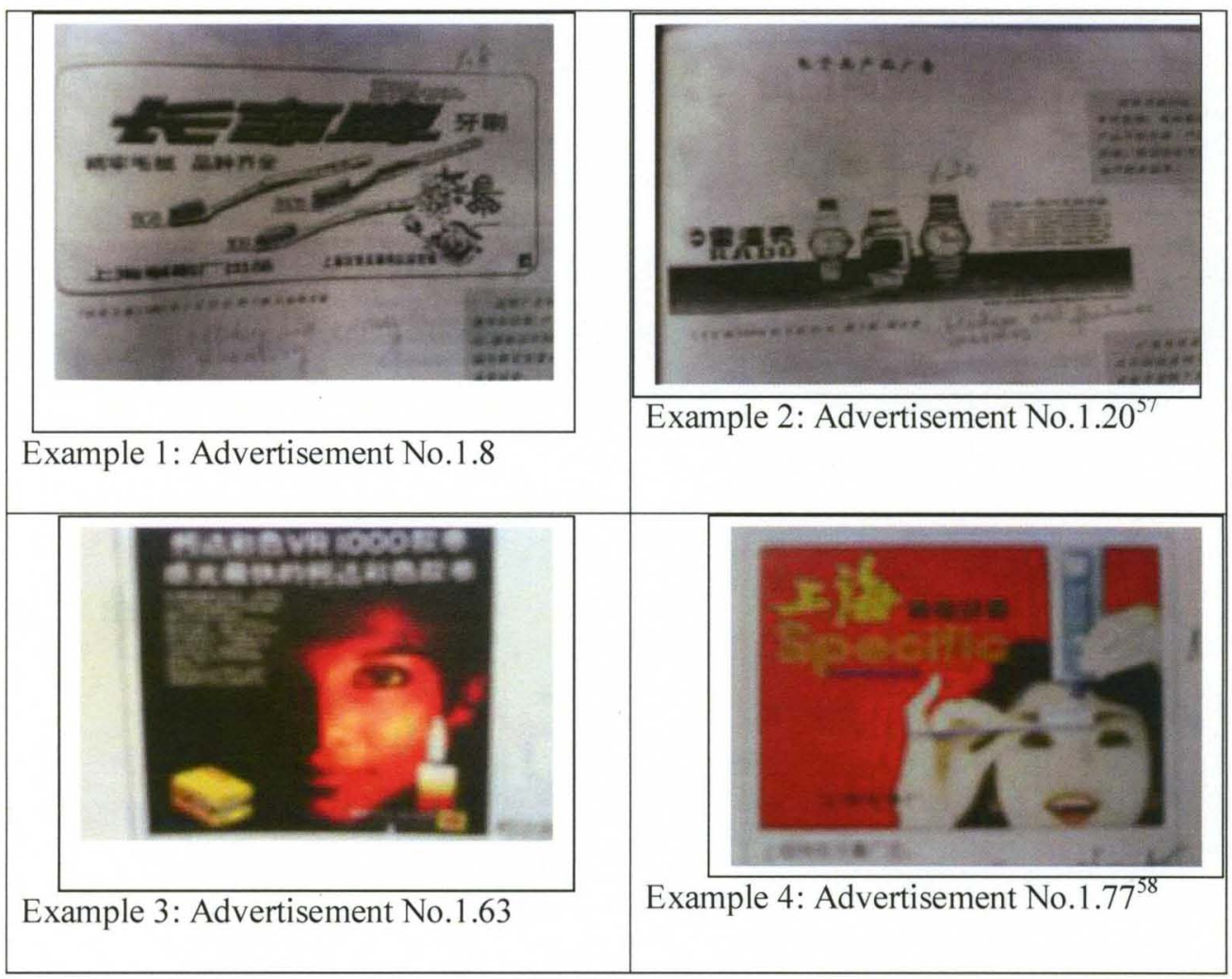

\footnotetext{
${ }^{57}$ Source: Zhou, Wei (Chief Editor) (2002). A Profile of Industry and Commerce: classic ads in one century in China Guangming Daily Press. (The book is written in Chinese. The English book name is translated by the dissertation author). Ad No.1.8 on p.171; Ad No.1.20 on p.173.

${ }^{58}$ Source: Liu, Libin (Chief Editor) (2004). Accelerated Growth of China 's Advertising Industry from 1979 to 2003. Huaxia Publish ing House. (The book is written in Chinese. The English book name is translated by the dissertation author). Ad No. 1.63 on p.40; Ad. No. 1.77 on p.56
} 
Figure I-2 Four Sample Ad Examples from 1989 to 1998

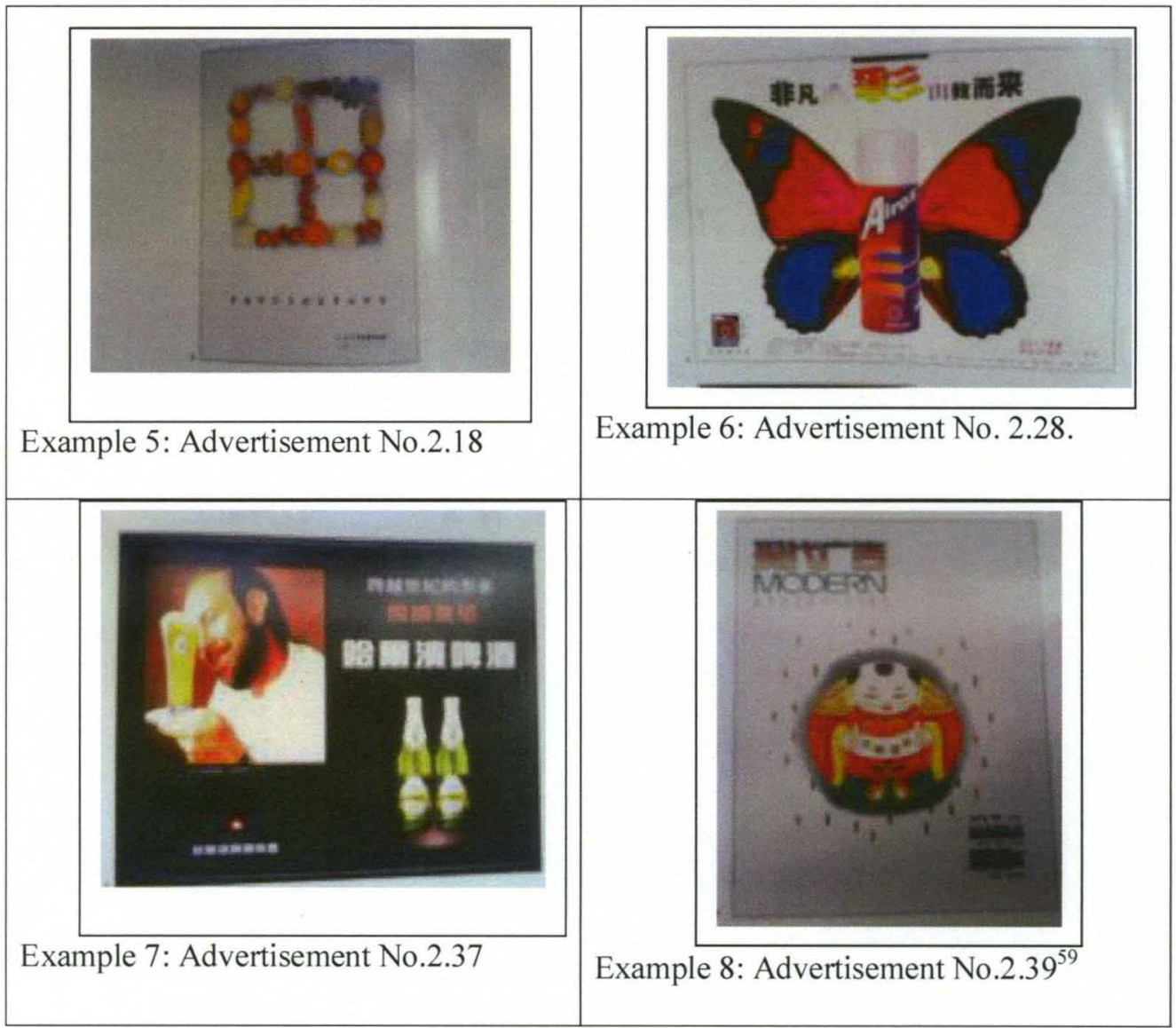

${ }^{59}$ China Advertising Association (ed.) (1997). Award-Winning Ad Collections from the Fifth National Popular Advertising Exhibition Guangzhou: LingNan Fine Arts Press. (The book is written in Chinese. The English book name is translated by the dissertation author). No.2.18 on p. 24 ; No.2.28 on p. 34 ; No. 2.37 on p. 43 ; No.2.39 on p. 45 . 
Figure I-3 Four Sample Ad Examples from 1999 to 2008

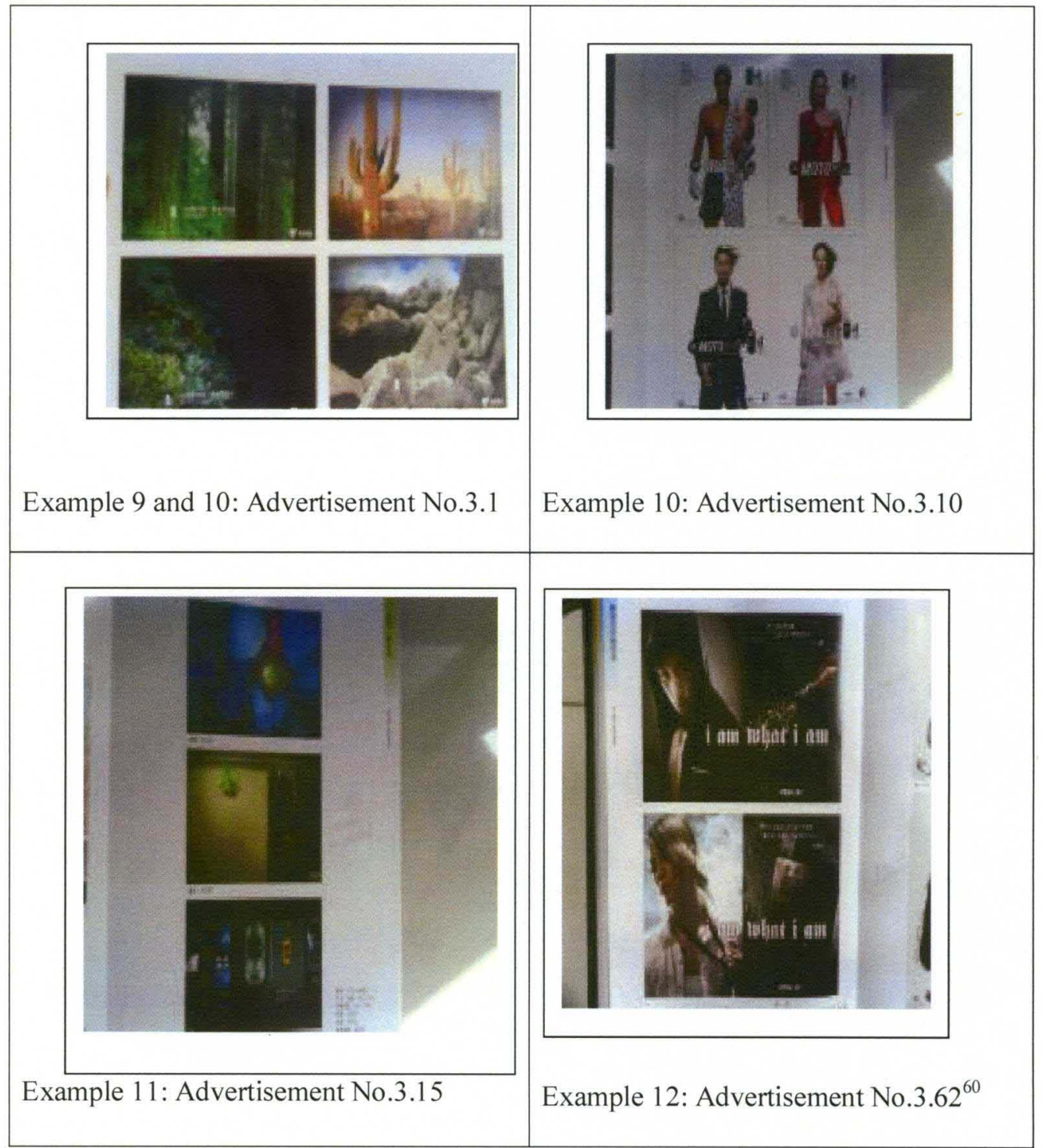

${ }^{60}$ Liu, Libin, Ding, Junjie, and Huang, Shengmin (2007). IAI China Advertising Yearbook 2007 Beijing: China Media University Press. (The book is written in Chinese. The English book name is translated by the dissertation author). No. 3.1 on p. 25 ; No. 3.10 on p. 57 ; No. 3.15 on p. $75 ;$ No. 3.62 on p. 304. 
Table I-1 100 Product Names, Key Words and Appeals from 1979 to 1988

\begin{tabular}{|c|c|c|c|}
\hline $\begin{array}{l}\text { Ad } \\
\text { No. }\end{array}$ & Product name (type) & $\begin{array}{l}\text { Advertising } \\
\text { appeals }\end{array}$ & $\begin{array}{l}\text { The key words (in ad message) } \\
\text { based on advertising copies }\end{array}$ \\
\hline 1.1 & Advertising company & Rational appeal & Effective campaign and publicity \\
\hline 1.2 & $\begin{array}{l}\text { Shanghai Food Industrial } \\
\text { Company }\end{array}$ & Rational appeal & $\begin{array}{l}\text { Product/brand/manufacturer's } \\
\text { name and display }\end{array}$ \\
\hline 1.3 & $\begin{array}{l}\text { Shanghai Arts and Crafts } \\
\text { Company }\end{array}$ & Rational appeal & Product/brand name and display \\
\hline 1.4 & Double Tiger Paints & Rational appeal & Superior quality \\
\hline 1.5 & The silk blouses & $\begin{array}{l}\text { Personal appeal } \\
\text { Rational appeal }\end{array}$ & $\begin{array}{l}\text { Beauty and happiness. } \\
\text { Product/brand name and display }\end{array}$ \\
\hline 1.6 & $\begin{array}{l}\text { Our electronics are hot } \\
\text { news. }\end{array}$ & Social appeal & $\begin{array}{l}\text { Information search. Coolest news } \\
\text { in hot weather }\end{array}$ \\
\hline 1.7 & Torches and batteries & Rational appeal & Product/brand name and display \\
\hline 1.8 & The toothbrushes & $\begin{array}{l}\text { Rational appeal } \\
\text { Personal appeal }\end{array}$ & $\begin{array}{l}\text { Durable and variety of product } \\
\text { Romantic }\end{array}$ \\
\hline 1.9 & $\begin{array}{l}\text { China Art \& Crafts Imp. } \\
\& \text { Exp. Company } \\
\text { Jewelries and precious } \\
\text { stones purchase }\end{array}$ & Rational appeal & Value price \\
\hline 1.10 & The bicycle & Rational appeal & Well-known brand name \\
\hline 1.11 & Shoes & Rational appeal & $\begin{array}{l}\text { Stylish, comfortable, bright color, } \\
\text { quality material }\end{array}$ \\
\hline 1.12 & $\begin{array}{l}\text { Shanghai } \quad \text { Sports } \\
\text { Products Manufacturer }\end{array}$ & Rational appeal & Award winner in quality \\
\hline 1.13 & $\begin{array}{l}\text { Shanghai Soft Mattress } \\
\text { Company }\end{array}$ & Rational appeal & $\begin{array}{l}\text { Guarantee of delivery, repair, } \\
\text { change }\end{array}$ \\
\hline 1.14 & $\begin{array}{l}\text { Shanghai Diesel Engine } \\
\text { Producer }\end{array}$ & Social appeal & Long history and popularity \\
\hline 1.15 & $\begin{array}{l}\text { Shanghai Machinery } \\
\text { Equipment Company }\end{array}$ & Social appeal & World-wide business connection \\
\hline 1.16 & The traditional medicine & Rational appeal & Product name and display \\
\hline 1.17 & $\begin{array}{ll}\text { Liver } & \text { Protection } \\
\text { Capsules } & \\
\end{array}$ & Rational appeal & Function and efficacy \\
\hline 1.18 & $\begin{array}{l}\text { Nasal Inhaler for stroke } \\
\text { and comas }\end{array}$ & Rational appeal & Fast/immediate efficacy \\
\hline 1.19 & The herbal medicines & Rational appeal & Provincial quality certificate \\
\hline 1.20 & Swiss Rado watches & Rational appeal & Modern features and functions \\
\hline 1.21 & Swiss Titoni watches & Rational appeal & Scientifically advanced \\
\hline 1.22 & The Beijing TV & Rational appeal & Top-ranking brand name \\
\hline 1.23 & Electric pressure adapter & Rational appeal & Problem-solving \\
\hline 1.24 & Casio memory stick & Rational appeal & New technology \\
\hline 1.25 & $\begin{array}{l}\text { Micro Electron Circuit } \\
\text { Products }\end{array}$ & Rational appeal & Product name and display \\
\hline
\end{tabular}




\begin{tabular}{|c|c|c|c|}
\hline 1.26 & Sanyo TV & Social appeal & Natural and homely \\
\hline 1.27 & $\begin{array}{ll}\text { Olympus } & \text { optical } \\
\text { equipment }\end{array}$ & Rational appeal & Serve you well \\
\hline 1.28 & $\begin{array}{l}\text { Liquid Chromatogram } \\
\text { Stick }\end{array}$ & Rational appeal & Value pricing \\
\hline 1.29 & The restaurant & Rational appeal & Product name and display \\
\hline 1.30 & The Food Town & Social appeal & Festival get-together products \\
\hline 1.31 & $\begin{array}{l}\text { Shanghai International } \\
\text { Trust Service Corp. }\end{array}$ & Personal appeal & Simple, considerate, reliable \\
\hline 1.32 & RICOH Camera & Rational appeal & Product name \\
\hline 1.33 & Nippon Airline & Rational appeal & Company name and logo display \\
\hline 1.34 & Lacovo Coco drink & Rational appeal & Delicious and thick \\
\hline 1.35 & $\begin{array}{l}\text { Chinese Arts \& Crafts } \\
\text { Firm }\end{array}$ & Personal appeal & Cultivate, sharpen, and enhance \\
\hline 1.36 & Lufthansa Airline & Rational appeal & Careful thoughtful service \\
\hline 1.37 & $\begin{array}{ll}\text { Japanese } & \text { National } \\
\text { Company } & \\
\end{array}$ & Social appeal & Colorful life \\
\hline 1.38 & $\begin{array}{l}\text { Tianjin Toothpaste } \\
\text { Factory }\end{array}$ & Rational appeal & Welcome to order \\
\hline 1.39 & Automatic Lathe & Rational appeal & Convenient to order \\
\hline 1.40 & $\begin{array}{l}\text { National Electronics } \\
\text { Window Display }\end{array}$ & Rational appeal & Product/brand name and display \\
\hline 1.41 & Shanghai Ad Agency & Social appeal & (Enter into) New era \\
\hline 1.42 & $\begin{array}{l}\text { Meilin Canned Food is a } \\
\text { family picnic. }\end{array}$ & Social appeal & Family get-together \\
\hline 1.43 & China Tire & Social appeal & New China \\
\hline 1.44 & Coca Cola & Personal appeal & Happy feeling \\
\hline 1.45 & $\begin{array}{l}\text { Chinese tea is a pot } \\
\text { flower of orchid. }\end{array}$ & Rational appeal & Product/brand name \& display \\
\hline 1.46 & Maxwell Coffee & Social appeal & Modern lifestyle \\
\hline 1.47 & $\begin{array}{l}\text { Foreign Ad Show is } \\
\text { bikini girl surfing. }\end{array}$ & Social appeal & World attention \\
\hline 1.48 & Bat Electronics & Rational appeal & Product name and display \\
\hline 1.49 & $\begin{array}{l}\text { Nutritious Capsule is a } \\
\text { gymnast. }\end{array}$ & Personal appeal & $\begin{array}{l}\text { Healthy, young, witty, and } \\
\text { beautiful }\end{array}$ \\
\hline 1.50 & "New Time" Dept. Store & Social appeal & American lifestyle \\
\hline 1.51 & Mitsubishi car & Rational appeal & Choice and selection \\
\hline 1.52 & Draft Fan Furnace & Rational appeal & Product name and display \\
\hline 1.53 & Sony & Rational appeal & $\begin{array}{l}\text { Product/company name and } \\
\text { display }\end{array}$ \\
\hline 1.54 & $\begin{array}{l}\text { "Old Beijing Story" } \\
\text { Movie are many faces. }\end{array}$ & Personal appeal & Nostalgia, old folk story \\
\hline 1.55 & Toyota car & Social appeal & Ubiquitous and popular \\
\hline 1.56 & $\begin{array}{l}\text { Thunderstorm Radio is a } \\
\text { trophy. }\end{array}$ & Rational appeal & Superior quality \\
\hline
\end{tabular}




\begin{tabular}{|c|c|c|c|}
\hline 1.57 & $\begin{array}{l}\text { National Repair Shop is } \\
\text { a monkey king. }\end{array}$ & Rational appeal & Electronic family, quality life \\
\hline 1.58 & Alarm clock & Personal appeal & Precious time \\
\hline 1.59 & $\begin{array}{l}\text { Yanwu Tape Recorder is } \\
\text { a singing and dancing } \\
\text { boy. }\end{array}$ & Personal appeal & $\begin{array}{l}\text { Fun making in singing and } \\
\text { dancing }\end{array}$ \\
\hline 1.60 & Konica film & Personal appeal & Graceful \\
\hline 1.61 & Santana car & Rational appeal & $\begin{array}{lll}\text { Product/company } & \text { name } & \text { and } \\
\text { display } & & \end{array}$ \\
\hline 1.62 & $\begin{array}{l}\text { Lion sneaker shoe is a } \\
\text { travel companion. }\end{array}$ & Personal appeal & Travel experience \\
\hline 1.63 & Kodak film & Rational appeal & Colorful and fastest exposure \\
\hline 1.64 & Dabao Fragrance Cream & Social appeal & Gentleman's manner \\
\hline 1.65 & Toshiba refrigerator & Social appeal & Fame and popularity \\
\hline 1.66 & Jianlibao sport drink & Personal appeal & Magic and heroic \\
\hline 1.67 & Northwest Airline & Rational appeal & Consistency \\
\hline 1.68 & Chrysanthemum alcohol & Social appeal & Soci \\
\hline 1.69 & $\begin{array}{l}\text { Weili Washing Machine } \\
\text { is love to mother. }\end{array}$ & Personal appeal & Dedicated love to Mum \\
\hline 1.70 & $\begin{array}{l}\text { Double fish lock is a } \\
\text { door guard. }\end{array}$ & Rational appeal & $\begin{array}{l}\text { Home guard and security } \\
\text { protection }\end{array}$ \\
\hline 1.71 & Modern Ad Magazine & Personal appeal & Secrets \\
\hline 1.72 & Stomach medicine & nal appeal & rity and health \\
\hline 1.73 & Woolen sweater & al appeal & ct/brand name \\
\hline 1.74 & Danggui herbal medicine & Social appeal & Family value \\
\hline 1.75 & Qiluowa Ice Box & Rational appeal & Thirsty crunch \\
\hline 1.76 & Agfa photo equipment & Social appeal & Diversity and breakthrough \\
\hline 1.77 & Specific toothpaste & appeal & Specific efficacy \\
\hline 1.78 & Fish Lock & l appeal & Solid and unbreakable \\
\hline 1.79 & Maxam Pearl Cream & l appeal & beauty \\
\hline 1.80 & O.B. stick napkin & Personal appeal & Comfort and confidence \\
\hline 1.81 & The Great Wall raincoat & Personal appeal & Model grace \\
\hline 1.82 & Chundu hams/sausage & Social appeal & Festive atmosphere \\
\hline 1.83 & $\begin{array}{ll}\text { Benz } & \text { construction } \\
\text { equipments } & \end{array}$ & Rational appeal & Satisfy your needs (functions) \\
\hline 1.84 & Boeing 757 & Personal appeal & Most suitable \\
\hline 1.85 & $\begin{array}{l}\text { Qiaoli face cleansing } \\
\text { milk }\end{array}$ & Personal appeal & White skin beautiful \\
\hline 1.86 & Tianli Shampoo & Personal appeal & Natural beauty \\
\hline 1.87 & Computerized typewriter & Personal appeal & Light-hearted smile \\
\hline 1.88 & Musical Stereos & Personal appeal & Stereo music center \\
\hline 1.89 & Yizhihua industrial Plant & Rational appeal & Brand name on TV tower \\
\hline 1.90 & Liquid Pressure Digger & Rational appeal & Product/brand name \\
\hline 1.91 & Haida watches & Rational appeal & Quality and integrity \\
\hline 1.92 & Xiafei Cosmetics & Rational appeal & No. 1 cosmetic in China \\
\hline
\end{tabular}




\begin{tabular}{|l|l|l|l|}
\hline 1.93 & Water Heater & Personal appeal & Happy families \\
\hline 1.94 & Martell Wine & Personal appeal & Antiquity \\
\hline 1.95 & Marlboro & Personal appeal & Countryside \\
\hline 1.96 & Tianli body shampoo & Personal appeal & Tender and beautiful skin \\
\hline 1.97 & Recorder tapes & Personal appeal & Melodious music \\
\hline 1.98 & Swiss Longines Watch & Social appeal & Upper class luxury \\
\hline 1.99 & Maxwell drink & Personal appeal & Champion \\
\hline 1.100 & Singing concert & Personal appeal & Modern and blue (sad) \\
\hline
\end{tabular}

Table I-2 100 Product Names, Key Words and Appeals from 1989 to 1998

\begin{tabular}{|c|c|c|c|}
\hline $\begin{array}{l}\text { Ad } \\
\text { No. }\end{array}$ & Product names (types) & Advertising appeals & $\begin{array}{l}\text { The key words (in ad } \\
\text { messages) based } \\
\text { advertising copies }\end{array}$ \\
\hline 2.1 & Hualin Garden & Personal appeal & Detailed work, perfectness \\
\hline 2.2 & Shanghai Santana & Social appeal & Speed plus space (lifestyle) \\
\hline 2.3 & Robust Purified Water & Rational appeal & Guaranteed quality \\
\hline 2.4 & $\begin{array}{ll}\text { Brain } & \text { Thrombus } \\
\text { Capsule } & \\
\end{array}$ & Personal appeal & Labyrinth and health \\
\hline 2.5 & Sefio Air Dryer & Personal appeal & Dry air \\
\hline 2.6 & LongJing Green Tea & Personal appeal & Taste and appreciate, relax \\
\hline 2.7 & Ad Design Agency & Personal appeal & Strategize and design \\
\hline 2.8 & China Telecom & Social appeal & Care and condolence \\
\hline 2.9. & Riverside Garden & Social appeal & Comparison (competition) \\
\hline 2.10 . & San Alliguel Garden & Social appeal & Olympic spirit \\
\hline 2.11 & Wanjiale Water Heater & Social appeal & China hope \\
\hline 2.12 & IBM & Personal appeal & Perfectness \\
\hline 2.13 & Gilette Blade & Personal appeal & Detailed groomed men \\
\hline 2.14 & China Mobile Gotone & Social appeal & Connection \\
\hline 2.15 & Guizhou Daily & Personal appeal & Sensational news \\
\hline 2.16 & Mineral Water & Social appeal & Human earth relationship \\
\hline 2.17 & Blue Star Beer & Social appeal & $\begin{array}{l}\begin{array}{l}\text { Naturally made, natural } \\
\text { beauty }\end{array} \\
\end{array}$ \\
\hline 2.18 & Nutritional Liquid & Social appeal & Colorful field \\
\hline 219 & Creative idea & Personal appeal & Creative idea \\
\hline 2.20 & $\begin{array}{l}\text { GFO accounting } \\
\text { software }\end{array}$ & Personal appeal & Calculative, shrewd \\
\hline 2.21 & Olympus Camera & Rational appeal & Miniature and clever \\
\hline 2.22 & Wanke Real Estate & Personal appeal & High-return investment \\
\hline 2.23 & Wanhe Gas Heater & Social appeal & (sky, earth, human) harmony \\
\hline 2.24 & Philips Computer & Personal appeal & Light speed, giant's mind \\
\hline 2.25 & $\begin{array}{ll}\text { Squibb's } & \text { Cough } \\
\text { Medicine } & \\
\end{array}$ & Social appeal & Help stranger \\
\hline 2.26 & IBM Solution & Personal appeal & Solution, way \\
\hline
\end{tabular}




\begin{tabular}{|c|c|c|c|}
\hline 2.27 & Mini-van & Personal appeal & Perfectness \\
\hline 2.28 & Nippon Paint (Airox) & Personal appeal & Extraordinary, outstanding \\
\hline 2.29 & LiNing Sportswear & Personal appeal & Heroic nature \\
\hline 2.30 & Bangdi woundplast & Rational appeal & Water-proof \\
\hline 2.31 & $\begin{array}{ll}\text { Earth } & \text { Digger } \\
\text { Equipment } & \\
\end{array}$ & Rational appeal & Miniature \\
\hline 2.32 & Motorola Modem & Personal appeal & $\begin{array}{l}\text { OK, No.1, thumb up, A's } \\
\text { work }\end{array}$ \\
\hline 2.33 & Audi car & Social appeal & Connect the world \\
\hline 2.34 & Texwood Garment & Personal appeal & Inspiration \& discovery \\
\hline 2.35 & Newspaper & Social appeal & $\begin{array}{l}\text { Information in topics, sports, } \\
\text { vogue }\end{array}$ \\
\hline 2.36 & GE Lightening & Social appeal & Lighten the whole world \\
\hline 2.37 & Haerbin Beer & Social appeal & $\begin{array}{l}\text { Centenary image/freedom \& } \\
\text { justice }\end{array}$ \\
\hline 2.38 & TV & Rational appeal & Economical, common people \\
\hline 2.39 & Modern Advertising & Social appeal & Civilization and progress \\
\hline 2.40 & Wanke Garden & Rational appeal & Wise choice \\
\hline 2.41 & Nangfang Daily & Personal appeal & Variety of life scenes \\
\hline 2.42 & Edible bird's nest & Personal appeal & Deep insight, expertise \\
\hline 2.43 & Shell Lubricant. & Rational appeal & Economical, trouble-free \\
\hline 2.44 & The Herbal Wine & Personal appeal & $\begin{array}{l}\text { representing love, happiness, } \\
\text { friendship, wealth, longevity, } \\
\text { smoothness }\end{array}$ \\
\hline 2.45 & Medicine for prostatitis & Rational appeal & Get rid of pain and suffering. \\
\hline 2.46 & Lihua Wine & Rational appeal & Natural and pure \\
\hline 2.47 & The Beer & Personal appeal & Beautiful and natural \\
\hline 2.48 & The Toothpaste & Rational appeal & Value price \\
\hline 2.49 & $\begin{array}{ll}\text { Goldlion } & \text { Men's } \\
\text { Fashion } & \\
\end{array}$ & Social appeal & Men's world \\
\hline 2.50 & The Alcohol & Social appeal & Eternity \\
\hline 2.51 & Legend/Lenovo & Personal appeal & Confidence and growth \\
\hline 2.52 & IPC Computer & Social appeal & Care and mutual concern \\
\hline 2.53 & Unicom Paging Service & Personal appeal & Facial expressions \\
\hline 2.54 & JVC Electronics & Personal appeal & Colorful rainbow (happy life) \\
\hline 2.55 & $\begin{array}{l}\text { HengYuanXiang } \\
\text { Woolen Products }\end{array}$ & Rational appeal & Licensed wool label \\
\hline 2.56 & Clark Air Shoes & Personal appeal & Comfort from high-tech \\
\hline 2.57 & Air-conditioner & Social appeal & American lifestyle \\
\hline 2.58 & Blue Sky Toothpaste & Social appeal & Environmental friendly \\
\hline 2.59 & Casio & Personal appeal & Pioneering and remembering \\
\hline 2.60 & YongGu Lock & Personal appeal & Double happiness \\
\hline 2.61 & $\begin{array}{l}\text { ChunLan } \\
\text { Conditioner }\end{array}$ & Personal appeal & Warmth of home \\
\hline 2.62 & Hemorrhoids/Piles & Social appeal & Social manner \\
\hline
\end{tabular}




\begin{tabular}{|c|c|c|c|}
\hline 2.63 & CHO embryo nutrient & Personal appeal & Healthy baby \\
\hline 2.64 & Throat Smoother & Personal appeal & Smooth melody \\
\hline 2.65 & $\begin{array}{l}\text { Sanzhu } \\
\text { Liquid }\end{array}$ & Personal appeal & Preying for health \\
\hline 2.66 & Ad Agency & Personal appeal & Success and timely \\
\hline 2.67 & Whitening Cream & Social appeal & Truth revealing \\
\hline 2.68 & Baby Nutritious Liquid & Personal appeal & Baby health \\
\hline 2.69 & YuanMing (real estate) & Personal appeal & Grandeur, splendid \\
\hline 2.70 & Dongdu (real estate) & Personal appeal & Sharp eye/insight \\
\hline 2.71 & $\begin{array}{l}\text { China Southeast Airline } \\
\text { is Dai Water Festival. }\end{array}$ & Personal appeal & Merry and affection \\
\hline 2.72 & PingAn Insurance & Personal appeal & Extraordinary \\
\hline 2.73 & Nortel Communication & Personal appeal & Awakening, calling \\
\hline 2.74 & Postcards & Personal appeal & True emotion \\
\hline 2.75 & Gansu Daily & Personal appeal & Pre-destination, pre-ordained \\
\hline 2.76 & Convene Soft Pillow & Personal appeal & Insomnia \\
\hline 2.77 & Beauty Cosmetics & Personal appeal & Beauty and health \\
\hline 2.78 & Donghuan Square & Social appeal & Ancient old city \\
\hline 2.79 & Nangfang Daily & Personal appeal & One strike success \\
\hline 2.80 & Motorola University & Personal appeal & Ladder to knowledge/success \\
\hline 2.81 & Maxam Suntan Lotion & Social appeal & Green shade (environment) \\
\hline 2.82 & Santana car & Personal appeal & Superstition \\
\hline 2.83 & Ad Agency & Personal appeal & Strategies and tactics \\
\hline 2.84 & Pond & Personal appeal & Skin care \\
\hline 2.85 & $\begin{array}{l}\text { The Relation between } \\
\text { Ad Agent and client }\end{array}$ & Rational appeal & Best combination/match \\
\hline 2.86 & KFC & Personal appeal & Heart beating/exciting \\
\hline 2.87 & Kadaner Suit & Personal appeal & Romantic man \\
\hline 2.88 & Parim eyeglass & Personal appeal & Attraction and charming \\
\hline 2.89 & $\begin{array}{l}\text { K.T. Shirt is lifelong } \\
\text { road and care. }\end{array}$ & Social appeal & Lifelong care \\
\hline 2.90 & $\begin{array}{ll}\text { Sanyo } & \text { Cooling } \\
\text { Machinery } & \end{array}$ & Social appeal & Coordination and integration \\
\hline 2.91 & Samsung Service & Social appeal & One world one family \\
\hline 2.92 & Motorola Pager & Personal appeal & Lucky and fortunate \\
\hline 2.93 & Coca Cola & Personal appeal & Enjoyment/fun \\
\hline 2.94 & Women's Wash & Personal appeal & Home assignment everyday \\
\hline 2.95 & $\begin{array}{ll}\text { Home } & \text { Furnishing } \\
\text { Center } & \\
\end{array}$ & Personal appeal & New feeling \\
\hline 2.96 & Roma/Smart Garment & Personal appeal & Smart \\
\hline 2.97 & Animal Feed & Rational appeal & Eat/sleep well value price \\
\hline 2.98 & $\begin{array}{l}\text { Mountain Scenery } \\
\text { Tickets }\end{array}$ & Social appeal & Natural scenery \\
\hline 2.99 & Butter from Tibet & Social appeal & Refined Tibetan style \\
\hline 2.100 & GuanglianLighting & Personal appeal & perfectness \\
\hline
\end{tabular}


Table I-3 100 Product Names, Key Words and Appeals from 1999 to 2008

\begin{tabular}{|c|c|c|c|}
\hline $\begin{array}{l}\text { Ad } \\
\text { No. }\end{array}$ & $\begin{array}{l}\text { Product } \\
\text { (types) }\end{array}$ & Advertising appeals & $\begin{array}{l}\begin{array}{l}\text { The key words (in ad } \\
\text { messages) based }\end{array} \\
\text { on } \\
\text { advertising copies }\end{array}$ \\
\hline 3.1 & China Telecom & Social appeal & $\begin{array}{l}\text { Far city, near world, } \\
\text { connection }\end{array}$ \\
\hline 3.2 & China Mobile & Personal appeal & Self-identity \\
\hline 3.3 & China Unicom & Personal appeal & Depth, width, height \\
\hline 3.4 & China Netcom & Social appeal & Changed, unchanged \\
\hline 3.5 & China Satcom & Social appeal & The value of connection \\
\hline 3.6 & Motorola & Personal appeal & Cool, happy, experience \\
\hline 3.7 & ChinaHR.com & Rational appeal & Suitable job \\
\hline 3.8 & Taobao.com & Personal appeal & Search, shining star \\
\hline 3.9 & Asus Computer & Personal appeal & New horizon, new height \\
\hline 3.10 & Motorola mobile phone & Personal appeal & $\begin{array}{l}\text { Insight, brilliant, multi- } \\
\text { task/role }\end{array}$ \\
\hline 3.11 & $\begin{array}{l}\text { Agricultural bank of } \\
\text { China }\end{array}$ & Personal appeal & Accompany you to grow \\
\hline 3.12 & Hi Bank & Rational appeal & Reduce the burden \\
\hline 3.13 & $\begin{array}{l}\text { Guangdong } \\
\text { Development Bank }\end{array}$ & Personal appeal & Release the instinct \\
\hline 3.14 & $\begin{array}{l}\text { Cumulative Point Card } \\
\text { is a lady in numbered } \\
\text { world. }\end{array}$ & Personal appeal & Cumulative point/exchange \\
\hline 3.15 & China Life Insurance & Personal appeal & Personal, private $\&$ reserved \\
\hline 3.16 & Mazda car & Personal appeal & Season greetings \\
\hline 3.17 & GiTi Tires & Personal appeal & Ugly but lucky \\
\hline 3.18 & Suzuki & Social appeal & Way of life \\
\hline 3.19 & Lubao car & Personal appeal & Intruder, love affair \\
\hline 3.20 & Jetta car & Rational appeal & Saving and economical \\
\hline 3.21 & Elantra car & Rational appeal & Fuel efficiency \\
\hline 3.22 & Regal car & Personal appeal & Dynamic but quiet \\
\hline 3.23 & Xianglong car & Rational appeal & Reliability \\
\hline 3.24 & ChengAn car & Rational appeal & Space king \\
\hline 3.25 & BaoGang Steel Plant & Rational appeal & Elastic and flexible \\
\hline 3.26 & HeYuan (real estate) & Personal appeal & $\begin{array}{l}\text { Get-together, geomancy, } \\
\text { cultured, and share. }\end{array}$ \\
\hline 3.27 & Green Gulf(real estate) & Rational appeal & Convenience \\
\hline 3.28 & Landscape City & Personal appeal & Being the first \\
\hline 3.29 & Binhai New Town & Personal appeal & Best angle for lake view \\
\hline 3.30 & $\begin{array}{ll}\begin{array}{l}\text { Splendid New } \\
\text { (real estate) }\end{array} & \text { Asia } \\
\end{array}$ & Personal appeal & Splendid and elaborate \\
\hline 3.31 & Global Villa & Social appeal & Synchronized with the world \\
\hline 3.32 & Ziwei Villa & Social appeal & Modern Chinese style \\
\hline
\end{tabular}




\begin{tabular}{|c|c|c|c|}
\hline 3.33 & $\begin{array}{l}\text { Nansha Compass (real } \\
\text { estate) }\end{array}$ & Social appeal & $\begin{array}{l}\text { Being close to nature, man } \\
\text { nature harmony }\end{array}$ \\
\hline 3.34 & Arrow (bath tub) & Personal appeal & American style heroes \\
\hline 3.35 & Paco Floor & Personal appeal & Protect and longevity \\
\hline 3.36 & Meidi Electronics & Rational appeal & Everyday fresh \\
\hline 3.37 & Swan washing machine & Personal appeal & Further and higher \\
\hline 3.38 & Royalstar Electronics & Personal appeal & Comfort and not twisted \\
\hline 3.39 & Electrolux & Personal appeal & Happiness and enjoyment \\
\hline 3.40 & Candy kitchen wares & Personal appeal & Coffee and Latin dance \\
\hline 3.41 & $\begin{array}{ll}\text { Kitchen } & \text { Smoke } \\
\text { Extractor } & \\
\end{array}$ & Rational appeal & Clean kitchen \\
\hline 3.42 & DongSheng Fans & Social appeal & Natural sea winds and breeze \\
\hline 3.43 & Meidi Moisturizer & Social appeal & Nature-like moisture \\
\hline 3.44 & $\begin{array}{ll}\text { Eagle } & \text { Electric } \\
\text { Appliance } & \\
\end{array}$ & Personal appeal & Affection and sufficiency \\
\hline 3.45 & Top Electric & Rational appeal & Security and safety \\
\hline 3.46 & Mengniu milk & Personal appeal & Growth and faire tale \\
\hline 3.47 & Sanyuan milk & Personal appeal & Mother's love \\
\hline 3.48 & Holiland & Personal appeal & Exploration and hunting \\
\hline 3.49 & Classic kiss cheese & Personal appeal & Mysterious Alps \\
\hline 3.50 & Youcan ice pop & Personal appeal & $\mathrm{Oh}, \mathrm{Ha}$, martial arts (health) \\
\hline 3.51 & Duoheshui water bottle & Rational appeal & Drink more \\
\hline 3.52 & Guangmin yoghurt & Personal appeal & Immune system enhancement \\
\hline 3.53 & Wanglaoji Drink & Personal appeal & Internal body balance \\
\hline 3.54 & The Great Wall wine & Social appeal & $\begin{array}{l}\text { Eastern civilization vs. } \\
\text { western civilization }\end{array}$ \\
\hline 3.55 & Carlsberg & Personal appeal & Free your wild nature \\
\hline 3.56 & Pain killer & Personal appeal & Noise vs. melody \\
\hline 3.57 & $\begin{array}{l}\text { Watermelon throat } \\
\text { soother }\end{array}$ & Social appeal & Help, help \\
\hline 3.58 & Sleeping Pills & Personal appeal & Fast asleep \\
\hline 3.59 & Your fallen hair & Social appeal & Save the extinguished spices \\
\hline 3.60 & $\begin{array}{ll}\text { Enriched } & \text { Calcium } \\
\text { Tablet } & \end{array}$ & Rational appeal & Concentrated, enriched \\
\hline 3.61 & $361^{\circ}$ sportswear & Personal appeal & Dare to be \\
\hline 3.62 & Reebok & Personal appeal & I am what I am, be myself \\
\hline 3.63 & LiNing sportswear & Personal appeal & Oriental hero \\
\hline 3.64 & Quicker shoe & Personal appeal & Forward for freedom \\
\hline 3.65 & Bull family shoes & Social appeal & Being close to nature \\
\hline 3.66 & DeMon mascara & Social appeal & Lively world \\
\hline 3.67 & Rejoice shampoo & Personal appeal & Super slippery hair \\
\hline 3.68 & Dencare toothpaste & Rational appeal & Stain worries \\
\hline 3.69 & Colgate toothpaste & Personal appeal & Superman, superwoman \\
\hline 3.70 & $\begin{array}{l}\text { Antibacteria hand } \\
\text { liquid }\end{array}$ & Personal appeal & Run away \\
\hline
\end{tabular}




\begin{tabular}{|c|c|c|c|}
\hline 3.71 & $\begin{array}{l}\text { Blue Moon cleaning } \\
\text { liquid }\end{array}$ & Rational appeal & Cleaning expert \\
\hline 3.72 & Bausch \& Lomb glass & Rational appeal & $\begin{array}{l}\text { Good eyesight to see sexy } \\
\text { girl }\end{array}$ \\
\hline 3.73 & Tango tissues & Social appeal & Circle, re-cycle, re-birth \\
\hline 3.74 & SiRou tissue & Rational appeal & Elastic and silky \\
\hline 3.75 & O.b. hygiene sliver & Personal appeal & Floral fragrance \\
\hline 3.76 & $\begin{array}{ll}\begin{array}{l}\text { European } \\
\text { garment }\end{array} & \text { winter } \\
\end{array}$ & Personal appeal & Swan posture (graceful) \\
\hline 3.77 & Jindingxuan restaurant & Rational appeal & 24 hour open, round clock \\
\hline 3.78 & Daoxiang Food Group & Personal appeal & $\begin{array}{l}\text { Filial son ordering food for } \\
\text { Mum }\end{array}$ \\
\hline 3.79 & Women club & Personal appeal & Sexy, beautiful and topical \\
\hline 3.80 & China Post & Personal appeal & Express delivery \\
\hline 3.81 & Shangdong TV station & Personal appeal & Far-flung influence \\
\hline 3.82 & $\begin{array}{l}\text { Yangcheng Evening } \\
\text { News }\end{array}$ & Personal appeal & Catch up the latest sport news \\
\hline 3.83 & Top Run AD Agency & Rational appeal & Efficacy and implementation \\
\hline 3.84 & China Times & Social appeal & Differences plus cooperation \\
\hline 3.85 & Puer tea & Social appeal & $\begin{array}{l}\text { Tea culture (Life, time, } \\
\text { belief) }\end{array}$ \\
\hline 3.86 & Tom Outdoor Media & Rational appeal & Big and spacious \\
\hline 3.87 & BH-AD.com & Personal appeal & Energizing and sensational \\
\hline 3.88 & $\begin{array}{l}\text { Cultural } \\
\text { Communication }\end{array}$ & Personal appeal & Time is money \\
\hline 3.89 & Millie.Chen Corp & Social appeal & $\begin{array}{l}\text { Human body, human brain } \\
\text { (collection } \\
\text { wisdom) }\end{array}$ \\
\hline 3.90 & Landao Ad Agency & Personal appeal & Stop (at this website) or hack \\
\hline 3.91 & BizNet & Rational appeal & Nutritional addition \\
\hline 3.92 & CCTV & Social appeal & $\begin{array}{l}\text { Football icon and nation-wide } \\
\text { game }\end{array}$ \\
\hline 3.93 & LiNing sportswear & Personal appeal & Oriental hero \\
\hline 3.94 & $\begin{array}{l}\text { The Great Wall Rice } \\
\text { Wine }\end{array}$ & Social appeal & Traditional Chinese culture \\
\hline 3.95 & ZhongGuang AD & Personal appeal & It's time to... \\
\hline 3.96 & Ad Competition & Personal appeal & Double happiness \\
\hline 3.97 & M-zone talent contest & Personal appeal & To top out, to win, to shine \\
\hline 3.98 & Dalian Travel Agency & Personal appeal & Romantic city of sea, date \\
\hline 3.99 & $\begin{array}{l}\text { Kunming Horticulture } \\
\text { Expo }\end{array}$ & Social appeal & The power of nature \\
\hline 3.100 & $\begin{array}{l}\text { Handy English learning } \\
\text { machine }\end{array}$ & Social appeal & East vs. west. Pk system \\
\hline
\end{tabular}


Table I-4 A Summary of the Key Words and Value Themes in Each Period

\begin{tabular}{|c|c|c|}
\hline Key Words & Periods & $\begin{array}{l}\text { Counting Results } \\
\text { Ranking in priority and frequency }\end{array}$ \\
\hline \multirow{3}{*}{ Nouns } & $1980 \mathrm{~s}$ & $\begin{array}{l}\text { Publicity (campaign), quality (guarantee), value price (value } \\
\text { for money), efficacy, (life)style, tradition (family), beauty, } \\
\text { happiness, health, popularity, manner (smile, grace, } \\
\text { posture), get-together, service }\end{array}$ \\
\hline & $1990 \mathrm{~s}$ & $\begin{array}{l}\text { Chinese five fortunes (affection, happiness, friendship, } \\
\text { longevity, smoothness), perfectness, success, care, world, } \\
\text { man/people, beauty, emotion (feeling), insight, value for } \\
\text { money, work, miniature, speed \& space }\end{array}$ \\
\hline & $2000 \mathrm{~s}$ & $\begin{array}{l}\text { Traditional Chinese culture (balance, harmony, Peking } \\
\text { opera \& martial art, tea manner), (the power of, being close } \\
\text { to) nature, world, happiness, hero (icon), longevity (health), } \\
\text { system/way, space, (life)style, connection, instinct, self- } \\
\text { identity (status), comfort \& convenience, money } \\
\text { (investment) }\end{array}$ \\
\hline \multirow{3}{*}{ Adjectives } & $1980 \mathrm{~s}$ & $\begin{array}{l}\text { Superior, solid and durable, well-known (top-ranking, } \\
\text { award-winning), effective, popular, scientific, colorful, } \\
\text { healthy and beautiful, modern (traditional), sociable. }\end{array}$ \\
\hline & $1990 \mathrm{~s}$ & $\begin{array}{l}\text { Natural, extraordinary/splendid/outstanding, detailed, best } \\
\text { (No.1, thumb up, A's work), environmental, colorful, } \\
\text { superstitious (pre-destined, pre-ordained), creative and } \\
\text { pioneering, calculative and shrewd, romantic, vogue, heroic. }\end{array}$ \\
\hline & $2000 \mathrm{~s}$ & $\begin{array}{l}\text { Far vs. near, east vs. west, Chinese vs. American, traditional } \\
\text { (filial) vs. modem, deeper/wider/higher, private \& personal, } \\
\text { lucky, elastic \& flexible, fast, sexy, fresh \& clean, natural \& } \\
\text { mysterious, super (man/woman) and cool. }\end{array}$ \\
\hline \multirow{3}{*}{ Verbs } & $1980 \mathrm{~s}$ & $\begin{array}{l}\text { be, publicize, welcome, establish, satisfy, choose \& select, } \\
\text { guarantee (promise), serve, exhibit, introduce, cultivate, } \\
\text { sharpen, strengthen. }\end{array}$ \\
\hline & $1990 \mathrm{~s}$ & $\begin{array}{l}\text { Appreciate, design, strategize, relax, make, accompany, } \\
\text { help, connect, get rid of, reveal, prey, awaken. }\end{array}$ \\
\hline & $2000 \mathrm{~s}$ & $\begin{array}{l}\text { Grow, (un)change, experience, search, release, share, } \\
\text { exchange, enhance, drink, free, help, save, dare, run away, } \\
\text { re-cycle \& re-born, hack, I am what I am, it's time to...date, } \\
\text { win, shine. }\end{array}$ \\
\hline
\end{tabular}

Table I-5 A Content Analysis of Advertising Appeals in Each Period

\begin{tabular}{|l|l|l|l|}
\hline Periods & Rational appeals & Personal appeals & Social appeals \\
\hline $1979-1988$ & $51 \%$ & $29 \%$ & $20 \%$ \\
\hline $1989-1998$ & $13 \%$ & $57 \%$ & $30 \%$ \\
\hline $1999-2008$ & $21 \%$ & $57 \%$ & $22 \%$ \\
\hline
\end{tabular}




\section{APPENDIX II}

Table II-1 100 Metaphorical Statements, Primary Subjects and Secondary Subjects and Their Corresponding Projected Features from 1979 to 1988

\begin{tabular}{|c|c|c|c|}
\hline $\begin{array}{l}\text { Ad. } \\
\text { No. }\end{array}$ & $\begin{array}{l}\text { Metaphorical } \\
\text { statements }\end{array}$ & $\begin{array}{l}\text { Primary subject vs. } \\
\text { secondary } \text { subject; } \\
\text { (Signifier vs. signified; } \\
\text { target domain vs. } \\
\text { source domain) }\end{array}$ & $\begin{array}{lr}\text { Projected } & \text { features } \\
\text { (entailments) } & \text { as } \\
\text { embodied in the images }\end{array}$ \\
\hline 1.1 & $\begin{array}{l}\text { Advertising company is } \\
\text { radio and movie. }\end{array}$ & $\begin{array}{l}\text { Advertising company; } \\
\text { Radio, movie }\end{array}$ & $\begin{array}{l}\text { Informative, entertaining, } \\
\text { publicity }\end{array}$ \\
\hline 1.2 & $\begin{array}{l}\text { Shanghai Food } \\
\text { Industrial Company }\end{array}$ & N.A $A^{61}$ & $\begin{array}{l}\text { Delicious food, product, } \\
\text { brand, manufacturer's } \\
\text { name and display }\end{array}$ \\
\hline 1.3 & $\begin{array}{l}\text { Shanghai Arts and } \\
\text { Crafts Company. }\end{array}$ & N.A & $\begin{array}{l}\text { Product/brand name and } \\
\text { display }\end{array}$ \\
\hline 1.4 & $\begin{array}{l}\text { Double Tiger Paints are } \\
\text { two tigers. }\end{array}$ & $\begin{array}{l}\text { Paint; } \\
\text { Two tigers }\end{array}$ & $\begin{array}{l}\text { Superior quality. In China } \\
\text { tiger is the king of all } \\
\text { animals-powerful. }\end{array}$ \\
\hline $1.5 \odot$ & $\begin{array}{l}\text { The silk blouses are } \\
\text { beautiful ladies and } \\
\text { happy couples. }\end{array}$ & $\begin{array}{l}\text { Silk blouse; } \\
\text { Beautiful ladies and } \\
\text { happy couples }\end{array}$ & Beauty and happiness. \\
\hline 1.6 & $\begin{array}{l}\text { Our electronics are hot } \\
\text { news. }\end{array}$ & $\begin{array}{l}\text { Electronics; } \\
\text { Hot news }\end{array}$ & $\begin{array}{ll}\text { Information } & \text { search. } \\
\text { Coolest news in hot } \\
\text { weather. }\end{array}$ \\
\hline 1.7 & Torches and batteries & N.A. & $\begin{array}{l}\text { Product/brand name and } \\
\text { display }\end{array}$ \\
\hline 1.8 & $\begin{array}{ll}\text { The toothbrushes are } & \text { and } \\
\text { rose } & \\
\text { chrysanthemum } & \end{array}$ & $\begin{array}{l}\text { Toothbrushes; } \\
\text { Rose \& chrysanthemum }\end{array}$ & Beauty and fragrance \\
\hline 1.9 & $\begin{array}{l}\text { China Art \& Crafts Imp. } \\
\& \text { Exp. Company } \\
\text { Jewelries and precious } \\
\text { stones purchase }\end{array}$ & N.A. & Value price \\
\hline
\end{tabular}

\footnotetext{
${ }^{61}$ In this table as well as table II-2 and II-3 the N. A. refers to Not Available because I can not identify any pictorial metaphors but can only see the pictures and descriptions of the product, brand and manufacturer and the contact methods. This direct introduction of the product, brand, company and display of them is a common way to design ads in the early period of $1980 \mathrm{~s}$ in China.
} 


\begin{tabular}{|c|c|c|c|}
\hline 1.10 & $\begin{array}{l}\text { The bicycle is Wuyang } \\
- \text { (the name of capital } \\
\text { city- Guangzhou) }\end{array}$ & $\begin{array}{l}\text { Bicycle; } \\
\text { Wuyang city }\end{array}$ & Well-known, popular \\
\hline 1.11 & Shoes are flowers. & $\begin{array}{l}\text { Shoes; } \\
\text { flowers }\end{array}$ & $\begin{array}{l}\text { Stylish, comfortable, } \\
\text { bright color, quality } \\
\text { material }\end{array}$ \\
\hline 1.12 & $\begin{array}{lc}\text { Shanghai } & \text { Sports } \\
\text { Products Manufacturer }\end{array}$ & N.A. & Award winner in quality \\
\hline 1.13 & $\begin{array}{l}\text { Shanghai Soft Mattress } \\
\text { Company }\end{array}$ & N.A. & $\begin{array}{l}\text { Guarantee of delivery, } \\
\text { repair, change }\end{array}$ \\
\hline 1.14 & $\begin{array}{l}\text { Shanghai Diesel Engine } \\
\text { Producer }\end{array}$ & N.A. & $\begin{array}{l}\text { Long history and } \\
\text { popularity }\end{array}$ \\
\hline 1.15 & $\begin{array}{l}\text { Shanghai Machinery } \\
\text { Equipment Company }\end{array}$ & N.A. & $\begin{array}{l}\text { World-wide business } \\
\text { connection }\end{array}$ \\
\hline $1.16 \odot$ & $\begin{array}{l}\text { The medicine is the } \\
\text { martial arts. }\end{array}$ & $\begin{array}{l}\text { Medicine; } \\
\text { Martial arts }\end{array}$ & $\begin{array}{l}\text { Body buildup, healthy } \\
\text { and strong body }\end{array}$ \\
\hline 1.17 & $\begin{array}{lr}\text { Liver } & \text { Protection } \\
\text { Capsules by } & \\
\text { Guangzhou } & \text { Xingqun } \\
\text { Pharmaceutical Factory }\end{array}$ & N.A. & Function and efficacy \\
\hline 1.18 & $\begin{array}{l}\text { Nasal Inhaler for stroke } \\
\text { and comas } \\
\text { Guangzhou Xingqun } \\
\text { Pharmaceutical Factory }\end{array}$ & N.A. & Fast/immediate efficacy \\
\hline 1.19 & $\begin{array}{l}\text { The herbal medicines } \\
\text { are cranes (the symbol } \\
\text { of longevity in Chinese } \\
\text { culture). }\end{array}$ & $\begin{array}{l}\text { Herbal medicine; } \\
\text { Cranes }\end{array}$ & $\begin{array}{l}\text { Longevity and good } \\
\text { health }\end{array}$ \\
\hline 1.20 & Swiss Rado watches & N.A. & Modern feature \\
\hline 1.21 & Swiss Titoni watches & N.A. & Scientifically advanced \\
\hline 1.22 & $\begin{array}{l}\text { The TV is Beijing (the } \\
\text { capital of China). }\end{array}$ & $\begin{array}{l}\text { TV; } \\
\text { Beijing }\end{array}$ & $\begin{array}{l}\text { Long history, well- } \\
\text { known, capital city }\end{array}$ \\
\hline $1.23 \odot$ & $\begin{array}{l}\text { Electric pressure adapter } \\
\text { is a call center. }\end{array}$ & $\begin{array}{l}\text { Electric pressure } \\
\text { adapter; a smiling lady }\end{array}$ & $\begin{array}{l}\text { Friendly, } \\
\text { solving }\end{array}$ \\
\hline 1.24 & $\begin{array}{l}\text { Casio memory stick is } \\
\text { an animation figure of } \\
\text { power. }\end{array}$ & $\begin{array}{l}\text { Casio memory stick; } \\
\text { Animation figure of } \\
\text { power. }\end{array}$ & $\begin{array}{l}\text { Powerful, popular cartoon } \\
\text { figure }\end{array}$ \\
\hline 1.25 & $\begin{array}{l}\text { Micro Electron Circuit } \\
\text { Products }\end{array}$ & N.A. & Product name and display \\
\hline $1.26 \bigcirc$ & $\begin{array}{l}\text { Sanyo TV is natural } \\
\text { scenery. }\end{array}$ & $\begin{array}{l}\text { Sanyo TV; } \\
\text { A boy holding a TV. }\end{array}$ & Natural and homely \\
\hline 1.27 & $\begin{array}{ll}\begin{array}{l}\text { Olympus } \\
\text { equipment }\end{array} & \text { optical } \\
\end{array}$ & N.A. & Serve you well \\
\hline 1.28 & $\begin{array}{l}\text { Liquid Chromatogram } \\
\text { Stick. }\end{array}$ & N.A & Value pricing \\
\hline
\end{tabular}




\begin{tabular}{|c|c|c|c|}
\hline $1.29 \odot$ & $\begin{array}{l}\text { Our restaurant is a } \\
\text { nymph in heaven. }\end{array}$ & $\begin{array}{l}\text { Restaurant; } \\
\text { A nymph in heaven }\end{array}$ & Beautiful and immortal \\
\hline 1.30 & $\begin{array}{l}\text { The Food Town is } \\
\text { festival decoration. }\end{array}$ & $\begin{array}{l}\text { The Food Town; } \\
\text { Festival decoration. }\end{array}$ & Lucky and happy \\
\hline 1.31 & $\begin{array}{l}\text { Shanghai International } \\
\text { Trust Service Corp. }\end{array}$ & N. A. & $\begin{array}{l}\text { Simple, } \\
\text { reliable }\end{array}$ \\
\hline 1.32 & RICOH Camera & N. A & Product name \\
\hline 1.33 & $\begin{array}{l}\text { Nippon Airline is a } \\
\text { flying logo. }\end{array}$ & $\begin{array}{l}\text { Nippon Airline; } \\
\text { Airline logo }\end{array}$ & Logo display, safety \\
\hline $1.34 \bigcirc$ & $\begin{array}{l}\text { Lacovo Coco drink is a } \\
\text { smiling man. }\end{array}$ & $\begin{array}{l}\text { Lacovo Coco drink; } \\
\text { A smiling man }\end{array}$ & $\begin{array}{l}\text { Delicious and thick, } \\
\text { satisfied }\end{array}$ \\
\hline 1.35 & $\begin{array}{l}\text { Chinese Arts \& Crafts } \\
\text { Firm is colorful kites. }\end{array}$ & $\begin{array}{l}\text { Chinese Arts \& Crafts } \\
\text { Firm; colorful kites }\end{array}$ & Tradition, cultivation \\
\hline $1.36 \odot$ & $\begin{array}{l}\text { Lufthansa is stewardess } \\
\text { smile. }\end{array}$ & $\begin{array}{l}\text { Lufthansa; } \\
\text { stewardess smile }\end{array}$ & $\begin{array}{l}\text { Warm, thoughtful, } \\
\text { considerate service }\end{array}$ \\
\hline $1.37 \odot$ & $\begin{array}{l}\text { Japanese } \\
\text { Company is a famional } \\
\text { photo. }\end{array}$ & $\begin{array}{l}\text { Japanese National } \\
\text { Company; family photo }\end{array}$ & $\begin{array}{l}\text { Colorful life, good } \\
\text { memories }\end{array}$ \\
\hline 1.38 & $\begin{array}{l}\text { Tianjin } \\
\text { Factory }\end{array}$ & N. A & Welcome to order \\
\hline 1.39 & Automatic Lathe & N. A & Convenient to order \\
\hline 1.40 & $\begin{array}{l}\text { National Electronics } \\
\text { Window Display }\end{array}$ & N. A & $\begin{array}{l}\text { Product/brand name and } \\
\text { display }\end{array}$ \\
\hline 1.41 & $\begin{array}{l}\text { Shanghai Ad Agency is } \\
\text { the Great Wall. }\end{array}$ & $\begin{array}{l}\text { Shanghai Ad Agency; } \\
\text { the Great Wall }\end{array}$ & $\begin{array}{l}\text { Historical sites and } \\
\text { cultural relics in new era }\end{array}$ \\
\hline $1.42 \bigcirc$ & $\begin{array}{l}\text { Meilin Canned Food is a } \\
\text { family picnic. }\end{array}$ & $\begin{array}{l}\text { Meilin Canned Food; } \\
\text { Family picnic }\end{array}$ & $\begin{array}{l}\text { Family } \\
\text { relaxation }\end{array}$ \\
\hline 1.43 & $\begin{array}{l}\text { China Tire is new } \\
\text { China. }\end{array}$ & $\begin{array}{l}\text { China Tire; } \\
\text { New China }\end{array}$ & New, beginning, hopeful \\
\hline $1.44 @$ & $\begin{array}{l}\text { Coca Cola is a happy } \\
\text { lady drinking. }\end{array}$ & $\begin{array}{l}\text { Coca Cola; } \\
\text { A happy lady. }\end{array}$ & Happy feeling \\
\hline 1.45 & $\begin{array}{l}\text { Chinese tea is a pot } \\
\text { flower of orchid. }\end{array}$ & $\begin{array}{l}\text { Chinese tea; } \\
\text { a pot flower of orchid }\end{array}$ & Cultured, fragrant \\
\hline 1.46 & $\begin{array}{l}\text { Maxwell Coffee } \\
\text { variety of coffee in } \\
\text { display. }\end{array}$ & $\begin{array}{l}\text { Maxwell Coffee; } \\
\text { Varieties of coffees }\end{array}$ & Modern lifestyle \\
\hline $1.47 \odot$ & $\begin{array}{l}\text { Foreign Ad Show is } \\
\text { bikini girl surfing. }\end{array}$ & $\begin{array}{l}\text { Foreign Ad Show; } \\
\text { bikini girl surfing }\end{array}$ & Sexy, cool, adventurous \\
\hline 1.48 & Bat Electronics & N. A & Product name and display \\
\hline $1.49 \odot$ & $\begin{array}{l}\text { Nutritious Capsule is a } \\
\text { gymnast. }\end{array}$ & $\begin{array}{l}\text { Nutritious Capsule; } \\
\text { a gymnast }\end{array}$ & $\begin{array}{l}\text { Healthy, slim, witty, and } \\
\text { beautiful }\end{array}$ \\
\hline 1.50 & $\begin{array}{l}\text { "New Time" Dept. Store } \\
\text { is White House. }\end{array}$ & $\begin{array}{l}\text { "New Time" Dept. } \\
\text { Store; White House }\end{array}$ & American lifestyle \\
\hline 1.51 & Mitsubishi car & N. A. & Choice and selection \\
\hline 1.52 & Draft Fan Furnace & N. A. & Product name and display \\
\hline 1.53 & Sony & N. A & Product/company name \\
\hline
\end{tabular}




\begin{tabular}{|c|c|c|c|}
\hline & & & and display \\
\hline $1.54 \odot$ & $\begin{array}{l}\text { "Beijing Story" Movie } \\
\text { are many faces. }\end{array}$ & $\begin{array}{l}\text { "Beijing Story" Movie; } \\
\text { Many faces }\end{array}$ & Nostalgia, old folk story \\
\hline 1.55 & $\begin{array}{l}\text { Toyota car is on the } \\
\text { road } \\
\text { Wherever there is road, } \\
\text { there is Toyota car. }\end{array}$ & N.A. & $\begin{array}{ll}\text { Ubiquitous, } & \text { travel } \\
\text { experience } & \end{array}$ \\
\hline 1.56 & $\begin{array}{l}\text { Thunderstorm Radio is a } \\
\text { trophy. }\end{array}$ & $\begin{array}{l}\text { Thunderstorm Radio; } \\
\text { A trophy }\end{array}$ & $\begin{array}{l}\text { Victory, (quality) award } \\
\text { winning }\end{array}$ \\
\hline 1.57 & $\begin{array}{l}\text { National Repair Shop is } \\
\text { a monkey king. }\end{array}$ & $\begin{array}{l}\text { National Repair Shop; } \\
\text { monkey king }\end{array}$ & $\begin{array}{l}\text { Resourceful, agile, } \\
\text { Electronic family, quality } \\
\text { life }\end{array}$ \\
\hline $1.58 \odot$ & $\begin{array}{l}\text { Alarm clock is a female } \\
\text { movie star. }\end{array}$ & $\begin{array}{l}\text { Alarm clock; } \\
\text { A female movie star. }\end{array}$ & Precious time \\
\hline $1.59 \odot$ & $\begin{array}{l}\text { Yanwu Tape Recorder } \\
\text { is a singing and dancing } \\
\text { boy. }\end{array}$ & $\begin{array}{l}\text { Yanwu Tape Recorder; } \\
\text { A boy singing and } \\
\text { dancing }\end{array}$ & Fun making, enjoy \\
\hline $1.60 \odot$ & $\begin{array}{l}\text { Konica film is an } \\
\text { aerobic gymnast. }\end{array}$ & $\begin{array}{l}\text { Konica film; } \\
\text { An aerobic gymnast }\end{array}$ & Graceful, dynamic, speed \\
\hline 1.61 & Santana car & N. A. & $\begin{array}{l}\text { Product/company name } \\
\text { and display }\end{array}$ \\
\hline $1.62 \odot$ & $\begin{array}{l}\text { Lion brand sneaker shoe } \\
\text { is a travel companion. }\end{array}$ & $\begin{array}{l}\text { Lion brand sneaker shoe } \\
\text { Travel companion }\end{array}$ & $\begin{array}{l}\text { Travel experience, a good } \\
\text { companion }\end{array}$ \\
\hline $1.63 \bigcirc$ & $\begin{array}{l}\text { Kodak film is a foreign } \\
\text { beauty in the candle } \\
\text { light. }\end{array}$ & $\begin{array}{l}\text { Kodak color film; } \\
\text { Foreign beauty }\end{array}$ & $\begin{array}{l}\text { Foreign beauty, good } \\
\text { exposure }\end{array}$ \\
\hline $1.64 \odot$ & $\begin{array}{l}\text { Dabao Fragrance Cream } \\
\text { is a snooker player. }\end{array}$ & $\begin{array}{l}\text { Dabao Fragrance Cream; } \\
\text { A man snooker player }\end{array}$ & Gentleman's manner \\
\hline $1.65 \odot$ & $\begin{array}{l}\text { Toshiba refrigerator is a } \\
\text { Q\&A test in cross talk. }\end{array}$ & $\begin{array}{l}\text { Toshiba refrigerator; } \\
\text { Cross talk }\end{array}$ & Fame and popularity \\
\hline $1.66 \oplus$ & $\begin{array}{l}\text { Jianlibao sport drink is a } \\
\text { national } \quad \text { volleyball } \\
\text { heroine. }\end{array}$ & $\begin{array}{ll}\text { Jianlibao sport drink; } \\
\text { National } & \text { volleyball } \\
\text { heroine } & \\
\end{array}$ & $\begin{array}{l}\text { Magic and heroic, } \\
\text { popular and eye-catching }\end{array}$ \\
\hline $1.67 \odot$ & $\begin{array}{l}\text { Northwest Airline is } \\
\text { first class service. }\end{array}$ & $\begin{array}{l}\text { Northwest Airline; } \\
\text { First class stewardess. }\end{array}$ & Consistent care and safety \\
\hline $1.68 \odot$ & $\begin{array}{l}\text { Chrysanthemum alcohol } \\
\text { is a social party. }\end{array}$ & $\begin{array}{l}\text { Chrysanthemum } \\
\text { alcohol; Social party }\end{array}$ & $\begin{array}{l}\text { Relationship } \\
\text { entertainment }\end{array}$ \\
\hline $1.69 \ominus$ & $\begin{array}{l}\text { Weili Washing Machine } \\
\text { is a gift to mother. }\end{array}$ & $\begin{array}{l}\text { Weili Washing Machine; } \\
\text { A gift to mother }\end{array}$ & $\begin{array}{l}\text { Dedicated love, care, } \\
\text { homesick }\end{array}$ \\
\hline 1.70 & $\begin{array}{l}\text { Double fish lock is a } \\
\text { door guard. }\end{array}$ & $\begin{array}{l}\text { Lock; } \\
\text { A door guard }\end{array}$ & $\begin{array}{l}\text { Home security and } \\
\text { protection }\end{array}$ \\
\hline $1.71 \Theta$ & $\begin{array}{l}\text { Ad Magazine is a } \\
\text { woman whispering to a } \\
\text { man. }\end{array}$ & $\begin{array}{l}\text { Ad Magazine; } \\
\text { A woman whispering to } \\
\text { a man }\end{array}$ & $\begin{array}{l}\text { Secrets share, confiding } \\
\text { in }\end{array}$ \\
\hline $1.72 \odot$ & $\begin{array}{l}\text { Stomach medicine is a } \\
\text { successful actor. }\end{array}$ & $\begin{array}{l}\text { Stomach medicine; } \\
\text { A successful actor }\end{array}$ & Health and celebrity \\
\hline
\end{tabular}




\begin{tabular}{|c|c|c|c|}
\hline $1.73 \odot$ & $\begin{array}{l}\text { Woolen sweater is a } \\
\text { foreign beauty. }\end{array}$ & $\begin{array}{l}\text { Woolen sweater; } \\
\text { A foreign beauty }\end{array}$ & Foreign/Exotic, beautiful \\
\hline $1.74 \odot$ & $\begin{array}{ll}\text { Danggui } & \text { herbal } \\
\text { medicine is a family } \\
\text { reunion. }\end{array}$ & $\begin{array}{l}\text { Herbal medicine; } \\
\text { a family reunion }\end{array}$ & $\begin{array}{l}\text { Home coming, warm } \\
\text { feeling, }\end{array}$ \\
\hline $1.75 \odot$ & $\begin{array}{l}\text { Qiluowa Ice Box is a } \\
\text { thirsty man in the } \\
\text { dessert }\end{array}$ & $\begin{array}{l}\text { Ice Box; } \\
\text { A thirsty man in the } \\
\text { dessert }\end{array}$ & $\begin{array}{l}\text { Chilled, thirsty crunch, } \\
\text { exploring }\end{array}$ \\
\hline 1.76 & Agfa photo equipment & N. A. & $\begin{array}{ll}\text { Diversity } & \text { and } \\
\text { breakthrough } & \end{array}$ \\
\hline $1.77 \odot$ & $\begin{array}{l}\text { Specific toothpaste is a } \\
\text { white teethed beauty. }\end{array}$ & $\begin{array}{l}\text { Specific toothpaste; } \\
\text { white teethed beauty }\end{array}$ & $\begin{array}{l}\text { Healthy teeth, beautiful, } \\
\text { fresh-looking }\end{array}$ \\
\hline $1.78 \odot$ & $\begin{array}{l}\text { Fish Lock is a guard } \\
\text { fighting against Monkey } \\
\text { King. }\end{array}$ & $\begin{array}{l}\text { Lock; a guard fighting } \\
\text { against Monkey King. }\end{array}$ & $\begin{array}{l}\text { Solid and unbreakable, } \\
\text { more powerful than } \\
\text { Monkey king }\end{array}$ \\
\hline $1.79 \odot$ & $\begin{array}{l}\text { Maxam Pearl Cream is a } \\
\text { foreign beauty. }\end{array}$ & $\begin{array}{l}\text { Maxam Pearl Cream; } \\
\text { foreign beauty }\end{array}$ & Foreign/exotic beauty \\
\hline $1.80 \bigcirc$ & $\begin{array}{l}\text { O.B. stick napkin is a } \\
\text { girl on the swing. }\end{array}$ & $\begin{array}{l}\text { O.B. stick napkin; } \\
\text { A girl on the swing. }\end{array}$ & Care-free, happy and free \\
\hline $1.81 \odot$ & $\begin{array}{l}\text { The Great Wall raincoat } \\
\text { is smart ladies. }\end{array}$ & $\begin{array}{l}\text { The raincoat; } \\
\text { Smart ladies }\end{array}$ & $\begin{array}{l}\text { Smart, } \\
\text { fashionable }\end{array}$ \\
\hline 1.82 & $\begin{array}{l}\text { Chundu hams are Spring } \\
\text { Festival lanterns. }\end{array}$ & $\begin{array}{l}\text { Hams; } \\
\text { Lanterns }\end{array}$ & $\begin{array}{l}\text { Festive and celebrating } \\
\text { atmosphere (喜庆, 祥 } \\
\text { 和) }\end{array}$ \\
\hline 1.83 & $\begin{array}{lr}\text { Benz } & \text { construction } \\
\text { equipments } & \text { are } \\
\text { construction sites. } & \end{array}$ & N.A. & Satisfy your needs \\
\hline 1.840 & $\begin{array}{l}\text { Boeing } 757 \text { is a matched } \\
\text { couple. }\end{array}$ & $\begin{array}{l}\text { Boeing } 757 \\
\text { Matched couple. }\end{array}$ & Most suitable \\
\hline $1.85 \odot$ & $\begin{array}{l}\text { Qiaoli face cleansing } \\
\text { milk is jade-white } \\
\text { beauty. }\end{array}$ & $\begin{array}{l}\text { Face cleansing milk; } \\
\text { Jade-white beauty }\end{array}$ & White skin, precious \\
\hline 1.86 & $\begin{array}{l}\text { Tianli Shampoo is a } \\
\text { beauty made of flowers. }\end{array}$ & $\begin{array}{l}\text { Shampoo; } \\
\text { flowers }\end{array}$ & $\begin{array}{ll}\text { Natural, fragrant, } \\
\text { beautiful }\end{array}$ \\
\hline $1.87 \odot$ & $\begin{array}{l}\text { Computerized } \\
\text { typewriter is a smiling } \\
\text { lady secretary. }\end{array}$ & $\begin{array}{l}\text { Typewriter; } \\
\text { lady secretary }\end{array}$ & $\begin{array}{l}\text { Light-hearted and happy } \\
\text { smile, easy and efficient } \\
\text { work }\end{array}$ \\
\hline $1.88 \odot$ & $\begin{array}{l}\text { Musical Stereos is } \\
\text { classic beauty playing } \\
\text { harp in a thunder } \\
\text { storming day. }\end{array}$ & $\begin{array}{l}\text { Musical Stereos; } \\
\text { Beauty playing harp }\end{array}$ & $\begin{array}{l}\text { Beautiful and expressive } \\
\text { melody }\end{array}$ \\
\hline 1.89 & $\begin{array}{l}\text { Yizhihua industrial } \\
\text { Plant is a TV tower. }\end{array}$ & $\begin{array}{l}\text { industrial Plant; } \\
\text { TV tower }\end{array}$ & Tall and giant, visible \\
\hline 1.90 & Liquid Pressure Digger & N.A. & Product/brand name \\
\hline
\end{tabular}




\begin{tabular}{|l|l|l|l|}
\hline 1.91 & Haida watches & N. A. & Quality and integrity \\
\hline $1.92 \odot$ & $\begin{array}{l}\text { Xiafei Cosmetics is Pan } \\
\text { Hong - a famous } \\
\text { Chinese female star. }\end{array}$ & $\begin{array}{l}\text { Cosmetics; famous Chinese } \\
\text { female star }\end{array}$ & $\begin{array}{l}\text { Well-known, shining star } \\
\text { and beauty }\end{array}$ \\
\hline $1.93 \odot$ & $\begin{array}{l}\text { Water Heater is } \\
\text { WangMingQuan - a } \\
\text { Hong Kong female star. }\end{array}$ & $\begin{array}{l}\text { Water Heater; Hong Kong female } \\
\text { star }\end{array}$ & Happy families \\
\hline 1.94 & $\begin{array}{l}\text { Martell is an antique } \\
\text { car. }\end{array}$ & $\begin{array}{l}\text { Martell; } \\
\text { Antique car }\end{array}$ & $\begin{array}{l}\text { Antiquity, } \\
\text { collection }\end{array}$ \\
\hline 1.95 & Marlboro is countryside. & $\begin{array}{l}\text { Marlboro; } \\
\text { Countryside }\end{array}$ & $\begin{array}{l}\text { Country, } \\
\text { romantic }\end{array}$ \\
\hline $1.96 \odot$ & $\begin{array}{l}\text { Tianli body shampoo is } \\
\text { a beauty in flower tub. }\end{array}$ & $\begin{array}{l}\text { Body shampoo; } \\
\text { Beauty }\end{array}$ & Tender and beautiful skin \\
\hline 1.97 & $\begin{array}{l}\text { Recorder tapes are } \\
\text { dancing silk ribbons. }\end{array}$ & $\begin{array}{l}\text { Recorder tapes; } \\
\text { Silk ribbons }\end{array}$ & $\begin{array}{l}\text { Smooth, } \\
\text { melodious }\end{array}$ \\
\hline $1.98 \odot$ & $\begin{array}{l}\text { Swiss Longines Watch } \\
\text { is upper class } \\
\text { man/woman. }\end{array}$ & $\begin{array}{l}\text { Swiss Longines Watch; } \\
\text { man/woman }\end{array}$ & Upper class, luxury \\
\hline 1.99 & Maxwell drink & N. A. & Champion \\
\hline 1.100 & Singing concert & N. A. & Modern and blue (sad) \\
\hline
\end{tabular}

Table II-2 100 Metaphorical Statements, Primary Subjects and Secondary Subjects and Their Corresponding Projected Features from 1989 to 1998

\begin{tabular}{|c|c|c|c|}
\hline $\begin{array}{l}\text { Ad } \\
\text { No. }\end{array}$ & $\begin{array}{l}\text { Metaphorical } \\
\text { statements }\end{array}$ & $\begin{array}{l}\text { Signifier \& signified } \\
\text { Primary subject } \\
\text { secondary subject }\end{array}$ & $\begin{array}{lr}\text { Projected } & \text { features } \\
\text { (entailments) } & \text { as } \\
\text { embodied in the } \\
\text { images }\end{array}$ \\
\hline 2.1 & $\begin{array}{l}\text { Hualin Garden is armrest } \\
\text { made in mahogany. }\end{array}$ & $\begin{array}{l}\text { Hualin Garden; armrest } \\
\text { made in mahogany }\end{array}$ & $\begin{array}{lll}\text { Detailed work, rare } \\
\text { material }\end{array}$ \\
\hline 2.2 & $\begin{array}{l}\text { Shanghai Santana is train } \\
\text { head and compartment. }\end{array}$ & $\begin{array}{l}\text { Santana car; train head } \\
\text { and compartment }\end{array}$ & Speedy plus spacious \\
\hline 2.3 & $\begin{array}{l}\text { Robust Purified Water is } \\
27 \text { layers of filters. }\end{array}$ & $\begin{array}{l}\text { Robust Purified Water; } \\
\text { filters }\end{array}$ & Pure, guaranteed quality \\
\hline 2.4 & $\begin{array}{l}\text { Brain Thrombus Capsule } \\
\text { is smooth brain } \\
\text { labyrinth. }\end{array}$ & $\begin{array}{l}\text { Capsule; } \\
\text { Smooth labyrinth }\end{array}$ & $\begin{array}{l}\text { Healthy and smooth } \\
\text { brain vessel }\end{array}$ \\
\hline$\overline{2.5}$ & $\begin{array}{l}\text { Sefio Air Dryer is } \\
\text { squeezed cloth. }\end{array}$ & N.A. & Dry air \\
\hline 2.6 & $\begin{array}{l}\text { LongJing Tea is (in } \\
\text { shape it looks like } \\
\text { Chinese word -Taste) }\end{array}$ & $\begin{array}{l}\text { LongJing Tea; } \\
\text { Three cups }\end{array}$ & $\begin{array}{l}\text { Taste and appreciate, } \\
\text { relax }\end{array}$ \\
\hline 2.7 & $\begin{array}{l}\text { Ad Design Agency is } \\
\text { different paper cuts. }\end{array}$ & $\begin{array}{l}\text { Ad Design Agency; Paper } \\
\text { cuts }\end{array}$ & $\begin{array}{l}\text { To cut (strategize and } \\
\text { design) }\end{array}$ \\
\hline $2.8(1)$ & $\begin{array}{l}\text { China Telecom is } \\
\text { marriage gown/ reliable }\end{array}$ & $\begin{array}{l}\text { China Telecom; marriage } \\
\text { gown, reliable shoulder }\end{array}$ & Care and condolence \\
\hline
\end{tabular}




\begin{tabular}{|c|c|c|c|}
\hline & shoulder. & & \\
\hline 2.9 . & $\begin{array}{l}\text { Riverside Garden is a } \\
\text { bigger fish pot. }\end{array}$ & $\begin{array}{l}\text { Riverside Garden; } \\
\text { Fish pot }\end{array}$ & $\begin{array}{l}\text { Comparison, more } \\
\text { natural scene }\end{array}$ \\
\hline 2.10 & $\begin{array}{l}\text { San Alliguel is (Xu } \\
\text { Haifeng's) missed target. }\end{array}$ & $\begin{array}{l}\text { San Alliguel real estate; } \\
\text { Miss- target hero }\end{array}$ & $\begin{array}{l}\text { You lose but still you } \\
\text { are the hero. You fight } \\
\text { to the end. Olympic } \\
\text { spirit }\end{array}$ \\
\hline 2.11 & $\begin{array}{l}\text { Wanjiale Water Heater is } \\
\text { PK game. }\end{array}$ & $\begin{array}{l}\text { Wanjiale Water Heater; } \\
\text { PK game }\end{array}$ & Competition, winning \\
\hline $2.12 \ominus$ & $\begin{array}{l}\text { IBM is a trouble free } \\
\text { man. }\end{array}$ & $\begin{array}{l}\text { IBM system; } \\
\text { A trouble-free man }\end{array}$ & $\begin{array}{l}\text { Trouble-free, bondage- } \\
\text { free man Perfectness }\end{array}$ \\
\hline 2.13 & $\begin{array}{l}\text { Gillette Blade is luxury } \\
\text { pen, tie, and buttons. }\end{array}$ & $\begin{array}{l}\text { Gillette Blade; } \\
\text { Luxury pen, tie, buttons }\end{array}$ & $\begin{array}{l}\text { Detailed well-groomed } \\
\text { men }\end{array}$ \\
\hline 2.14 & $\begin{array}{ll}\text { China } & \text { Mobile } \\
\text { Gotone } & \text {. }\end{array}$ & N. A & Connection \\
\hline $2.15 \odot$ & $\begin{array}{l}\text { Guizhou City Daily is } \\
\text { newsman's head. }\end{array}$ & $\begin{array}{l}\text { Newspaper; } \\
\text { Man's head }\end{array}$ & $\begin{array}{l}\text { Sensational home and } \\
\text { abroad news }\end{array}$ \\
\hline 2.16 & Mineral Water is a bride. & $\begin{array}{l}\text { Mineral Water; } \\
\text { A bride }\end{array}$ & $\begin{array}{l}\text { Perfect opening, newly } \\
\text { launched, mysterious }\end{array}$ \\
\hline 2.17 & $\begin{array}{l}\text { Blue Star Beer is whole } \\
\text { malt field. }\end{array}$ & $\begin{array}{l}\text { Beer; } \\
\text { Whole malt field }\end{array}$ & Natural crop made \\
\hline 2.18 & $\begin{array}{l}\text { Nutritional Liquid is } \\
\text { fruit \& vegetable field. }\end{array}$ & $\begin{array}{l}\text { Nutritional Liquid; } \\
\text { Fruit and vegetable field }\end{array}$ & Colorful, harvest field \\
\hline 219 & $\begin{array}{l}\text { Shanghai Ad } \\
\text { Communication Firm is } \\
\text { a match-made piano. }\end{array}$ & $\begin{array}{l}\text { Ad firm (Creative idea) } \\
\text { A match-made piano }\end{array}$ & $\begin{array}{l}\text { Inspiration, creative } \\
\text { idea, artistic design }\end{array}$ \\
\hline 2.20 & $\begin{array}{l}\text { GFO accounting } \\
\text { software is } 6 \\
\text { abacuses/chips. }\end{array}$ & $\begin{array}{l}\text { Accounting software; } \\
6 \text { abacuses (like } 6 \text { chips) }\end{array}$ & Fast calculation, shrewd \\
\hline 2.21 & $\begin{array}{l}\text { Olympus Camera is a } \\
\text { lovely mini-cat. }\end{array}$ & $\begin{array}{l}\text { Olympus Camera; } \\
\text { Mini pet cat }\end{array}$ & $\begin{array}{l}\text { Mini body, clever } \\
\text { design, multi-function, } \\
\text { good quality, lovely like } \\
\text { a pet cat }\end{array}$ \\
\hline 2.22 & $\begin{array}{l}\text { Wanke Real Estate is } \\
\text { hen laying eggs. }\end{array}$ & $\begin{array}{l}\text { Real Estate; } \\
\text { Hen laying eggs }\end{array}$ & $\begin{array}{l}\text { High-return investment, } \\
\text { value investment }\end{array}$ \\
\hline 2.23 & $\begin{array}{l}\text { Wanhe Gas Heater is a } \\
\text { camel. }\end{array}$ & $\begin{array}{l}\text { Wanhe Gas Heater } \\
\text { A camel }\end{array}$ & $\begin{array}{l}\text { (Still function) when } \\
\text { water level and pressure } \\
\text { is low. }\end{array}$ \\
\hline $2.24 \odot$ & $\begin{array}{l}\text { Philips Computer is } \\
\text { Einstein's prophet. }\end{array}$ & $\begin{array}{l}\text { Philips Computer; } \\
\text { Einstein's prophet }\end{array}$ & $\begin{array}{l}\text { Light speed, giant's } \\
\text { mind }\end{array}$ \\
\hline $2.25 \bigcirc$ & $\begin{array}{l}\text { Squibb's Cough } \\
\text { Medicine is a doctor on } \\
\text { express. }\end{array}$ & $\begin{array}{l}\text { Cough Medicine; } \\
\text { A doctor on express }\end{array}$ & $\begin{array}{l}\text { Help stranger, fast } \\
\text { treatment and cure }\end{array}$ \\
\hline 2.26 & $\begin{array}{l}\text { IBM Solution is twisted } \\
\text { rope, the moon cake. }\end{array}$ & $\begin{array}{l}\text { IBM Solution; } \\
\text { twisted rope, the moon } \\
\text { cake }\end{array}$ & $\begin{array}{l}\text { Find out solution/way } \\
\text { to.. } \\
\text { Once a year opportunity }\end{array}$ \\
\hline
\end{tabular}




\begin{tabular}{|c|c|c|c|}
\hline 2.27 & $\begin{array}{l}\text { Mini-van without air- } \\
\text { conditioner is a steamer } \\
\text { \& a fever patient. }\end{array}$ & $\begin{array}{l}\text { Mini-van without air- } \\
\text { conditioner; } \\
\text { A steamer and a fever } \\
\text { patient }\end{array}$ & $\begin{array}{l}\text { Steam-hot, high fever, } \\
\text { miserable }\end{array}$ \\
\hline 2.28 & $\begin{array}{l}\begin{array}{l}\text { Nippon Paint is a } \\
\text { butterfly. }\end{array} \\
\end{array}$ & $\begin{array}{l}\text { Nippon Paint; } \\
\text { Butterfly }\end{array}$ & $\begin{array}{ll}\text { Colorful, } & \text { bright, } \\
\text { extraordinary }\end{array}$ \\
\hline $2.29 \odot$ & $\begin{array}{l}\text { LiNing Sportswear is a } \\
\text { famous male gymnast. }\end{array}$ & $\begin{array}{l}\text { Sportswear; } \\
\text { A famous male gymnast }\end{array}$ & $\begin{array}{l}\text { Heroic nature, Olympic } \\
\text { champion }\end{array}$ \\
\hline 2.30 & $\begin{array}{l}\text { Bangdi woundplast is a } \\
\text { submarine. }\end{array}$ & $\begin{array}{l}\text { Bangdi woundplast; } \\
\text { A submarine }\end{array}$ & $\begin{array}{l}\text { Water-proof, tight } \\
\text { compartment }\end{array}$ \\
\hline 2.31 & $\begin{array}{l}\text { Earth Digger Equipment } \\
\text { is an ear picker. }\end{array}$ & $\begin{array}{l}\text { Earth Digger Equipment } \\
\text { An ear picker }\end{array}$ & Miniature \\
\hline 2.32 & $\begin{array}{l}\text { Motorola Modem is (4) } \\
\text { praise signs. }\end{array}$ & $\begin{array}{l}\text { Motorola Modem; } \\
\text { OK, thumb up, No.1, A's } \\
\text { work }\end{array}$ & $\begin{array}{l}\text { Different users, the } \\
\text { same praise }\end{array}$ \\
\hline 2.33 & $\begin{array}{l}\text { is the unfolding } \\
\text { p. }\end{array}$ & $\begin{array}{l}\text { Audi car; } \\
\text { Unfolding world map }\end{array}$ & ct the world \\
\hline 2.34 & $\begin{array}{l}\text { od Garment is a } \\
\text { ng apple. }\end{array}$ & $\begin{array}{l}\text { Texwood Garment; } \\
\text { a glistering apple }\end{array}$ & $\begin{array}{l}\text { Newton, inspiration \& } \\
\text { discovery }\end{array}$ \\
\hline 2.35 & $\begin{array}{l}\text { Newspaper is dictionary, } \\
\text { tea cup, football, } \\
\text { fashion. }\end{array}$ & $\begin{array}{l}\text { Newspaper; dictionary, } \\
\text { tea cup, football, fashion }\end{array}$ & $\begin{array}{l}\text { Information in } \\
\text { publication, topics, } \\
\text { sports, and fashion. }\end{array}$ \\
\hline 2.36 & $\begin{array}{l}\text { GE Lightening is the } \\
\text { moon. }\end{array}$ & $\begin{array}{l}\text { GE Lightening; } \\
\text { The moon }\end{array}$ & $\begin{array}{l}\text { Lighten the whole world } \\
\text { at night, } 100 \text { years } \\
\text { history }\end{array}$ \\
\hline $2.37 \odot$ & $\begin{array}{l}\text { Haerbin Beer is Jean- } \\
\text { Paul Sartre (French } \\
\text { philosopher). }\end{array}$ & $\begin{array}{l}\text { Beer; } \\
\text { Jean-Paul Sartre }\end{array}$ & $\begin{array}{l}\text { One century image, } \\
\text { influential, freedom }\end{array}$ \\
\hline 2.38 & $\begin{array}{l}\text { TV is Chinese cabbage, } \\
\text { piggy bank, fish \& bear } \\
\text { paw together. }\end{array}$ & $\begin{array}{l}\text { TV; cabbage, piggy bank, } \\
\text { get both fish and bear } \\
\text { paw }\end{array}$ & $\begin{array}{l}\text { Value for money (low } \\
\text { price but high quality), } \\
\text { for common people }\end{array}$ \\
\hline $2.39 \odot$ & $\begin{array}{l}\text { Modern Advertising is a } \\
\text { traditional Chinese saint. }\end{array}$ & $\begin{array}{l}\text { Modern Advertising; } \\
\text { A traditional saint }\end{array}$ & $\begin{array}{l}\text { Civilization and } \\
\text { progress, a learned and } \\
\text { ethical role model }\end{array}$ \\
\hline 2.40 & $\begin{array}{l}\text { Wanke Garden is all } \\
\text { eggs put in one basket. }\end{array}$ & $\begin{array}{l}\text { Wanke Garden; } \\
\text { Eggs put in one basket }\end{array}$ & $\begin{array}{l}\text { Wise choice and } \\
\text { investment, no need to } \\
\text { share risk }\end{array}$ \\
\hline $2.41 @$ & $\begin{array}{l}\text { Nangfang Daily } \\
\text { Peking Opera masks. }\end{array}$ & $\begin{array}{l}\text { Newspaper; } \\
\text { Peking Opera masks }\end{array}$ & $\begin{array}{l}\text { Variety of life scenes } \\
\text { and person characters } \\
\text { on stage }\end{array}$ \\
\hline 2.42 & $\begin{array}{l}\text { Edible bird's nest is a } \\
\text { fable of Buole (expert } \\
\text { eye for really good } \\
\text { horses). }\end{array}$ & $\begin{array}{l}\text { Bird's nest; } \\
\text { Good eye for good horses }\end{array}$ & Deep insight, expertise \\
\hline 2.43 & $\begin{array}{l}\text { Shell Lubricant is a car } \\
\text { of piggy bank. }\end{array}$ & $\begin{array}{l}\text { Shell Lubricant; } \\
\text { piggy bank car }\end{array}$ & $\begin{array}{l}\text { Economical, } \\
\text { free }\end{array}$ \\
\hline
\end{tabular}




\begin{tabular}{|c|c|c|c|}
\hline 2.44 & $\begin{array}{l}\text { Herbal Wine is heart, } \\
\text { fan, Opera mask, money } \\
\text { god, paper cut and kite. }\end{array}$ & $\begin{array}{l}\text { Herbal Wine; } \\
\text { Chinese } 6 \text { fortunes }\end{array}$ & \begin{tabular}{lr} 
representing & \multicolumn{1}{c}{ love, } \\
happiness, & friendship, \\
wealth, & longevity, \\
smoothness &
\end{tabular} \\
\hline 2.45 & $\begin{array}{l}\text { Medicine for prostatitis } \\
\text { is whistle, pop can, and } \\
\text { water tap. }\end{array}$ & $\begin{array}{l}\text { Medicine for prostatitis; } \\
\text { Whistle, pop can, and } \\
\text { water tap }\end{array}$ & $\begin{array}{l}\text { Get rid of pain and } \\
\text { suffering. }\end{array}$ \\
\hline 2.46 & $\begin{array}{l}\text { Lihua Wine is bundles of } \\
\text { grapes. }\end{array}$ & $\begin{array}{l}\text { Wine; } \\
\text { Bundles of grapes }\end{array}$ & Natural and pure \\
\hline 2.47 & $\begin{array}{l}\text { The Beer is Jingbuo } \\
\text { Lake in the beer bottle. }\end{array}$ & $\begin{array}{l}\text { Beer; } \\
\text { lake }\end{array}$ & Beautiful and natural \\
\hline 2.48 & $\begin{array}{l}\text { The Toothpaste is } \\
\text { calculation }(+/-/ \times / \\
\div)\end{array}$ & $\begin{array}{l}\text { Toothpaste; } \\
\text { Arithmetic calculation }\end{array}$ & Value price \\
\hline 2.49 & $\begin{array}{l}\text { Goldlion Men's Fashion } \\
\text { is a rooster/a horse. }\end{array}$ & $\begin{array}{l}\text { Men's fashion; } \\
\text { Rooster, horse }\end{array}$ & $\begin{array}{l}\text { Men's world, } \\
\text { masculinity }\end{array}$ \\
\hline 2.50 & $\begin{array}{l}\text { The Alcohol is a temple } \\
\text { of heaven in golden } \\
\text { field. }\end{array}$ & $\begin{array}{l}\text { Alcohol bottle; } \\
\text { Temple of heaven }\end{array}$ & Holy or royal eternity \\
\hline 2.51 & $\begin{array}{l}\text { Legend is father's hand } \\
\text { holding your hand. }\end{array}$ & $\begin{array}{l}\text { Legend (Lenovo); } \\
\text { Father's hand }\end{array}$ & Confidence and growth \\
\hline 2.52 & $\begin{array}{l}\text { IPC Computer is mother } \\
\text { and father free of } \\
\text { trouble. }\end{array}$ & $\begin{array}{l}\text { Computer; } \\
\text { Mom and Pa no trouble }\end{array}$ & $\begin{array}{l}\text { Care and mutual } \\
\text { concern }\end{array}$ \\
\hline $2.53 \bigcirc$ & $\begin{array}{l}\text { Unicom Paging } \\
\text { is lady's fervice } \\
\text { expression. }\end{array}$ & $\begin{array}{l}\text { Paging service; } \\
\text { Lady's facial expression }\end{array}$ & Warm and considerate \\
\hline 2.54 & $\begin{array}{l}\text { JVC Electronics is } \\
\text { rainbow. }\end{array}$ & $\begin{array}{l}\text { Electronics; } \\
\text { rainbow }\end{array}$ & $\begin{array}{l}\text { Colorful and beautiful } \\
\text { life }\end{array}$ \\
\hline 2.55 & $\begin{array}{l}\text { HengYuanXiang } \\
\text { Woolen Products are } \\
\text { sheep. }\end{array}$ & $\begin{array}{l}\text { Woolen products; } \\
\text { sheep }\end{array}$ & Licensed wool label \\
\hline 2.56 & $\begin{array}{l}\text { Clark Air Shoes are } \\
\text { energizer and softener. }\end{array}$ & $\begin{array}{l}\text { Air shoes; } \\
\text { Energizer and softener }\end{array}$ & Comfort from high-tech \\
\hline 2.57 & $\begin{array}{l}\text { Air-conditioner is } \\
\text { American White House. }\end{array}$ & $\begin{array}{l}\text { Air-conditioner; } \\
\text { White House }\end{array}$ & American lifestyle \\
\hline 2.58 & $\begin{array}{l}\text { Blue Sky Toothpaste is a } \\
\text { flying airliner in blue } \\
\text { sky. }\end{array}$ & $\begin{array}{l}\text { Toothpaste; } \\
\text { Airliner in blue sky }\end{array}$ & Environmental friendly \\
\hline $2.59 \bigcirc$ & $\begin{array}{l}\begin{array}{l}\text { Casio is } \\
\text { pioneer } \\
\text { sculpture. }\end{array} \\
\text { presidents' }\end{array}$ & $\begin{array}{l}\text { Casio company; } \\
\text { Pioneer president }\end{array}$ & $\begin{array}{l}\text { Pioneering } \\
\text { remembering }\end{array}$ \\
\hline 2.60 & $\begin{array}{l}\text { YongGu Lock is forever } \\
\text { happiness. }\end{array}$ & $\begin{array}{l}\text { Lock; } \\
\text { Forever happiness }\end{array}$ & Double happiness \\
\hline 2.61 & $\begin{array}{lr}\text { ChunLan } & \text { Air } \\
\text { Conditioner } & \text { is } \quad \text { a }\end{array}$ & $\begin{array}{l}\text { Air conditioner; } \\
\text { Comfortable home }\end{array}$ & Warmth of home \\
\hline
\end{tabular}




\begin{tabular}{|c|c|c|c|}
\hline & comfortable home. & & \\
\hline 2.62 & $\begin{array}{l}\text { Hemorrhoids/Piles are } \\
\text { cactus/swords/knives. }\end{array}$ & $\begin{array}{l}\text { Hemorrhoids disease; } \\
\text { cactus/swords/knives }\end{array}$ & Social manner \\
\hline 2.63 & $\begin{array}{l}\text { CHO is happy embryo in } \\
\text { a healthy womb. }\end{array}$ & $\begin{array}{l}\text { CHO medicine; } \\
\text { Embryo, healthy womb }\end{array}$ & Healthy baby \\
\hline 2.64 & $\begin{array}{l}\text { Throat Smoother is } \\
\text { saxophone, violin, drum, } \\
\text { Erhu, guitar. }\end{array}$ & $\begin{array}{l}\text { Throat smoother; } \\
\text { Western and eastern } \\
\text { musical instruments }\end{array}$ & Smooth melody \\
\hline $2.65 \odot$ & $\begin{array}{l}\text { Sanzhu Nutritious } \\
\text { Liquid is prey. }\end{array}$ & $\begin{array}{l}\text { Nutritious liquid; } \\
\text { prey }\end{array}$ & Preying for health \\
\hline 2.66 & $\begin{array}{l}\text { Ad Agency is a clock } \\
\text { with core, hand, } \\
\text { dimension. }\end{array}$ & $\begin{array}{l}\text { Ad agency; } \\
\text { clock }\end{array}$ & Success and timely \\
\hline $2.67 \odot$ & $\begin{array}{l}\text { Whitening Cream is } \\
\text { foreign man's face. }\end{array}$ & $\begin{array}{l}\text { Whitening cream; } \\
\text { Foreign man's face }\end{array}$ & Truth revealing \\
\hline 2.68 & $\begin{array}{l}\text { Baby Nutritious Liquid } \\
\text { is incubator. }\end{array}$ & $\begin{array}{l}\text { Nutritious liquid; } \\
\text { incubator }\end{array}$ & Baby health \\
\hline 2.69 & $\begin{array}{l}\text { YuanMing (real estate) } \\
\text { is Yuan Ming Yuan } \\
\text { Garden. }\end{array}$ & $\begin{array}{l}\text { Real estate project; } \\
\text { Yuan Ming Yuan }\end{array}$ & Grandeur, splendid \\
\hline $2.70 \odot$ & $\begin{array}{l}\text { Dongdu (real estate) is } \\
\text { mother and } \\
\text { businessman's } \\
\text { eyes/foresight/insight }\end{array}$ & $\begin{array}{l}\text { Real estate project; } \\
\text { Eyesight, foresight }\end{array}$ & Sharp eye/insight \\
\hline $2.71 \odot$ & $\begin{array}{l}\text { China Southeast Airline } \\
\text { is Dai Water Festival. }\end{array}$ & $\begin{array}{l}\text { Airline; } \\
\text { Dai ethnic water festival }\end{array}$ & Merry and exotic \\
\hline 2.72 & $\begin{array}{l}\text { PingAn Insurance is } \\
\text { secured/reinforced chair. }\end{array}$ & $\begin{array}{l}\text { Insurance; } \\
\text { Reinforced chair }\end{array}$ & Security, extraordinary \\
\hline 2.73 & $\begin{array}{l}\text { Nortel Communication } \\
\text { is Putala Palace and the } \\
\text { Great Wall. }\end{array}$ & $\begin{array}{l}\text { Communication firm; } \\
\text { Putala Palace, the Great } \\
\text { Wall }\end{array}$ & $\begin{array}{l}\text { Connect great historical } \\
\text { and cultural relics, easy } \\
\text { travel }\end{array}$ \\
\hline 2.74 & $\begin{array}{l}\text { Postcards are cows and } \\
\text { horse; microphone and } \\
\text { earphone; balloons and } \\
\text { rockets; books and pens. }\end{array}$ & $\begin{array}{l}\text { Postcards; } \\
\text { Cows \& horse; } \\
\text { microphone \& earphone; } \\
\text { balloon \& rocket; books } \\
\text { \& pens }\end{array}$ & $\begin{array}{l}\text { True emotion delivery, } \\
\text { variety of life }\end{array}$ \\
\hline 2.75 & $\begin{array}{l}\text { Gansu Daily is chemistry } \\
\text { as if by pre-destination. }\end{array}$ & $\begin{array}{l}\text { Newspaper; } \\
\text { Chemistry, pre-ordained } \\
\text { relation }\end{array}$ & $\begin{array}{ll}\text { Love relation, } & \text { pre- } \\
\text { destination, } & \text { pre- } \\
\text { ordained relation } & \end{array}$ \\
\hline 2.76 & $\begin{array}{l}\text { Convene Soft Pillow is } \\
\text { sleeping pill. }\end{array}$ & $\begin{array}{l}\text { Pillow; } \\
\text { Sleeping pill }\end{array}$ & $\begin{array}{l}\text { Insomnia curing, good } \\
\text { night sleep }\end{array}$ \\
\hline $2.77 \odot$ & $\begin{array}{l}\text { Beauty Cosmetics are } \\
\text { healthy factory workers. }\end{array}$ & $\begin{array}{l}\text { Beauty Cosmetics; } \\
\text { Healthy factory workers }\end{array}$ & Good health is beauty \\
\hline $2.78 \odot$ & $\begin{array}{l}\text { Donghuan Square is a } \\
\text { disc-made face. }\end{array}$ & $\begin{array}{l}\text { Donghuan Square; } \\
\text { A disc-made face. }\end{array}$ & $\begin{array}{l}\text { Introduction to the } \\
\text { Square (real estate) on } \\
\text { disc. }\end{array}$ \\
\hline
\end{tabular}




\begin{tabular}{|c|c|c|c|}
\hline 2.79 & $\begin{array}{l}\text { Nangfang Daily is } \\
\text { snooker opening. }\end{array}$ & $\begin{array}{l}\text { Newspaper; } \\
\text { Snooker game opening }\end{array}$ & $\begin{array}{l}\text { One strike success, } \\
\text { accurate report/coverage }\end{array}$ \\
\hline 2.80 & $\begin{array}{l}\text { Motorola University is a } \\
\text { ladder to the sky. }\end{array}$ & $\begin{array}{l}\text { Motorola University; } \\
\text { A ladder to the sky }\end{array}$ & $\begin{array}{ll}\text { Ladder } & \text { to } \\
\text { knowledge/success }\end{array}$ \\
\hline 2.81 & $\begin{array}{l}\text { Maxam Suntan Lotion is } \\
\text { green shade everywhere. }\end{array}$ & $\begin{array}{l}\text { Suntan Lotion; } \\
\text { Green shade }\end{array}$ & Sun light proof \\
\hline 2.82 & $\begin{array}{l}\text { Santana car is a lucky } \\
\text { day on an oracle } \\
\text { calendar. }\end{array}$ & $\begin{array}{l}\text { Car; } \\
\text { Lucky day on a calendar }\end{array}$ & $\begin{array}{l}\text { Suitable for driving, } \\
\text { bringing good luck }\end{array}$ \\
\hline $2.83 \odot$ & $\begin{array}{l}\text { Ad Agency is } \\
\text { ZhuGeliang (legendary } \\
\text { figure in Chinese history } \\
\text { for strategies and tactics) }\end{array}$ & $\begin{array}{l}\text { Ad agency; } \\
\text { ZhuGe Liang (military } \\
\text { strategist) }\end{array}$ & $\begin{array}{l}\text { Help you win the } \\
\text { business war, compete } \\
\text { successfully in war }\end{array}$ \\
\hline $2.84 \odot$ & $\begin{array}{l}\text { Pond's is a beauty under } \\
\text { protection. }\end{array}$ & $\begin{array}{l}\text { Pond's; } \\
\text { Protection of beauty }\end{array}$ & $\begin{array}{l}\text { Beautiful skin care and } \\
\text { protection }\end{array}$ \\
\hline 2.85 & $\begin{array}{l}\text { The Relation between } \\
\text { Ad Agent and client is } \\
\text { the best striking point in } \\
\text { golf ball. }\end{array}$ & $\begin{array}{l}\text { Ad agency; } \\
\text { Accurate golf striking } \\
\text { point }\end{array}$ & $\begin{array}{l}\text { Best } \\
\text { combination/match, win } \\
\text { in golf game }\end{array}$ \\
\hline 2.86 & $\begin{array}{lr}\text { KFC } & \text { is } \\
\text { electrokymograph } & \text { from } \\
\text { USA. } & \end{array}$ & okymograph & Heart beating/exciting \\
\hline $2.87 \odot$ & $\begin{array}{l}\text { Kadaner Suit is } \\
\text { successful man holding a } \\
\text { rose. }\end{array}$ & $\begin{array}{l}\text { Men's suit; } \\
\text { Man holding a rose }\end{array}$ & $\begin{array}{l}\text { Winning the heart of a } \\
\text { lover, romantic }\end{array}$ \\
\hline $2.88 \odot$ & $\begin{array}{l}\text { Parim eyeglass is } \\
\text { graceful foreign lady. }\end{array}$ & foreign lady & Attraction and charming \\
\hline 2.89 & $\begin{array}{l}\text { K.T. Shirt is road with } \\
\text { scenery and trees }\end{array}$ & $\begin{array}{l}\text { Men's shirt; } \\
\text { Road \& scenery \& trees }\end{array}$ & $\begin{array}{l}\text { Lifelong companion and } \\
\text { care }\end{array}$ \\
\hline 2.90 & $\begin{array}{l}\text { Sanyo Cooling } \\
\text { Machinery is well- } \\
\text { conditioned and well- } \\
\text { coordinated bearings. }\end{array}$ & $\begin{array}{l}\text { Cooling machinery; } \\
\text { Bearings }\end{array}$ & $\begin{array}{l}\text { Coordination and } \\
\text { integration }\end{array}$ \\
\hline 2.91 & $\begin{array}{l}\text { Samsung Service is } \\
\text { spanner or wrench. }\end{array}$ & $\begin{array}{l}\text { Electronic service; } \\
\text { Spanner or wrench }\end{array}$ & $\begin{array}{l}\text { Problem-solving, one } \\
\text { world one family }\end{array}$ \\
\hline $2.92 \bigcirc$ & $\begin{array}{l}\text { Motorola Pager is a } \\
\text { match maker and new } \\
\text { year opening ceremony. }\end{array}$ & $\begin{array}{l}\text { Pager; } \\
\text { Match-maker, new year } \\
\text { opening ceremony }\end{array}$ & $\begin{array}{l}\text { Doing good deeds, } \\
\text { lucky and fortunate }\end{array}$ \\
\hline 2.93 & $\begin{array}{l}\text { Coca Cola is athlete's } \\
\text { thirst } \\
\text { cruncher/enjoyment. }\end{array}$ & $\begin{array}{l}\text { Coca Cola; } \\
\text { Drinking athlete }\end{array}$ & Enjoyment/fun \\
\hline $2.94 \odot$ & $\begin{array}{l}\text { Women Wash liquid is } \\
\text { happy faces of women. }\end{array}$ & $\begin{array}{l}\text { Wash liquid for women; } \\
\text { Happy faces }\end{array}$ & $\begin{array}{l}\text { Cleaning as a home } \\
\text { assignment everyday }\end{array}$ \\
\hline $2.95 \bigcirc$ & $\begin{array}{l}\text { Home Furnishing Center } \\
\text { is happy foreign men. }\end{array}$ & $\begin{array}{l}\text { Home furnishing; } \\
\text { Happy foreign man }\end{array}$ & New feeling \\
\hline 2.96 & Roma/Smart Garment is & Garment; & Smart, $n$ \\
\hline
\end{tabular}




\begin{tabular}{|c|c|c|c|}
\hline & city view. & Modern city view & \\
\hline 2.97 & $\begin{array}{l}\text { Animal Feed is fat } \\
\text { lovely pig. }\end{array}$ & Animal feed; pig & $\begin{array}{l}\text { Eat/sleep well, value } \\
\text { price }\end{array}$ \\
\hline 2.98 & $\begin{array}{l}\text { Mountain } \\
\text { Tickets are four-season } \\
\text { views. }\end{array}$ & $\begin{array}{l}\text { Scenery ticket; } \\
\text { Four season scenery }\end{array}$ & Natural beauty/wonder \\
\hline 2.99 & $\begin{array}{l}\text { Butter from Tibet is } \\
\text { Tibetan style kettle, cup, } \\
\text { temple }\end{array}$ & $\begin{array}{l}\text { Tibetan butter; } \\
\text { Kettle, cup, and temple }\end{array}$ & $\begin{array}{l}\text { Exotic and refined } \\
\text { Tibetan lifestyle }\end{array}$ \\
\hline 2.100 & $\begin{array}{l}\text { Guanglian Lighting is } \\
\text { perfect } \\
\text { performance. }\end{array}$ & $\begin{array}{l}\text { Lighting company; } \\
\text { Orchestra performance }\end{array}$ & $\begin{array}{l}\text { Coordination } \\
\text { perfectness }\end{array}$ \\
\hline
\end{tabular}

Table II-3 100 Metaphorical Statements, Primary Subjects and Secondary Subjects and Their Corresponding Projected Features from 1999 to 2008

\begin{tabular}{|l|l|l|l|}
\hline $\begin{array}{l}\text { Ad } \\
\text { No. }\end{array}$ & Metaphorical statements & $\begin{array}{l}\text { Signifier \& signified } \\
\text { Primary subject \& } \\
\text { secondary subject }\end{array}$ & $\begin{array}{l}\text { Projected features } \\
\text { (entailments) as } \\
\text { embodied in the } \\
\text { images }\end{array}$ \\
\hline 3.1 & $\begin{array}{l}\text { China Telecom is } \\
\text { forest/desert/ocean/mountain. }\end{array}$ & $\begin{array}{l}\text { China Telecom; } \\
\text { Four remote and natural } \\
\text { places }\end{array}$ & $\begin{array}{l}\text { City is far, world is } \\
\text { near, connection with } \\
\text { the world }\end{array}$ \\
\hline 3.2 & $\begin{array}{l}\text { China Mobile is a family photo } \\
\text { with wrong and correct } \\
\text { clothes. }\end{array}$ & $\begin{array}{l}\text { China Mobile; } \\
\text { Family photo in wrong } \\
\text { and correct clothes }\end{array}$ & $\begin{array}{l}\text { Correct self-identity } \\
\text { (who am I?) }\end{array}$ \\
\hline 3.3 & $\begin{array}{l}\text { China Unicom is deep-water } \\
\text { fish, desert antelope, wild } \\
\text { goose. }\end{array}$ & $\begin{array}{l}\text { China Unicom; } \\
\text { Fish, antelope, wild } \\
\text { goose }\end{array}$ & $\begin{array}{l}\text { Connect the world } \\
\text { with depth, width, } \\
\text { height }\end{array}$ \\
\hline 3.4 & $\begin{array}{l}\text { China Netcom is changed } \\
\text { telephones }\end{array}$ & $\begin{array}{l}\text { China Netcom; } \\
\text { changed telephones }\end{array}$ & $\begin{array}{l}\text { Changed telephone, } \\
\text { unchanged integrity } \\
\text { in 100 years }\end{array}$ \\
\hline 3.5 & $\begin{array}{l}\text { China Satcom is Tibetan } \\
\text { mountain, rainforest tree. }\end{array}$ & $\begin{array}{l}\text { China Satcom; } \\
5780 \text { meter Tibetan } \\
\text { mountain, rainforest tree } \\
\text { with well-connected root }\end{array}$ & $\begin{array}{l}\text { The value of } \\
\text { communication and } \\
\text { connection between } \\
\text { heaven and earth }\end{array}$ \\
\hline 3.6 & $\begin{array}{l}\text { Motorola is downloadable } \\
\text { game. }\end{array}$ & $\begin{array}{l}\text { Motorola; Downloadable } \\
\text { game, experience bar }\end{array}$ & $\begin{array}{l}\text { Cool, } \\
\text { experience happy, }\end{array}$ \\
\hline 3.7 & $\begin{array}{l}\text { ChinaHR.com is superman } \\
\text { hunting for a job. }\end{array}$ & $\begin{array}{l}\text { ChinaHR.com; } \\
\text { Superman is doing shoe } \\
\text { polishing, painting, } \\
\text { dusting, postman job }\end{array}$ & $\begin{array}{l}\text { Quick way to find } \\
\text { suitable job, no } \\
\text { compromise }\end{array}$ \\
\hline 3.8 & $\begin{array}{l}\text { Taobao.com is 36091 stars in } \\
\text { the dark sky. }\end{array}$ & $\begin{array}{l}\text { Taobao com; } \\
\text { night stars }\end{array}$ & $\begin{array}{l}\text { Search for a lamp, } \\
\text { Taobao gives me } \\
\text { 36091 shining stars }\end{array}$ \\
\hline 3.9 & Asus Computer is plane flying & Computer; & New horizon, new \\
\hline
\end{tabular}




\begin{tabular}{|c|c|c|c|}
\hline & higher. & Airplane & height \\
\hline $\begin{array}{l}3.10 \\
(9)\end{array}$ & $\begin{array}{l}\text { Moto mobile phone is multi- } \\
\text { tasking heroes }\end{array}$ & $\begin{array}{l}\text { Moto mobile phone; } \\
\text { Multi-tasking heroes }\end{array}$ & $\begin{array}{l}\text { Insightful, brilliant, } \\
\text { capable people }\end{array}$ \\
\hline 3.11 & $\begin{array}{l}\text { Agricultural bank of China is a } \\
\text { golden key. }\end{array}$ & $\begin{array}{l}\text { Bank; } \\
\text { Golden key }\end{array}$ & $\begin{array}{l}\text { Accompany and help } \\
\text { you grow }\end{array}$ \\
\hline $\begin{array}{l}3.12 \\
0\end{array}$ & $\begin{array}{l}\text { Hi Bank is car Taxi but not } \\
\text { tricycle taxi. }\end{array}$ & $\begin{array}{l}\text { Bank; } \\
\text { Tricycle taxi }\end{array}$ & $\begin{array}{l}\text { Reduce the burden, } \\
\text { debt drives you crazy }\end{array}$ \\
\hline $\begin{array}{l}3.13 \\
\ominus\end{array}$ & $\begin{array}{l}\text { Credit cards by Guangdong } \\
\text { Development Bank are cool } \\
\text { youngsters. }\end{array}$ & $\begin{array}{ll}\text { Credit cards; } \\
\text { Cool } \\
\text { youngsters }\end{array}$ & $\begin{array}{l}\text { Release the instinct, } \\
\text { Swipe }\end{array}$ \\
\hline $\begin{array}{l}3.14 \\
\odot)\end{array}$ & $\begin{array}{l}\text { Cumulative Point Card is a } \\
\text { lady in numbered world. }\end{array}$ & $\begin{array}{l}\text { Cumulative point card; } \\
\text { A sexy lady surrounded } \\
\text { by numbered world }\end{array}$ & $\begin{array}{ll}\text { Exchange } & \text { everything } \\
\text { with } & \text { cumulative } \\
\text { points but not } \\
\text { yourself }\end{array}$ \\
\hline 3.15 & $\begin{array}{l}\text { China Life Insurance is } \\
\text { umbrella, wardrobe, and car } \\
\text { park (reserved space) }\end{array}$ & $\begin{array}{l}\text { Life insurance; } \\
\text { Umbrella, wardrobe, car } \\
\text { park }\end{array}$ & $\begin{array}{l}\text { Reserved private and } \\
\text { personal space. }\end{array}$ \\
\hline 3.16 & Mazda car is Christmas tree. & $\begin{array}{l}\text { Mazda car; } \\
\text { Christmas tree }\end{array}$ & Season greetings \\
\hline 3.17 & $\begin{array}{l}\text { BYD car is a cartoon figure } \\
\text { Xiaofu. }\end{array}$ & $\begin{array}{l}\text { BYD car; } \\
\text { Cartoon figure }\end{array}$ & $\begin{array}{l}\text { I am small, ugly but } \\
\text { lucky }\end{array}$ \\
\hline 3.18 & $\begin{array}{l}\text { Suzuki is flying cars in } \\
\text { metropolitan city. }\end{array}$ & $\begin{array}{l}\text { Suzuki cars; } \\
\text { Metropolitan city }\end{array}$ & Way of life \\
\hline $\begin{array}{l}3.19 \\
-(9)\end{array}$ & Lubao car is a love affair. & $\begin{array}{l}\text { Lubao car; } \\
\text { Triangle love affair }\end{array}$ & $\begin{array}{l}\text { Timely, Intruder, love } \\
\text { affair }\end{array}$ \\
\hline 3.20 & $\begin{array}{l}\text { Jetta car is a halved spanner, } \\
\text { gas pump, key. }\end{array}$ & $\begin{array}{l}\text { Jetta car; } \\
\text { Halved spanner, gas } \\
\text { pump, and carkey }\end{array}$ & $\begin{array}{l}\text { Saving and } \\
\text { economical }\end{array}$ \\
\hline 3.21 & Elantra car is sensational news. & $\begin{array}{l}\text { Elantra car; } \\
\text { Sensational news }\end{array}$ & $\begin{array}{l}\text { Breakthrough in fuel } \\
\text { efficiency }\end{array}$ \\
\hline 3.22 & $\begin{array}{l}\text { Regal car is driving in different } \\
\text { weather. }\end{array}$ & $\begin{array}{l}\text { Regal (Buick) car; } \\
\text { Different weather }\end{array}$ & Dynamic but quiet \\
\hline 3.23 & $\begin{array}{l}\text { Xianglong car is a car on a } \\
\text { Kekexili (bumpy) road. }\end{array}$ & $\begin{array}{l}\text { Xianglong car; } \\
\text { Kekexili Tibetan road }\end{array}$ & Reliability \\
\hline 3.24 & $\begin{array}{l}\text { ChengAn car is an ape with } 10 \\
\text { boxes. }\end{array}$ & $\begin{array}{l}\text { ChengAn car; } \\
\text { Powerful ape }\end{array}$ & Space king \\
\hline 3.25 & $\begin{array}{l}\text { BaoGang Steel is a car on a } \\
\text { folded Chinese fan. }\end{array}$ & $\begin{array}{l}\text { BaoGang Steel; } \\
\text { Car on a folded fan }\end{array}$ & Elastic and flexible \\
\hline 3.26 & $\begin{array}{l}\text { HeYuan (real estate) is Taihe } \\
\text { Temple, Summer Palace, Yuan } \\
\text { Mingyuan, Yue Yang Pagoda. }\end{array}$ & $\begin{array}{l}\text { HeYuan (real estate); } \\
\text { Taihe temple, Summer } \\
\text { Palace, Yuan Mingyuan, } \\
\text { Yue Yang Pagoda }\end{array}$ & $\begin{array}{l}\text { Get-together, } \\
\text { geomancy, } \\
\text { cultivation, and share. }\end{array}$ \\
\hline 3.27 & $\begin{array}{l}\text { Green Gulf is useless credit } \\
\text { card, car, ice box. }\end{array}$ & $\begin{array}{l}\text { Green Gulf(real estate); } \\
\text { Credit card, car, ice box }\end{array}$ & $\begin{array}{l}\text { Low cost and } \\
\text { convenience }\end{array}$ \\
\hline 3.28 & $\begin{array}{l}\text { Landscape City is the first } \\
\text { person to fly, tailor luxury }\end{array}$ & $\begin{array}{l}\text { Landscape (real estate); } \\
\text { First person to fly a }\end{array}$ & $\begin{array}{l}\text { Bing the first, } \\
\text { innovative }\end{array}$ \\
\hline
\end{tabular}




\begin{tabular}{|c|c|c|c|}
\hline & fashion, drive & $\begin{array}{l}\text { plane, tailor a fashion, } \\
\text { drive a car }\end{array}$ & \\
\hline 3.29 & $\begin{array}{l}\text { Binhai New Town is beautiful } \\
\text { lake view. }\end{array}$ & $\begin{array}{l}\text { New town (real estate); } \\
\text { Lake view }\end{array}$ & $\begin{array}{l}\text { Best angle for lake } \\
\text { view }\end{array}$ \\
\hline 3.30 & $\begin{array}{l}\text { Splendid New Asia is } \\
\text { elaborately sculptured vase, } \\
\text { wall, and flower decoration. }\end{array}$ & $\begin{array}{l}\text { Splendid New Asia (real } \\
\text { estate); Sculptured stone } \\
\text { vase, wall, and flower } \\
\text { decoration }\end{array}$ & $\begin{array}{l}\text { Splendor and } \\
\text { elaboration }\end{array}$ \\
\hline 3.31 & $\begin{array}{l}\text { Global Villa is peacock and } \\
\text { forest. }\end{array}$ & $\begin{array}{l}\text { Global Villa (real estate); } \\
\text { Peacock in forest }\end{array}$ & $\begin{array}{l}\text { Synchronized life } \\
\text { with the world }\end{array}$ \\
\hline 3.32 & $\begin{array}{l}\text { Ziwei Villa is upturned eaves, } \\
\text { arch door/vault, courtyard with } \\
\text { bamboo. }\end{array}$ & $\begin{array}{l}\text { Ziwei Villa (real estate); } \\
\text { Upturned eaves, vault, } \\
\text { courtyard with bamboo }\end{array}$ & Modern Chinese style \\
\hline $\begin{array}{l}3.33 \\
-(-)\end{array}$ & $\begin{array}{l}\text { Nansha Compass is the } \\
\text { philosophy, the sound, the } \\
\text { aesthetics of nature. }\end{array}$ & $\begin{array}{l}\text { Nansha Compass; } \\
\text { Yoga, relaxation, Taiji } \\
\text { boxing in nature }\end{array}$ & $\begin{array}{l}\text { Being close to nature, } \\
\text { renaissance of natural } \\
\text { beauty }\end{array}$ \\
\hline $\begin{array}{l}3.34 \\
\oplus-9\end{array}$ & $\begin{array}{l}\text { Arrow (bath tub) is Spiderman } \\
\text { and superman in shower. }\end{array}$ & $\begin{array}{l}\text { Bath tub; } \\
\text { Spiderman \& superman } \\
\text { in shower }\end{array}$ & $\begin{array}{l}\text { American style } \\
\text { heroes }\end{array}$ \\
\hline 3.35 & $\begin{array}{l}\text { Paco Floor is a wooden } \\
\text { umbrella and tortoise. }\end{array}$ & $\begin{array}{l}\text { Paco floor; } \\
\text { Wooden umbrella and } \\
\text { tortoise }\end{array}$ & $\begin{array}{l}\text { Support, protect and } \\
\text { longevity }\end{array}$ \\
\hline 3.36 & $\begin{array}{l}\text { Meidi refrigerator is } \\
\text { skyscraper wheel of orange, } \\
\text { rollercoaster of Pea, merry-go- } \\
\text { round of mushroom. }\end{array}$ & $\begin{array}{l}\text { Meidi refrigerator; } \\
\text { Skyscraper wheel, } \\
\text { rollercoaster, and merry- } \\
\text { go-round }\end{array}$ & $\begin{array}{l}\text { Everyday fresh and } \\
\text { fun }\end{array}$ \\
\hline 3.37 & $\begin{array}{l}\text { Swan washing machine is } \\
\text { sprinter board (made of } \\
\text { machine cover) and wild goose } \\
\text { (White T-shirt) }\end{array}$ & $\begin{array}{l}\text { Washing machine; } \\
\text { Sprinter board and wild } \\
\text { goose }\end{array}$ & $\begin{array}{l}\text { (run) Further and } \\
\text { (fly) higher }\end{array}$ \\
\hline 3.38 & $\begin{array}{l}\text { Royalstar washing machine is } \\
\text { water therapy. }\end{array}$ & $\begin{array}{l}\text { Washing machine; } \\
\text { Water therapy }\end{array}$ & $\begin{array}{l}\text { Comfort, tender and } \\
\text { not twisted }\end{array}$ \\
\hline 3.39 & $\begin{array}{l}\text { Electrolux is happiness and } \\
\text { enjoying life. }\end{array}$ & N.A. & $\begin{array}{l}\text { Happiness and } \\
\text { enjoyment }\end{array}$ \\
\hline 3.40 & $\begin{array}{l}\text { Candy kitchen wear is coffee } \\
\text { and Latin dance. }\end{array}$ & $\begin{array}{l}\text { Kitchen ware; } \\
\text { Black coffee, red Latin }\end{array}$ & $\begin{array}{l}\text { Coffee and Latin } \\
\text { dance in the kitchen, } \\
\text { romantic }\end{array}$ \\
\hline 3.41 & $\begin{array}{l}\text { Kitchen Smoke Extractor is a } \\
\text { half extracted bottle of cooking } \\
\text { oil. }\end{array}$ & $\begin{array}{l}\text { Kitchen smoke extractor; } \\
\text { Cooking oil bottle }\end{array}$ & $\begin{array}{lll}\text { Clean no } & \text { smoke } \\
\text { kitchen } & & \end{array}$ \\
\hline 3.42 & $\begin{array}{l}\text { DongSheng Fans are sea } \\
\text { waves and white clouds. }\end{array}$ & $\begin{array}{l}\text { Fans; } \\
\text { Sea waves, white clouds }\end{array}$ & $\begin{array}{l}\text { Natural sea winds } \\
\text { and breeze }\end{array}$ \\
\hline 3.43 & $\begin{array}{l}\text { Meidi Moisturizer is small } \\
\text { fish, shrimp, and crabs. }\end{array}$ & $\begin{array}{l}\text { Moisturizer; } \\
\text { Small fish, shrimp, and } \\
\text { crabs }\end{array}$ & Nature-like moisture \\
\hline 3.44 & Eagle Electric Appliance is & Electric appliance firm; & Affection \\
\hline
\end{tabular}




\begin{tabular}{|c|c|c|c|}
\hline & $\begin{array}{l}\text { heart and house made of } \\
\text { smiling faces. }\end{array}$ & $\begin{array}{l}\text { Heart and house made of } \\
\text { smiling faces and socket }\end{array}$ & sufficiency \\
\hline 3.45 & $\begin{array}{l}\text { Top Electric is lightening } \\
\text { arrester, door fastener and fire } \\
\text { extinguisher. }\end{array}$ & $\begin{array}{l}\text { Top electric; } \\
\text { Lightening arrester, door } \\
\text { fastener, and fire } \\
\text { extinguisher }\end{array}$ & Security and safety \\
\hline $\begin{array}{l}3.46 \\
\ominus\end{array}$ & $\begin{array}{l}\text { Mengniu milk is snow white } \\
\text { and seven dwarfs. }\end{array}$ & $\begin{array}{l}\text { Milk; } \\
\text { Fairy tale story of Snow } \\
\text { White }\end{array}$ & Growth and faire tale \\
\hline $\begin{array}{l}3.47 \\
\odot\end{array}$ & $\begin{array}{l}\text { Sanyuan milk is baby sucking } \\
\text { milk (breast shape). }\end{array}$ & $\begin{array}{l}\text { Milk; } \\
\text { Foreign baby sucking } \\
\text { breast milk }\end{array}$ & $\begin{array}{l}\text { Mother's love, breast } \\
\text { milk nutrition }\end{array}$ \\
\hline 3.48 & $\begin{array}{l}\text { Holiland is maze or labyrinth } \\
\text { hunting for fresh baked bread. }\end{array}$ & $\begin{array}{l}\text { Bakery; } \\
\text { Maze or labyrinth } \\
\text { hunting }\end{array}$ & $\begin{array}{l}\text { Exploration } \\
\text { hunting }\end{array}$ \\
\hline 3.49 & Classy Kiss yoghurt is Alps. & Yoghurt; Alps & Mysterious Alps taste \\
\hline $\begin{array}{l}3.50 \\
\ominus\end{array}$ & $\begin{array}{l}\text { Youcan ice pop is Chinese } \\
\text { Gongfu master Lixiaolong. }\end{array}$ & $\begin{array}{l}\text { Ice pop; } \\
\text { Gongfu (martial } \quad \text { arts) } \\
\text { master }\end{array}$ & Oh, Ha, martial arts \\
\hline $\begin{array}{l}3.51 \\
-8\end{array}$ & $\begin{array}{l}\text { Duoheshui water bottle is a } \\
\text { half fish and half man. }\end{array}$ & $\begin{array}{l}\text { Water bottle; } \\
\text { Fish }\end{array}$ & Drink more \\
\hline $\begin{array}{l}3.52 \\
\oplus-)^{3}\end{array}$ & $\begin{array}{l}\text { Guangmin yoghurt is guardian } \\
\text { Gods. }\end{array}$ & $\begin{array}{l}\text { Yoghurt; } \\
\text { Guardian gods }\end{array}$ & $\begin{array}{l}\text { Immune system } \\
\text { enhancement, } \\
\text { protection of your } \\
\text { health }\end{array}$ \\
\hline 3.53 & $\begin{array}{l}\text { Wanglaoji Drink is all Chinese } \\
\text { characters with water and fire. }\end{array}$ & $\begin{array}{l}\text { Health drink; } \\
\text { Water and fire character }\end{array}$ & Internal body balance \\
\hline 3.54 & $\begin{array}{l}\text { The Great Wall wine is the } \\
\text { Great Wall and Athenian } \\
\text { Parthenon in wine cups. }\end{array}$ & $\begin{array}{l}\text { Wine; } \\
\text { The Great Wall, } \\
\text { Athenian Parthenon }\end{array}$ & $\begin{array}{lr}\text { Eastern } & \text { civilization } \\
\text { vs. } & \text { western } \\
\text { civilization } & \\
\end{array}$ \\
\hline 3.55 & $\begin{array}{l}\text { Carlsberg is paws, cobra and } \\
\text { lions in bottle shape. }\end{array}$ & $\begin{array}{l}\text { Carlsberg (beer); } \\
\text { Paws, cobra, lions }\end{array}$ & Free your wild nature \\
\hline 3.56 & $\begin{array}{l}\text { Pain killer is bird's singing and } \\
\text { phonograph's music }\end{array}$ & $\begin{array}{l}\text { Pain killer; } \\
\text { Bird's singing, } \\
\text { phonograph's music }\end{array}$ & $\begin{array}{l}\text { With pain in you } \\
\text { head } \\
\text { becomes noise }\end{array}$ \\
\hline 3.57 & $\begin{array}{l}\text { Watermelon throat soother is } \\
\text { throat savors. }\end{array}$ & $\begin{array}{l}\text { Throat smoother; } \\
\text { Throat savor }\end{array}$ & Help, help \\
\hline 3.58 & $\begin{array}{l}\text { Sleeping Pills are swinging } \\
\text { pendulum. }\end{array}$ & $\begin{array}{l}\text { Sleeping pills; } \\
\text { Swinging pendulum }\end{array}$ & $\begin{array}{l}\text { Rhythmic and fast } \\
\text { asleep }\end{array}$ \\
\hline 3.59 & $\begin{array}{l}\text { Your fallen hair is panda, } \\
\text { dinosaur and tiger in tub. }\end{array}$ & $\begin{array}{l}\text { Hair beauty pills; } \\
\text { Panda, dinosaur, tiger }\end{array}$ & $\begin{array}{l}\text { Save the extinguished } \\
\text { spices }\end{array}$ \\
\hline 3.60 & $\begin{array}{l}\text { Enriched Calcium Tablet is an } \\
\text { overloaded lift. }\end{array}$ & $\begin{array}{l}\text { Calcium tablet; } \\
\text { Overloaded lift }\end{array}$ & $\begin{array}{l}\text { Concentrated, } \\
\text { enriched }\end{array}$ \\
\hline $\begin{array}{l}3.61 \\
\ominus\end{array}$ & $\begin{array}{l}361^{\circ} \text { sportswear is basketball } \\
\text { stars. }\end{array}$ & $\begin{array}{l}\text { Sportswear; } \\
\text { Basketball stars }\end{array}$ & Dare to be, courage \\
\hline 3.62 & Reebok is $\mathrm{HK}$ & Reebok sportswear; & I am what I am, I like \\
\hline
\end{tabular}




\begin{tabular}{|c|c|c|c|}
\hline (2) & swimmer and movie star. & HK celebrities & being myself. \\
\hline $\begin{array}{l}3.63 \\
\oplus\end{array}$ & $\begin{array}{lcc}\text { LiNing } & \text { sportswear } & \text { is wind } \\
\text { (attack) } & \text { and } & \text { mountain } \\
\text { (defend). } & & \\
\end{array}$ & $\begin{array}{l}\text { Sportswear; } \\
\text { Wind (attack) } \\
\text { mountain (defend) }\end{array}$ & $\begin{array}{l}\text { Oriental hero, game } \\
\text { play }\end{array}$ \\
\hline $\begin{array}{l}3.64 \\
-(-)\end{array}$ & $\begin{array}{l}\text { Quicker shoe is a man } \\
\text { breaking out from a cage and } \\
\text { wall. }\end{array}$ & $\begin{array}{l}\text { Shoes; } \\
\text { Man breaking out from a } \\
\text { cage and wall }\end{array}$ & Forward for freedom \\
\hline 3.65 & $\begin{array}{l}\text { Bull \& Traditional shoes are } \\
\text { footprints and shoeprints. }\end{array}$ & $\begin{array}{l}\text { Shoes; } \\
\text { Footprints \& shoeprints }\end{array}$ & Being close to nature \\
\hline 3.66 & $\begin{array}{l}\text { DeMon mascara is porcupine, } \\
\text { globefish, and cactus. }\end{array}$ & $\begin{array}{l}\text { Mascara; } \\
\text { Porcupine, globefish, and } \\
\text { cactus (curly hair) }\end{array}$ & Lively world \\
\hline 3.67 & $\begin{array}{l}\text { Rejoice shampoo is a comb on } \\
\text { a slippery hair with a speedy } \\
\text { ticket. }\end{array}$ & $\begin{array}{l}\text { Shampoo; } \\
\text { Slippery hair, speedy } \\
\text { ticket }\end{array}$ & $\begin{array}{l}\text { Super slippery hair, } \\
\text { speedy }\end{array}$ \\
\hline 3.68 & $\begin{array}{l}\text { Dencare toothpaste is stainless } \\
\text { tea, coffee cup. }\end{array}$ & $\begin{array}{l}\text { Toothpaste; } \\
\text { Stainless tea, coffee cup }\end{array}$ & $\begin{array}{l}\text { Remove stain worries } \\
\text { on teeth }\end{array}$ \\
\hline $\begin{array}{l}3.69 \\
-(-)\end{array}$ & $\begin{array}{l}\text { Colgate toothpaste are smiling } \\
\text { superboy/girls. }\end{array}$ & $\begin{array}{l}\text { Toothpaste; } \\
\text { Smiling superboy/girl }\end{array}$ & $\begin{array}{l}\text { Superman, } \\
\text { superwoman }\end{array}$ \\
\hline 3.70 & $\begin{array}{l}\text { Antibacteria hand liquid is run- } \\
\text { away black ghost. }\end{array}$ & $\begin{array}{l}\text { Hand liquid; } \\
\text { Run-away black ghost }\end{array}$ & Drive away bacteria \\
\hline 3.71 & $\begin{array}{l}\text { Blue Moon cleaning liquid is } \\
\text { bee and bird. }\end{array}$ & $\begin{array}{l}\text { Cleaning liquid; } \\
\text { Bee and bird } \\
\end{array}$ & $\begin{array}{l}\text { Window cleaning } \\
\text { expert }\end{array}$ \\
\hline $\begin{array}{l}3.72 \\
\ominus\end{array}$ & $\begin{array}{l}\text { Bausch \& Lomb glass is } \\
\text { eyesight schedule with lines of } \\
\text { stripping girls. }\end{array}$ & $\begin{array}{l}\text { Contact lens glass; } \\
\text { Stripping girls }\end{array}$ & $\begin{array}{l}\text { Good eyesight to see } \\
\text { sexy girl }\end{array}$ \\
\hline 3.73 & $\begin{array}{l}\text { Tango tissues are circle and } \\
\text { recycle. }\end{array}$ & $\begin{array}{l}\text { Tissues; } \\
\text { Circle, recycle }\end{array}$ & $\begin{array}{l}\text { Circle, re-cycle, re- } \\
\text { birth }\end{array}$ \\
\hline 3.74 & $\begin{array}{l}\text { SiRou tissue is catapult ribbon } \\
\text { and silky cord. }\end{array}$ & $\begin{array}{l}\text { Tissue; } \\
\text { Catapult ribbon, silky } \\
\text { cord }\end{array}$ & Elastic and silky \\
\hline 3.75 & $\begin{array}{l}\text { O.b. hygiene sliver is a bundle } \\
\text { of orchid flowers. }\end{array}$ & $\begin{array}{l}\text { O.b. hygiene sliver; } \\
\text { Two bundle of Orchids }\end{array}$ & $\begin{array}{l}\text { Orchid shape, floral } \\
\text { fragrance }\end{array}$ \\
\hline 3.76 & $\begin{array}{l}\text { European winter garment is } \\
\text { swan in nature. }\end{array}$ & $\begin{array}{l}\text { Winter garment; } \\
\text { Swan in nature }\end{array}$ & $\begin{array}{ll}\begin{array}{l}\text { Swan } \\
\text { (graceful) }\end{array} & \text { posture } \\
\end{array}$ \\
\hline $\begin{array}{l}3.77 \\
0\end{array}$ & $\begin{array}{l}\text { Jindingxuan restaurant is } \\
\text { happy customers eating around } \\
\text { the clock. }\end{array}$ & $\begin{array}{l}\text { Restaurant; } \\
\text { Happy customers eating } \\
\text { around the clock }\end{array}$ & $\begin{array}{l}24 \text { hour open, round } \\
\text { clock }\end{array}$ \\
\hline \begin{tabular}{l}
3.78 \\
\hdashline
\end{tabular} & $\begin{array}{l}\text { Daoxiang Food Group is a } \\
\text { filial son. }\end{array}$ & $\begin{array}{l}\text { Food Group; } \\
\text { Filial son }\end{array}$ & $\begin{array}{l}\text { Filial son ordering } \\
\text { food for Mum }\end{array}$ \\
\hline 3.79 & $\begin{array}{l}\text { Women club is underwear } \\
\text { shape of tennis ball, lady } \\
\text { figure of bowling ball, trophy } \\
\text { shape of golf ball. }\end{array}$ & $\begin{array}{l}\text { Women club; } \\
\text { Underwear, lady body; } \\
\text { cup }\end{array}$ & $\begin{array}{l}\text { Sexy, beautiful and } \\
\text { topical }\end{array}$ \\
\hline 3.80 & $\begin{array}{l}\text { China Post is arrived letter in } \\
\text { wet glue. }\end{array}$ & $\begin{array}{l}\text { China Post; } \\
\text { Letter arrived with wet }\end{array}$ & Express delivery \\
\hline
\end{tabular}




\begin{tabular}{|c|c|c|c|}
\hline & & glue & \\
\hline 3.81 & $\begin{array}{l}\text { Shangdong TV station is aerial } \\
\text { on grape and vegetable vine in } \\
\text { a country courtyard. }\end{array}$ & $\begin{array}{l}\text { TV station; } \\
\text { Aerial on grape and } \\
\text { vegetable vine in a } \\
\text { country courtyard }\end{array}$ & Far-flung influence \\
\hline $\begin{array}{l}3.82 \\
0\end{array}$ & $\begin{array}{l}\text { Yangcheng Evening News is } \\
\text { Football World Cup. }\end{array}$ & $\begin{array}{l}\text { Evening News; } \\
\text { Football world cup }\end{array}$ & $\begin{array}{l}\text { Catch up the latest } \\
\text { sport news }\end{array}$ \\
\hline 3.83 & $\begin{array}{l}\text { Top Run AD Agency is drips } \\
\text { of water. }\end{array}$ & $\begin{array}{l}\text { Ad agency; } \\
\text { Drips of water }\end{array}$ & $\begin{array}{l}\text { Wasted ad } \\
\text { expenditure, effective } \\
\text { implementation }\end{array}$ \\
\hline 3.84 & $\begin{array}{l}\text { China Times is an old store } \\
\text { with } 2 \text { brands. }\end{array}$ & $\begin{array}{l}\text { China Times; } \\
\text { Time-honored store with } \\
2 \text { lines of businesses }\end{array}$ & $\begin{array}{l}\text { Differences plus } \\
\text { cooperation }\end{array}$ \\
\hline 3.85 & $\begin{array}{l}\text { Puer tea is tea-brewing process } \\
\text { and traditional Chinese tea } \\
\text { culture. }\end{array}$ & $\begin{array}{l}\text { Puer tea; } \\
\text { Traditional tea } \\
\text { processing method }\end{array}$ & $\begin{array}{l}\text { Tea culture (Life, } \\
\text { time, belief) }\end{array}$ \\
\hline 3.86 & $\begin{array}{l}\text { Tom Outdoor Media is big } \\
\text { brand names. }\end{array}$ & $\begin{array}{l}\text { Media; } \\
\text { Big brand names }\end{array}$ & Big and spacious \\
\hline $\begin{array}{l}3.87 \\
\odot\end{array}$ & $\begin{array}{l}\text { BH-AD.com is robotic and } \\
\text { extraterrestrial being. }\end{array}$ & $\begin{array}{l}\text { BH-AD.com; } \\
\text { Robotic, extraterrestrial } \\
\text { being }\end{array}$ & $\begin{array}{l}\text { Energizing } \\
\text { sensational }\end{array}$ \\
\hline 3.88 & $\begin{array}{l}\text { Cultural Communication is } \\
\text { many bar codes. }\end{array}$ & $\begin{array}{l}\text { Communication firm; } \\
\text { Many bar codes }\end{array}$ & $\begin{array}{lr}\text { Terminal, fast } \\
\text { delivery, time is } \\
\text { money, }\end{array}$ \\
\hline $\begin{array}{l}3.89 \\
0\end{array}$ & $\begin{array}{l}\text { Millie.Chen Corp. is brain } \\
\text { made of nude bodies. }\end{array}$ & $\begin{array}{l}\text { Millie.Chen Corp; } \\
\text { Brian made of nude } \\
\text { bodies }\end{array}$ & $\begin{array}{l}\text { Brain trust with } \\
\text { talented people }\end{array}$ \\
\hline $\begin{array}{l}3.90 \\
0\end{array}$ & $\begin{array}{l}\text { Landao Ad Agency is a looter, } \\
\text { mugger, plunder, and hacker. }\end{array}$ & $\begin{array}{l}\text { Ad agency; } \\
\text { Looter, mugger, plunder, } \\
\text { and hacker }\end{array}$ & $\begin{array}{l}\text { Stop (at this website) } \\
\text { or hack }\end{array}$ \\
\hline 3.91 & $\begin{array}{l}\text { BizNet is a well-nourished } \\
\text { Ginseng. }\end{array}$ & $\begin{array}{l}\text { BizNet; } \\
\text { Well-nourished Ginseng }\end{array}$ & Nutritional addition \\
\hline 3.92 & $\begin{array}{l}\text { CCTV is mahjong playing on a } \\
\text { football field. }\end{array}$ & $\begin{array}{l}\text { CCTV; } \\
\text { Mahjong playing on a } \\
\text { football field }\end{array}$ & $\begin{array}{l}\text { Football icon and } \\
\text { nation-wide game }\end{array}$ \\
\hline $\begin{array}{l}3.93 \\
-9\end{array}$ & $\begin{array}{l}\text { LiNing sportswear is oriented } \\
\text { basketball hero. }\end{array}$ & $\begin{array}{l}\text { Sportswear; } \\
\text { Oriental basketball hero }\end{array}$ & Oriental hero \\
\hline 3.94 & $\begin{array}{l}\text { The Great Wall Rice wine is a } \\
\text { farewell ceremony for the } \\
\text { warriors of war on the Great } \\
\text { Wall. }\end{array}$ & $\begin{array}{l}\text { Rice wine; } \\
\text { Farewell ceremony for } \\
\text { warriors of war on the } \\
\text { Great Wall }\end{array}$ & $\begin{array}{l}\text { Traditional Chinese } \\
\text { culture }\end{array}$ \\
\hline 3.95 & $\begin{array}{l}\text { ZhongGuang } \mathrm{AD} \text { is bounded } \\
\text { hands, blind eyes, shackled } \\
\text { feet. }\end{array}$ & $\begin{array}{l}\text { Ad forum; } \\
\text { Bounded hands, blind } \\
\text { eyes, shackled feet }\end{array}$ & $\begin{array}{l}\text { It's time } \\
\text { unbound... }\end{array}$ \\
\hline 3.96 & $\begin{array}{l}\text { Ad Competition is double } \\
\text { happiness match box. }\end{array}$ & $\begin{array}{l}\text { Ad photo competition; } \\
\text { Double happiness match }\end{array}$ & Double happiness \\
\hline
\end{tabular}




\begin{tabular}{|l|l|l|l|}
\hline $\begin{array}{l}3.97 \\
\odot\end{array}$ & $\begin{array}{l}\text { M-zone talent contest is } \\
\text { performers propping out of } \\
\text { water. }\end{array}$ & $\begin{array}{l}\text { Talent contest; } \\
\text { Performers propping out } \\
\text { of water }\end{array}$ & $\begin{array}{l}\text { To top out, to win, to } \\
\text { shine }\end{array}$ \\
\hline $\begin{array}{l}\text { 3.98 } \\
\text { Dalian Travel Agency is dating } \\
\text { with the sea. }\end{array}$ & $\begin{array}{l}\text { Travel Agency; } \\
\text { Date with the sea }\end{array}$ & $\begin{array}{l}\text { Romance in city of } \\
\text { sea }\end{array}$ \\
\hline 3.99 & $\begin{array}{l}\text { Kunming Horticulture Expo is } \\
\text { a socket and switch made of } \\
\text { natural field. }\end{array}$ & $\begin{array}{l}\text { Horticulture Expo; } \\
\text { Socket and switch made } \\
\text { of natural plants and } \\
\text { flowers. }\end{array}$ & The power of nature \\
\hline 3.10 \\
$0 \odot)$ & $\begin{array}{l}\text { Handy English learning } \\
\text { machine is monkey king vs. } \\
\text { superman, Nezha vs. Harry } \\
\text { Porter, Huamulan vs. Snow } \\
\text { Whites. }\end{array}$ & $\begin{array}{l}\text { Handy learning machine; } \\
\text { superman, Nezha vs. vang } \\
\text { Harry Porter, Huamulan } \\
\text { vs. Snow Whites }\end{array}$ & $\begin{array}{l}\text { East vs. west. PK } \\
\text { system }\end{array}$ \\
\hline
\end{tabular}

Table II-4 A Summary of Advertisements That Contain Human Images in Each Period

\begin{tabular}{|l|l|l|l|}
\hline & Human images & $\begin{array}{l}\text { Total ad numbers } \\
\text { with metaphors }\end{array}$ & $\begin{array}{l}\text { Percentage of ads } \\
\text { with human images }\end{array}$ \\
\hline $1980 \mathrm{~s}$ & 42 & 68 & $62 \%$ \\
\hline $1990 \mathrm{~s}$ & 24 & 98 & $24 \%$ \\
\hline $2000 \mathrm{~s}$ & 30 & 99 & $30 \%$ \\
\hline Total numbers & 96 & 265 & $100 \%$ \\
\hline
\end{tabular}

Table II-5 Human Representational Image Categories for Appearance

\begin{tabular}{|l|l|l|l|l|l|}
\hline $\begin{array}{l}\text { Representationa } \\
\text { l image category } \\
\text { items }\end{array}$ & Periods & $\begin{array}{l}\text { Single vs. } \\
\text { group } \\
\text { pictures }\end{array}$ & $\begin{array}{l}\text { Male vs. } \\
\text { female } \\
\text { ads }\end{array}$ & $\begin{array}{l}\text { Young vs. } \\
\text { middle-aged }\end{array}$ & $\begin{array}{l}\text { Upper vs. } \\
\text { whole body }\end{array}$ \\
\hline $\begin{array}{l}\text { Appearance } \\
\text { Single or group } \\
\text { picture; Gender; } \\
\text { Age; body size }\end{array}$ & $1980 \mathrm{~s}$ & $30 / 42$ & $6 / 30$ & $16 / 30$ & $21 / 42$ \\
& & $12 / 42$ & $24 / 30$ & $14 / 30$ & $21 / 42$ \\
\cline { 2 - 6 } & $1990 \mathrm{~s}$ & $71 \%: 29 \%$ & $20 \%: 80 \%$ & $53 \%: 47 \%$ & $50 \%: 50 \%$ \\
\hline & $16 / 24$ & $11 / 16$ & $1 / 16$ & $15 / 24$ \\
& $8 / 24$ & $5 / 16$ & $15 / 16$ & $9 / 24$ \\
\cline { 2 - 6 } & $2000 \mathrm{~s}$ & $67 \%: 33 \%$ & $69 \%: 31 \%$ & $6 \%: 94 \%$ & $63 \%: 37 \%$ \\
\hline & $13 / 30$ & $12 / 13$ & $3 / 13$ & $5 / 30$ \\
& $17 / 30$ & $1 / 13$ & $10 / 13$ & $25 / 30$ \\
& $43 \%: 57 \%$ & $92 \%: 8 \%$ & $23 \%: 77 \%$ & $17 \%: 83 \%$ \\
\hline
\end{tabular}


Table II-6 Human Representational Image Categories for Manner

\begin{tabular}{|l|l|l|l|l|}
\hline $\begin{array}{l}\text { Representationa } \\
\text { l image category } \\
\text { items }\end{array}$ & Periods & $\begin{array}{l}\text { Facial } \\
\text { expressions }\end{array}$ & Eye contact & Pose \\
\hline Manner & $1980 \mathrm{~s}$ & $26 / 42$ & $6 / 42$ & $27 / 42$ \\
$\begin{array}{l}\text { With vs. without } \\
\text { Facial expression; }\end{array}$ & & $16 / 42$ & $36 / 42$ & $15 / 42$ \\
Eye contact; Pose & $1990 \mathrm{~s}$ & $62 \%: 38 \%$ & $14 \%: 86 \%$ & $64 \%: 36 \%$ \\
\cline { 2 - 5 } & & $12 / 24$ & $2 / 24$ & $8 / 24$ \\
& & $50 \%: 50 \%$ & $22 / 24$ & $16 / 24$ \\
\cline { 2 - 5 } & $2000 \mathrm{~s}$ & $9 / 30$ & $4 / 30$ & $33 \%: 67 \%$ \\
\hline & $21 / 30$ & $26 / 30$ & $14 / 30$ \\
& & $30 \%: 70 \%$ & $13 \%: 87 \%$ & $16 / 30$ \\
\hline
\end{tabular}

Table II-7 Human Representational Image Categories for Activity

\begin{tabular}{|l|l|l|l|l|}
\hline $\begin{array}{l}\text { Representational } \\
\text { image category } \\
\text { items }\end{array}$ & Periods & $\begin{array}{l}\text { Touch \& } \\
\text { intimacy }\end{array}$ & $\begin{array}{l}\text { Body } \\
\text { movement }\end{array}$ & $\begin{array}{l}\text { Positional } \\
\text { communication }\end{array}$ \\
\hline $\begin{array}{l}\text { Activities and } \\
\text { Touch } \\
\text { intimacy; Body } \\
\text { movement; }\end{array}$ & $1980 \mathrm{~s}$ & $27 / 42$ & $35 / 42$ & $31 / 42$ \\
\cline { 2 - 5 } $\begin{array}{l}\text { Positional } \\
\text { communication }\end{array}$ & $1990 \mathrm{~s}$ & $15 / 42$ & $7 / 42$ & $11 / 42$ \\
& & $64 \%: 36 \%$ & $83 \%: 17 \%$ & $74 \%: 26 \%$ \\
\cline { 2 - 5 } & $2000 \mathrm{~s}$ & $8 / 3 / 24$ & $9 / 24$ & $22 / 24$ \\
& & $22 / 30$ & $15 / 24$ & $2 / 24$ \\
& & $27 \%: 73 \%$ & $38 \%: 62 \%$ & $92 \%: 8 \%$ \\
\hline
\end{tabular}

Table II-8 Human Representational Image Categories for Settings

\begin{tabular}{|l|l|l|l|l|l|l|}
\hline $\begin{array}{l}\text { Representationa } \\
\text { l image category } \\
\text { items }\end{array}$ & Periods & $\begin{array}{l}\text { Family } \\
\text { setting }\end{array}$ & $\begin{array}{l}\text { Natural } \\
\text { setting }\end{array}$ & $\begin{array}{l}\text { Workplace } \\
\text { setting }\end{array}$ & $\begin{array}{l}\text { Social } \\
\text { setting }\end{array}$ & $\begin{array}{l}\text { No } \\
\text { props }\end{array}$ \\
\hline $\begin{array}{l}\text { Props \& settings } \\
\text { Background and } \\
\text { environment }\end{array}$ & $1980 \mathrm{~s}$ & $5 / 42$ & $6 / 42$ & $6 / 42$ & $8 / 42$ & $17 / 42$ \\
\cline { 2 - 7 } & $1990 \mathrm{~s}$ & $2 / 24$ & $3 / 24$ & $4 / 24$ & $5 / 24$ & $10 / 24$ \\
\hline
\end{tabular}




\begin{tabular}{|l|l|l|l|l|l|l|}
\hline & & $8 \%$ & $12 \%$ & $17 \%$ & $21 \%$ & $42 \%$ \\
\cline { 2 - 7 } & $2000 \mathrm{~s}$ & $2 / 30$ & $6 / 30$ & $2 / 30$ & $8 / 30$ & $12 / 30$ \\
& & $7 \%$ & $20 \%$ & $7 \%$ & $26 \%$ & $40 \%$ \\
\hline
\end{tabular}

Table II-9 Frequently Appeared Images as Signifieds and Projected Features from 19791988

\begin{tabular}{|c|c|c|}
\hline $\begin{array}{l}\text { Total } \\
\text { numbers }\end{array}$ & $\begin{array}{l}\text { Frequently appeared images as } \\
\text { signifieds and secondary subject }\end{array}$ & Projected features \\
\hline $\begin{array}{l}\text { Group 1: } \\
23 \\
34 \%\end{array}$ & $\begin{array}{l}\text { Women include } \\
\text { Beautiful, smiling and happy ladies } \\
\text { (9), smiling stewardesses (2), } \\
\text { gymnasts (2), Chinese movie \& } \\
\text { sport stars (4), foreign beauties (3), } \\
\text { a nymph in heaven, a bikini girl } \\
\text { surfing, a girl on the swing }\end{array}$ & $\begin{array}{l}\text { Beautiful, happy feeling, friendly, } \\
\text { efficient, tender, white-teethed, } \\
\text { white-skinned; considerate, warm, } \\
\text { consistent care; slim, healthy, } \\
\text { graceful, dynamic; magic, heroic, } \\
\text { popular, shining; exotic, beautiful; } \\
\text { healthy, immortal; sexy adventurous; } \\
\text { happy, care-free. }\end{array}$ \\
\hline $\begin{array}{l}\text { Group 2: } \\
8 \\
12 \%\end{array}$ & $\begin{array}{l}\text { Men include } \\
\text { Smiling \& successful man (2), } \\
\text { movie \& sport stars (2), boys (2), } \\
\text { ancient guard, an animation cartoon } \\
\text { figure }\end{array}$ & $\begin{array}{l}\text { Delicious (food or drink), healthy, } \\
\text { well-mannered, famous, enjoy \& fun- } \\
\text { making, protective, powerful }\end{array}$ \\
\hline $\begin{array}{l}\text { Group } 3: \\
10 \\
15 \%\end{array}$ & $\begin{array}{l}\text { Group pictures include } \\
\text { Family photo, family picnic, family } \\
\text { reunion, matched couple (2), } \\
\text { woman whispering to man, cross- } \\
\text { talk actors, many faces, party scene, } \\
\text { lady models }\end{array}$ & $\begin{array}{l}\text { Colorful life, good memories, warm } \\
\text { feeling \& home-coming, relaxing \& } \\
\text { suitable, happy \& luxury, secret } \\
\text { sharing (confiding), exploring \& } \\
\text { popular, nostalgia, social relation \& } \\
\text { entertaining, smart \& fashionable }\end{array}$ \\
\hline $\begin{array}{l}\text { Group } 4: \\
7 \\
10 \%\end{array}$ & $\begin{array}{l}\text { Tradition includes } \\
\text { Martial arts, festive decorations, } \\
\text { kites, the Great wall, legendary } \\
\text { figure Monkey King, Monkey King } \\
\text { fighting against door guard, red } \\
\text { lanterns }\end{array}$ & $\begin{array}{l}\text { Healthy \& strong, happy lucky } \\
\text { atmosphere, tradition \& cultivation, } \\
\text { historical \& cultural, agile \& } \\
\text { resourceful, powerful \& solid, festive } \\
\text { \& celebrating }\end{array}$ \\
\hline $\begin{array}{l}\text { Group 5: } \\
2 \\
3 \%\end{array}$ & $\begin{array}{l}\text { Animals includ } \\
\text { Tiger, crane }\end{array}$ & Superior quality, longevity $\&$ health \\
\hline $\begin{array}{l}\text { Group 6: } \\
3 \\
5 \%\end{array}$ & $\begin{array}{l}\text { Modern convenience includes } \\
\text { Airline logo, TV tower, antique car }\end{array}$ & $\begin{array}{l}\text { Safe, tall \& giant, valuable \& worth } \\
\text { collecting }\end{array}$ \\
\hline $\begin{array}{l}\text { Group } 7 \text { : } \\
5 \\
7 \% \\
\end{array}$ & $\begin{array}{l}\text { Natural scenes include } \\
\text { Rose \& chrysanthemum, flowers } \\
\text { (2), orchid, countryside }\end{array}$ & $\begin{array}{l}\text { Beautiful \& fragrant, colorful \& } \\
\text { stylish, cultivated, care-free } \& \\
\text { romantic }\end{array}$ \\
\hline
\end{tabular}




\begin{tabular}{|l|l|l|}
\hline $\begin{array}{l}\text { Group 8: } \\
3 \%\end{array}$ & $\begin{array}{l}\text { Recreation includes } \\
\text { Radio \& movie, newspaper }\end{array}$ & Informative \& entertaining, \\
\hline $\begin{array}{l}\text { Group 9: } \\
3 \%\end{array}$ & $\begin{array}{l}\text { Daily necessities include } \\
\text { coffee, silk ribbon }\end{array}$ & $\begin{array}{l}\text { Modem lifestyle, smooth \& } \\
\text { melodious music }\end{array}$ \\
\hline $\begin{array}{l}\text { Group 10 } \\
8 \%\end{array}$ & $\begin{array}{l}\text { Others include } \\
\text { trophy, gift, Wuyang city, Beijing }\end{array}$ & $\begin{array}{l}\text { Informative, hope, American lifestyle, } \\
\text { triumphant in quality, dedicated love } \\
\text { to Mom, well-known, historical, } \\
\text { popular }\end{array}$ \\
\hline $\begin{array}{l}\text { Total: } 68 \\
100 \%\end{array}$ & $\begin{array}{l}\text { Beauty, health, happiness, power, } \\
\text { care-free, popular, tradition }\end{array}$ \\
\hline
\end{tabular}

Table II-10 Frequently Appeared Images as Signifieds and Projected Features from 19891998

\begin{tabular}{|c|c|c|}
\hline Total & $\begin{array}{l}\text { Frequently appeared images as } \\
\text { signifieds and secondary subject }\end{array}$ & Projected features \\
\hline $\begin{array}{l}\text { Group 1: } \\
7 \\
7 \%\end{array}$ & $\begin{array}{l}\text { Women include } \\
\text { Bride, foreign beauties ( } 2 \text { ), female } \\
\text { doctor on express, lady's facial } \\
\text { expression, disc-made face, beauty } \\
\text { protected }\end{array}$ & $\begin{array}{l}\text { New beginning, mini \& graceful } \\
\text { design, charming, caring \& fast } \\
\text { treatment, warm \& considerate, } \\
\text { informing, skin care }\end{array}$ \\
\hline $\begin{array}{l}\text { Group 2: } \\
15 \\
15 \%\end{array}$ & $\begin{array}{l}\text { Men include } \\
\text { Man's broad shoulder, Olympic hero, } \\
\text { trouble-free man, man's head, } \\
\text { Einstein, gymnast, Jean-Paul Sartre, } \\
\text { Chinese ancient saint, father's hand, } \\
\text { foreign man's face, man on the sky } \\
\text { ladder, legendary person - Zhu } \\
\text { Geliang, man holding a rose, athlete, } \\
\text { happy foreign man }\end{array}$ & $\begin{array}{l}\text { Caring \& condolence, heroic spirit, } \\
\text { solution, news sources, great mind, } \\
\text { champion, intellectual \& freedom, } \\
\text { learned and civilized, confidence, } \\
\text { truth revealing, knowledge \& } \\
\text { success, winning strategy, romantic, } \\
\text { enjoy, homely feeling }\end{array}$ \\
\hline $\begin{array}{l}\text { Group 3: } \\
4 \\
4 \%\end{array}$ & $\begin{array}{l}\text { Group pictures include } \\
\text { Group prey, factory workers, happy } \\
\text { faces, American presidents }\end{array}$ & $\begin{array}{l}\text { Good wish, health is beauty, } \\
\text { beautiful skin, pioneering }\end{array}$ \\
\hline $\begin{array}{l}\text { Group 4: } \\
16 \\
17 \%\end{array}$ & $\begin{array}{l}\text { Tradition includes } \\
\text { Mahogany armrest, labyrinth, paper } \\
\text { cuts, abacuses, moon cake, Peking } \\
\text { opera masks, proverb story of Buole, } \\
\text { Chinese six fortunes, temple of } \\
\text { Heaven, double happiness sign, Yuan } \\
\text { Ming Yuan Garden, Dai ethnic water } \\
\text { festival, Putala Palace \& the Great } \\
\text { Wall, Chinese style marriage, prophet } \\
\text { calendar, match-maker }\end{array}$ & $\begin{array}{l}\text { Detailed work \& quality material, } \\
\text { smooth brain, strategize, shrewd, } \\
\text { once-a-year opportunity, diversified } \\
\text { life scenes, sharp eye, (love, } \\
\text { happiness, friendship, wealth, } \\
\text { longevity, smoothness), holy \& } \\
\text { eternity, double happiness, } \\
\text { grandeurs and splendid, merry \& } \\
\text { exotic, connect \& easy travel, } \\
\text { chemistry or pre-ordained relation, }\end{array}$ \\
\hline
\end{tabular}




\begin{tabular}{|c|c|c|}
\hline & & lucky days, doing good deeds \\
\hline $\begin{array}{l}\text { Group 5: } \\
11 \\
11 \%\end{array}$ & $\begin{array}{l}\text { Animals include } \\
\text { Cat, hen \& egg (2), camel, butterfly, } \\
\text { fish \& bear paw, piggy bank, rooster } \\
\& \text { horse, sheep, cows \& horse, fat pig }\end{array}$ & $\begin{array}{l}\text { Pet, wise investment, function well } \\
\text { in bad condition, bright color, value } \\
\text { for money, saving \& economical, } \\
\text { manly, pure wool label, true emotion } \\
\text { delivery, lovely }\end{array}$ \\
\hline $\begin{array}{l}\text { Group 6: } \\
11 \\
11 \%\end{array}$ & $\begin{array}{l}\text { Modern convenience includes } \\
\text { Train, filter, pk game, steamer or } \\
\text { oven, submarine, air cushion, airliner, } \\
\text { clock, electro-kymograph, bearings, } \\
\text { spanner or wrench }\end{array}$ & $\begin{array}{l}\text { Speed \& space, purest water, } \\
\text { competitive, hot \& fever, tight \& } \\
\text { water-proof, comfort, blue sky, } \\
\text { timely \& success, heart-beating \& } \\
\text { exciting, coordinate \& integrate, } \\
\text { problem-solving }\end{array}$ \\
\hline $\begin{array}{l}\text { Group 7: } \\
9 \\
9 \%\end{array}$ & $\begin{array}{l}\text { Natural scenes include } \\
\text { Fields (2), the moon, lake, rainbow, } \\
\text { green shade, road scenery, modern } \\
\text { city view, four season scenery }\end{array}$ & $\begin{array}{l}\text { Naturally made, harvest, light the } \\
\text { world, natural beauty, colorful \& } \\
\text { beautiful, sunlight proof, lifelong } \\
\text { companion, modern \& smart, natural } \\
\text { beauty }\end{array}$ \\
\hline $\begin{array}{l}\text { Group 8: } \\
5 \\
5 \%\end{array}$ & $\begin{array}{l}\text { Recreation includes } \\
\text { Piano, musical instruments, snooker } \\
\text { opening strike, golf club striking the } \\
\text { ball, orchestra performance }\end{array}$ & $\begin{array}{l}\text { Inspiring \& creative, smooth \& } \\
\text { melodious, one-strike success, best } \\
\text { striking point, perfectness }\end{array}$ \\
\hline $\begin{array}{l}\text { Group 9: } \\
13 \\
13 \%\end{array}$ & $\begin{array}{l}\text { Daily necessity includes } \\
\text { Cups, (pen, tie, button), ear-picker, } \\
\text { unfolded world map, apple, } \\
\text { (dictionary, tea cup, football, fashion), } \\
\text { (whistle, pop can, water tap), bundle } \\
\text { of grapes, home, (cactus, swords, } \\
\text { knives), strapped chair, sleeping pill, } \\
\text { (kettle, cup, Putala Palace) }\end{array}$ & $\begin{array}{l}\text { Taste, (well-groomed man), } \\
\text { miniature, connect the world, } \\
\text { Newton's inspiration, (latest } \\
\text { news/topics), (pain of disease), } \\
\text { natural wine, comfortable, (loss of } \\
\text { social manner-disease), safe \& } \\
\text { secure, good night sleep, (exotic \& } \\
\text { refined Tibetan lifestyle) }\end{array}$ \\
\hline $\begin{array}{l}\text { Group 10: } \\
7 \\
7 \%\end{array}$ & $\begin{array}{l}\text { Others include } \\
\text { Praise sign (Ok, thumb up, A's work, } \\
\text { No.1), arithmetic signs }(+,-, \times, \div) \text {, } \\
\text { trouble-free parents, the White House, } \\
\text { embryo in womb, incubator, } \\
\text { man/woman's faces }\end{array}$ & $\begin{array}{l}\text { Good word of mouth, value price, } \\
\text { mutual concern \& care, American } \\
\text { lifestyle, healthy baby, baby health, } \\
\text { foresight \& insightful }\end{array}$ \\
\hline & & \\
\hline
\end{tabular}

Table II-1 1 Frequently Appeared Images as Signifieds and Projected Features from 19992008

\footnotetext{
${ }^{62}$ The total percentage for the 10 -group images is $99 \%$ rather than $100 \%$ because the figures in all the groups are given in rounded numbers instead of fractures with any percentage figure smaller than $0.5 \%$ being omitted.
} 


\begin{tabular}{|c|c|c|}
\hline $\begin{array}{l}\text { Total } \\
\text { numbers }\end{array}$ & $\begin{array}{l}\text { Frequently appeared images as } \\
\text { signifieds and secondary subject }\end{array}$ & Projected features \\
\hline $\begin{array}{l}\text { Group 1: } \\
4 \\
4 \%\end{array}$ & $\begin{array}{l}\text { Women include } \\
\text { Sexy lady, triangle love affair, throat } \\
\text { savor, stripping girl }\end{array}$ & $\begin{array}{l}\text { cumulative points, intruder, help, } \\
\text { good eyesight }\end{array}$ \\
\hline $\begin{array}{l}\text { Group 2: } \\
8 \\
8 \%\end{array}$ & $\begin{array}{l}\text { Men include } \\
\text { Superman, Chinese cartoon figure, } \\
\text { Spiderman \& superman, foreign baby, } \\
\text { Gongfu master Li Xiaolong, man breaking } \\
\text { out of a cage, run-away black ghost, son } \\
\text { ordering food }\end{array}$ & $\begin{array}{l}\text { Unyielding in finding a suitable } \\
\text { job, ugly but lucky, American } \\
\text { style heroes, mother's love, Oh, } \\
\text { Ha master, forward for freedom, } \\
\text { killed bacteria, filial piety }\end{array}$ \\
\hline $\begin{array}{l}\text { Group 3: } \\
15 \\
15 \%\end{array}$ & $\begin{array}{l}\text { Group pictures include } \\
\text { Family photo, multi-tasking heroes, cool } \\
\text { instinctive youngsters, basketball stars, } \\
\text { HK celebrities, smiling super boy \& girl, } \\
\text { happy customers eating \& talking, } \\
\text { extraterrestrial being, human brain made } \\
\text { of nude bodies, looter \& hacker, } \\
\text { basketball players, farewell ceremony for } \\
\text { warriors of war on the Great Wall, } \\
\text { (bounded hands, blind eyes, shackled } \\
\text { feet), performers propping out of water, } \\
\text { date with the sea }\end{array}$ & $\begin{array}{l}\text { Correct self-identity, insightful } \\
\& \text { brilliant, release the instinct, } \\
\text { dare to be, I am what I am, super } \\
\text { power, round clock opening, } \\
\text { brain trust with talented people, } \\
\text { stop on my website, oriental } \\
\text { hero, traditional Chinese culture, } \\
\text { it's time to unbound, to top out } \\
\& \text { to win \& to shine, romance in } \\
\text { sea city }\end{array}$ \\
\hline $\begin{array}{l}\text { Group } 4: \\
12 \\
12 \%\end{array}$ & $\begin{array}{l}\text { Tradition includes } \\
\text { (Taihe Temple, the Summer Palace, Yuan } \\
\text { Mingyuan, Yueyang Pagoda), (Baroque- } \\
\text { style vase, wall, flower); (upturned eaves, } \\
\text { vault, bamboo courtyard); Yoga \& Taiji } \\
\text { boxing, Snow White fairy tale, maze or } \\
\text { labyrinth hunting, guardian gods, Chinese } \\
\text { character of fire and water, the Great Wall } \\
\& \text { Athenian Parthenon, time-honored store } \\
\text { with two brands, traditional tea process } \\
\text { methods, (Monkey king vs. superman, } \\
\text { Nezha vs. Harry Porter, Huamulan vs. } \\
\text { Snow White) }\end{array}$ & 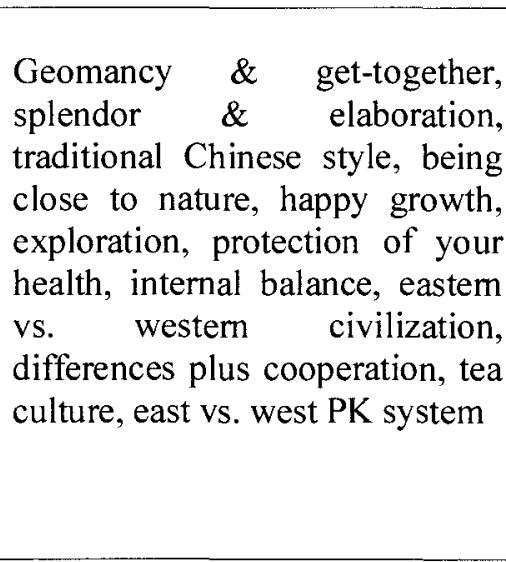 \\
\hline $\begin{array}{l}\text { Group 5: } \\
13 \\
13 \%\end{array}$ & $\begin{array}{l}\text { Animals include } \\
\text { (fish, antelope, wild goose), ape, peacock } \\
\text { in forest, tortoise, wild goose, (fish, } \\
\text { shrimp, crabs), half fish \& half man, } \\
\text { (paws, cobra, lions), bird's singing, } \\
\text { (panda, dinosaur, tiger), (porcupine, } \\
\text { globefish), (bee \& bird), swan in nature }\end{array}$ & $\begin{array}{l}\text { Connection with the world, } \\
\text { power, synchronized with the } \\
\text { world, longevity, fly higher, } \\
\text { nature-like moisture, natural } \\
\text { water, free your wild nature, } \\
\text { melodious, save the extinguished } \\
\text { spices, lively world, window } \\
\text { cleaning expert, graceful }\end{array}$ \\
\hline Group 6: & & \\
\hline
\end{tabular}




\begin{tabular}{|c|c|c|}
\hline $\begin{array}{l}14 \\
14 \%\end{array}$ & $\begin{array}{l}\text { Telephone in change, computer game, } \\
\text { airplane, golden key, tricycle taxi, (halved } \\
\text { spanner, gas pump, car key), car-driving } \\
\text { in different weather, car on folded fan, } \\
\text { (credit card, car, ice box), (plane, fashion, } \\
\text { car), (lightening arrestor, door fastener, } \\
\text { fire extinguisher), overloaded lift, TV } \\
\text { aerial in countryside, commodity bar- } \\
\text { codes }\end{array}$ & $\begin{array}{l}\text { Changed \& unchanged, cool \& } \\
\text { happy experience, fly higher \& } \\
\text { new horizon, accompany and } \\
\text { help, reduce the burden, saving } \\
\& \text { economical, dynamic but } \\
\text { quiet, elastic \& flexible, } \\
\text { convenience, being the first to do } \\
\text { sth. security \& safety, } \\
\text { concentrated \& enriched, far- } \\
\text { flung influence, fast delivery }\end{array}$ \\
\hline $\begin{array}{l}\text { Group } 7: \\
11 \\
11 \%\end{array}$ & $\begin{array}{l}\text { Natural scenes include } \\
\text { Remote natural places (forest, desert, } \\
\text { ocean, mountain), Tibetan mountain \& } \\
\text { rain forest, night stars, metropolitan city, } \\
\text { Tibetan highland, lake view, sea waves \& } \\
\text { white clouds, Alps, wind attack and } \\
\text { mountain defend, drips of water, natural } \\
\text { plant and flowers }\end{array}$ & $\begin{array}{l}\text { Connection with the world, } \\
\text { connect heaven and earth, search } \\
\text { for the brightest star, way of life, } \\
\text { reliability, best angle to } \\
\text { appreciate natural beauty, natural } \\
\text { sea breeze, mysterious, oriental } \\
\text { hero in game play, wasted } \\
\text { money, the power of nature }\end{array}$ \\
\hline $\begin{array}{l}\text { Group 8: } \\
6 \\
6 \%\end{array}$ & $\begin{array}{l}\text { Recreation includes } \\
\text { Amusement park (skyscraper wheel, } \\
\text { rollercoaster, merry-go-round), water } \\
\text { therapy, footprint \& shoeprint, catapult } \\
\text { ribbon \& silky cord, Football World Cup, } \\
\text { Mahjong playing on a football field }\end{array}$ & $\begin{array}{l}\text { Fresh and fun, comfort and } \\
\text { tender, being close to nature, } \\
\text { elastic \& silky, catch-up the } \\
\text { latest sports news, nation-wide } \\
\text { game \& attention }\end{array}$ \\
\hline $\begin{array}{l}\text { Group } 9: \\
13 \\
13 \%\end{array}$ & $\begin{array}{l}\text { Daily necessity includes } \\
\text { (Umbrella, wardrobe, car park), Christmas } \\
\text { tree, black coffee \& red Latin, cooking } \\
\text { oil, heart \& house made of smiling faces, } \\
\text { swinging pendulum, comb \& speedy } \\
\text { ticket, stainless tea \& coffee cup, circle \& } \\
\text { recycle of tissue, bundle of Orchids, } \\
\text { (lady's underwear, body shape, wine } \\
\text { cups), letter arrival with wet glue, match } \\
\text { boxes }\end{array}$ & $\begin{array}{l}\text { Reserved private \& personal } \\
\text { space, season greetings, western } \\
\text { lifestyle \& romance, clean oil- } \\
\text { free kitchen, affection \& } \\
\text { sufficiency, fast asleep, super } \\
\text { slippery hair, removal of stain } \\
\text { worry on teeth, environmental } \\
\text { friendly, floral shape \& } \\
\text { fragrance, sexy \& beautiful \& } \\
\text { topical, fast delivery, double } \\
\text { happiness }\end{array}$ \\
\hline $\begin{array}{l}\text { Group 10: } \\
3 \\
3 \%\end{array}$ & $\begin{array}{l}\text { Others include } \\
\text { well-grown Ginseng, sensational news, } \\
\text { big brand names }\end{array}$ & $\begin{array}{l}\text { nutritional addition, } \\
\text { breakthrough in fuel efficiency, } \\
\text { big \& spacious, }\end{array}$ \\
\hline $\begin{array}{l}\text { Total: } 99 \\
99 \%{ }^{63}\end{array}$ & & \\
\hline
\end{tabular}

${ }^{63}$ The same reason as explained in footnote 66. 
Figure II-1 Four Sample Ad Examples from 1979 to 1988

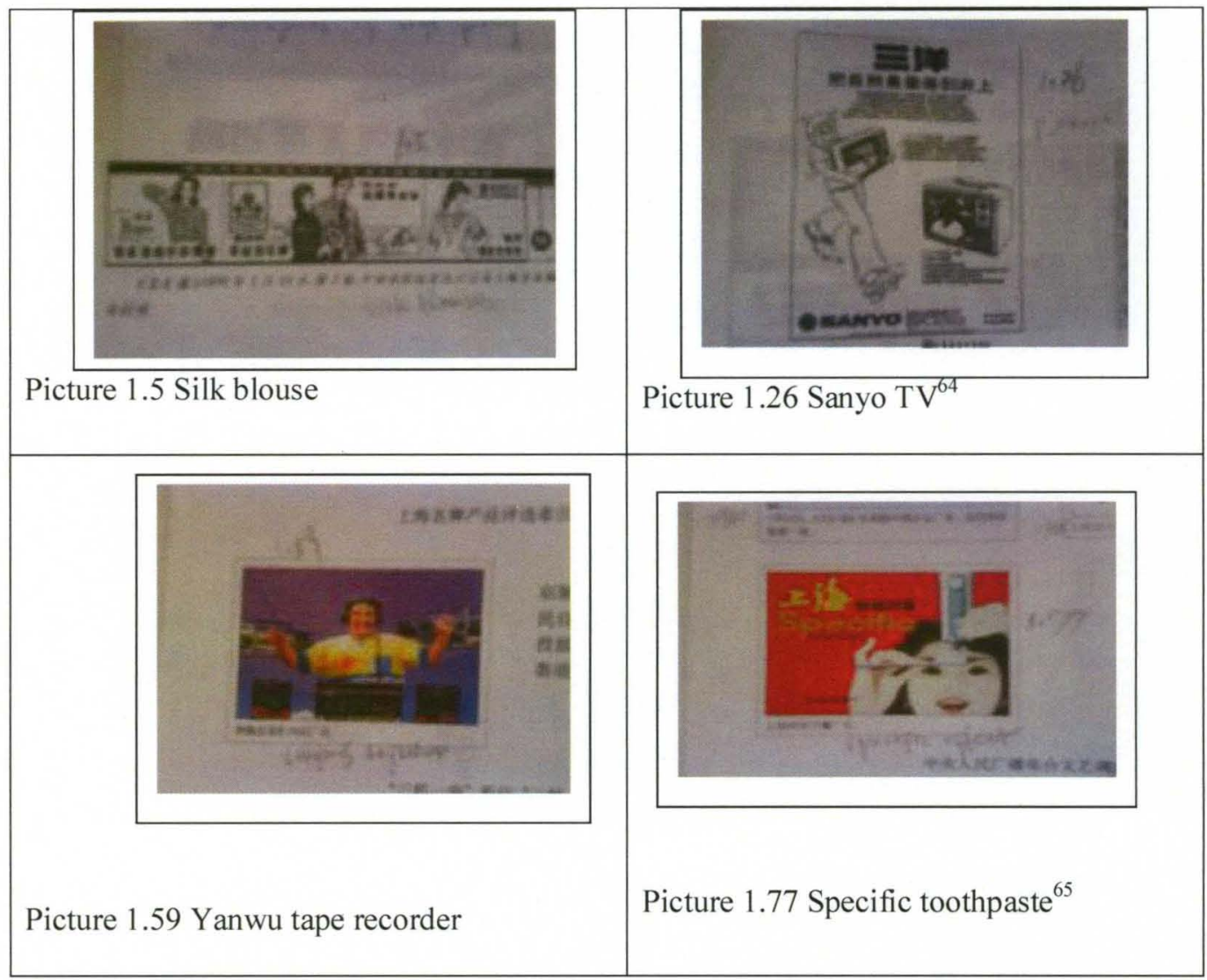

\footnotetext{
${ }^{64}$ Source: Zhou, Wei (Chief Editor) (2002). A Profile of Industry and Commerce: classic ads in one century in China Guangming Daily Press. (The book is written in Chinese. The English book name is translated by the dissertation author). Ad No.1.5 on p.169; Ad No.1.26 on p.179.

${ }^{65}$ Source: Liu, Libin (Chief Editor) (2004). Accelerated Growth of China 's Advertising Industry from 1979 to 2003. Huaxia Publishing House. (The book is written in Chinese. The English book name is translated by the dissertation author). Ad No. 1.59 on p.36; Ad. No. 1.77 on p.56
} 
Figure II-2 Four Sample Ad Examples from 1989 to 1998

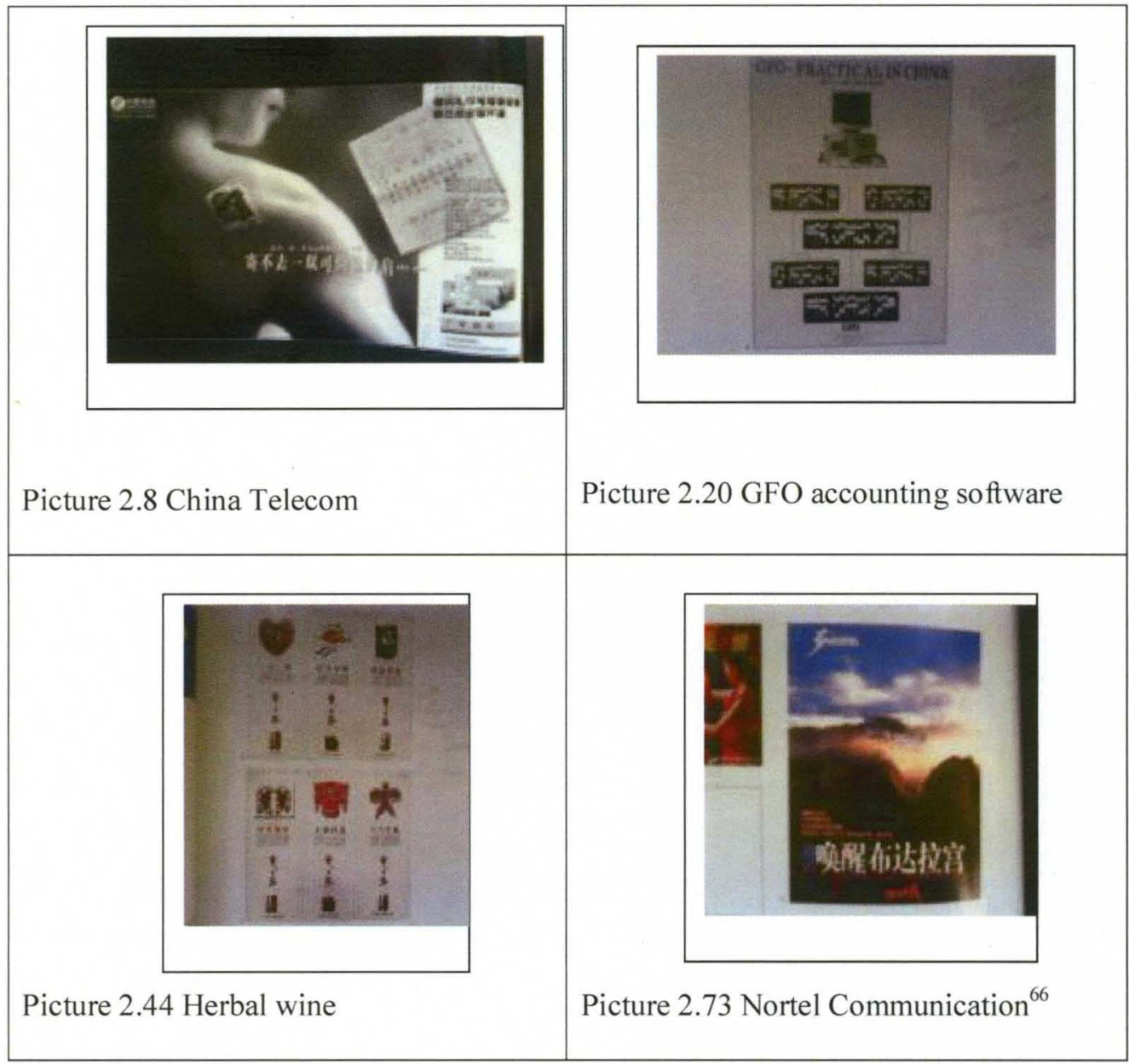

${ }^{66}$ China Advertising Association (ed.) (1997). Award-Winning Ad Collections from the Fifth National Popular Advertising Exhibition Guangzhou: LingNan Fine Arts Press. (The book is written in Chinese. The English book name is translated by the dissertation author). No. 2.8 on p. 14 ; No. 2.20 on p. 25 ; No. 2.44 on p.105; No. 2.73 on p. 144 
Figure II-3 Four Sample Ad Examples from 1999 to 2008

\begin{tabular}{|l|l|l|}
\hline Picture 3.10 Moto mobile phone & Picture 3.19 Lubao car \\
\hline Picture 3.54 The Great Wall wine & Picture 3.62 Reebok sportswear \\
\hline
\end{tabular}

${ }^{67}$ Liu, Libin, Ding, Junjie, and Huang, Shengmin. (Eds) (2007). IAI China Advertising Yearbook 2007 Beijing: China Media University Press. (The book is written in Chinese. The English book name is translated by the dissertation author). No.3.10 on p.57; No.3.19 on p. 97 ; No.3.54 on p. 256 ; No.3.62 on p.304 


\section{CURRICULUM VITAE}

NAME:

ADDRESS:

JOB:

EDUCATION:

TRAINING:
Jiang, Chun

Fengtai District, Qingta Xilu, Building 14, Apt 013, Beijing, P.R. China, Zip: 100141 (Home).

Post Box 2, School of International Studies, University of International Business \& Economics. Huixin East Street 10, Chao Yang District, Beijing, P. R. China 100029, (Office).

Associate Professor in School of International Studies, University of International Business and Economics (UIBE), Beijing, P. R. China.

B.A. English, School of International Studies, University of International Business and Economics (UIBE), Beijing, P. R. China. M.A. Applied linguistics, School of International Studies, University of International Business and Economics (UIBE), Beijing, P. R. China.

MBA. School of Public Policy and Management, Korea Development Institute (KDI), Seoul, South Korea.

One year in teaching methodology in Institute of Education, Singapore University

One year in international business in Seton Hall University, USA.

PUBLICATIONS: Translate the book "Warren Buffet's Portfolio"

Translate the book "Survivor's Guide to Small Business"

Translate the book "International Marketing" "Marketing of Nations"

Write textbooks for university students "Business English Reader", "Advanced Listening and Speaking in Business English", "English Business Dialogues", "English for Marketing", "Introduction to Global Economic Environment", "English for Business Negotiations".

Write a book "A Multi-perspective Research into Business English"

Publish articles in China's SSCI journals and ICS in US. 